\title{
SALINIZACIÓN Y OTROS CAMBIOS \\ HIDROGEOQUÍMICOS ASOCIADOS A \\ DISTINTOS USOS DEL SUELO EN LA REGIÓN \\ CENTRO-SUR BONAERENSE, ARGENTINA.
}

\section{Tesis doctoral}

DOCTORANDO:

ING. AGR. GERMÁN M. MILIONE (IHLLA-CONICET-UNCPBA)

DIRECTOR:

DR. JAVIER E. GYENGE (CONICET)

CODIRECTOR:

DR. SERGIO A. BEA JOFRÉ (IHLLA-CONICET)

ASESOR ACADÉMICO:

DR. CORINA GRACIANO (INFIVE-CONICET-UNLP)

15 de Noviembre de 2018, Facultad de Cs. Agr. Y Ftales., UNLP. La Plata, Bs. As., Argentina. 
LISTADO DE ABREVIATURA Y SIMBOLOS.....................................................

INDICE DE TABLAS

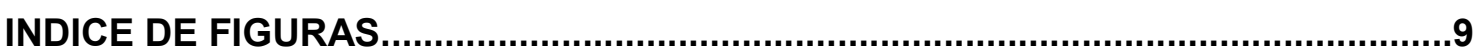

INDICE DE GRÁFICOS .............................................................................

AGRADECIMIENTOS

DEDICATORIA

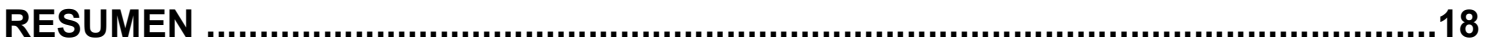

ABSTRACT

1. CAPÍTULO 1. Introducción.

1.1. INTRODUCCIÓN GENERAL......................................................................23

1.1.1. Estado de las forestaciones de argentina en el contexto

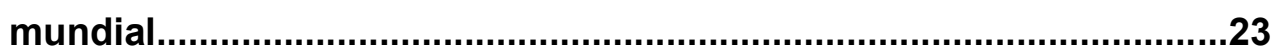

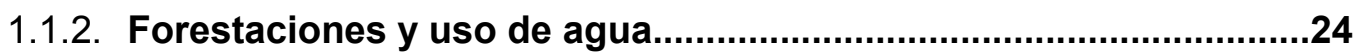

1.1.3. Forestaciones y salinización secundaria.........................................27

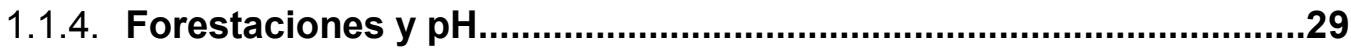

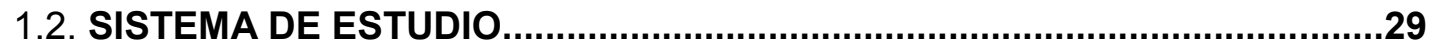

1.3. MODELO HIPOTÉTICO.........................................................................

1.4. OBJETIVOS

2. CAPÍTULO 2. Transiciones entre sistemas leñosos y herbáceos en la llanura pampeana. Su consecuencia sobre la CE y pH del suelo.

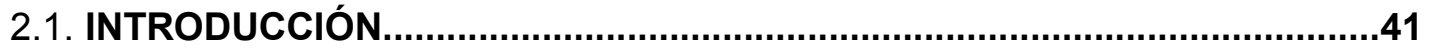

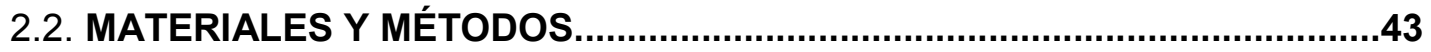

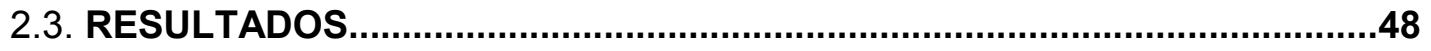

2.3.1. Estructura de las forestaciones.....................................................48

2.3.2. Variables de suelo durante la estación invernal.............................50

2.3.2.1. Agrupación de la CE por localidad geográfica............................51

2.3.2.2. Agrupación de la CE por textura del suelo.................................52

2.3.2.3. CE a distintas profundidades del suelo.......................................53

2.3.2.4. $\mathrm{pH}$ a distintas profundidades de suelo.......................................56

2.3.3. Variables de suelo durante la estación estival..................................58

2.3.3.1. Agrupación de la CE por localidad geográfica..............................58

2.3.3.2. Agrupación de la CE por textura del suelo..................................59 
2.3.3.3. CE a distintas profundidades del suelo.......................................60

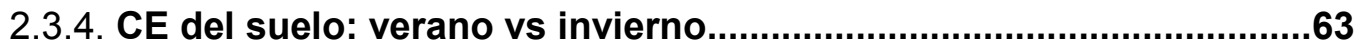

2.4. DISCUSIÓN...........................................................................................64

2.4.1. Factores biológicos, hidrogeológicos y climáticos.........................64

2.4.2. Efecto de la estación del año en la CE.............................................67

2.4.3. Efecto de las especies de Eucalyptus en la CE................................68

2.4.4. Efecto de la edad y el manejo de las forestaciones en la CE............68

2.5. CONSIDERACIONES FINALES..................................................................69

3. CAPÍTULO 3. Especies forestales y manejo ¿Cómo afectan la CE y el pH del suelo? Estudio de dos sitios con suelos contrastantes.

3.1. INTRODUCCIÓN........................................................................................72

3.2. MATERIALES Y MÉTODOS.....................................................................74

3.2.1. Descripción y toma de muestras en el sitio SST.............................76

3.2.2. Descripción y toma de muestras en el sitio CRS..............................77

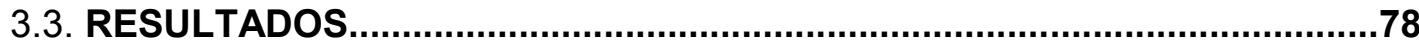

3.3.1. Caracterización de las forestaciones................................................78

3.3.2. Variables de suelo por especie y manejo en SST...........................81

3.3.3. Variables de suelo para cada especie en CRS.................................83

3.4. DISCUSIÓN..............................................................................................84

3.4.1. Características de las forestaciones................................................84

3.4.2 Efectos en la CE y el pH del suelo producto del cambio de uso del suelo en SST

3.4.3 Efectos en la CE y el pH del suelo producto de la forestación con dos especies de Eucalyptus

3.5. CONSIDERACIONES FINALES

4. CAPÍTULO 4. ¿Los Eucalyptus son bombas de agua? Evaluación del impacto hidrogeoquímico de una forestación de Eucalyptus viminalis vs un pastizal natural.

4.1. INTRODUCCIÓN. .89

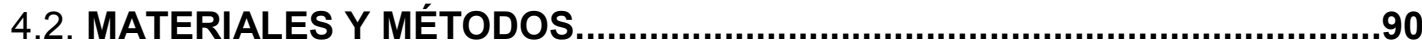

4.2.1. Descripción del sitio, clima y suelo.................................................90

4.2.2. Características de bosques y pastizales............................................91

4.2.3. Mediciones climáticas e hidrológicas...............................................93

4.2.4. Estimación de la transpiración individual y a nivel de rodal.............96 
4.2.5. Simulación de la transpiración cultivos...........................................97

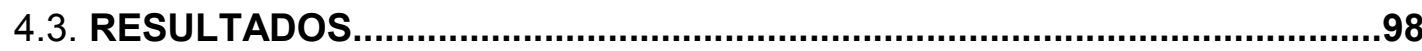

4.3.1. Características de la forestación y pastizal......................................98

4.3.2. Mediciones climáticas e hidrológicas...........................................98

4.3.2.1. Mediciones climáticas.........................................................98

4.3.2.2. Mediciones en el perfil del suelo.............................................100

4.3.2.3. Mediciones en el acuífero freático............................................103

4.3.3. Estimación de la transpiración individual y a nivel de rodal.........106

4.3.4. Transpiración de cultivos vs forestación........................................107

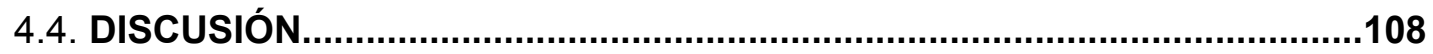

4.4.1. Mediciones climáticas e hidrológicas............................................108

4.4.2. Mediciones en el perfil del suelo...................................................109

4.4.2.1. Humedad volumétrica.................................................................109

4.4.2.2. Conductividad eléctrica..............................................................109

4.4.3. Mediciones en el acuífero freático..................................................110

4.4.3.1. Profundidad del acuífero...........................................................110

4.4.3.2. Conductividad eléctrica del acuífero...........................................111

4.4.4. Estimación de la transpiración individual y a nivel de rodal.........112

4.4.5. Transpiración de cultivos vs forestación.......................................113

4.5. CONSIDERACIONES FINALES.............................................................113

5. CAPÍTULO 5. Discusión final y conclusiones

5.1. DISCUSIÓN FINAL..................................................................................116

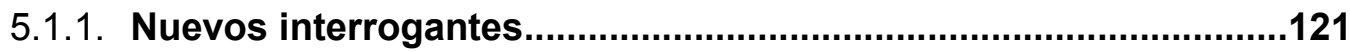

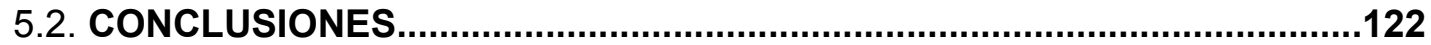

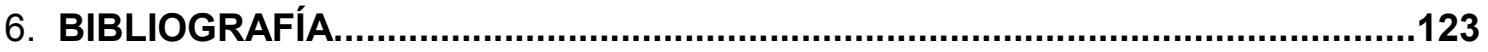




\section{LISTADO DE ABREVIATURAS Y SIMBOLOS}

+/- $\triangle$ Alm. Sub.

$+/-\Delta$ Alm. Super.

A

A. Exp.

A. imp.

$A B$

Afl. Sub.

Afl. Super.

ANOVA

Av

B

$\mathrm{Br}$

CE

Cob.

CRS

DAP

DPV

Ec

Ed

Ef

Efl. Sub.

Efl. Super.

Eg

Sp.

ETP

EU

Ev

EVT

$\mathrm{F}$

FAO

G

Gs

$\mathrm{H}$

I
Variación del almacenaje subterráneo Variación del almacenaje superficial Localidad de Azul Agua exportada Agua importada

Área basal Afluencia subterránea Afluencia Superficial Análisis de varianza

Avena sativa Localidad de Balcarce-Lobería

Barbecho

Conductividad eléctrica

Cobertura aérea del dosel arbóreo Pampa deprimida situada en la cuenca del Río Salado Diámetro a la altura del pecho Déficit de presión de vapor Eucalyptus camaldulensis Eucalyptus dalrympeana Escurrimiento fustal Efluencia subterránea Efluencia superficial Eucalyptus globulus Especie Evapotranspiración potencial Macizo de Eucalyptus Eucalyptus viminalis Evapotranspiración real Flujo de savia Food and Agriculture Organization Localidad de Guaminí Helianthus annuus Altura de los arboles dominantes Interceptación de las precipitaciones 
MAGPyA

N

NE

NO

Pas

Pc

p.e.

$p_{i}$

Pn

pp

$\mathrm{Pr}$

S

SA

SAGPYA

SE

SO

SST

$\mathrm{T}$

$\mathrm{T}^{\circ}$

Tg

TR

$\mathrm{Tr}$

u

U

Vol. sc

$\Delta \mathrm{T}_{\text {real }}$

$\Delta \mathrm{T}_{\text {máxima }}$
Ministerio de agricultura, ganadería, pesca y alimentos

Densidad de árboles

Noreste

Noroeste

Pastura

Pastura cortada

Por ejemplo

Proporción de cada clase diamétrica

Pastizal natural

Precipitaciones

Pinus radiata

Glycine max

Área del xilema activo

Secretaría de agricultura, ganadería, pesca y alimentos

Sudeste

Sudoeste

Sierras de Tandil

Traspiración diaria promedio

Temperatura

Triticum sp.

Tala rasa

Trascolación

Densidad del flujo de savia

Flujo de savia medio diario

Volumen sin corteza

Real diferencia de temperatura en cada momento Máxima diferencia máxima de temperatura entre termocuplas 


\section{INDICE DE TABLAS}

Tabla II.1. Localidades, ubicación geodésica de las parcelas de medición, máxima profundidad estudiada del perfil y textura del suelo

Tabla II.2. Variables descriptoras de los rodales. Sp.= especie $(E g=$ Eucalyptus globulus, $\mathrm{Ev}=$ Eucalyptus viminalis, $\mathrm{EC}=$ Eucalyptus camaldulensis); $\mathrm{N}=$ Densidad (árboles ha $\left.{ }^{-1}\right) ; \mathrm{DAP}=$ diámetro del fuste a $1,30 \mathrm{~m} ; \mathrm{AB}=$ área basal $\left(\mathrm{m}^{2} \mathrm{ha}^{-1}\right) ; \mathrm{H}=$ altura dominante $(\mathrm{m})$; Cob = cobertura aérea del dosel arbóreo (\%) y Edad en años desde la plantación.

Tabla II.3. Descripción de las parcelas muestreadas. Cobertura $(E g=$ Eucalyptus globulus, $\mathrm{Ev}=$ Eucalyptus viminalis, $\mathrm{EC}=$ Eucalyptus camaldulensis, $\mathrm{Pn}=$ pastizal natural, $\mathrm{Br}=$ barbecho, $\mathrm{Tg}=$ Triticum sp., $\mathrm{M}=$ Zea mays, $\mathrm{Gs}=$ Helianthus annuus, $\mathrm{Pc}$ = pastura cortada, $S=$ Glycine max), conductividad eléctrica del suelo (CE, $\mu S \mathrm{~cm}^{-1}$ ) y $\mathrm{pH}$ promedios de todo el perfil de suelo. Con un asterisco se denotan aquellas parcelas apareadas en donde se encontraron diferencias significativas en cada estación del año en al menos una profundidad del perfil. .50

Tabla III.1. Sitios (SST; sierras de Tandil y CRS; Pampa Deprimida situada en la cuenca del río Salado), ubicación geodésica de las parcelas, textura del suelo, cobertura $(\mathrm{Ed}=$ Eucalyptus dalrympeana, $\mathrm{Ev}=$ Eucalyptus viminalis, $\operatorname{Pr}=$ Pinus radiata, $\mathrm{Pn}=$ Pastizal natural, $\mathrm{Av}=$ Avena sativa, $\mathrm{TR}=$ Tala rasa)

Tabla III.2. Variables descriptoras de los rodales. Sp. = especie $(\mathrm{Ed}=$ Eucalyptus dalrympeana, $\mathrm{Ev}=$ Eucalyptus viminalis, $\mathrm{Pr}=$ Pinus radiata); $\mathrm{N}=$ Densidad (árboles ha ${ }^{-}$ $\left.{ }^{1}\right)$; DAP = diámetro del fuste a 1,30 m; $A B=$ área basal $\left(\mathrm{m}^{2} \mathrm{ha}^{-1}\right) ; \mathrm{H}=$ altura dominante $(\mathrm{m}) ;$ Cob = cobertura aérea del dosel arbóreo (\%) y Edad en años desde la plantación.

Tabla III.3. Variables descriptoras de los rodales. Sp. = especie $(\mathrm{Ec}=$ Eucalyptus camaldulensis, $\mathrm{Ev}=$ Eucalyptus viminalis); $\mathrm{N}=$ Densidad (árboles ha ${ }^{-1}$ ); $\mathrm{DAP}=$ diámetro del fuste a $1,30 \mathrm{~m} ; \mathrm{AB}=$ área basal $\left(\mathrm{m}^{2} \mathrm{ha}^{-1}\right) ; \mathrm{H}=$ altura dominante $(\mathrm{m})$ y Cob = cobertura aérea del dosel arbóreo (\%). 
Tabla III.4. Conductividad eléctrica del suelo promedio (CE, $\mu \mathrm{S} \mathrm{cm}^{-1}$ ) y desvíos en la localidad de Tandil de las parcelas por especie y tipo de sistema de producción, discriminando los valores por profundidad de muestreo. Letras distintas indican diferencias significativas para cada profundidad con un $p<0,05$

Tabla III.5. pH del suelo promedio y desvíos en el sitio SSP (localidad de Tandil), de las parcelas por especie y tipo de sistema de producción, discriminando los valores por profundidad de muestreo. Letras distintas indican diferencias significativas entre sitios para cada profundidad con un $p<0,05$

Tabla III.6. Conductividad eléctrica del suelo promedio $\left(\mathrm{CE}, \mu \mathrm{S} \mathrm{cm}^{-1}\right)$ y desvíos en el sitio CRS (localidad de Pila), de las parcelas por especie y discriminando los valores por profundidad de muestreo. Letras distintas indican diferencias significativas para cada profundidad con un $p<0,05$.

Tabla III.7. $\mathrm{pH}$ del suelo promedio y desvíos en la localidad de Pila, de las parcelas por especie y discriminando los valores por profundidad de muestreo. Letras distintas indican diferencias significativas para cada profundidad con un $p<0,05$. .84

Tabla IV.1. Variables descriptoras del rodal. Especie; $D=$ Densidad (árboles ha ${ }^{-1}$ ); $\mathrm{DAP}=$ diámetro del fuste a $1,30 \mathrm{~m} ; \mathrm{AB}=$ área basal $\left(\mathrm{m}^{2} \mathrm{ha}{ }^{-1}\right) ; \mathrm{H}=$ altura promedio $(\mathrm{m})$; Cob = cobertura aérea del dosel arbóreo (\%) y Edad en años desde la plantación.

Tabla IV.2. Transpiración promedio $\left(\mathrm{mm} \mathrm{día}^{-1}\right)$ simulada para los cultivos agrícolas vs medida en la forestación. Letras diferentes indican diferencias significativas. Test LSD Fisher para un $p<0,05$ 


\section{INDICE DE FIGURAS}

Figura I.1. Mapa de la provincia de Buenos Aires con sus regiones naturales (extraído de http://anterior.inta.gov.ar/suelos/cartas/index.htm). Se detalla la región de estudio y la gradación de texturas de suelo en dirección. .30

Figura 1.2. Mapa de la región en donde se muestra el gradiente NE-SO del balance hídrico anual (Water balance).Con líneas negras se demarca el área de estudio propuesta por los autores donde la vegetación originaria era el pastizal (Extraído de Nosetto et al., 2008). 31

Figura I.3. Modelo jerárquico de condiciones que favorecen el proceso de salinización por cambios de vegetación. Extraído de Nosetto et al. (2008) y Jobbágy et al. (2006)

Figura II.1. Distribución de las parcelas apareadas. Las parcelas (puntos negros) se agruparon en tres localidades de la provincia de Buenos Aires, Argentina: (G) Guaminí, (A) Azul y (B) Balcarce-Lobería. Con líneas punteadas se denota la isolinea correspondiente a los balances hídricos calculados como la diferencia entre la precipitación media anual y la evapotranspiración de referencia de Penman-Montheith (modificado a partir de Nosetto et al. 2008). .44

Figura II.2. Ejemplo de cómo fueron establecidas dentro de la forestación las parcelas muestreadas (los puntos negros representan los árboles). Estas parcelas tenían un tamaño diferente, dependiendo de la densidad y la distribución espacial de los árboles

Figura III.1. Ubicación de las zonas de muestreo (círculos huecos donde SST; sierras de Tandil y CRS; Pampa Deprimida situada en la cuenca del río Salado) con sus parcelas apareadas (puntos negros), en gris se denota las forestaciones. Con líneas punteadas se denotan los balances hídricos calculados como la diferencia entre la precipitación media anual y la evapotranspiración potencial de Penman-Montheith (modificado a partir de Nosetto et al. 2008). .75

Figura IV.1. Vista aérea de las parcelas intensivas forestal (A) y herbácea (B). Foto gentileza de la Ing. Georgina Cazenave. .92 
Figura IV.2. Ubicación de las parcelas intensivas forestal (A) y herbácea (B) y vista de

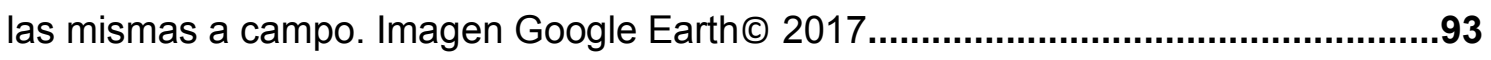

Figura IV.3. Embudo instalado en 4 árboles tipo, para medir escurrimiento fustal y pluviómetros para cuantificar la trascolación.

Figura IV.4. Perfil de suelo en la parcela forestal mostrando la secuencia de horizontes y la ubicación de los sensores del acuífero y suelo.

.95

Figura IV.5. Instalación de sensores para la medición del flujo de savia por el método de Granier (p.ej., véase Granier 1985 y 1987). .96 


\section{INDICE DE GRÁFICOS}

Grafico I.1. Relación entre la evapotranspiración y precipitación anual (A) y el excedente de agua (precipitación - evapotranspiración anual, B) utilizando la fórmula de Zhang et al. (2001). Adaptación al castellano del texto original.

Grafico I.2. Conceptualización del modelo hipotético propuesto por Jobbágy y Jackson (2004) sobre la acumulación de sales en el suelo bajo distintos usos productivos .37

Gráfico II.1. Relación entre la densidad (árboles ha- $\left.{ }^{-1}, A\right)$ y el área basal $\left(A B, m^{2} h^{-1}\right)$ y entre la cobertura aérea del dosel arbóreo (\%) y el área basal (B) de los distintos rodales de Eucalyptus spp.

Gráfico II.2. Conductividad eléctrica del suelo (CE, $\mu S \mathrm{~cm}^{-1}$ ) en invierno de las parcelas con una cobertura herbácea (cultivos y pastizales) y forestal, en las distintas localidades (Balcarce-Lobería, Azul y Guaminí) a lo largo de la transecta estudiada. Letras diferentes indican diferencias significativas para un $p<0,05$ .52

Gráfico II.3. Conductividad eléctrica del suelo (CE, $\mu S \mathrm{~cm}^{-1}$ ) en invierno de las parcelas herbáceas y forestales en las distintas texturas de suelo. Letras diferentes indican diferencias significativas para un $p<0,05$

Gráfico II.4. Conductividad eléctrica del suelo (CE, $\left.\mu \mathrm{S} \mathrm{cm}^{-1}\right)$ en invierno a las distintas profundidades de muestreo de las parcelas herbáceas y forestales, en tres sitios (G2, G4 y G5) ubicados en la localidad de Guaminí (sector Oeste de la transecta). El asterisco muestra la profundidad en la que se encontraron diferencias significativas ( $p$ $<0,05)$.

Gráfico II.5. Conductividad eléctrica del suelo (CE, $\mu S \mathrm{~cm}^{-1}$ ) en invierno a las distintas profundidades de muestreo en las parcelas herbáceas y forestales, en seis sitios (A2, A3, A4, A5, A6 y A7) ubicados en la localidad de Azul (sector centro de la transecta). El asterisco muestra la profundidad en la que se encontraron diferencias significativas $(p<0,05)$ 
Gráfico II.6. Conductividad eléctrica del suelo ( $\left.C E, \mu S \mathrm{~cm}^{-1}\right)$ en invierno a las distintas profundidades de muestreo de las parcelas herbáceas y forestales en el sitio B3, ubicado en la localidad de Balcarce-Lobería (sector este de la transecta). El asterisco muestra la profundidad en la que se encontraron diferencias significativas ( $p<$ $0,05)$

Gráfico II.7. $\mathrm{pH}$ del suelo en invierno a las distintas profundidades de muestreo en las parcelas herbáceas y forestales, en cinco sitios (G1, G2, G4, G5 y G6) ubicados en la localidad de Guaminí (Oeste de la transecta). El asterisco muestra la profundidad en la que se encontraron diferencias significativas $(p<0,05)$. .57

Gráfico II.8. pH del suelo en invierno a las distintas profundidades de muestreo en las parcelas herbáceas y forestales, en cuatro sitios (A2, A4, A5 y A7) ubicados en la localidad de Azul (sector centro de la transecta). El asterisco muestra la profundidad en la que se encontraron diferencias significativas $(p<0,05)$ .57

Gráfico II.9. pH del suelo en invierno a las distintas profundidades de muestreo de las parcelas herbáceas y forestales en los sitios B1,B2 y B3, ubicados en la localidad de Balcarce-Lobería (sector este de la transecta). El asterisco muestra la profundidad en la que se encontraron diferencias significativas $(p<0,05)$.

Gráfico II.10. Conductividad eléctrica del suelo (CE, $\mu \mathrm{S} \mathrm{cm}^{-1}$ ) en verano de las parcelas con una cobertura herbácea (cultivos y pastizales) y forestal, en las distintas localidades (Balcarce-Lobería, Azul y Guaminí) a lo largo de la transecta estudiada. Letras diferentes indican diferencias significativas para un $p<0,05$.

.59

Gráfico II.11. Conductividad eléctrica del suelo (CE, $\mu S \mathrm{~cm}^{-1}$ ) en verano de las parcelas herbáceas y forestales en las distintas texturas de suelo. Letras diferentes indican diferencias significativas para un $p<0,05$. .60

Gráfico II.12. Conductividad eléctrica del suelo (CE, $\mu S \mathrm{~cm}^{-1}$ ) en verano a las distintas profundidades de muestreo de las parcelas herbáceas y forestales, en tres sitios (G2, G4 y G5) ubicados en la localidad de Guaminí (sector Oeste de la transecta). El asterisco muestra la profundidad en la que se encontraron diferencias significativas ( $p$ $<0,05)$ 
Gráfico II.13. Conductividad eléctrica del suelo (CE, $\mu S \mathrm{~cm}^{-1}$ ) en verano a las distintas profundidades de muestreo en las parcelas herbáceas y forestales, en seis sitios (A2, A3, A4, A5, A6 y A7) ubicados en la localidad de Azul (sector centro de la transecta). El asterisco muestra la profundidad en la que se encontraron diferencias significativas $(p<0,05)$ 62

Gráfico II.14. Conductividad eléctrica del suelo (CE, $\mu S \mathrm{~cm}^{-1}$ ) en verano a las distintas profundidades de muestreo de las parcelas herbáceas y forestales en el sitio B1, ubicado en la localidad de Balcarce-Lobería (sector este de la transecta). El asterisco muestra la profundidad en la que se encontraron diferencias significativas ( $p<$ $0,05)$.

Gráfico II.15. Conductividad eléctrica del suelo ( $\left.\mathrm{CE}, \mu \mathrm{S} \mathrm{cm}^{-1}\right)$ verano vs invierno hasta los $40 \mathrm{~cm}$ de profundidad, de las parcelas con una cobertura herbácea (cultivos y pastizales) y forestal, en las distintas localidades (Balcarce-Lobería, Azul y Guaminí) a lo largo de la transecta estudiada. Letras diferentes indican diferencias significativas para un $p<0,05$

Gráfico III.1. Cobertura del dosel arbóreo (\%) y sus desvíos para cada parcela de la localidad de Tandil. Entre paréntesis especie correspondiente a cada parcela (Pr: Pinus radiata, Ev: Eucalyptus viminalis, Ed: Eucalyptus dalrympeana). Letras distintas indican diferencias significativas entre parcelas con un $p<0,05$

Gráfico III.2. Relación entre la cobertura (\%) de distintas parcelas forestadas con Pinus radiata y la CE del suelo promedio $\left(\mu \mathrm{S} \mathrm{cm}^{-1}\right)$. PD1, PD2 y PD3 representan macizos forestales sin manejo; F11 y F21 representan las fajas silvopastoriles y TR la tala rasa. .80

Gráfico III.3. Cobertura del dosel arbóreo (\%) y sus desvíos para cada parcela del sitio CRS (localidad de Pila). Entre paréntesis especie correspondiente a cada parcela (Ev: Eucalyptus viminalis, Ec: Eucalyptus camaldulensis). Letras distintas indican diferencias significativas entre parcelas forestadas con un $p<0,05$. .81

Gráfico IV.1. Evolución de las precipitaciones totales 2016-2017 a lo largo de las estaciones del año. $\mathrm{pp}=$ precipitaciones en $\mathrm{mm}$ .99 
Gráfico IV.2. Distribución de los componentes; $\mathrm{Tr}=$ trascolación, Ef = escurrimiento fustal e I = Interceptación, en relación con la precipitación total que incide sobre la plantación de Eucalyptus viminalis.

Gráfico IV.3. Redistribución porcentual de los componentes; Trascolación, interceptación y escurrimiento fustal sobre la forestación de Eucalyptus viminalis. .100

Gráfico IV.4. Humedad volumétrica del suelo promedio $\left(\mathrm{m}^{3} \mathrm{~m}^{-3}\right)$ a $20 \mathrm{~cm}$ de profundidad, para la parcela herbácea y forestal en cada estación del año, a lo largo de los dos años de muestreo (no se muestran los desvíos en orden de tener mayor claridad en el gráfico) 101

Gráfico IV.5. Humedad volumétrica del suelo promedio $\left(\mathrm{m}^{3} \mathrm{~m}^{-3}\right)$ a $50 \mathrm{~cm}$ de profundidad para la parcela herbácea y forestal en cada estación del año, a lo largo de los dos años de muestreo (no se muestran los desvíos en orden de tener mayor claridad en el gráfico). .102

Gráfico IV.6. Conductividad eléctrica del suelo promedio (CE; $\mu S \mathrm{~cm}^{-1}$ ) a $20 \mathrm{~cm}$ de profundidad, para la parcela herbácea y forestal en cada estación del año, a lo largo de los dos años de muestreo (no se muestran los desvíos en orden de tener mayor claridad en el gráfico). 103

Gráfico IV.7. Conductividad eléctrica del suelo promedio (CE; $\mu S \mathrm{~cm}^{-1}$ ) a $50 \mathrm{~cm}$ de profundidad para la parcela herbácea y forestal en cada estación del año, a lo largo de los dos años de muestreo (no se muestran los desvíos en orden de tener mayor claridad en el gráfico) 103

Gráfico IV.8. Profundidad del acuífero freático $(\mathrm{m})$ para la parcela herbácea y forestal en cada estación del año, a lo largo de los dos años de muestreo 104

Gráfico IV.9. Profundidad del acuífero freático $(\mathrm{m})$ para la parcela herbácea y forestal, desde el 20/9/2017 al 22/9/17, durante la mínima profundidad medida. 104 
Gráfico IV.10. Profundidad del acuífero freático $(\mathrm{m})$ para la parcela herbácea y forestal, desde el 9/12/2017 al 11/12/2017, cuando la profundidad es menor en la parcela herbácea.

Gráfico IV.11. Conductividad eléctrica del acuífero freático $\left(\mathrm{CE} ; \mu \mathrm{S} \mathrm{cm}^{-1}\right)$ para la parcela herbácea y forestal en cada estación del año, a lo largo de los dos años de muestreo.

.105

Gráfico IV.12. Precipitación ( $\mathrm{pp}, \mathrm{mm}$ ), transpiración promedio $\left(\mathrm{T} ; \mathrm{mm}\right.$ día $^{-1}$ ) y déficit de presión de vapor (DPV; kPa) durante los meses de Febrero y Marzo del 2016.........106

Gráfico IV.13. Transpiración promedio $\left(T ; \mathrm{mm} \mathrm{día}^{-1}\right)$ en función de cada una de las clases diamétricas. 107

Gráfico IV.14. Transpiración diaria $\left(\mathrm{T}, \mathrm{mm}\right.$ día $\left.{ }^{-1}\right)$ medida para Eucalyptus viminalis y simulada durante el mismo periodo para los cultivos de maíz (Zea mays), soja (Glycine max) y girasol (Helianthus annuus). .108 


\section{AGRADECIMIENTOS}

En primer lugar a mi mujer Melina, compañera de vida en los buenos y malos momentos. Gracias por alentarme, retarme, aguantarme, amarme, y sobre todo por darme esa visión distinta de las cosas que tantas veces me aclaro el horizonte.

A mis padres Marcelo y Adriana, por su sacrificio y amor que me permitió desarrollarme sin limitantes y en tranquilidad en cada etapa de mi vida. A mi hermana Rocío, mi amiga y compinche preferida. A mis abuelos Raúl y Aida, por su amor eterno que marcó mi vida, siempre estarán en lo más profundo de mi corazón.

A mi país, por la oportunidad de tener educación gratuita de calidad. A dios por darme salud y mostrarme que el camino más duro a seguir es el que más satisfacciones da.

A mis amigos Javier Grosso y Claudio Mujica, por las tantas charlas y reniegos que nos hemos trasmitido mutuamente, siempre me resulta una sana terapia.

A Horacio Borzone, por mostrarme el camino a seguir en el mundo académico y ser el pie que permitió mi formación de postgrado.

A Javier Gyenge, por guiarme en el paso a paso y colaborar en cada etapa de mi formación.

A Corina Graciano y Sergio Bea, por sus participaciones salvadoras y oportunas cada vez que fue necesario.

Al IHLLA, por darme muchas de las herramientas necesarias para mi formación, nuevamente a Javier Gyenge, Claudio Mujica y Diego Daguer por la colaboración en la tareas a campo, a Rafael Bilotta por la disposición de sus forestaciones y a Bernardo Lamas por su interés y disposición plena del campo durante más de 2 años. 


\section{DEDICATORIA}

En memoria de Aida Alonso y Raúl Milione. Siempre van a estar en mi corazón. 


\section{RESUMEN}

La forestación con especies de rápido crecimiento donde la vegetación original era la de pastizal puede traer aparejado cambios en los flujos de agua, causando la movilización de las sales disueltas en el suelo y en las aguas subterráneas. Así, el proceso de salinización secundaría debido al cambio de vegetación, dependerá de factores climáticos, hidrogeológicos y biológicos. Para caracterizar este proceso se realizó un muestreo extensivo, donde se midió la conductividad eléctrica (CE) y el pH del suelo. En primer lugar se establecieron 16 parcelas apareadas (forestación con Eucalyptus spp. vs agricultura / pastizal) distribuidas a lo largo de una transecta de 500 km con dirección Este-Oeste en el centro Sur de la Provincia de Buenos Aires para determinar el efecto de la vegetación dominante, la textura del suelo y el balance hídrico. Este muestreo se repitió en verano e invierno para determinar si existía una fluctuación en relación a la época del año. Además, para determinar el impacto del manejo forestal, las especies forestales y la vegetación dominante sobre las variables mencionadas, se establecieron 12 parcelas apareadas (forestación con Eucalyptus spp., y Pinus radiata vs agricultura / pastizal) en el sistema de Sierras de Tandilia y 5 parcelas en la Cuenca del Salado (dos forestaciones de Eucalyptus viminalis Labill, dos con Eucalyptus camaldulensis Dehnh, y otra en un pastizal natural bajo uso pastoril). Finalmente para analizar la dinámica de las sales y el agua en el suelo de manera continua en función de los parámetros atmosféricos e hidrogeológicos, se establecieron dos parcelas en la localidad de Azul, una ubicada en una forestación con Eucalyptus viminalis Labill y otra en un pastizal herbáceo pareado.

Los resultados obtenidos en la transecta indicaron que los valores de la CE del suelo bajo forestaciones, pastizales o cultivos estuvieron por debajo de aquellos que puedan comprometer la producción futura. Se observó que los menores valores de CE se correspondieron con los suelos de textura arenosa y balances hídricos negativos, independientemente de la vegetación dominante. Por otro lado, se encontraron los valores más altos de CE en los suelos de textura franco-fina y balances hídricos positivos, en la mayoría de los casos superiores en la parcela forestal. Además la CE del suelo no presentó un claro patrón estacional.

Se encontró una relación entre las variables del suelo analizadas y el manejo forestal. En este sentido, se detectó una correlación positiva entre la cobertura y la CE del suelo, observándose además, un rápido lavado de las sales acumuladas luego de realizar el aprovechamiento de la masa forestal. Asimismo, no se encontraron 
diferencias de CE del suelo bajo las forestaciones con especies más tolerantes a la salinidad.

Finalmente, en el muestreo continuo se hipotetizó una ausencia de conexión de la vegetación con el acuífero freático, y se encontró un perfil de suelo más seco debajo de la forestación. Además, se registraron niveles de transpiración en la forestación que fueron similares a los resultados obtenidos mediante el modelado numérico de un cultivo de Glycine max en el mismo momento y sitio.

Se concluyó que, para la zona de estudio, no existen evidencias de un proceso generalizado de salinización secundaria del suelo debido al cambio de vegetación. Asimismo, se remarca la importancia del manejo forestal como factor fundamental para mantener el equilibrio hídrico-salino. En este sentido son necesarios los estudios a escala local, para desarrollar y aplicar normas de manejo sustentable a nivel de predio o parcela, en base a los impactos sobre los recursos del suelo producidos por las actividades productivas mencionadas. 


\section{ABSTRACT}

Afforestation with fast-growing species where the original vegetation was grassland can change water flows, causing also the mobilization of dissolved salts in the soil and in groundwater. The process and magnitude of secondary salinization due to the change in vegetation, will depend on climatic, hydrogeological and biological factors. To characterize this process an extensive sampling was carried out, where the electrical conductivity (CE) and the $\mathrm{pH}$ of the soil were measured. At the first time, 16 paired plots (afforestation with Eucalyptus spp. vs. agriculture / grassland) were distributed along a $500 \mathrm{~km}$ transect with East-West direction in the South Center of the Province of Buenos Aires to study the effect of the dominant vegetation, soil texture and water balance. This sampling was repeated in summer and winter in order to determine the fluctuation of CE in relation to the time of year,. Also, in order to analyze the effect of forest management, forest species and dominant vegetation, we stablished 12 paired plots (afforestation with Eucalyptus spp. and Pinus radiata vs. agriculture / pasture) in the system of Tandilia saws and 5 plots in the salty basin situated in the Salado river basin (two afforestation of Eucalyptus viminalis Labill, two with Eucalyptus camaldulensis Dehnh, and another in a natural pasture under livestock use). Finally, to analyze the dynamics of salts and water in the soil based on the atmospheric and hydrogeological parameters in an continuous way, two plots were established in the town of Azul, one located in a plantation with Eucalyptus viminalis Labill and another in a herbaceous paired pasture.

The EC values of the soil founded under afforestation, pasture or crops never reached a threshold that could jeopardize future production. It was observed that the lower EC values of the soil correspond to the soils of sandy texture and negative water balances, independently of the dominant vegetation. On the other hand, the highest EC values were found in the soils with loam-fine texture and positive water balances, in most cases higher in the forest plot. In addition, the CE of the soils did not show a clear seasonal pattern.

A relationship between the soil variables analyzed and forest management was found. In this sense, a positive correlation was detected between the forest cover and the EC of the soil, observing in addition, a very low values of CE in soil after two years of forest harvesting, indicating a rapid washing of the accumulated salts. Likewise, no differences were found of CE of the soil under afforestation with species more tolerant to salinity. 
Finally, in intensive sampling there was an hypothesized absence of connection of the vegetation with the water table and found, a drier soil profile below the afforestation. In addition, transpiration levels in the afforestation were similar to those estimated through a numerical modeling of a Glycine max culture at the same time and site.

It was concluded that there is no evidence of a generalized process of secondary soil salinization due to vegetation change. Likewise, the importance of forest management as a fundamental factor to maintain the water-salt balance is highlighted. In this sense, studies at a local scale are necessary to develop and apply sustainable management norms at the plot level, based on the impacts on soil resources produced by the mentioned productive activities. 


\section{Capítulo 1}

Introducción 


\subsection{INTRODUCCIÓN GENERAL}

\subsubsection{Estado de las forestaciones de Argentina en el contexto mundial}

Según datos de la Organización de las Naciones Unidas para la Agricultura y la Alimentación (Food and Agriculture Organization, FAO), para el año 2010 las plantaciones forestales constituían aproximadamente el $7 \%$ del área total de bosques, equivalente a 264 millones de hectáreas, y se calcula que para el año 2020 el área de bosques plantados habrá llegado a ocupar 300 millones de hectáreas en todo el mundo (MAGPyA 2014). Los impulsores de este incremento constante pueden ser económicos; debido a la entrada en vigencia del protocolo de Kyoto en el 2005 con la consecuente expansión del mercado de bonos de carbono a lo cual se le suma el crecimiento de la población mundial acompañado por un aumento de la demanda de productos forestales (BCBA 2015, WWAP 2015, Wright et al. 2000).

Datos oficiales del Ministerio de Agricultura, Ganadería, Pesca y Alimentos (MAGPyA 2014) muestran que Argentina cuenta con 1,2 millones de hectáreas de bosques cultivados, predominando las forestaciones de pinos (Pinus spp.), eucaliptos (Eucalyptus spp.), sauces (Salix spp.) y álamos (Populus spp.), de las cuales el $80 \%$ se concentra en la Mesopotamia (provincias de Misiones, Corrientes y Entre Ríos) y en el delta del río Paraná. Si bien en los últimos años el crecimiento de la superficie de bosques cultivados en Argentina ha sido lento y está lejos del máximo alcanzado en el período 1992-2001 (donde se pasó de 23.000 a 125.000 ha plantadas anualmente) (SAGPyA 2002), se sigue observando un incremento del número de hectáreas bajo uso forestal. Desde el año 2002 a la fecha el país paso de 1,1 a 1,2 millones de hectáreas de bosques cultivados (es decir aproximadamente 7000 ha/año) (MAGPyA 2016). Por otro lado, como aliciente para que la expansión continúe, Argentina dispone de una gran superficie con tierras aptas para la forestación, además de diversidad de climas y suelos lo cual asegura una producción forestal económicamente competitiva. La productividad de las plantaciones en Argentina es alta ya que iguala o supera a la de muchos países tradicionalmente forestales. Sumado a lo anterior existe evidencia experimental de que la misma puede ser aumentada con mejoramiento genético (MAGyP 2014). Desde un punto de vista económico, existen grandes ventajas comparativas a través de los incentivos para la producción forestal otorgados por el Estado Nacional que garantizan una estabilidad fiscal, un apoyo económico no reintegrable a las plantaciones forestales y un tratamiento impositivo muy favorable para las inversiones en el sector forestal a través de la Ley $N^{\circ} \mathbf{2 5 . 0 8 0}$ de Inversiones para Bosques Cultivados, prorrogada y modificada por la Ley $\mathrm{N}^{\circ} 26.432$, siendo la autoridad de aplicación el Ministerio de Agroindustria de la Nación (actual Secretaría). 
De esta manera se beneficia la instalación de nuevos proyectos foresto-industriales y las ampliaciones de los existentes, mediante beneficios impositivos e importes para el manejo sostenible, mientras exista el compromiso de aumentar la oferta maderera a través de la generación de nuevas plantaciones (MAGyP 2014).

\subsubsection{Forestaciones y uso de agua}

Existe una opinión generalizada, que supone que los cambios más abruptos en la hidrología se generan ante procesos de deforestación y el posterior reemplazo por cultivos herbáceos. Pero su proceso inverso, es decir la introducción de árboles en sistemas dominados originalmente por herbáceas, también ha sido considerado como una fuente de cambios edáficos e hidrológicos (Zhang et al. 2003, Nosetto et al. 2012, Farley et al. 2005). En este sentido, tanto los modelos climáticos como el crecimiento poblacional indican que para el año 2030 el mundo tendrá que enfrentarse a una reducción de las reservas de agua dulce (WWAP 2015), así se origina la preocupación por estudiar el impacto del avance de las forestaciones con especies de rápido crecimiento sobre los recursos hídricos.

Para cuantificar el ciclo hidrológico (la cantidad de agua que circula y se almacena en una determinada cuenca) es necesario el análisis de la ecuación general de balance hídrico. De manera sencilla, Ruíz de Galarreta y Rodríguez (2013) mencionan que la variación en el almacenaje de agua en el suelo depende de la diferencia entre la magnitud de agua que ingresa y egresa del sistema:

$$
\text { Ingresos - egresos = variación en el almacenaje }
$$

Matemáticamente se puede desglosar la ecuación anterior en distintos subcomponentes:

(Afl. Super. + Afl. Sub. + pp + A. imp.) - (Efl. Super. + Efl. Sub. + EVT+ A. Exp.) $=+/-\Delta$ Alm. Super. $+/-\Delta$ Alm. Sub.

\section{Donde:}

Ingresos a la cuenca:

Afl. Super.: Afluencia superficial (entrada superficial; es decir ríos, arroyos, etc.)

Afl. Sub.: Afluencia subterránea (entrada de agua subterránea)

pp: precipitaciones (entrada de agua atmosférica)

A. imp.: Agua importada (entrada de agua antrópica, por ejemplo riego) 
Egresos de la cuenca:

Efl. Super.: Efluencia superficial (salida superficial; es decir ríos, arroyos, etc.)

Efl. Sub.: Efluencia subterránea (salida de agua subterránea)

EVT: Evapotranspiración (salidas por acción conjunta de la evaporación y transpiración)

A. Exp.: Agua exportada (salida de agua antrópica, por ejemplo riego o consumo)

Variación del almacenaje:

+/- $\Delta$ Alm. Super.: Variación del almacenaje superficial (agua retenida en los sectores bajos de la cuenca)

+/- $\Delta$ Alm. Sub.: Variación del almacenaje subterráneo (aumento o disminución de los niveles piezométricos)

Es conocido como la vegetación ejerce una fuerte influencia sobre la dinámica del agua y los solutos, determinando cambios en distintos parámetros de este balance hídrico y químico del suelo. Así, los flujos de evapotranspiración real (EVT) y de escorrentía o drenaje (afluencias y efluencias) pueden variar su magnitud ante el cambio de la cobertura y/o sustitución de las especies vegetales en interacción con las características propias del sitio. Zhang et al. (2001) modelaron la relación entre la (EVT) anual de un ecosistema y la precipitación media anual del sitio a partir de datos de evapotranspiración potencial (ETP), precipitación y cobertura vegetal (Grafico I.1. A). Estos autores encontraron una relación asintótica en donde el valor máximo de EVT de los pastizales es menor que el de los bosques (Grafico I.1. A). Las forestaciones a través de su gran rugosidad y bajo albedo (Kelliher et al., 1993, Calder 1998, Zhang et al. 2001), sumado a la capacidad de sus sistemas radiculares de explorar perfiles profundos de suelo, pueden lograr altos valores de EVT de un sistema (Gyenge et al. 2011, Jobbágy y Jackson 2004). Dada la distinta magnitud de la EVT de cada ecosistema, los excedentes hídricos (precipitación anual menos la EVT anual) a un mismo nivel de precipitación, serán mayores en un pastizal que en un bosque (Grafico I.1. B). A pesar de la sencillez del modelo desarrollado por Zhang et al. (2001), el mismo representa con una alta precisión el comportamiento hidrológico observado en cuencas apareadas en donde en una de ellas se practicó la introducción o cosecha de árboles (forestación y/o deforestación, Brown et al. 2005). Sin embargo, es importante mencionar que existen diferencias de EVT dentro de cada grupo funcional (árboles, cultivos o pasturas). Por ejemplo, si se compara el consumo de 
agua de especies forestales, los árboles de rápido crecimiento consumen más agua que los de menor productividad (bosques implantados en comparación con ciertos bosques nativos; Gyenge et al. 2011, Nosetto et al. 2008, 2012). Incluso, el impacto sobre los recursos hídricos será distinto comparando especies forestales cultivadas entre sí. En este sentido, son claras las diferencias del impacto producido sobre los recursos hídricos al comparar dos géneros de especies forestales perennes, eucaliptos y pinos (Farley et al. 2005). Otros elementos a considerar en la dinámica hídrica son: a) el aumento del consumo de agua a medida que el árbol incrementa su tamaño (Gyenge et al. 2008), b) las variaciones debido al grado de competencia intraespecífica experimentado por cada individuo (Gyenge et al. 2012) y c) la cantidad de área foliar manejada a través de la poda (Gyenge et al. 2009). De manera similar, la EVT de los cultivos no-leñosos también difiere entre sí, observándose que en conjunto, muestran menor uso del agua que los bosques (Nosetto et al. 2012). En este sentido, Nosetto et al. (2008) a partir del análisis de 13 imágenes Landsat, estimaron para la zona este de Entre Ríos, Argentina, una EVT similar entre bosques nativos y plantaciones forestales (promedio de aproximadamente $3,15 \mathrm{~mm} \mathrm{día}^{-1}$ ), siendo mayor que la de pastizales y el conjunto de Triticum sp. / Glycine max (aproximadamente 2,15 $\mathrm{mm}$ día $^{-1}$ ), estimándose un menor consumo aún con el cultivo exclusivo de Glycine max (1,85 mm día $\left.{ }^{-1}\right)$. Así, si bien el modelo de Zhang et al. (2001) estima un valor promedio (Gráfico I.1.), es importante determinar el verdadero uso del agua del sistema si se quiere establecer posibles impactos sobre los recursos hídricos de las distintas coberturas vegetales.
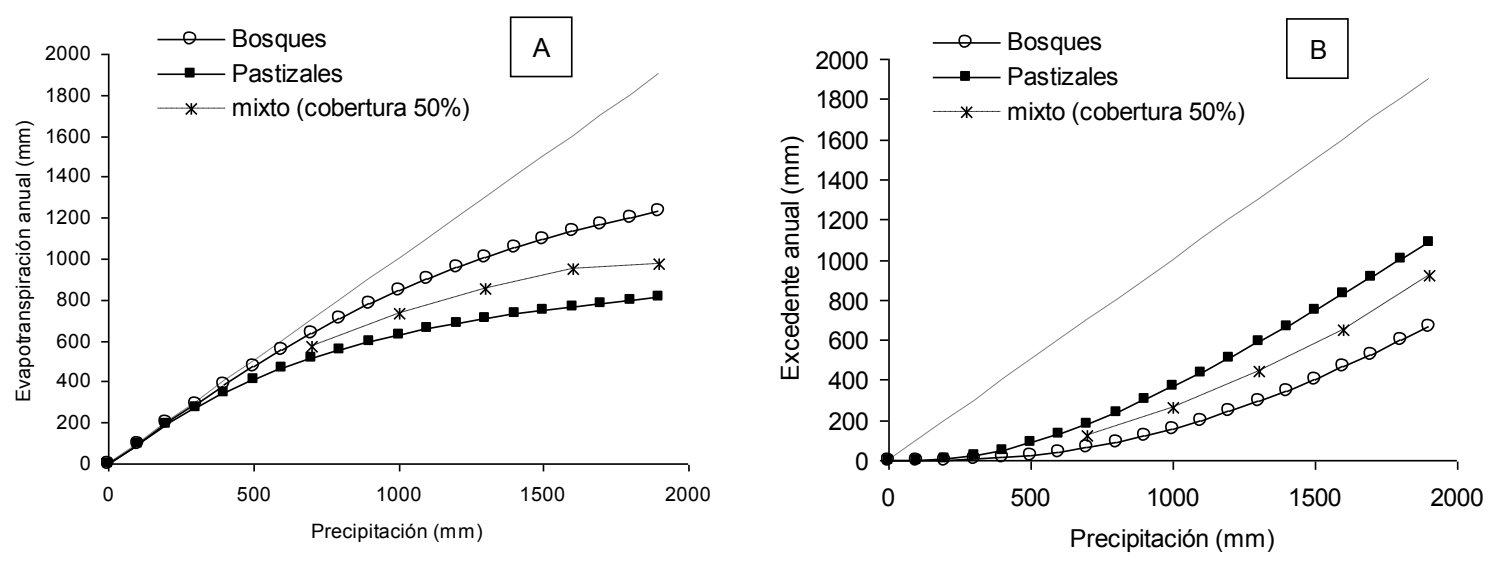

Grafico I.1. Relación entre la evapotranspiración y precipitación anual (A) y el excedente de agua (precipitación - evapotranspiración anual, B) utilizando la fórmula de Zhang et al. (2001). Adaptación al castellano del texto original. 
Dependiendo de la profundidad del acuífero freático, la textura del suelo y la presencia de horizontes masivos, la vegetación puede hacer uso del agua subterránea desacoplando su transpiración del contenido de agua en la zona del suelo no saturada. Este desacople significa que la planta podrá seguir transpirando a una alta tasa aunque el potencial agua en el suelo no saturado esté muy bajo. Es conocida la capacidad de los árboles de explorar suelos profundos, aunque también los cultivos pueden acceder al acuífero freático o a los perfiles de suelo que se recargan de manera capilar (Engel et al. 2005, Nosetto et al. 2009). Esta capacidad de acceder a una fuente relativamente estable de agua permite mantener altas tasas de uso de la misma y de fijación de carbono, procesos que determinarán la productividad de los cultivos (Nosetto et al. 2009) y su eficiencia en el uso del agua. De esta manera, como mencionan Jobbágy et al. (2007), el análisis de los riesgos y oportunidades asociados al uso del acuífero freático no debe ignorar que los agroecosistemas afectan los niveles freáticos regulando el excedente de precipitaciones que alimenta el acuífero (recarga), así como también, su consumo y evacuación evaporativa (descarga).

Los ejemplos anteriormente expuestos ponen en evidencia, que si bien podría hacerse una generalización sobre el uso del agua en relación a los distintos usos primarios de la tierra (pastizal, cultivos agrícolas, forestaciones, bosques nativos, p.e.), es necesario tener en cuenta los principios biológicos que determinan las tasas de uso del agua (área foliar, rugosidad, capacidad de explorar distintas profundidades de suelo, entre otras) en interacción con las características ecológicas del sitio (profundidad, textura del suelo, horizontes compactados, concentración de sales, humedad atmosférica, entre los principales.) para poder estimar el verdadero impacto que un cambio en el uso del suelo puede tener sobre los recursos hídricos locales.

\subsubsection{Forestaciones y salinización secundaria}

Así como la vegetación influye sobre la dinámica del agua en el suelo, también lo hace sobre los solutos de la misma, documentándose numerosos ejemplos de cambios en la magnitud de nutrientes o sales en el suelo bajo distintos tipos de vegetación (Karmakar et al. 2016). Este último proceso, denominado salinización secundaria, se produce como fruto de alguna actividad antrópica que rompe el equilibrio hídrico causando la removilización de las sales desde fuentes cercanas (subsuelos salinos, aguas subterráneas, p.e.). Esta salinización puede observarse tanto a nivel de paisaje como de predio o parcela. En este sentido, es paradigmático el caso de Australia en donde la deforestación de una amplia superficie de las partes altas de las cuencas y el reemplazo por cultivos herbáceos, generó un lixiviado de 
sales almacenadas en grandes cantidades en perfiles profundos del suelo y un incremento de la recarga del acuífero. Como consecuencia de la recarga se produjo un ascenso progresivo del acuífero, el cual trajo consigo sales acumuladas en perfiles profundos del suelo, generando una extensa salinización de suelos situados en la parte baja de la cuenca (George et al. 1997, Rengasamy 2006). Este proceso de aumento de la recarga y ascenso del acuífero, parecería replicarse en la provincia fitogeográfica Chaqueña (Argentina), con un ecosistema boscoso de parque que fue y sigue siendo reemplazado por cultivos anuales (Amdan et al. 2013), aunque sin el problema consecuente de la salinización. A una escala predial, Nosetto et al. (2008) midieron en la región de la Cuenca del Río Salado (provincia de Buenos Aires) una mayor salinidad en el suelo debajo de forestaciones que de pastizales, incrementándose dichas diferencias en los sitios con balances hídricos inferiores a los $50 \mathrm{~mm}$ año ${ }^{-1}$ (diferencia entre el valor de precipitación media anual y el valor de evapotranspiración potencial según Penman-Monteith). Estos mismos autores también encontraron en maizales (Zea mays) de Córdoba, Argentina, donde la media anual de precipitaciones es de $740 \mathrm{~mm}$ año ${ }^{-1}$, un incremento en la salinización de suelos a medida que avanzaba la temporada de crecimiento (Nosetto et al. 2009). Este efecto fue más marcado en los sitios donde el acuífero freático (con más de $7 \mathrm{dS} \mathrm{m}^{-1}$ ) presentó una menor profundidad. Sin embargo, tanto el contenido de sales del suelo como la profundidad del acuífero freático mostraron valores acordes a la situación testigo seis meses luego de la cosecha de Zea mays (Nosetto et al. 2009). Los autores hipotetizaron que la magnitud de la salinización de suelo y del acuífero se debió al consumo diferencial de agua dado por las características ecofisiológicas de las especies que conforman la cobertura vegetal (capacidad de explorar mayores profundidades de suelo y así establecer una conexión con la capa freática, tolerancia a la salinidad, entre otros), la presencia de un acuífero freático con sales, balances hídricos negativos y la ausencia de lavado de sales del suelo. Este último factor es de suma importancia, ya que los sistemas de producción anuales permitirían un lavado de sales que no ocurriría, u ocurriría en menor escala, en los sistemas de cobertura permanente.

Así se demostró que asociado a los cambios de magnitud de los componentes del balance hídrico, se podría producir una acumulación de sales debajo de las forestaciones motivada por diversos aspectos de índole biológico, climático y edáfico (Nosetto et al. 2008). Por estos motivos, es importante delimitar dos niveles de análisis, aquellos a escala de parcela y aquellos a nivel de paisaje, teniendo en cuenta aquellos factores que permiten el drenaje y lavado de sales. 


\subsubsection{Forestaciones y $\mathrm{pH}$}

El uso agrícola del suelo, en especial la siembra directa, en conjunto con el uso de fertilizantes de reacción ácida, genera una paulatina acidificación de los suelos (Wyngaard et al. 2012, Divito et al. 2011). Asimismo, las forestaciones también pueden ocasionar acidez en los suelos debido a la alta extracción de cationes (Amiotti et al. 2000, Jobbágy and Jackson 2003). Sin embargo, este proceso está influenciado por la especie arbórea en cuestión (Castro Diez et al. 2012), así por ejemplo Jobbágy et al. (2006) citan que debido a la acumulación en corteza y biomasa, los Eucalyptus spp. generaron caídas de $\mathrm{pH}$ significativamente más fuertes que los pinos.

El estudio de estos cambios es fundamental, dado que el $\mathrm{pH}$ del suelo cumple un rol en el ciclo y disponibilidad de los macronutrientes (nitrógeno y fósforo p.e.) y en la mineralización de la materia orgánica (Amiotti et al. 2000, Nair et al. 2004).

\subsection{SISTEMA DE ESTUDIO}

El área de estudio, centro-sur de la provincia de Buenos Aires (Figura I.1.), comprende distintas regiones geográficas con características particulares de suelos en cuanto a profundidad y granulometría, diferencias en la precipitación media anual y nivel de sales en suelo y agua, que determinan distintos usos de la tierra. Básicamente, en todas estas regiones, la productividad primaria se reduce a cultivos extensivos (Triticum sp., Hordeum vulgare, Zea mays, Glycine max, Helianthus annuus, entre los principales), manejo ganadero en pastizales naturales y, en menor proporción, actividad forestal. Así los suelos más profundos, sin problemas de drenaje o salinidad, se destinan a la agricultura, quedando el resto destinados a la producción ganadera (pastizales) o al cultivo de especies forestales de rápido crecimiento. 


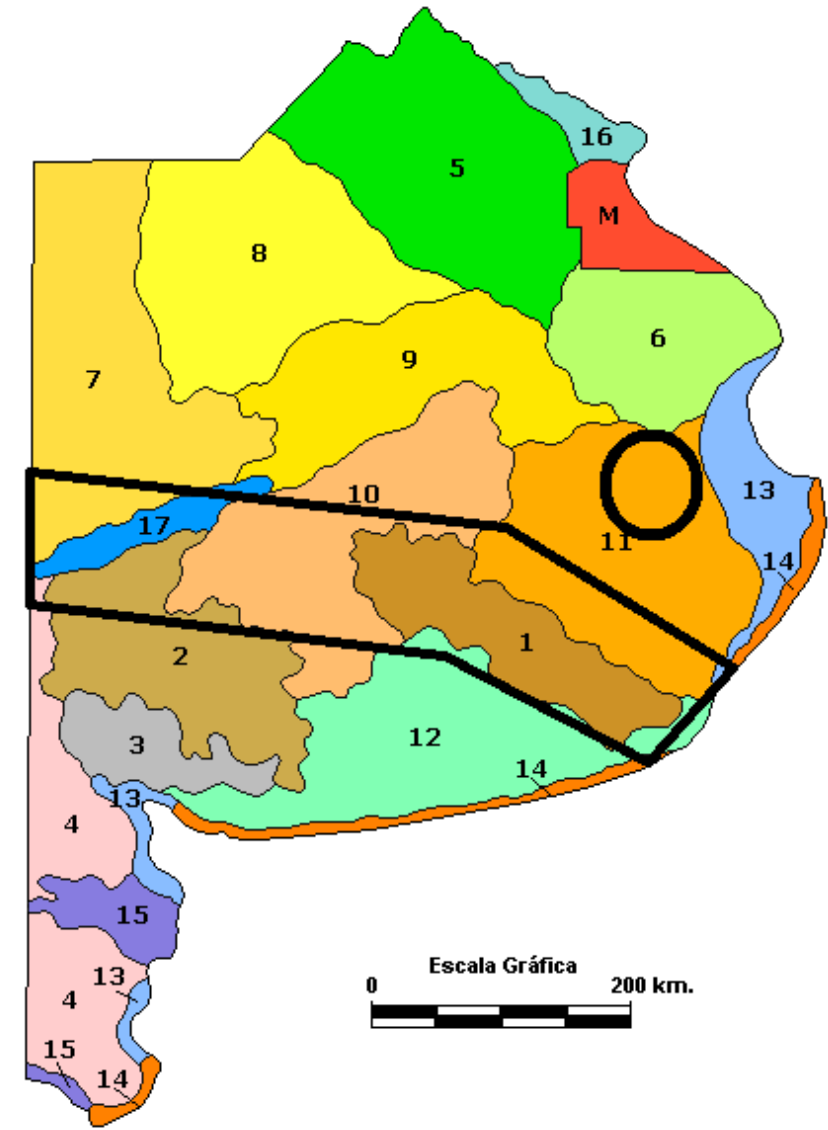

\begin{tabular}{|r|r|r|}
\hline \multicolumn{2}{|c|}{ LEYENDA } & $\begin{array}{c}\text { Sup. } \\
\mathbf{\%}\end{array}$ \\
\hline $\mathbf{1}$ & Sierras y pedemonte de Tandilia & 4,90 \\
\hline $\mathbf{2}$ & Sierras y pedemonte de Ventania & 6,70 \\
\hline $\mathbf{3}$ & Mesetas subventánicas & 2,40 \\
\hline $\mathbf{4}$ & Mesetas patagónicas & 6,00 \\
\hline $\mathbf{5}$ & Pampa ondulada alta & 10,10 \\
\hline $\mathbf{6}$ & Pampa ondulada baja & 5,20 \\
\hline $\mathbf{7}$ & Pampa arenosa occidental & 10,10 \\
\hline $\mathbf{8}$ & Pampa arenosa central & 9,20 \\
\hline $\mathbf{9}$ & Pampa arenosa oriental & 7,00 \\
\hline $\mathbf{1 0}$ & Pampa deprimida occidental & 8,80 \\
\hline $\mathbf{1 1}$ & Pampa deprimida oriental & 9,80 \\
\hline $\mathbf{1 2}$ & Pampa interserrana & 8,50 \\
\hline $\mathbf{1 3}$ & Llanuras marinas & 3,70 \\
\hline $\mathbf{1 4}$ & Cordones de dunas litorales & 1,80 \\
\hline $\mathbf{1 5}$ & Llanuras fluviales & 1,70 \\
\hline $\mathbf{1 6}$ & Delta & 1,00 \\
\hline $\mathbf{1 7}$ & Depresión lacunar & 1,80 \\
\hline $\mathbf{M}$ & Miscelánea (área urbana) & \\
\hline
\end{tabular}

Arenoso $\longrightarrow$ Arcilloso a Franco arcilloso $\longrightarrow$ Franco arcilloso a Franco

Figura I.1. Mapa de la provincia de Buenos Aires con sus regiones naturales (extraído de http://anterior.inta.gov.ar/suelos/cartas/index.htm). Se detalla la región de estudio y la gradación de texturas de suelo en dirección Oeste a Este

En términos generales, el balance hídrico anual (calculado como la diferencia entre el valor de precipitación media anual y el valor de evapotranspiración de referencia según Penman-Monteith) muestra una gradación NE-SO, pasando de valores positivos o cercanos a cero a valores negativos de hasta $-400 \mathrm{~mm}$ año ${ }^{-1}$ en los límites entre las provincias de Buenos Aires y La Pampa (Figura I.2.). 


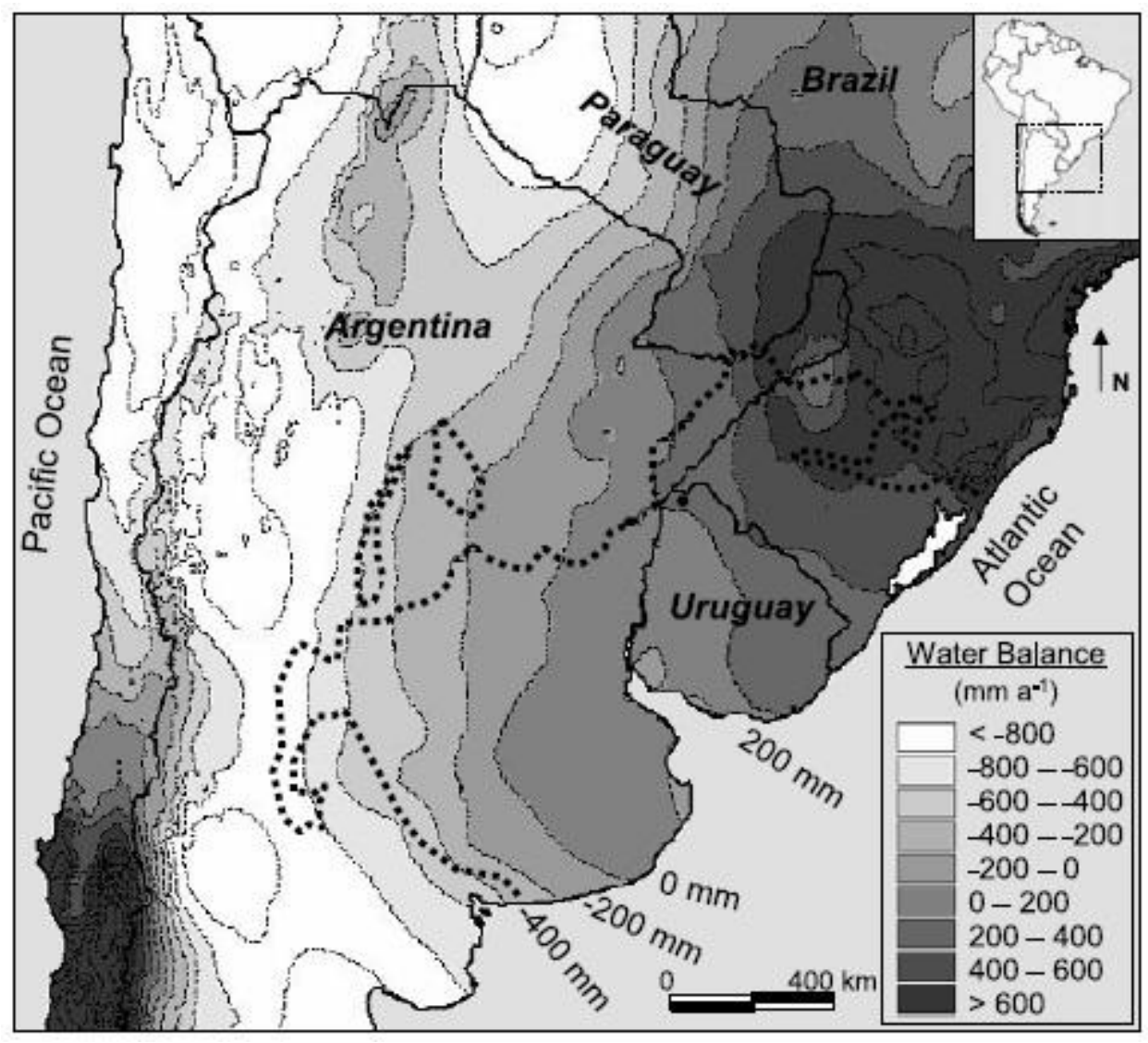

Figura I.2. Mapa de la región en donde se muestra el gradiente NE-SO del balance hídrico anual (Water balance).Con líneas negras se demarca el área de estudio propuesta por los autores donde la vegetación originaria era el pastizal (Extraído de Nosetto et al., 2008).

En el área bajo estudio es posible identificar la subregión Pampa Deprimida (áreas 10 y 11 en la Figura I.1), la cual se corresponde con la cuenca del río Salado. La misma se caracteriza por su producción pastoril, pudiéndose desarrollar cultivos agrícolas o forestales en las zonas más altas (zonas de "loma" dentro del paisaje general). Esta subregión muestra una geografía plana, con suelos de elevados contenidos de arcilla, lo que produce una baja capacidad de drenaje y también una alta retención de agua, alternando períodos de anegamiento y sequía que dificultan el establecimiento de los cultivos. Así, los excesos hídricos son difícilmente evacuados a través de ríos y permanecen en el paisaje hasta ser evacuados por transpiración y evaporación de suelo y charcos/lagunas. De esta manera el acuífero se presenta naturalmente a escasa profundidad interactuando en forma directa con la vegetación y el clima como resultado de la combinación de un balance hídrico positivo y un paisaje con una pobre red de escurrimiento superficial. En estos ambientes, donde el transporte vertical de agua y el almacenamiento local predominan sobre la escorrentía 
superficial (Taboada et al. 2009), la evaporación de los excedentes puede representar entre 90 y $100 \%$ de la descarga total del sistema (Fuschini Mejía 1994; Varni and Usunoff 1999). Así, en el caso de un encharcamiento, Lavado y Taboada (1988) encontraron que el agua de la solución del suelo en la capa superior tenía una CE de $0,3 \mathrm{dS} \mathrm{m}^{-1}$, mientras que el acuífero freático a $0,50 \mathrm{~m}$ de profundidad (en el pico del ascenso) era de $45 \mathrm{dS} \mathrm{m}^{-1}$. Además, en la mayoría de su extensión, se observa un horizonte arcilloso $(\mathrm{Bt})$ bastante impermeable que delimita tanto el lavado de agua dulce de lluvia como el ascenso de una freática cargada de sales. Hacia el sur de esta subregión, se encuentra el área de sierras e intersierras (1, 2 y 12 en la Figura I.1). En general, se observa la alternancia de suelos medianamente profundos y profundos, aptos para el laboreo, con suelos de menor profundidad dada la presencia de rocas o tosca, sitios en donde se asienta mayoritariamente la producción de forrajes y forestal. La heterogeneidad del paisaje en esta región es marcada, existiendo un gradiente de salinidad, aunque con bajos niveles de CE del agua de la freática, entre 0,65 y 0,79 dS $\mathrm{m}^{-1}$, y de profundidad de la freática (de 2 a $15 \mathrm{~m}$ ), dependiendo de la distancia a las zonas de recarga de la cuenca hidrogeológica (Barranquero et al. 2012, Pessolano et al. 2012). Finalmente, hacia el oeste se observan los sitios con balances hídricos más negativos (Figura I.2.) y suelos con altos contenido de arena (subregión pampa arenosa; área 7 en la Figura I.1.) y freáticas con contenidos variables de sales (Nosetto et al. 2009 midieron una CE de agua subterránea de hasta $7 \mathrm{dS} \mathrm{m}^{-1}$ ). De esta manera, como puede observarse, se verifican distintas condiciones ecológicas para los distintos usos del suelo mencionados en donde se podrá poner a prueba las hipótesis que se detallan al final de la introducción.

En la región, el conocimiento del uso y eficiencia en el uso de los recursos que explica la productividad de cultivos y pastizales es absolutamente desigual en relación al de la actividad forestal. Como ejemplo numérico del uso del agua de cultivos, se ha estimado una EVT promedio del cultivo de Glycine max y Zea mays de 3,4 mm día ${ }^{-1}$ para la zona de Balcarce con mínimos de 1,8 y máximos de $5 \mathrm{~mm}$ día ${ }^{-1}$ dependiendo del grado de desarrollo del cultivo, Valenzuela et al. 2009). Para la región de la Depresión del Salado, un análisis espacial del uso consuntivo de agua en la zona arrojó valores promedio de $4 \pm 1$ y $4,7 \pm 1,4 \mathrm{~mm}$ día $^{-1}$ para lotes con pasturas y Glycine max, respectivamente, analizando dos imágenes del mes de marzo (Rivas y Carmona 2013). Por otro lado, existen escasos antecedentes sobre el uso consuntivo de agua de las forestaciones en comparación con otros sistemas en la región, pudiéndose mencionar los trabajos de Engel et al. (2005) y Rébori et al. (2001). Engel et al. (2005), mediante la medición del flujo de savia de los árboles en un rodal de Eucalyptus 
camaldulensis en Castelli (Depresión del Salado), estimaron un promedio anual de 2 $\mathrm{mm}$ día ${ }^{-1}$, con valores máximos de $3,7 \mathrm{~mm}$ día $^{-1}$. Mientras que Rébori et al. (2001), utilizando el modelo SIMGRO, en un rodal de Eucalyptus dunii en el departamento de San Lorenzo (región pampeana, Santa Fe) estimaron un promedio anual de 3,8 mm día $^{-1}$. Estos valores no sugieren un consumo excesivo de agua, ya que, en términos comparativos, se estimó una evapotranspiración de entre 3 y $4 \mathrm{~mm}$ día ${ }^{-1}$ en pastizales de Paspalum quadrifarium en la misma región (Sakalauskas et al. 2001). Estos valores de uso del agua se correspondieron con los estimados por Rivas y Carmona (2013) para lotes de Glycine max y pastizal en la misma región. Estos ejemplos puntuales no permiten hacer una estricta comparación entre sistemas, ya que no son estudios apareados sino resultados obtenidos en distintos años y en sitios con distintas características de suelo. Asimismo, para explicar el fenómeno de salinización en la zona de la Depresión del Salado observado en rodales de Eucalyptus camaldulensis, se utilizó como estimación de su tasa de transpiración la información obtenida por los mismos autores (Nosetto et al. 2008) en rodales de Eucalyptus grandis en la provincia de Entre Ríos. Esta especie, que por su intolerancia a bajas temperaturas no se cultiva en la región de estudio, difiere en distintos aspectos ecofisiológicos con Eucalyptus camaldulensis (la especie medida en la provincia de Buenos Aires), lo que se traduce en enormes diferencias en productividad y seguramente, en el uso de agua. En este sentido, Eucalyptus grandis es la especie de mayor tasa de crecimiento (hasta $56 \mathrm{~m}^{3}$ $\left.\mathrm{ha}^{-1} \mathrm{año}^{-1}\right)$ y menor densidad de madera $\left(400 \mathrm{~kg} \mathrm{~m}^{-3}\right)$ de los eucaliptos cultivados en Argentina (y de mayor grado de mejora genética) mientras que Eucalyptus camaldulensis, es la de menor productividad (15- $20 \mathrm{~m}^{3} \mathrm{ha}^{-1} \mathrm{año}^{-1}$ en sitios óptimos para la especie) y mayor densidad de madera $\left(900 \mathrm{~kg} \mathrm{~m}^{-3}\right)$, aspectos que tienen estrecha relación con el uso de agua y la resistencia al estrés ambiental. Es decir, si bien son dos especies del mismo género, la diferenciación anátomo-fisiológica entre ambas indica que no pueden explicarse patrones de uso de agua de una en base a datos de la otra.

Por otro lado, un estudio realizado en forestaciones cercanas a la ciudad de La Plata analizó la redistribución de las precipitaciones en rodales de Pinus radiata y Eucalyptus viminalis, donde encontraron diferencias en la interceptación de las precipitaciones producto de la distinta arquitectura de la canopia entre especies (Besteiro y Rodríguez Vagaría 2012). En este sentido, la presencia de una u otra especie determinaría cambios en el balance hídrico local, disminuyendo la trascolación y así, los flujos verticales de agua en el suelo. 
Así, existe un amplio conocimiento sobre la tasa y eficiencia de uso del agua de diversos cultivos, lo que ha permitido generar modelos validados de simulación. Sin embargo, son escasos los trabajos que estimen estos procesos en pastizales naturales y/o forestaciones en el centro y sur de la provincia de Buenos Aires. Dado este vacío de conocimiento en la región, se pondrá a prueba un modelo hipotético (Figura I.3.) en donde los autores (Nosetto et al. 2008 y Jobbágy et al. 2006) proponen un mayor uso consuntivo del agua de las forestaciones que de otras especies, tal como lo sugiere el modelo de Zhang et al. (2001).

Finalmente, existen algunos antecedentes que muestran tanto el incremento de la CE como la acumulación de sodio en el suelo en sistemas con distintos cultivos en la provincia de Buenos Aires. En la subregión de la Depresión del Salado y hacia el NO de la provincia, Nosetto et al. (2008) midieron un incremento en la CE de los suelos bajo forestaciones con Eucalyptus camaldulensis. En Sierra de la Ventana, hacia el sur de la provincia, Amiotti et al. (2000) observaron un aumento del contenido de $\mathrm{Na}$ en el suelo bajo forestaciones de Pinus radiata en comparación con pastizales próximos. Esto demostraría que es posible observar dicho fenómeno de salinización, aunque la magnitud del cambio posiblemente dependerá de la especie forestal. Así, Nosetto et al. (2008) indican que la CE del acuífero freático debajo de forestaciones tiene una relación lineal y esta positivamente correlacionada con la tolerancia a la salinidad de las distintas especies forestales. A partir de una revisión en donde discuten distintos impactos que se observan por la introducción de las forestaciones en pastizales, Jobbágy et al. (2006) concluyeron que si bien se verifican cambios en la dinámica de agua, redistribución de nutrientes y de $\mathrm{pH}$, la magnitud del mismo dependerá de la especie forestal utilizada (por ejemplo, especies perennes vs caducifolias) en sinergia con el ambiente (entre otros, balance hídrico, profundidad y salinidad de la freática, tipo de suelo) y el manejo forestal (sistemas densos vs ralos). Estos cambios se producirían por el mayor uso de agua de las forestaciones, que generaría flujos de agua subterránea hacia las mismas, las que arrastrarían las sales disueltas produciéndose una acumulación por exclusión debajo del sitio con árboles. Sin embargo, es interesante resaltar nuevamente que la única información de uso consuntivo de agua por los árboles en la región (Engel et al. 2005) no corroboraría dicha hipótesis ya que el uso del agua estimado es menor que las estimaciones de especies herbáceas (Sakalauskas et al. 2001, Rivas y Carmona 2013).

La región pampeana es uno de los motores económicos de la Argentina, por lo que la prevención de la salinización de sus suelos es de suma importancia. Siendo los agroecosistemas forestales muy distintos a los ecosistemas naturales y 
agroecosistemas con cultivos, es importante determinar el impacto que esta actividad productiva puede provocar sobre el ciclo hidrológico y la salinidad del suelo. De esta manera poder predecir y evitar la disminución de la productividad de la región.

\subsection{MODELO HIPOTÉTICO}

Como se mencionó en las anteriores secciones, existen varios factores que predispondrían a la salinización de suelos, entre los que se destacan la presencia de un acuífero freático somero y vegetación cuyas raíces puedan acceder a este, y el impedimento de lavado de sales del suelo dado por la geomorfología de la región y/o la presencia de cobertura vegetal perenne que aumente la interceptación de precipitaciones y el consumo de agua. De hecho, en un contexto más general y atendiendo distintas escalas geográficas, Nosetto et al. (2008) proponen que la probabilidad de salinización de suelos depende de factores climáticos (balances hídrico menores a $100 \mathrm{~mm}$ año-1), hidrogeológicos (profundidad de capa freática, conductividad hidráulica del suelo dependiente de la textura del suelo), y biológicos (capacidad de hacer uso del agua y tolerancia a la salinidad). En este sentido, la probabilidad de que sea observado el fenómeno de salinización secundaria por el cambio de vegetación aumentará en un sitio con balances hídricos negativos en donde el sistema vegetal puede acceder a la freática que posee un cierto contenido de sales. En este marco, suelos con mayor conductividad hidráulica permitirán alimentar esta alta tasa de consumo de agua mientras que la tolerancia a la salinidad de la especie determinará la máxima concentración de sales en el suelo. En la Figura I.3. puede verse claramente el modelo jerárquico de las condiciones que favorecen el proceso de salinización por cambios de vegetación propuesto por Nosetto et al. (2008) y Jobbágy et al. (2006). En la misma pueden verse los factores que influyen a distintas escalas; región: balance hídrico climático negativo es decir descarga mayor a la recarga, paisaje: configuración hidrogeológica favorece el acceso a los acuíferos y la conductividad hidráulica permite tasas altas de flujo de agua subterránea hacia las plantas, parcela: altas tasas de EVT generan balance hídrico negativo, en tanto los umbrales de tolerancia a la salinidad definen la máxima salinidad alcanzada. 


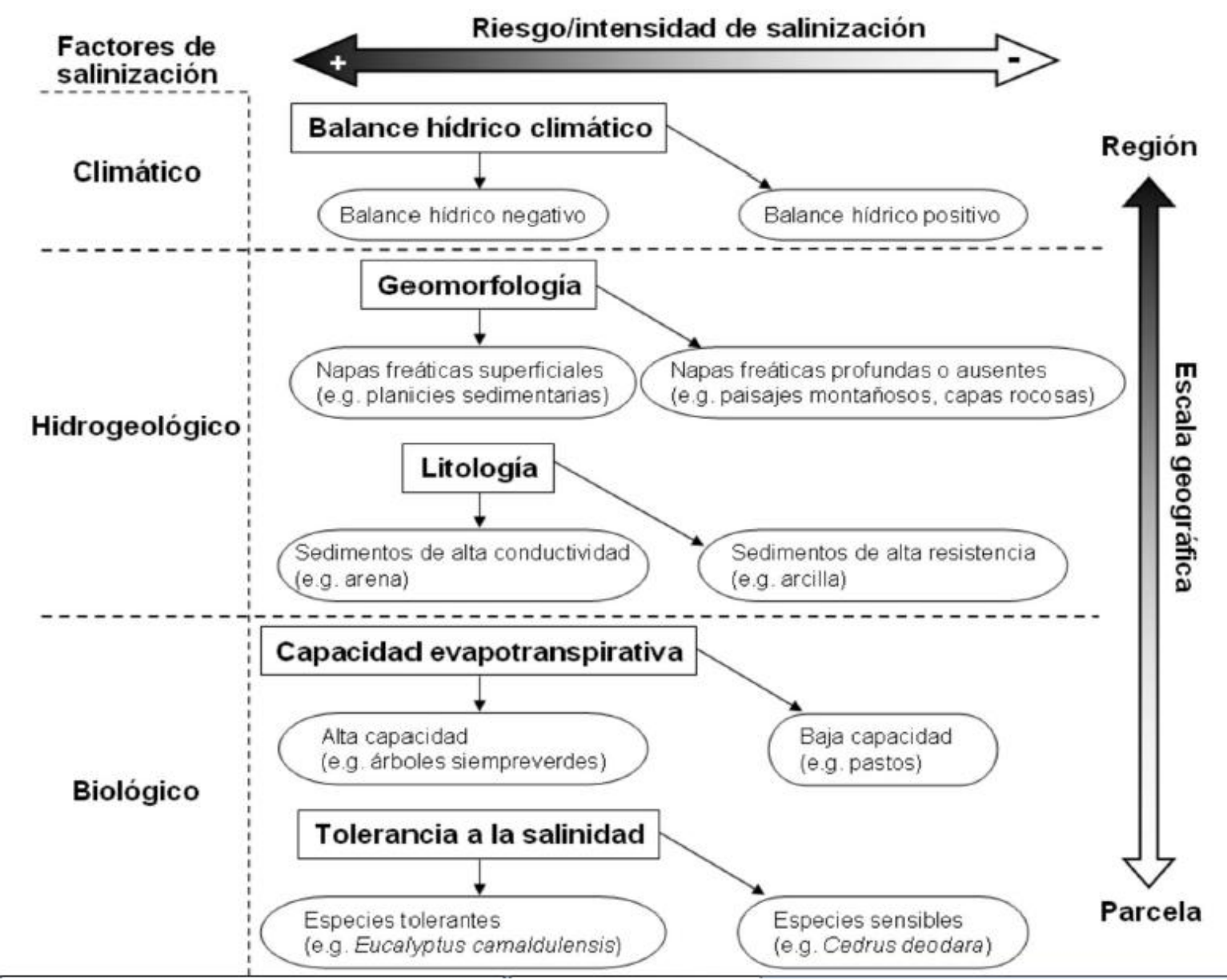

Figura I.3. Modelo jerárquico de condiciones que favorecen el proceso de salinización por cambios de vegetación. Extraído de Nosetto et al. (2008) y Jobbágy et al. (2006).

Basados en estos antecedentes, los mencionados autores proponen que la salinización secundaria de suelos en los sistemas vegetales se relacionará directamente con la capacidad evaporativa de las especies, su resistencia a la salinidad, su posibilidad de extraer agua del acuífero y la conductividad hidráulica del suelo determinada por la textura del mismo. A la vez, se relacionará de manera negativa con el balance hídrico local.

Se espera entonces, un mayor contenido de sales en el suelo bajo uso forestal en relación a otros usos, y que en el sistema de estudio, dichas diferencias se acentuarán hacia el oeste de la provincia de Buenos Aires donde los balances hídricos son más negativos y las texturas del suelo más arenosas.

A la vez, analizando la dinámica de sales del suelo en el lapso de un año calendario, tanto los cultivos anuales más importantes en la región (Triticum sp., Hordeum vulgare, Glycine max, Zea mays, y Helianthus annuus), como las forestaciones, presentarán un ciclo determinado por una acumulación de sales durante los períodos de mayor actividad biológica seguidos de una disminución en el contenido 
de sales por lavado en los momentos de menor actividad o postcosecha (gráfico I.2.). En el caso de las plantaciones forestales, se esperan tres dinámicas distintas de acuerdo al tipo de forestaciones (gráfico I.2.). En plantaciones de baja densidad, se espera el lavado de sales especialmente durante el invierno, momento en que la transpiración es baja o nula, debido a la menor cobertura arbórea. Mientras que en forestaciones con alta densidad bajo manejo forestal, se espera durante los raleos y podas un lavado de las sales acumuladas que se expresaría aún más abruptamente en postcosecha. Por último para el caso de las forestaciones con alta densidad sin manejo comercial, se espera el mayor impacto por acumulación de sales debido a que la ausencia de un manejo forestal induciría una ocupación plena del sitio, acumulando además, una gran cantidad de broza que incrementará la interceptación de lluvias. A su vez, este modelo hipotético propuesto por Jobbágy y Jackson (2004), asume que los pastizales naturales o semi-alterados por la introducción de especies herbáceas exóticas, poseen el balance hídrico más equilibrado con las condiciones del sitio, actuando como línea de base contra la cual comparar los potenciales cambios en el balance hídrico y químico de los suelos producidos por la agricultura y forestación. En este sentido, el modelo para la zona no saturada dentro de la llanura pampeana (gráfico I.2.), podría ser válido en general, mientras que en otros sectores la propia dinámica de los solutos acumulados en la zona no saturada por exclusión al ser utilizada el agua del acuífero por la vegetación, podría ser el responsable de la salinización de las aguas subterráneas.

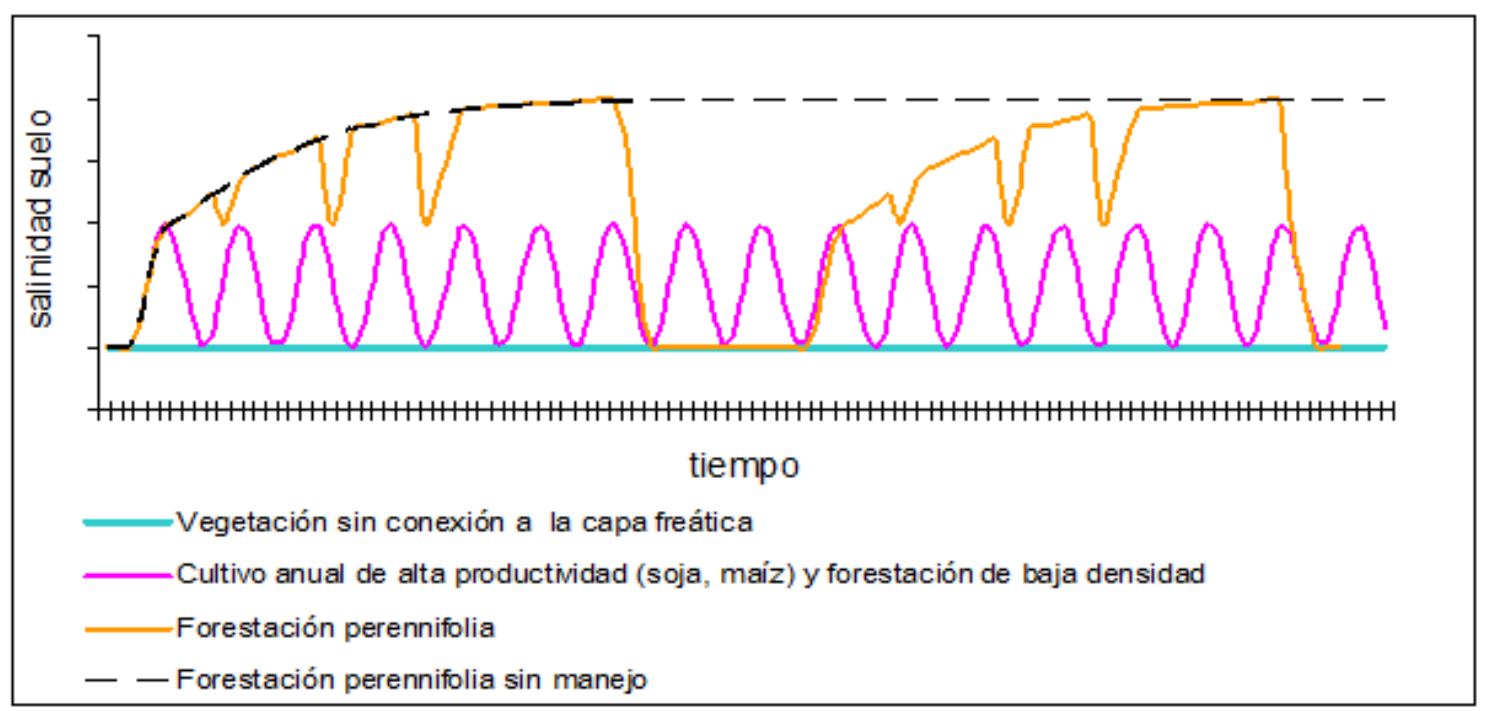

Grafico I.2. Conceptualización del modelo hipotético propuesto por Jobbágy y Jackson (2004) sobre la acumulación de sales en el suelo bajo distintos usos productivos. 
En base al modelo hipotético propuesto se pondrán a prueba las siguientes predicciones:

1. Ante similares condiciones ecológicas y debido al mayor uso consuntivo de agua, se observará mayor CE de suelos en las forestaciones con Eucalyptus spp. que en los ciclos anuales de cultivo o bajo uso pastoril (capítulos 2 y 4);

2. en el caso de suelos arenosos (Oeste bonaerense) se registrará una mayor CE del suelo bajo forestaciones que en cultivos o pastizales, mientras que las diferencias no serán tan marcadas en los suelos con mayor contenido de arcillas (capítulo 2);

3. la diferencia en el contenido de sales del suelo entre forestaciones y otros usos del suelo, será mayor en la región oeste de la provincia debido a las diferencias en balance hídrico entre regiones (capítulo 2);

4. los cultivos más importantes en la región y las forestaciones, presentarán un ciclo determinado por una acumulación de sales durante los períodos de mayor actividad biológica seguidos de una disminución en el contenido de sales por lavado en los momentos de menor actividad o postcosecha (capítulo 2 y 4 );

5. habría una menor acumulación de sales, y por lo tanto, menores valores de CE en el suelo con baja cobertura forestal (bajas densidades) debido al lavado de sales especialmente durante el invierno (capítulo 3);

6. se espera un mayor contenido de sales en el suelo bajo forestaciones de alta resistencia a la salinidad que aquel sometido a otros usos (capítulos 2 y 3 );

\subsection{OBJETIVOS}

El objetivo principal de esta tesis fue determinar los cambios hidrogeoquímicos asociados a las modificaciones en el uso del suelo, comprendiendo las producciones agrícolas, pastoriles y forestales en el centro-sur de la provincia de Buenos Aires. Para el logro del mismo, se fijaron los siguientes objetivos específicos:

1. Caracterizar la dinámica temporal y magnitud de los flujos de sales en suelos sometidos a los usos agrícolas, pastoriles y forestales.

2. Estimar el uso consuntivo de agua en cultivos y forestaciones de la región.

3. Determinar, en un ambiente típico del centro de la provincia de Buenos Aires, los impactos provocados en la dinámica hídrica y de sales que puede tener la forestación de pastizales 
4. Desarrollar recomendaciones de manejo sustentable ante posibles cambios desfavorables sobre los recursos del suelo producidos por las actividades productivas mencionadas. 


\title{
Capítulo 2
}

\author{
Transiciones entre sistemas leñosos y \\ herbáceos en la llanura pampeana. Su \\ consecuencia sobre la CE y pH del suelo
}




\subsection{INTRODUCCIÓN}

Como se habló en la introducción general, el impacto sobre los flujos de agua y sales en el suelo debido a la introducción de una forestación en un sitio donde la vegetación original era el pastizal, adquiere relevancia en la actualidad (Jobbágy et al. 2006). El impacto de este cambio está dado por la acumulación de sales debajo de las forestaciones, motivada por diversos aspectos de índole biológico, climático y edáfico (Nosetto et al. 2008). Estas condiciones ecológicas, que en general ocurren en las planicies expuestas a climas sub-húmedos de distintas regiones del mundo, también se las puede encontrar en la región Pampeana Argentina. Esta región conforma una gran extensión del territorio Argentino, ubicada en el centro-este del país entre las latitudes $32^{\circ}$ y $40^{\circ} \mathrm{W}$, y longitudes $57^{\circ}$ y $63^{\circ} \mathrm{S}$ (SAGPyA 2001). Investigaciones previas indican que la introducción de forestaciones en este ambiente generaron un proceso conocido como salinización secundaria (Jobbágy yJackson 2004, Jobbágy et al. 2006). A partir de este conocimiento, se generalizó la hipótesis de que era factible de observar este fenómeno de salinización secundaria por la introducción de forestaciones en toda la región pampeana (Nosetto et al. 2008). Sin embargo, hacia al sur de dicha región, las condiciones climáticas y edáficas difieren de las observadas en estos estudios, por lo que resulta de interés verificar si también se dan estos procesos.

En este sentido, Jobbágy et al. (2008) y Nosetto et al. (2009) generaron un modelo hipotético para explicar la salinización secundaria provocada por el reemplazo de la vegetación original de pastizal por plantaciones forestales, a distintas escalas (paisaje, predio o parcela). Así, existirían factores biológicos, hidrogeológicos y climáticos que explicarían la probabilidad de ocurrencia de este proceso. El factor biológico tiene dos componentes principales, el consumo diferencial de agua dado por las características ecofisiológicas de las especies que conforman la cobertura vegetal y la tolerancia de éstas a la salinidad. Así, sería mayor el riesgo / intensidad del proceso de salinización en aquellas especies con mayor capacidad de hacer uso del agua y que además, sean más tolerantes a la salinidad. De esta manera, debido a que la evapotranspiración de un ecosistema depende, principalmente, del tipo de vegetal dominante (árboles, cultivos o pasturas; Gyenge et al. 2011, Nosetto et al. 2008, 2012), cabe esperar que los aumentos en la productividad asociados a la forestación de pastizales sean acompañados por aumentos en la transpiración (debido al menor albedo, mayor rugosidad, mayor profundidad del sistema radicular, entre otros; Zhang et al. 2001). En este mismo ítem del modelo, enfocándonos en las forestaciones, también hay que mencionar la influencia que pueda general el grado de ocupación de sitio representado por su densidad y en una forma más precisa por el área basimétrica 
(AB). Por ejemplo Jobbágy y Jackson (2004) explican que el raleo, densidades de plantación adecuadas y las alternativas productivas como los sistemas silvopastoriles, son opciones para aumentar la reservas de agua del suelo. En cambio, como mencionan estos autores, es de esperarse que situaciones de alto grado de ocupación de sitio (determinadas por altas $A B$ y coberturas), maximicen el consumo de agua y por lo tanto el proceso de salinización secundaría. Por otro lado, el grado de permanencia de la forestación (representado por la edad) es nombrado también como un factor clave por diversos autores (Nosetto et al. 2008, Jobbágy y Jakson 2004)

El factor hidrogeológico tiene en cuenta la posibilidad de acceso de la vegetación al agua subterránea, y la litología del suelo (textura de los sedimentos y presencia de horizontes compactados o roca). Así, existiría un mayor riesgo/intensidad de salinización secundaria cuando el acuífero freático es más superficial, y las texturas del suelo más gruesas y permeables, y cuando no se observen limitantes en la profundidad que impidan el acceso de las raíces a las aguas subterráneas.

Por último el factor climático influye a través del balance hídrico (Jobbágy et al. 2008). En esta línea, y apoyando el modelo propuesto, Nosetto et al. (2008) observó en la región Pampeana Argentina, una mayor salinización en los suelos debajo de las forestaciones que de pastizales, incrementándose dichas diferencias en los sitios con balances hídricos inferiores a los $50 \mathrm{~mm}$ año ${ }^{-1}$. Además estos autores también han observado que en los pastizales pampeanos, el establecimiento de forestaciones sólo genera salinización en áreas con precipitaciones inferiores a $\sim 1100 \mathrm{~mm}$ año ${ }^{-1}$ (ver también Jobbágy et al. 2008).

En este contexto general, y atendiendo a las distintas escalas geográficas, es plausible de plantear para nuestra área de estudio, el modelo sugerido por Nosetto et al. (2008) que determina las condiciones bajo las cuales se observarían procesos de salinización secundaria. El mismo se evaluó mediante el análisis de la conductividad eléctrica (CE) del suelo para determinar los cambios en la concentración de sales en sitios ubicados a lo largo de un gradiente climático y de textura de suelos en el centrosur de la provincia de Buenos Aires incluyendo distintos usos del suelo, las producciones agrícolas, pastoriles y forestaciones con Eucalyptus spp.. Además, como complemento, serán apreciadas otras modificaciones en propiedades químicas del suelo, como el pH, que fue numerosas veces citado como uno de los cambios más importantes al introducir forestaciones en sistemas de pastizales (por ejemplo; Caldato 2011 y Delgado et al. 2006). 


\subsection{MATERIALES Y MÉTODOS}

Se realizó una transecta de $500 \mathrm{~km}$ de longitud con sentido Este-Oeste en el centro sur de la provincia de Buenos Aires en donde se establecieron 16 sitios de medición (Figura II.1., Tabla II.1.). Cada sitio constó de dos parcelas apareadas, una parcela forestal con Eucalyptus spp. (Eucalyptus globulus Labill., Eucalyptus viminalis Labill. y Eucalyptus camaldulensis Dehnh.), y otra herbácea, bajo uso agrícola o pastoril (Tabla 1). El clima de la región es templado húmedo, con temperaturas medias anuales de $14-15^{\circ} \mathrm{C}$ (SAGPyA 2001), y precipitaciones de $1000 \mathrm{~mm}$ año-1 hacia el Este e inferiores a los $800 \mathrm{~mm}_{\text {año }}{ }^{-1}$ en el extremo Oeste de la transecta mencionada, distribuidas de manera más o menos homogénea a lo largo del año (Barros et al. 2013). Esto hace que en el mismo sentido de la transecta se verifique un gradiente de balance hídrico, que abarca desde valores positivos o cercanos a cero en el NE, hasta negativos de $-200 \mathrm{~mm}$ año ${ }^{-1}$ en el sector SO (Nosetto et al. 2008; Figura 1). En cuanto a los suelos, se observan cambios en la profundidad y granulometría, pasando en sentido Este-Oeste, de suelos franco arcillosos relativamente someros por presencia de un horizonte petrocálcico o roca, a arenosos y profundos (Tabla II.1.). 


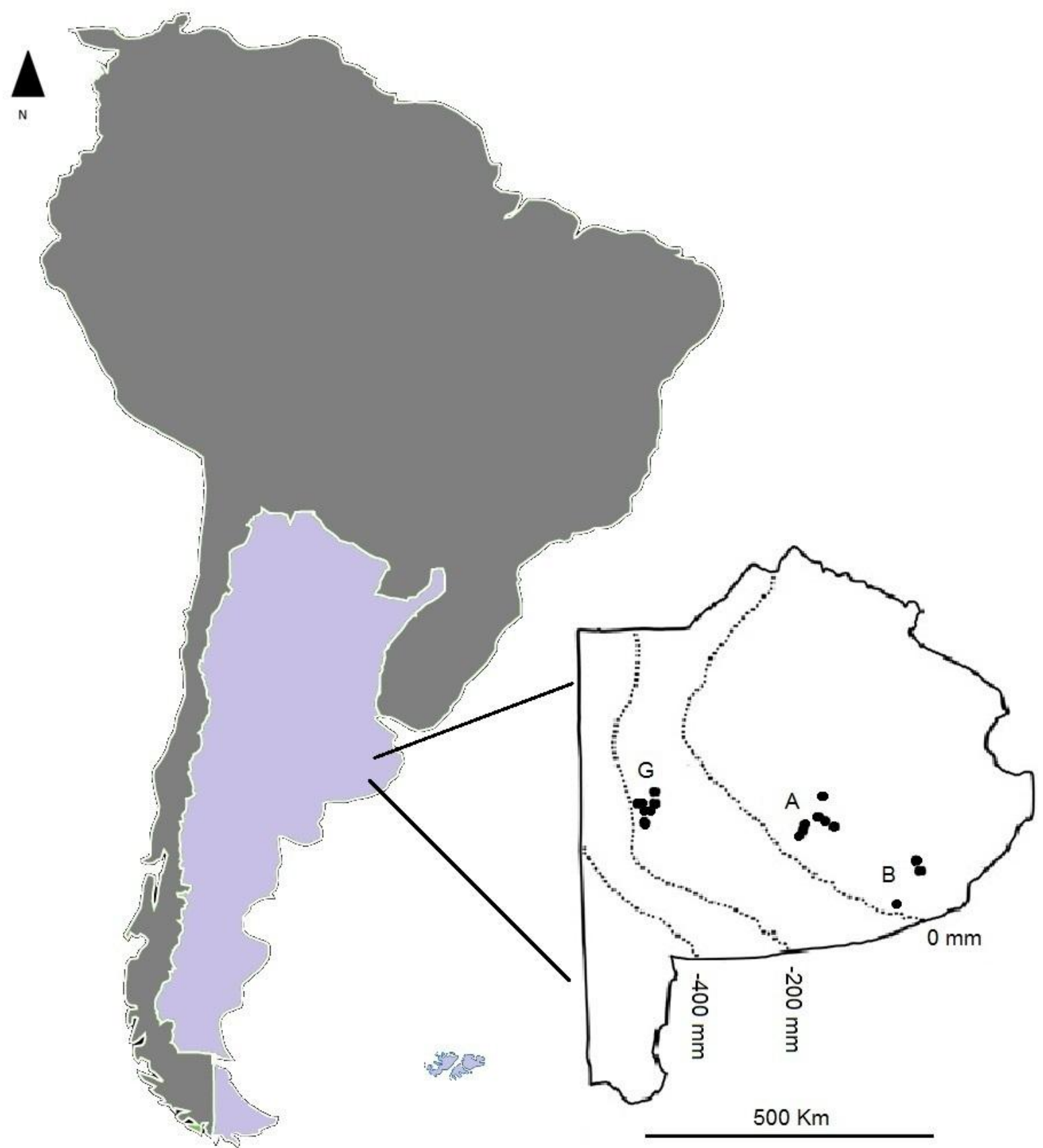

Figura II.1. Distribución de las parcelas apareadas. Las parcelas (puntos negros) se agruparon en tres localidades de la provincia de Buenos Aires, Argentina: (G) Guaminí, (A) Azul y (B) Balcarce-Lobería. Con líneas punteadas se denota la isolinea correspondiente a los balances hídricos calculados como la diferencia entre la precipitación media anual y la evapotranspiración de referencia de Penman-Montheith (modificado a partir de Nosetto et al. 2008). 
Tabla II.1. Localidades, ubicación geodésica de las parcelas de medición, máxima profundidad estudiada del perfil y textura del suelo.

\begin{tabular}{|c|c|c|c|c|}
\hline $\begin{array}{l}\text { Localidades } \\
\text { Balcarce-Lob }\end{array}$ & sitios & Ubicación & $\begin{array}{l}\text { Profundidad } \\
\text { del suelo }(\mathrm{cm})\end{array}$ & Textura del suelo \\
\hline & $\mathrm{B} 1$ & $37^{\circ} 45,699 ' S$ & 120 & Franco \\
\hline & & $58^{\circ} 17,264^{\prime} \mathrm{O}$ & & \\
\hline & B2 & $37^{\circ} 45,667^{\prime} \mathrm{S}$ & 60 & Arcilloso \\
\hline & & $58^{\circ} 17,313^{\prime} O$ & & \\
\hline & B3 & $38^{\circ} 14,636^{\prime} S$ & 100 & Franco Arcilloso \\
\hline & & $58^{\circ} 42,993^{\prime} O$ & & \\
\hline \multicolumn{5}{|l|}{ Azul } \\
\hline & $\mathrm{A} 1$ & $37^{\circ} 07,944 ' S$ & 60 & Franco Arcilloso \\
\hline & & $60^{\circ} 03,769^{\prime} \mathrm{O}$ & & \\
\hline & $\mathrm{A} 2$ & $37^{\circ} 07,833^{\prime} S$ & 60 & Franco Arcilloso \\
\hline & & $60^{\circ} 03,735^{\prime} \mathrm{O}$ & & \\
\hline & A3 & $37^{\circ} 08,138^{\prime} \mathrm{S}$ & 60 & Franco Arcilloso \\
\hline & & $60^{\circ} 03,786^{\prime} \mathrm{O}$ & & \\
\hline & A4 & $37^{\circ} 03,364^{\prime} S$ & 40 & Franco Arcilloso \\
\hline & & $59^{\circ} 54,563^{\prime} \mathrm{O}$ & & \\
\hline & A5 & $37^{\circ} 03,117^{\prime} \mathrm{S}$ & 60 & Franco Arcilloso \\
\hline & & $59^{\circ} 55,436^{\prime} \mathrm{O}$ & & \\
\hline & A6 & $36^{\circ} 44,491^{\prime} S$ & 80 & Franco Arcilloso \\
\hline & & $59^{\circ} 47,666^{\prime} \mathrm{O}$ & & \\
\hline & A7 & $37^{\circ} 08,377^{\prime} \mathrm{S}$ & 80 & Franco \\
\hline & & $59^{\circ} 41,517^{\prime} \mathrm{O}$ & & \\
\hline \multicolumn{5}{|l|}{ Guaminí } \\
\hline & $\mathrm{G} 1$ & $37^{\circ} 6^{\prime} 29,24 " S$ & 60 & Franco Arcilloso \\
\hline & & $62^{\circ} 26^{\prime} 42,1 " \mathrm{O}$ & & \\
\hline & $\mathrm{G} 2$ & $36^{\circ} 50^{\prime} 49,12 " \mathrm{~S}$ & 200 & Franco Limoso \\
\hline & & $62^{\circ} 21^{\prime} 35,4^{\prime \prime O}$ & & \\
\hline & G3 & $36^{\circ} 50^{\prime} 56,96 " S$ & 200 & Arena \\
\hline & & $62^{\circ} 17^{\prime} 1,86^{\prime \prime O}$ & & \\
\hline & G4 & $36^{\circ} 50^{\prime} 29,34^{\prime \prime S}$ & 200 & Arenoso Franco \\
\hline & & $62^{\circ} 19^{\prime} 5,01 " \mathrm{O}$ & & \\
\hline & G5 & $36^{\circ} 50^{\prime} 15,69^{\prime \prime S}$ & 200 & Limoso \\
\hline & & $62^{\circ} 15^{\prime} 42,2^{\prime \prime O}$ & & \\
\hline & G6 & $\begin{array}{l}36^{\circ} 50^{\prime} 42,67^{\prime \prime S} \\
62^{\circ} 16^{\prime} 40,9^{\prime \prime} \mathrm{O}\end{array}$ & 200 & Arenoso Franco \\
\hline
\end{tabular}

En dos temporadas (verano e invierno), en cada una de las localidades y en cada parcela, se extrajeron muestras de suelo cada $20 \mathrm{~cm}$ de profundidad en 5 puntos 
al azar, en invierno hasta alcanzar los $200 \mathrm{~cm}$, o la máxima profundidad posible en caso de la existencia de limitaciones de profundidad (dadas en invierno por la presencia de un horizonte petrocálcico y en verano por perfiles secos y compactos). En cada muestra de suelo se analizó la conductividad eléctrica (CE, $\mu \mathrm{sm}^{-1}$ ) y el $\mathrm{pH}$ en diluciones 1:2,5 por medio de un lector OAKTON PC700 con sonda de pH ColePalmer 05992-62 y sonda de CE-temperatura 35608-74. De la misma manera, se determinó la textura del suelo de cada muestra por el método de Bouyoucos (p.ej., Bouyoucos, 1962; Elliot et al., 1999).

Para analizar las características estructurales del rodal y tomar las muestras de suelo en las parcelas situadas en las forestaciones se demarcó una superficie que tuvo distinto tamaño dependiendo de la densidad y la distribución de los árboles. Así, en unos sitios con distribución irregular de los árboles (sitios A3, A4, A5, A6 y G3) se delimitaron superficies circulares de 10 y 30 metros de diámetro dependiendo del distanciamiento entre los árboles, mientras que en los sitios con una distribución regular (sitios A1, A2, A7, B1, B2, B3, G1, G2, G4, G5 y G6) se establecieron parcelas de 4 filas por 10 árboles, midiendo a posteriori la superficie ocupada (Figura II.2.). 

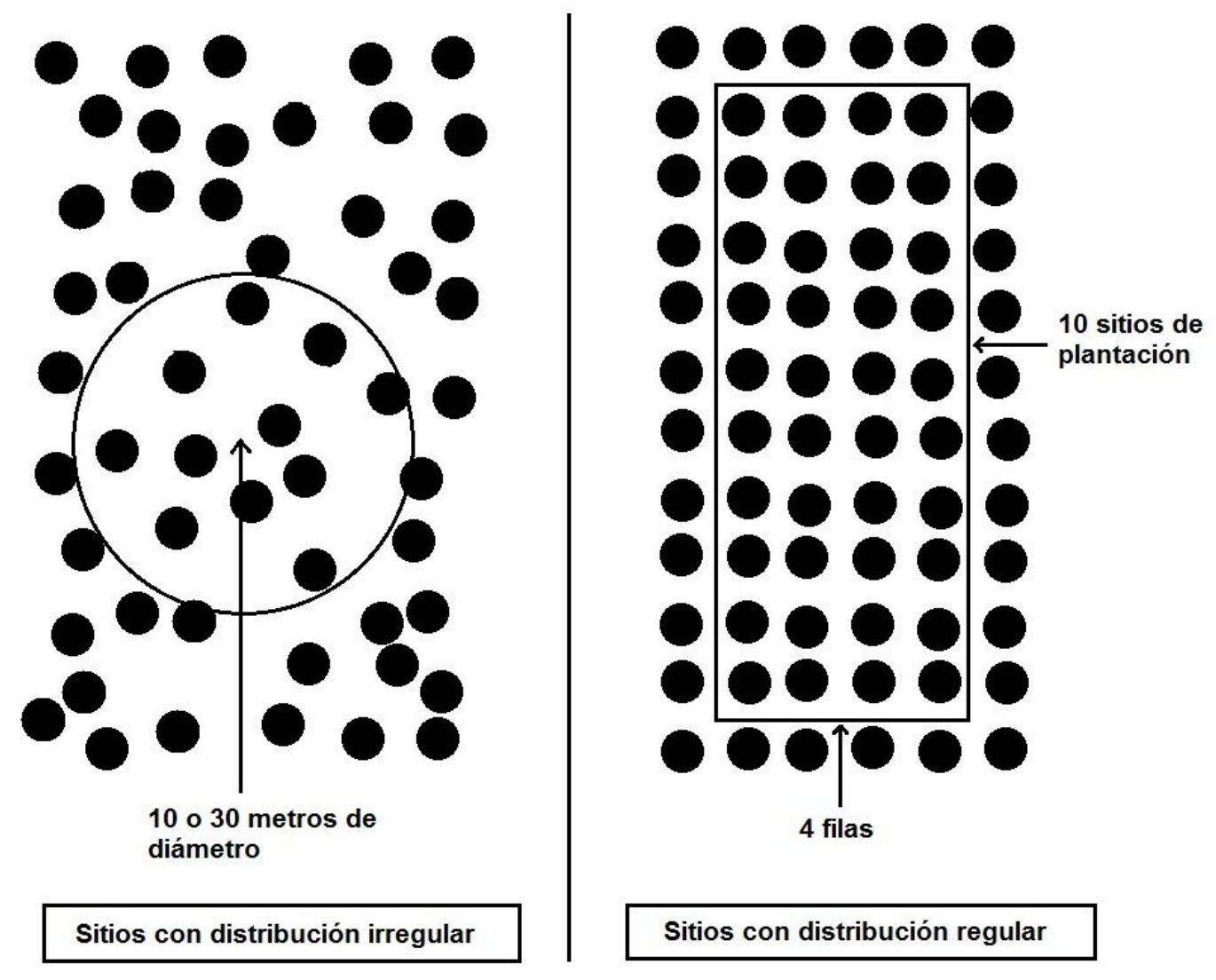

Figura II.2. Ejemplo de cómo fueron establecidas dentro de la forestación las parcelas muestreadas (los puntos negros representan los árboles). Estas parcelas tenían un tamaño diferente, dependiendo de la densidad y la distribución espacial de los árboles.

Dentro de cada parcela forestal se midió con cinta diamétrica el diámetro a la altura del pecho (DAP, $\mathrm{cm}$ ), de todos los árboles vivos y la altura de los árboles dominantes $(\mathrm{H}, \mathrm{m})$ mediante clinómetro Suunto PM-5/360PC (Suunto, Finlandia). Se consideró como pie individual a todos aquellos fustes mayores de $3 \mathrm{~cm}$ de diámetro. A partir de estos estadísticos se estimó la densidad (árboles ha ${ }^{-1}$ ) y área basal del rodal $\left(A B, \mathrm{~m}^{2} \mathrm{ha}^{-1}\right.$; Tabla II.2.) calculada a partir de la sumatoria de todas las áreas individuales obtenidas a partir del DAP. La cobertura forestal se estimó a partir del análisis de fotografías planas mediante el programa Image 1.48v (Wayne Rasband, National Institutes of Health, EEUU). En varios casos, la edad de las forestaciones era desconocida para los actuales propietarios o usuarios del suelo (B3, A3, A4, A5, A7), por lo que se las estimó usando imágenes de Google Earth@ Versión 7.3.2. La parcela apareada con cultivo agrícola se identificó según la especie y en caso de ser un lote forrajero, se clasificó en pastizal natural o pastura.

Se aplicó ANOVA para determinar diferencias estadísticas entre las variables comparando parcelas apareadas (CE y pH promedio de cada profundidad) y luego 
comparando las mismas profundidades entre parcelas en cada sitio, (número de repeticiones $=5$ puntos por parcela $\times 2$ parcelas). Para poder realizar comparaciones válidas, la profundidad máxima estudiada en cada sitio corresponde a la menor profundidad alcanzada en una de las parcelas apareadas. Así, la máxima profundidad podría diferir entre parcelas y en general ésta se debe a la aparición de un perfil petrocálcico. Por otro lado, también se agruparon las parcelas teniendo en cuenta las localidades (Balcarce-Lobería, Azul y Guaminí, Gráfico II.2.), la textura del suelo (arcilla, limo, limo, arena, Gráfico II.3.) y la estación del año (verano e inverno, Gráfico II.15.). Se verificaron las suposiciones de ANOVA en cada caso, y se aplicó test de LSD de Fisher $(p<0,05)$, como una comparación post hoc entre los valores promedio, usando InfoStat versión 2011. Se estimó una relación entre la cobertura del dosel y las variables que describen las parcelas forestadas $(\mathrm{DBH}, \mathrm{AB})$ mediante un análisis de regresión usando el mismo software.

\subsection{RESULTADOS}

\subsubsection{Estructura de las forestaciones}

Las forestaciones estudiadas carecían de manejo silvícola (podas y raleos). La densidad de plantación varió desde 283 hasta 3438 árboles ha ${ }^{-1}$, mientras que la edad de la plantación varió desde 6 hasta más de 100 años (Tabla II.2.). Por otro lado, las mayores y menores densidades se midieron en Eucalyptus viminalis y Eucalyptus camaldulensis, respectivamente (Tabla II.2.). El área basal de los rodales varió de aproximadamente 13 a $83 \mathrm{~m}^{2}$ ha-1 (Tabla II.2.), aunque no se relacionó la densidad de individuos con el área basal (Gráfico II.1. A) ni la cobertura aérea (Gráfico II.1. B). La cobertura aérea de los rodales mostró una escasa variación, sobre todo a partir de un área basal de $20 \mathrm{~m}^{2}$ ha $^{-1}$ en donde fluctuó entre un 50 y $60 \%$ (Gráfico II.1. B). 
Tabla II.2. Variables descriptoras de los rodales. Sp. = especie $(\mathrm{Eg}=$ Eucalyptus globulus, $\mathrm{Ev}=$ Eucalyptus viminalis, $\mathrm{Ec}=$ Eucalyptus camaldulensis); $\mathrm{N}=$ Densidad (árboles ha $\left.{ }^{-1}\right) ; \mathrm{DAP}=$ diámetro del fuste a $1,30 \mathrm{~m} ; \mathrm{AB}=$ área basal $\left(\mathrm{m}^{2}\right.$ ha $\left.{ }^{-1}\right) ; \mathrm{H}=$ altura dominante $(m)$; Cob = cobertura aérea del dosel arbóreo $(\%)$ y Edad en años desde la plantación.

\begin{tabular}{llllllll}
\hline Sitios & Sp. & N & DAP & AB & H & Cob & Edad \\
\hline B1 & Eg & 1370 & 21,6 & 56,3 & 31,4 & 56 & 19 \\
B2 & Eg & 1975 & 14,7 & 53,5 & 26,9 & 69 & 17 \\
B3 & Eg & 2433 & 7,7 & 15,4 & 14,0 & 46 & $>33$ \\
A1 & Ev & 1852 & 17,0 & 47,0 & 28,8 & 47 & 16 \\
A2 & Ev & 2037 & 21,0 & 83,2 & 23,05 & 61 & 16 \\
A3 & Ec & 283 & 46,0 & 52,1 & 33,1 & 52 & $>33$ \\
A4 & Ev & 923 & 24,0 & 47,5 & 30,4 & 54 & $>33$ \\
A5 & Ev & 1655 & 15,0 & 34,9 & 25,3 & 55 & $>33$ \\
A6 & Ev & 3438 & 12,1 & 50,2 & 21,3 & 56 & $>100$ \\
A7 & Ec & 700 & 33,6 & 70,9 & 26,8 & 65 & $>33$ \\
G1 & Ev & 889 & 24,3 & 46,5 & 28,1 & 61 & 16 \\
G2 & Ev & 1625 & 18,4 & 46,2 & 18,2 & 51 & 8 \\
G3 & Ev & 1056 & 11,8 & 13,3 & 11,9 & 34 & 6 \\
G4 & Ev & 311 & 51 & 74,9 & 30,3 & 62 & 54 \\
G5 & Ev & 1037 & 24,3 & 54,3 & 28 & 60 & 17 \\
G6 & Ev & 917 & 13 & 13,6 & 12,2 & 31 & 6 \\
\hline
\end{tabular}

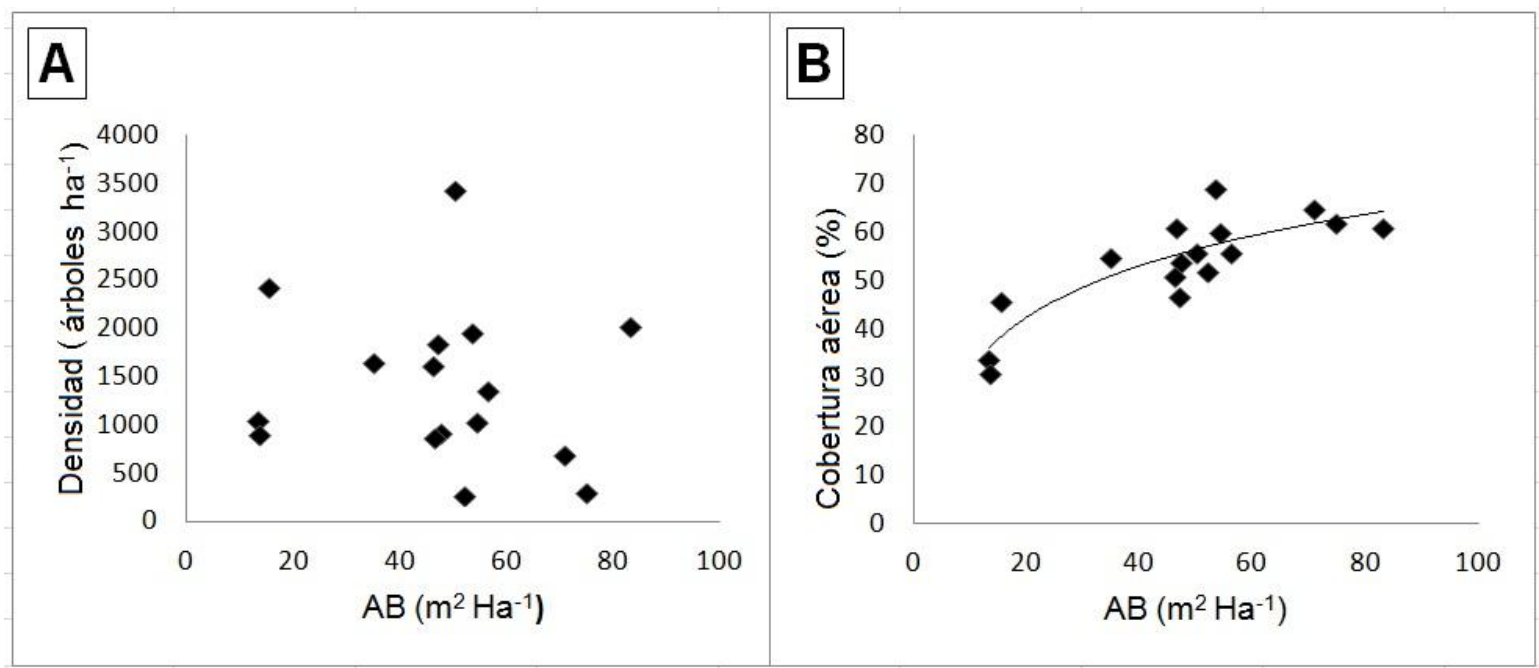

Gráfico II.1. Relación entre la densidad (árboles ha- $\left.{ }^{-1}, A\right)$ y el área basal $\left(A B, m^{2} h^{-1}\right)$ y entre la cobertura aérea del dosel arbóreo (\%) y el área basal $(B)$ de los distintos rodales de Eucalyptus spp. 


\subsubsection{Variables de suelo durante la estación invernal}

La textura a lo largo de toda la transecta varió desde suelos con mayores contenidos de arcillas en el sector Este (localidades de Balcarce-Lobería, sitios B en Tabla II.3.), a aquellos con mayor contenido de arenas en el Oeste (Guaminí, sitios G en Tabla II.3.). Cabe destacar que la profundidad máxima de comparación entre parcelas fue menor en Azul (de 40 a $80 \mathrm{~cm}$; sitios A Tabla II.3.) que Balcarce-Lobería (60 a 120cm; sitios B Tabla II.3.) y Guaminí (de 60 a >200cm; sitios G Tabla II.3.). La CE promedio de todo el perfil de suelo varió desde los 50 hasta los $800 \mu \mathrm{S} \mathrm{cm}^{-1}$ en el caso de los suelos bajo forestaciones, y desde 50 hasta $350 \mu \mathrm{S} \mathrm{cm}^{-1}$ para los otros usos del suelo (Tabla II.3.).

Tabla II.3. Descripción de las parcelas muestreadas. Cobertura $(E g=$ Eucalyptus globulus, $\mathrm{Ev}=$ Eucalyptus viminalis, $\mathrm{EC}=$ Eucalyptus camaldulensis, $\mathrm{Pn}=$ pastizal natural, $\mathrm{Br}=$ barbecho, $\mathrm{Tg}=$ Triticum sp., $\mathrm{M}=$ Zea mays, $\mathrm{Gs}=$ Helianthus annuus, $\mathrm{Pc}$ = pastura cortada, $S=$ Glycine max), conductividad eléctrica del suelo $\left(C E, \mu S \mathrm{~cm}^{-1}\right) \mathrm{y}$ $\mathrm{pH}$ promedios de todo el perfil de suelo. Con un asterisco se denotan aquellas parcelas apareadas en donde se encontraron diferencias significativas en cada estación del año en al menos una profundidad del perfil.

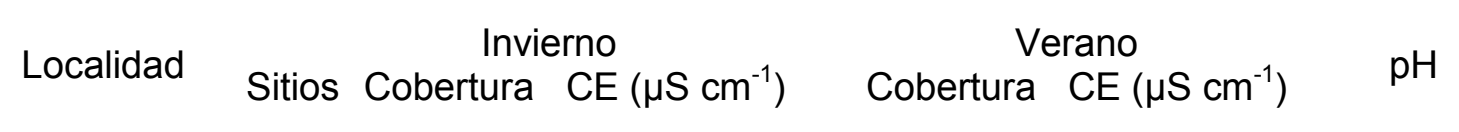

Balcarce

-Lobería

\begin{tabular}{|c|c|c|c|c|c|c|}
\hline & \multirow[t]{2}{*}{ B1 } & $\mathrm{Eg}$ & $124,90 \pm 21,68$ & $\mathrm{Eg}$ & $97,16 \pm 12,04^{*}$ & $7,2^{*}$ \\
\hline & & $\mathrm{Pn}$ & $114,69 \pm 14,57$ & $P n$ & $152,42 \pm 33,34^{*}$ & $7,4^{*}$ \\
\hline & \multirow[t]{2}{*}{ B2 } & $\mathrm{Eg}$ & $158,83 \pm 19,09$ & $\mathrm{Eg}$ & $124,98 \pm 33,64$ & $6,4^{*}$ \\
\hline & & $\mathrm{Br}$ & $162,04 \pm 22,14$ & $S$ & $158,16 \pm 8,41$ & $7,8^{*}$ \\
\hline & \multirow[t]{2}{*}{ B3 } & $\mathrm{Eg}$ & $539,91 \pm 242,40$ * & $\mathrm{Eg}$ & $143,28 \pm 25,26$ & $7,1^{*}$ \\
\hline & & $\mathrm{Br}$ & $125,36 \pm 8,43$ * & $\mathrm{S}$ & $126,34 \pm 18,87$ & $7,7^{*}$ \\
\hline \multirow[t]{10}{*}{$\overline{\text { Azul }}$} & & & & & & \\
\hline & \multirow[t]{2}{*}{ A1 } & Ev & $350,24 \pm 286,55$ & Ev & $81,76 \pm 3,36^{*}$ & 8 \\
\hline & & Pn & $153,55 \pm 37,28$ & $P n$ & $96,69 \pm 8,91^{*}$ & 7,7 \\
\hline & \multirow[t]{2}{*}{$\mathrm{A} 2$} & Ev & $108,01 \pm 14,95$ * & Ev & $95,90 \pm 15,31$ & $6,5^{*}$ \\
\hline & & Pn & $153,55 \pm 37,28$ * & $P n$ & $96,69 \pm 8,91$ & $7,7^{*}$ \\
\hline & \multirow[t]{2}{*}{ A3 } & $\mathrm{Ec}$ & $249,20 \pm 52,93$ * & Ec & $186,51 \pm 17,92^{*}$ & 7,4 \\
\hline & & Pn & $153,55 \pm 37,28$ * & $\mathrm{Pn}$ & $96,69 \pm 8,91^{*}$ & 7,7 \\
\hline & \multirow[t]{2}{*}{ A4 } & Ev & $231,53 \pm 23,74$ * & Ev & $130,5 \pm 30,6$ & $6,7^{*}$ \\
\hline & & $\mathrm{Br}$ & $136,50 \pm 22,78$ * & $M$ & $160,73 \pm 45,29$ & $7,5^{*}$ \\
\hline & A5 & Ev & $254,23 \pm 68,94$ * & Ev & $186,61 \pm 28,12^{*}$ & $6,9^{*}$ \\
\hline
\end{tabular}




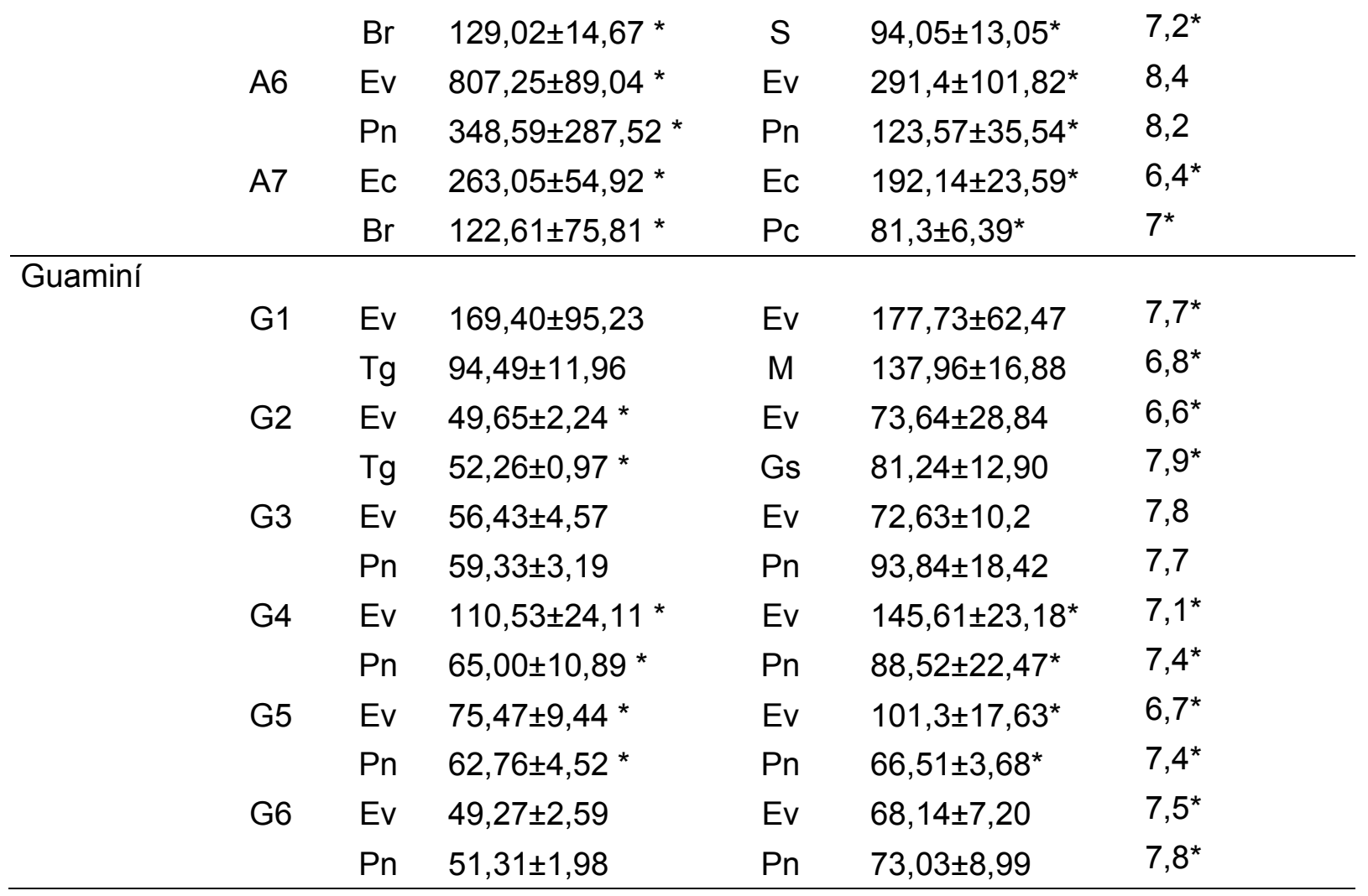

\subsubsection{Agrupación de la CE por localidad geográfica}

La comparación entre parcelas apareadas agrupadas por localidad (BalcarceLobería, Azul y Guaminí; Tabla II.3.) indicó una gradación en la CE del suelo, con menores valores en las parcelas situadas al Oeste de la transecta, localidad de Guaminí (alrededor de $75 \mu \mathrm{S} \mathrm{cm}{ }^{-1}$ ), y mayores en el sector centro y Este, localidades de Azul (246 $\left.\mu \mathrm{S} \mathrm{cm}^{-1}\right)$ y Balcarce-Lobería (223 $\mu \mathrm{S} \mathrm{cm}^{-1}$; Gráfico II.2.). Así, si bien en cada localidad no se observaron diferencias significativas entre la CE promedio de los distintos usos del suelo, sí se observó que la CE de las forestaciones en las localidades de Azul y Balcarce-Lobería fueron mayores que los resultados encontrados en Guaminí (Gráfico II.2.). También es interesante resaltar la mayor dispersión encontrada en las parcelas forestadas (Gráfico II.2.). 


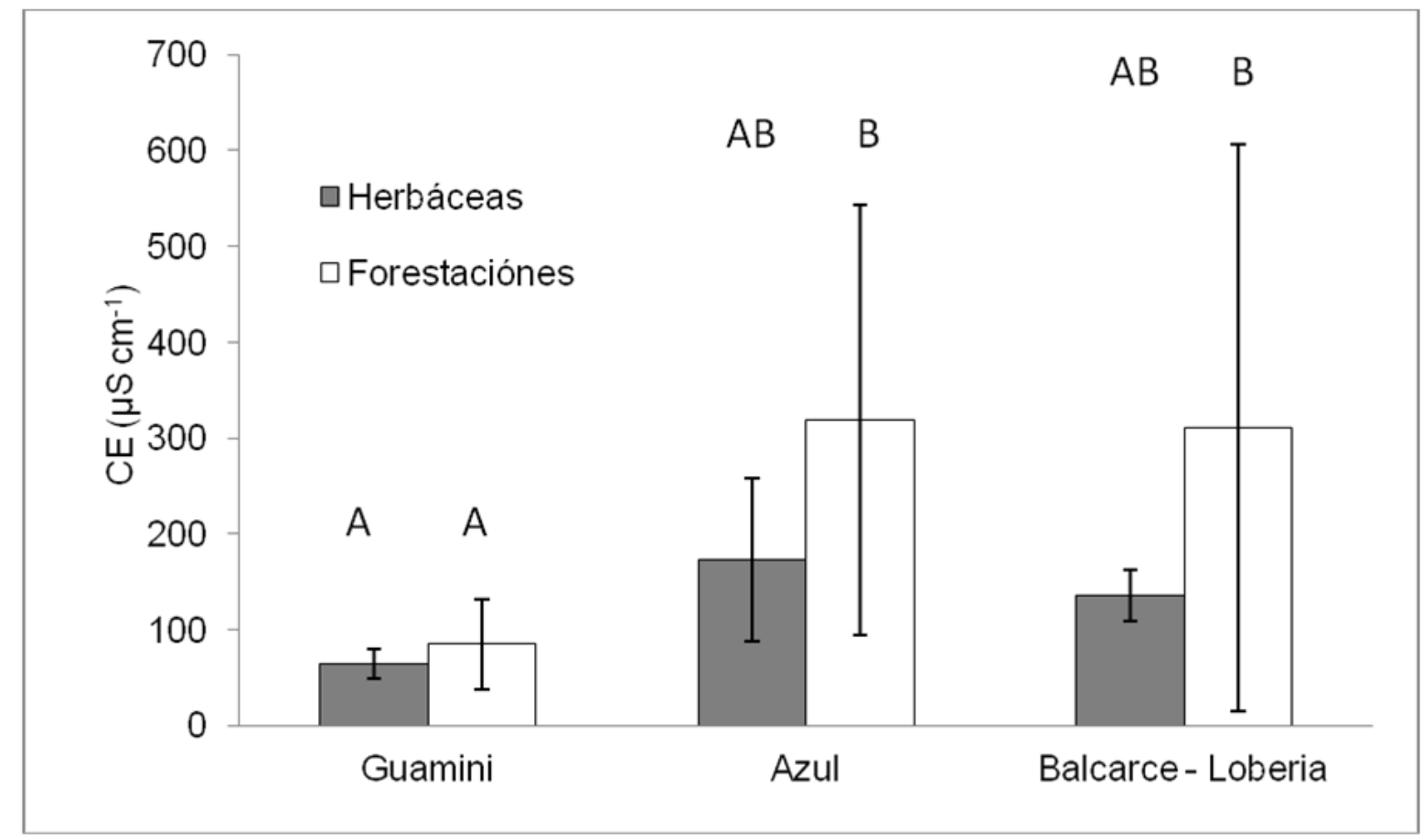

Gráfico II.2. Conductividad eléctrica del suelo $\left(C E, \mu S \mathrm{~cm}^{-1}\right)$ en invierno de las parcelas con una cobertura herbácea (cultivos y pastizales) y forestal, en las distintas localidades (Balcarce-Lobería, Azul y Guaminí) a lo largo de la transecta estudiada. Letras diferentes indican diferencias significativas para un $p<0,05$

\subsubsection{Agrupación de la CE por textura del suelo}

El agrupamiento de las parcelas por uso y texturas de suelo, indicó que las parcelas forestales establecidas sobre suelos arcillosos presentan una mayor CE que las parcelas sobre suelos limosos y arenosos (Gráfico II.3.). Sin embargo las forestaciones no muestran diferencias significativas con sus parcelas herbáceas apareadas, ni con las forestaciones y herbáceas que se encuentran sobre suelos francos (Gráfico II.3.). Para el caso de las parcelas herbáceas, las mismas no muestran diferencias significativas de CE comparando los distintos tipos de suelos muestreados (Gráfico II.3.). Nuevamente se observa una gran variabilidad, que se expresa más en los sitios forestados de suelos arcillosos y francos (Gráfico II.3.). 


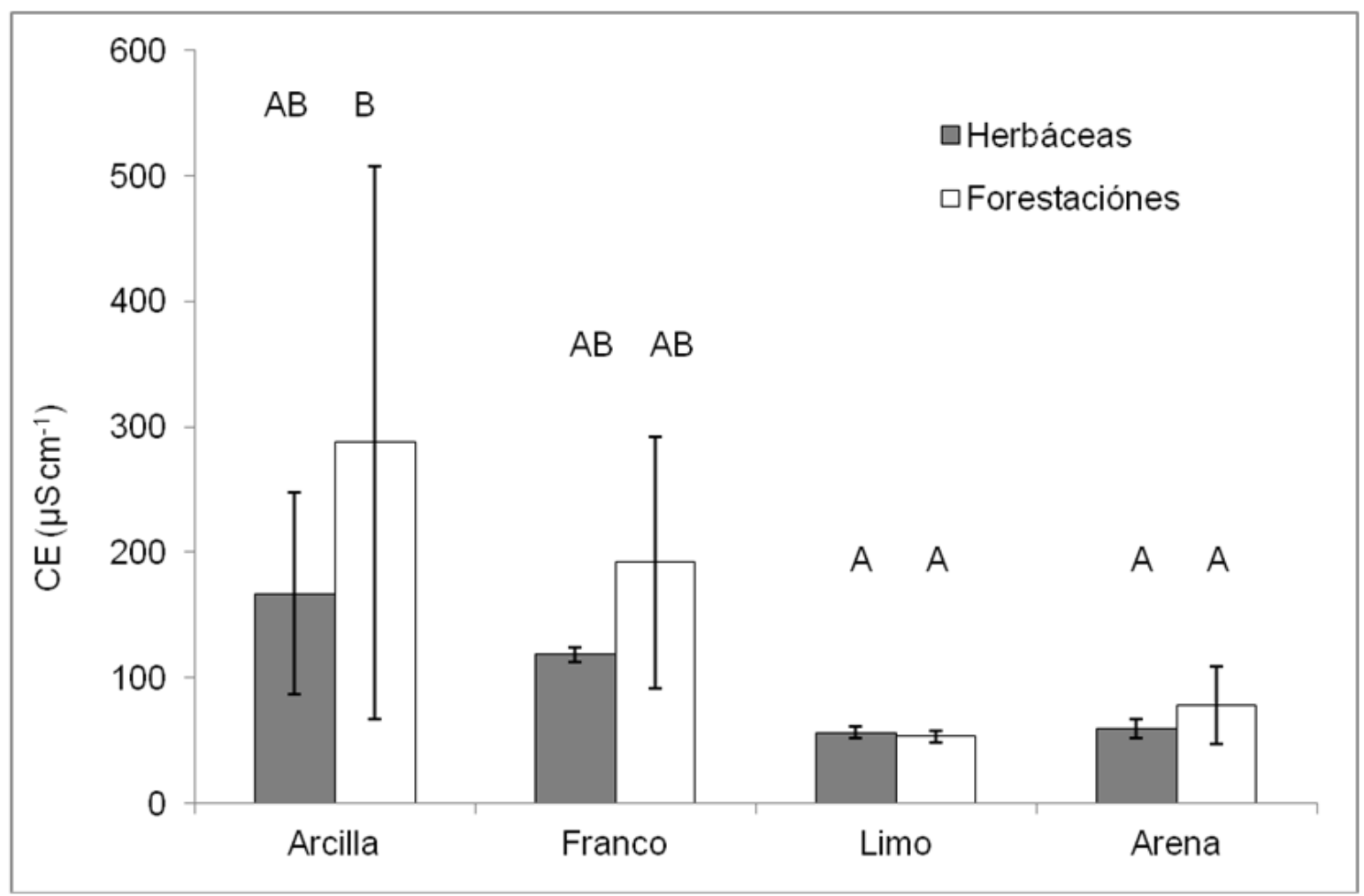

Gráfico II.3. Conductividad eléctrica del suelo (CE, $\mu S \mathrm{~cm}^{-1}$ ) en invierno de las parcelas herbáceas y forestales en las distintas texturas de suelo. Letras diferentes indican diferencias significativas para un $p<0,05$.

\subsubsection{CE a distintas profundidades del suelo}

Más allá de los valores promedios, otro análisis pertinente involucra el estudio de la distribución de sales en las distintas profundidades de suelo, atendiendo la posible distribución de las raíces en interacciones con los perfiles petrocálcicos presentes en la región. En este sentido, se encontraron diferencias significativas en alguna profundidad de suelo entre las parcelas apareadas en 10 de las 16 situaciones analizadas. Así se observa entre las parcelas herbáceas y forestales situadas en la localidad Guaminí, ubicada en el extremo Oeste de la transecta (donde las precipitaciones son menores y el balance hídrico es más negativo), tres patrones de distribución de la CE: por un lado diferencias en la CE del suelo sólo en la porción más superficial (sitio G2), en otro caso diferencias en todo el perfil de suelo (G4) y por último diferencias sólo a mayor profundidad (G5) (Gráfico II.4.). Es interesante resaltar que en el caso en donde se observó diferencias sólo en la parte superior del perfil, la mayor CE se verificó en la parcela herbácea y no en la forestal (sitio G2; Tabla II.1., Gráfico II.4.). 


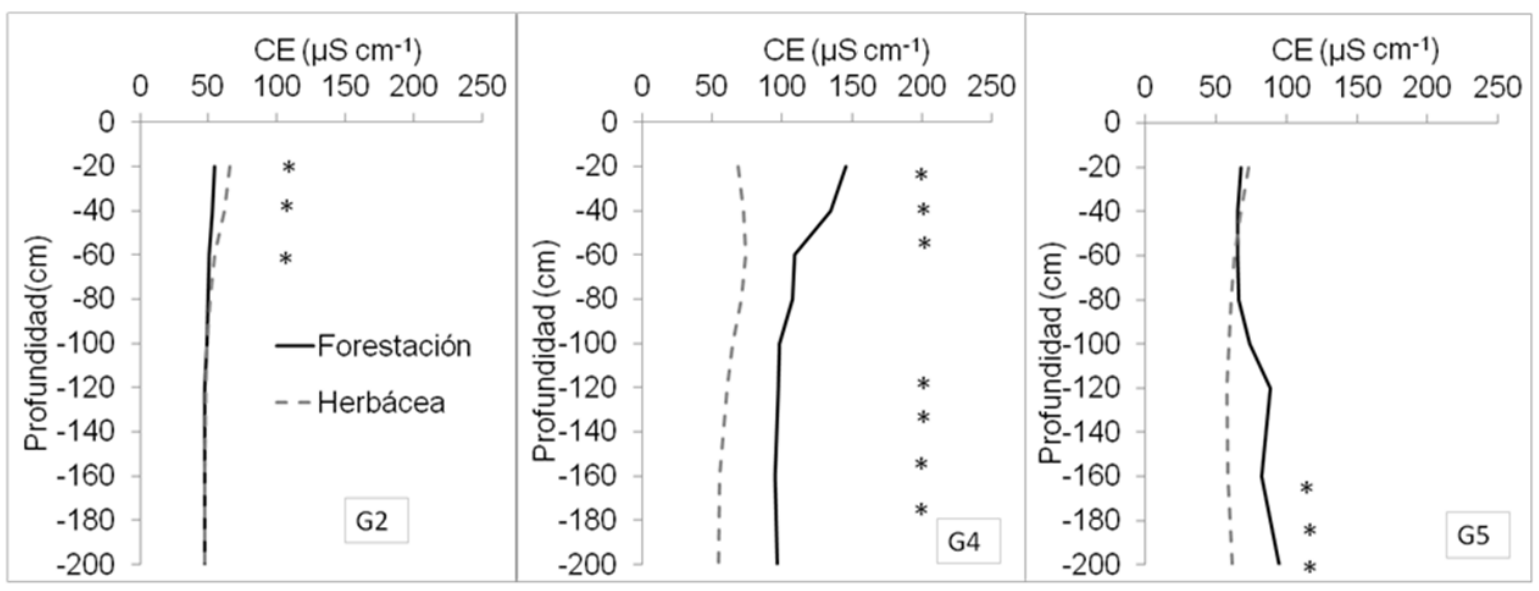

Gráfico II.4. Conductividad eléctrica del suelo (CE, $\mu \mathrm{S} \mathrm{cm}^{-1}$ ) en invierno a las distintas profundidades de muestreo de las parcelas herbáceas y forestales, en tres sitios (G2, G4 y G5) ubicados en la localidad de Guaminí (sector Oeste de la transecta). El asterisco muestra la profundidad en la que se encontraron diferencias significativas ( $p$ $<0,05)$.

En el centro de la transecta estudiada (localidad de Azul), los resultados fueron muy variables. En este caso, la profundidad del suelo se ve limitada por la presencia de horizontes petrocálcicos entre los 40 y los $80 \mathrm{~cm}$ de profundidad. De manera similar a lo observado en Guaminí, si bien en la mayoría de los casos la CE del suelo de la parcela forestal fue superior en todo el perfil, se observó en el sitio A2 que la CE de la parcela herbácea fue mayor que en la forestación (Gráfico II.5.). Además se registraron casos donde la $C E$ es mayor en las capas inferiores del perfil (A2, A6 y A7), sólo en la parte superior del perfil (A3 y A4) y diferencias de CE en todo el perfil del suelo (A5) (Gráfico II.5.). Por otro lado las más amplias diferencias entre la parcelas herbáceas y forestales se observa en el sitio A6 donde las condiciones de salinidad son naturalmente altas (Gráfico II.5.). 


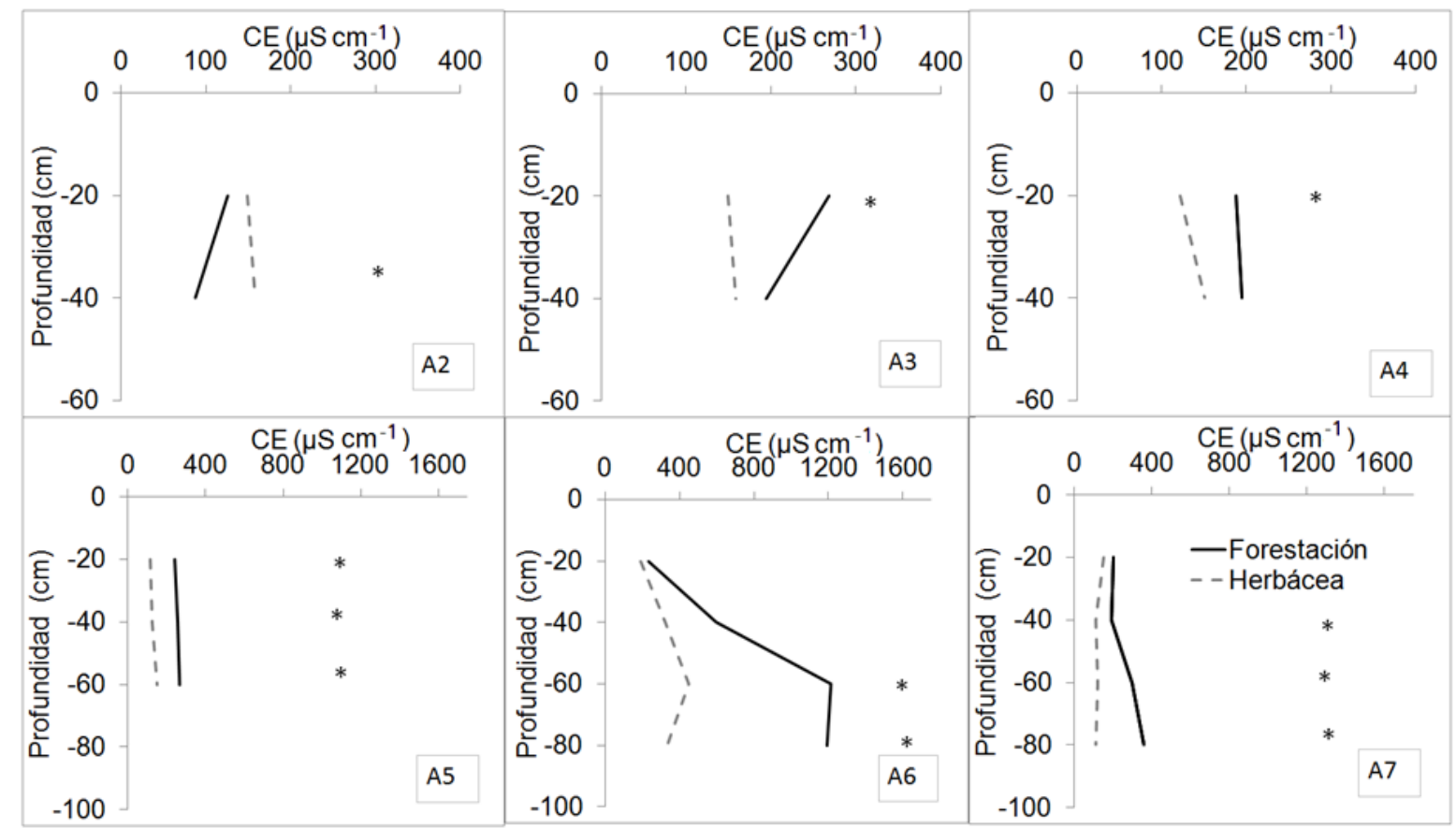

Gráfico II.5. Conductividad eléctrica del suelo (CE, $\mu \mathrm{S} \mathrm{cm}^{-1}$ ) en invierno a las distintas profundidades de muestreo en las parcelas herbáceas y forestales, en seis sitios (A2, A3, A4, A5, A6 y A7) ubicados en la localidad de Azul (sector centro de la transecta). El asterisco muestra la profundidad en la que se encontraron diferencias significativas $(p<0,05)$.

En las localidades de Balcarce-Lobería ubicadas al este de la transecta, donde el balance hídrico es más positivo y las precipitaciones más elevadas, se observaron diferencias significativas en una sola parcela apareada (B3, Gráfico II.6.), en donde se encontró una mayor CE de la parcela forestada en todo el perfil, alcanzando las mayores diferencias a medida que profundizamos en el suelo (Gráfico II.6.). 


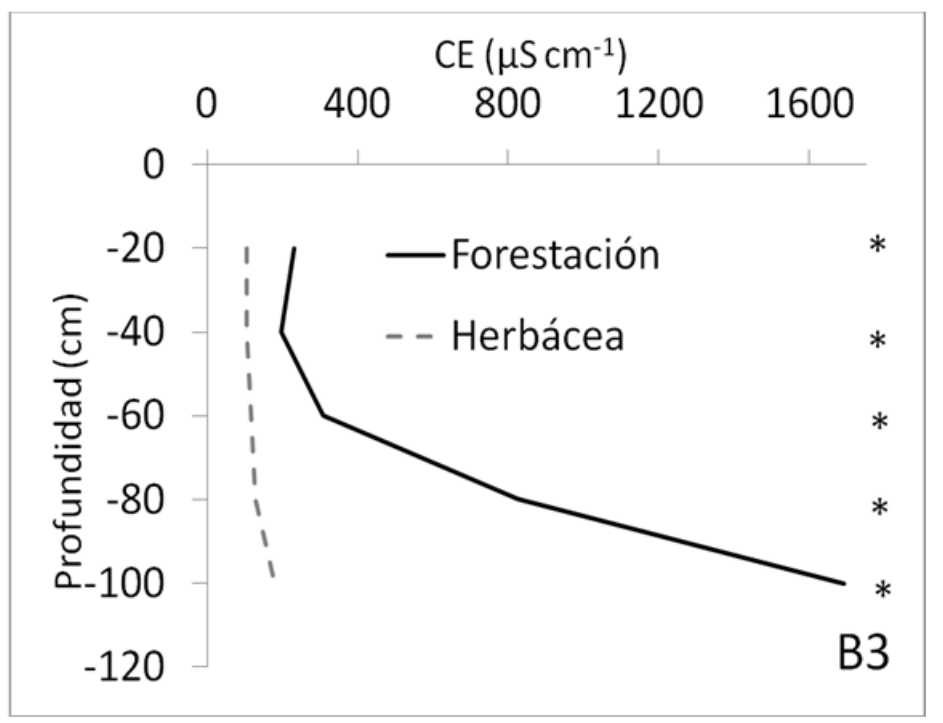

Gráfico II.6. Conductividad eléctrica del suelo ( $\left.C E, \mu S \mathrm{~cm}^{-1}\right)$ en invierno a las distintas profundidades de muestreo de las parcelas herbáceas y forestales en el sitio B3, ubicado en la localidad de Balcarce-Lobería (sector este de la transecta). El asterisco muestra la profundidad en la que se encontraron diferencias significativas $(p<0,05)$.

\subsubsection{4 $\mathrm{pH}$ a distintas profundidades de suelo}

No se encontraron diferencias significativas entre vegetación herbácea y forestación en los sitios A1, A3, A6 y G3 (Tabla II.3.), en otras parcelas la diferencia se expresó a favor de un menor $\mathrm{pH}$ en la parcela forestal principalmente en las muestras más superficiales, reduciéndose las diferencias a medida que profundizamos (B1, B2, B3, A2, A4, A5, A7, G2, G4, G5 y G6, Gráficos II.7., II.8. y II.9.) y solo en un caso el pH fue superior en la parcela forestal que en la herbácea (G1; Gráfico II.7.). 


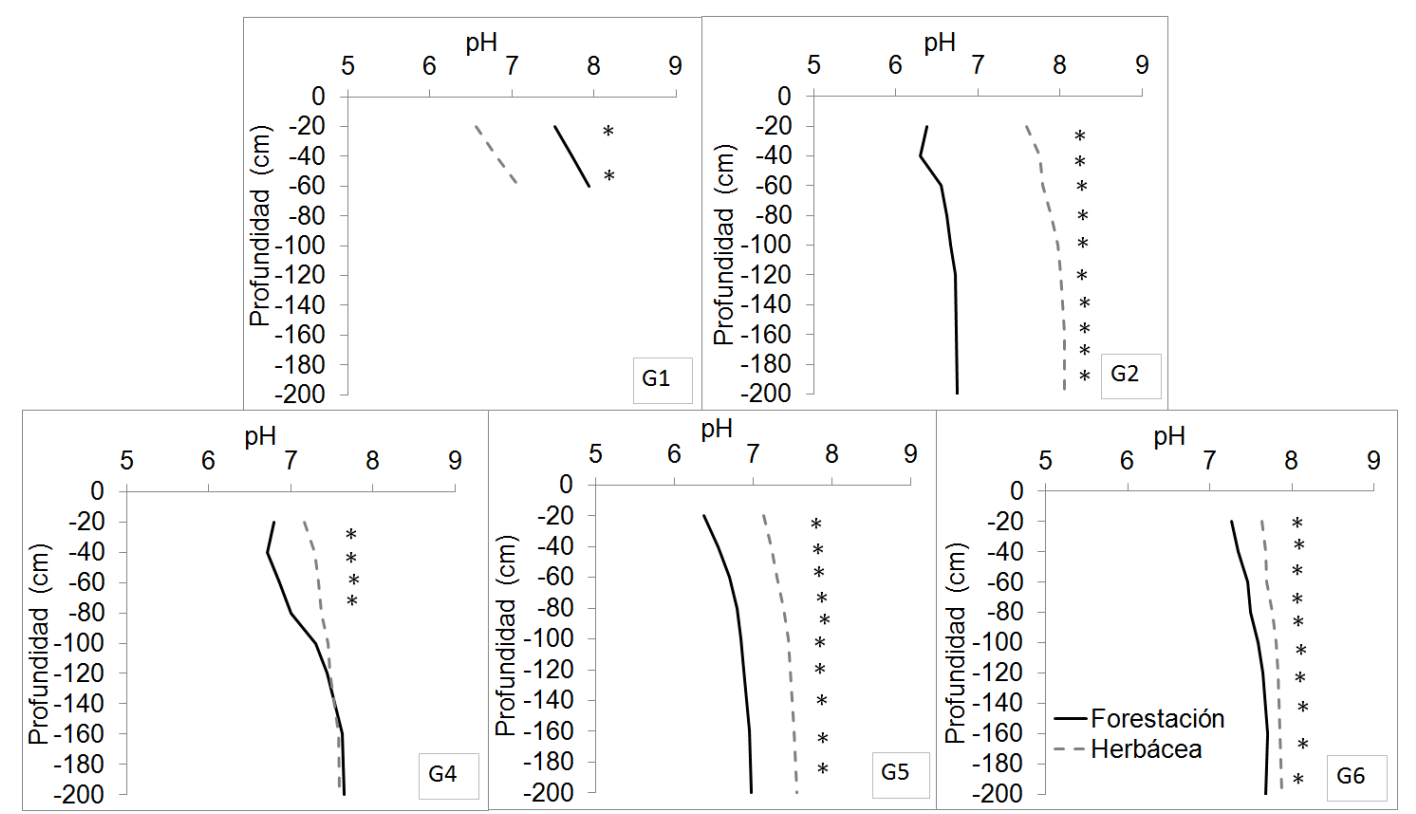

Gráfico II.7. pH del suelo en invierno a las distintas profundidades de muestreo en las parcelas herbáceas y forestales, en cinco sitios (G1, G2, G4, G5 y G6) ubicados en la localidad de Guaminí (Oeste de la transecta). El asterisco muestra la profundidad en la que se encontraron diferencias significativas $(p<0,05)$.

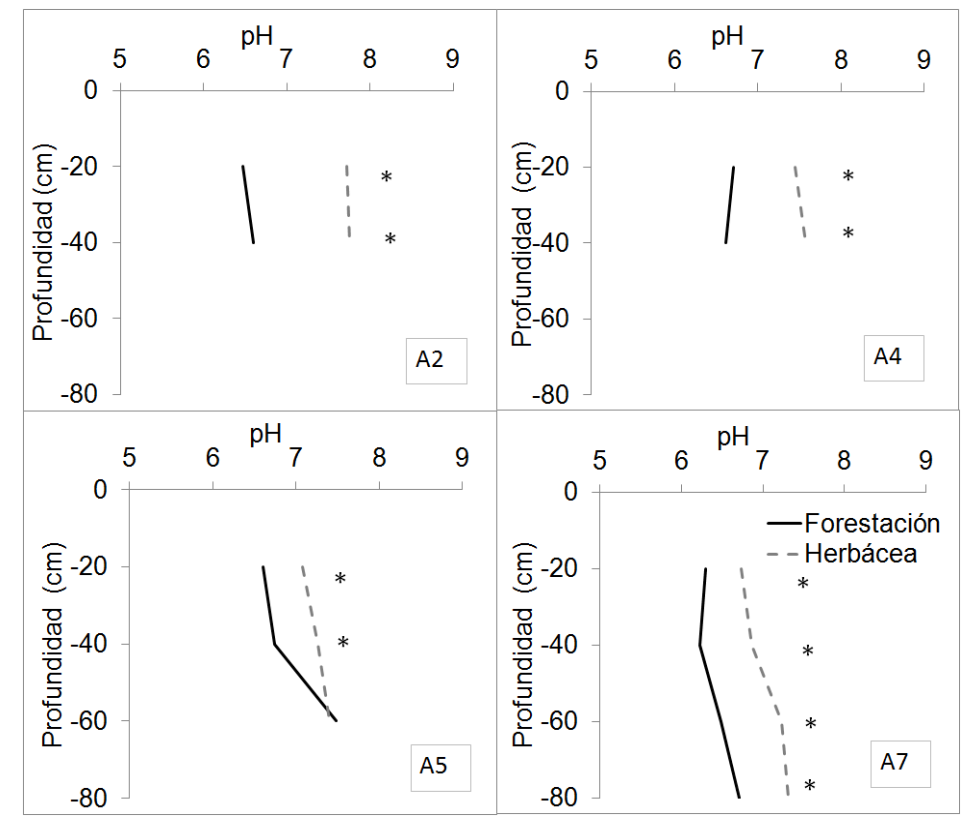

Gráfico II.8. $\mathrm{pH}$ del suelo en invierno a las distintas profundidades de muestreo en las parcelas herbáceas y forestales, en cuatro sitios (A2, A4, A5 y A7) ubicados en la localidad de Azul (sector centro de la transecta). El asterisco muestra la profundidad en la que se encontraron diferencias significativas $(p<0,05)$. 


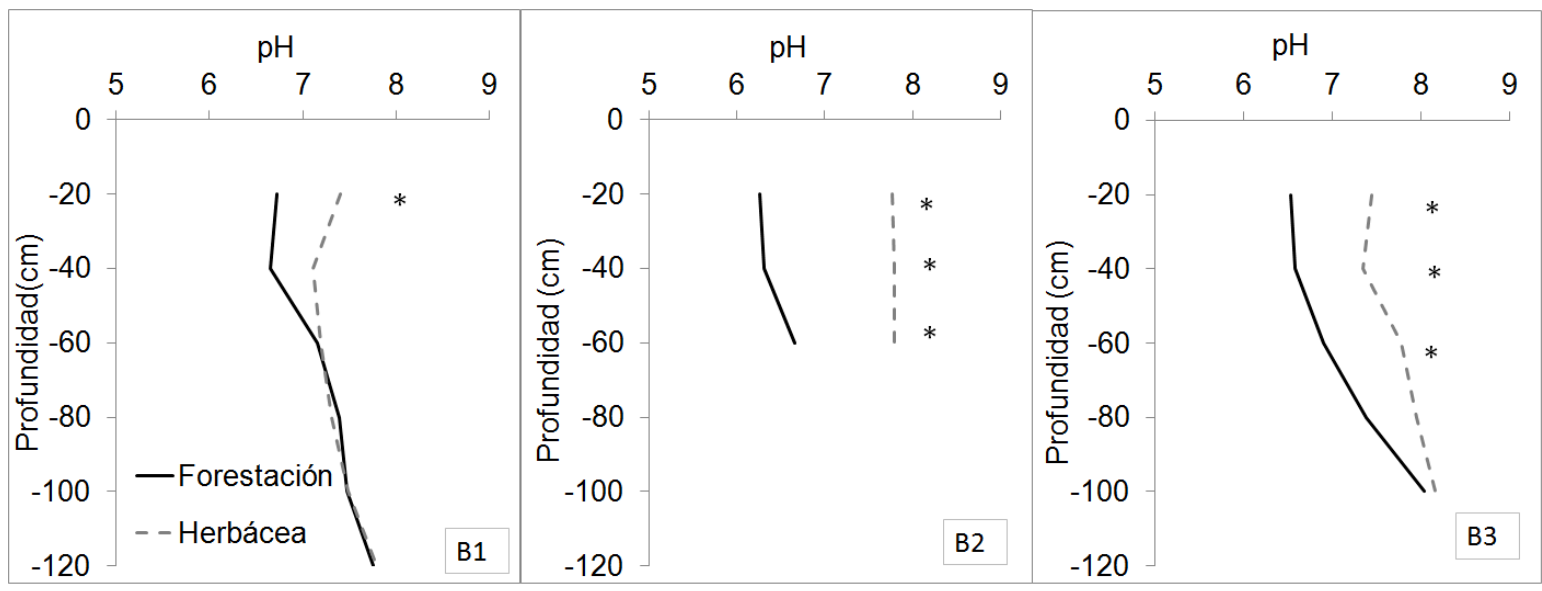

Gráfico II.9. pH del suelo en invierno a las distintas profundidades de muestreo de las parcelas herbáceas y forestales en los sitios B1, B2 y B3, ubicados en la localidad de Balcarce-Lobería (sector este de la transecta). El asterisco muestra la profundidad en la que se encontraron diferencias significativas $(p<0,05)$.

\subsubsection{Variables de suelo durante la estación estival}

La CE promedio de todo el perfil de suelo varió desde los 68 hasta los $300 \mu \mathrm{S}$ $\mathrm{cm}^{-1}$ en el caso de los suelos bajo forestaciones, y desde 66 hasta $160 \mu \mathrm{S} \mathrm{cm}^{-1}$ para los otros usos del suelo (Tabla II.3.).

\subsubsection{Agrupación de la CE por localidad geográfica}

La comparación entre parcelas apareadas agrupadas por localidad (BalcarceLobería, Azul y Guaminí; Tabla II.3.) indicó una gradación en la CE del suelo, con menores valores en las parcelas situadas al Oeste de la transecta, localidad de Guaminí (alrededor de $98 \mu \mathrm{S} \mathrm{cm} \mathrm{cm}^{-1}$ ), y mayores en el sector centro y Este, localidades de Azul (139 $\left.\mu \mathrm{S} \mathrm{cm}^{-1}\right)$ y Balcarce-Lobería (134 $\mu \mathrm{S} \mathrm{cm}^{-1}$; Gráfico II.10.). Así, en la localidad de Azul se observaron diferencias significativas entre la CE promedio de los distintos usos del suelo, además se observó que la CE de las forestaciones en las localidades de Azul fueron mayores que los resultados encontrados en Guaminí (Gráfico II.10.). También, como sucedió en el invierno, es interesante resaltar la mayor dispersión encontrada en las parcelas forestadas (Gráfico II.10.). 


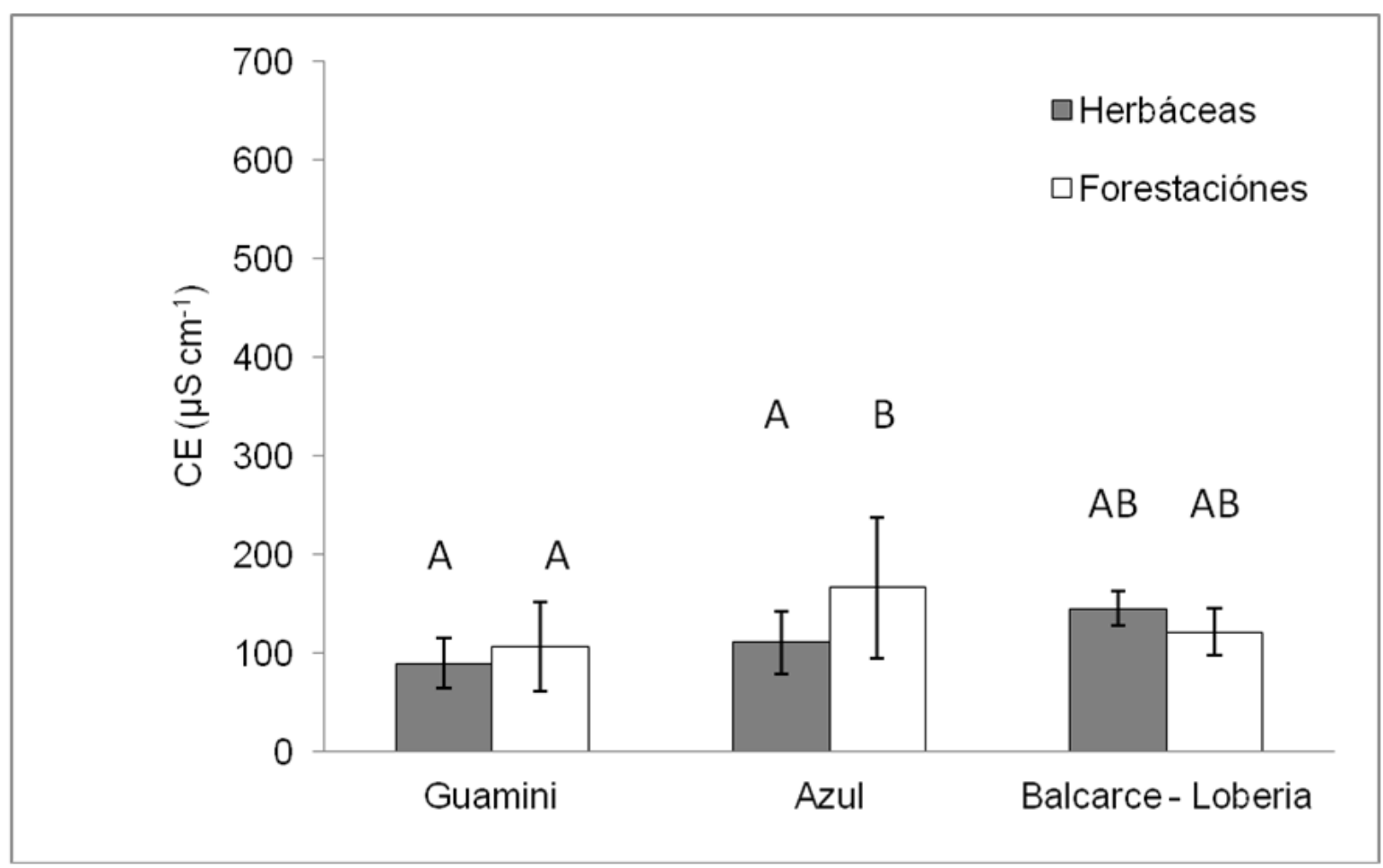

Gráfico II.10. Conductividad eléctrica del suelo (CE, $\mu S \mathrm{~cm}^{-1}$ ) en verano de las parcelas con una cobertura herbácea (cultivos y pastizales) y forestal, en las distintas localidades (Balcarce-Lobería, Azul y Guaminí) a lo largo de la transecta estudiada. Letras diferentes indican diferencias significativas para un $p<0,05$

\subsubsection{Agrupación de la CE por textura del suelo}

El agrupamiento de las parcelas por uso y texturas de suelo indicó que las forestaciones no mostraron diferencias significativas con sus parcelas herbáceas apareadas en ningún tipo textural (Gráfico II.11.). Sin embargo se observaron diferencias significativas a favor de una mayor CE en las forestaciones sobre suelos arcillosos únicamente al contrastarlas con las forestaciones sobre suelos limosos y las parcelas herbáceas en suelos arenosos (Gráfico II.11.). Nuevamente se observa una gran variabilidad, que se expresa más en los sitios forestados de suelos arcillosos y francos (Gráfico II.11.). 


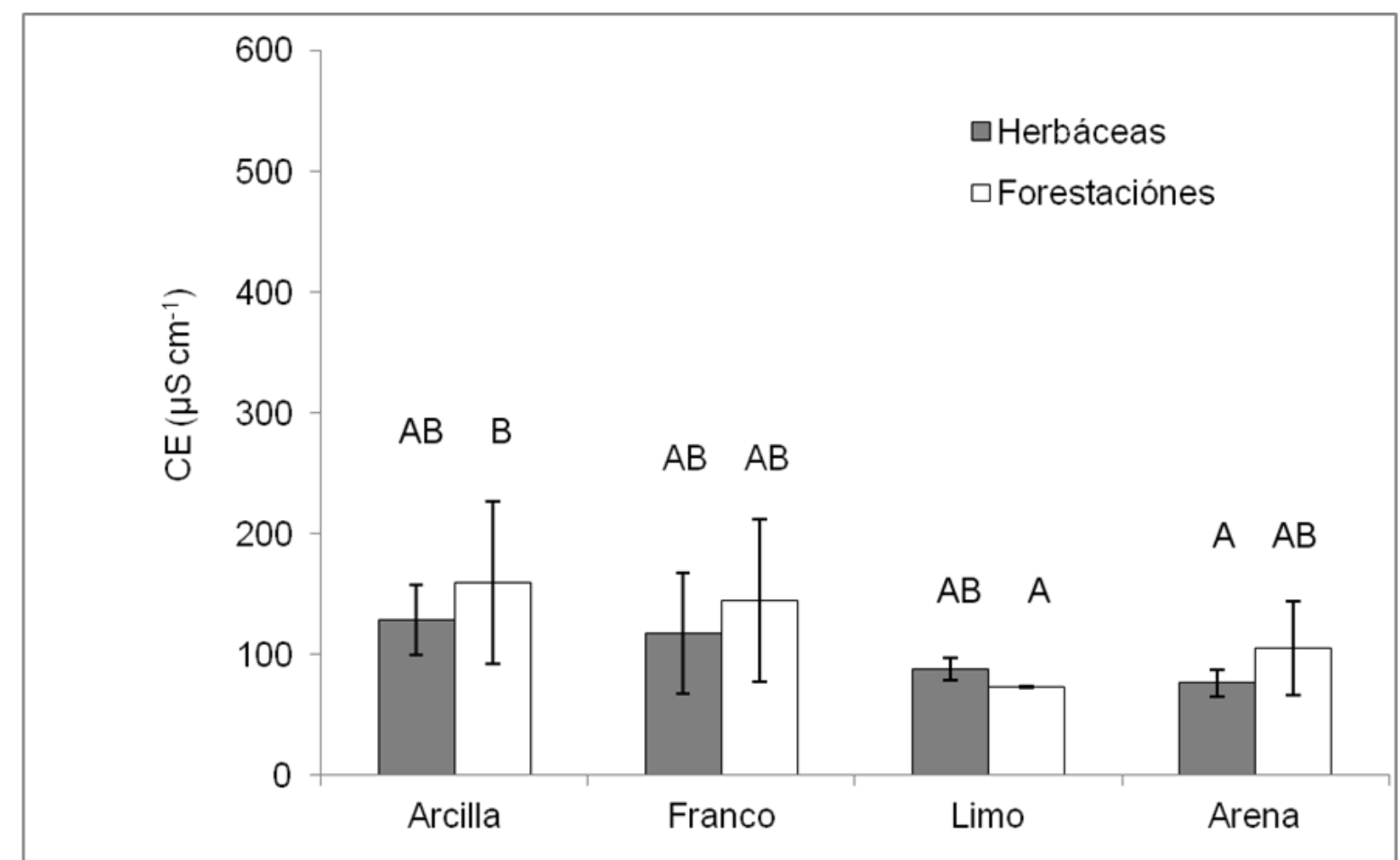

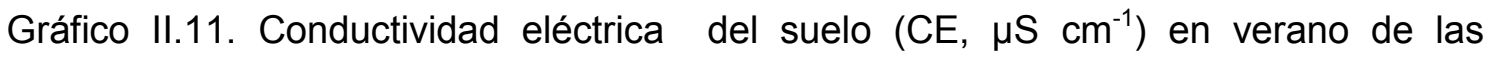
parcelas herbáceas y forestales en las distintas texturas de suelo. Letras diferentes indican diferencias significativas para un $p<0,05$.

\subsubsection{CE a distintas profundidades del suelo}

Sólo se encontraron diferencias significativas, en alguna profundidad de suelo entre las parcelas apareadas en 8 de las 16 situaciones analizadas (Tabla II.3.). Se observó entre las parcelas herbáceas y forestales situadas en la localidad Guaminí, ubicada en el extremo Oeste de la transecta (donde las precipitaciones son menores y el balance hídrico es más negativo), dos patrones de distribución de la CE: en ambos casos hubo diferencias en todo el perfil estudiado de suelo, aunque en G4 la CE disminuía a medida que aumentaba la profundidad mientras que en la parcela herbácea de G5 esta se incrementó (Gráfico II.12.). Es interesante resaltar que en ambos casos la mayor CE se verificó en la parcela forestal (Tabla II.3., Gráfico II.12.). 


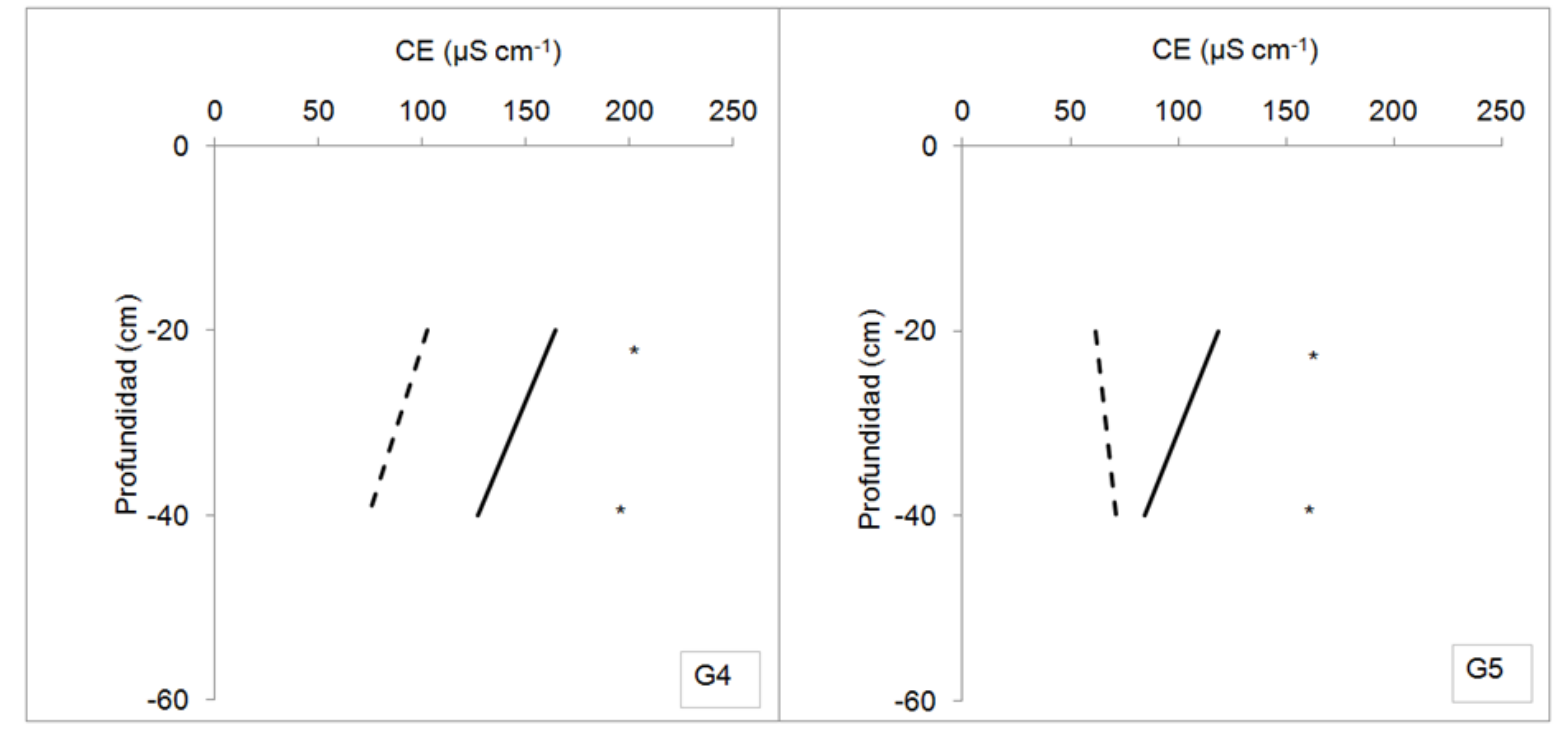

Gráfico II.12. Conductividad eléctrica del suelo (CE, $\mu S \mathrm{~cm}^{-1}$ ) en verano a las distintas profundidades de muestreo de las parcelas herbáceas y forestales, en tres sitios (G2, G4 y G5) ubicados en la localidad de Guaminí (sector Oeste de la transecta). E asterisco muestra la profundidad en la que se encontraron diferencias significativas ( $p$ $<0,05)$.

En el centro de la transecta estudiada (localidad de Azul), los resultados fueron muy variables. Si bien en la mayoría de los casos la CE del suelo de la parcela forestal fue superior en todo el perfil, se observó sólo en el sitio A1 que la CE de la parcela herbácea fue mayor que en la forestación (Gráfico II.13.). Además en la mayoría de los casos la CE es menor en los perfiles inferiores del perfil (A1, A3, A5 y A7), mientras que solo en la parcela apareada $A 6$ la CE se incremento a mayor profundidad (Gráfico II.13.). Por otro lado las más amplias diferencias entre la parcelas herbáceas y forestales ocurrió en el sitio donde las condiciones de salinidad son naturalmente altas (sitio A6) (Gráfico II.13.). 


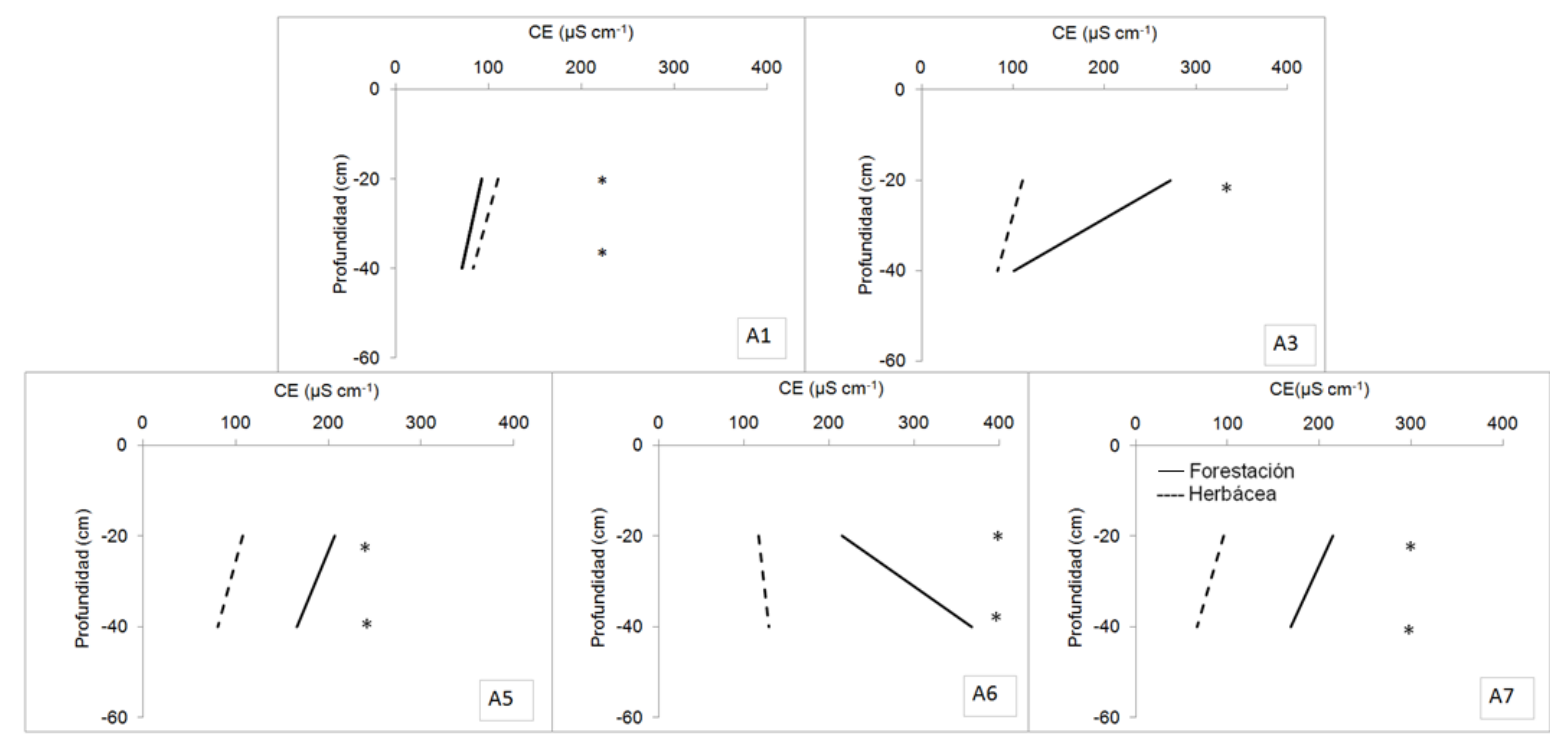

Gráfico II.13. Conductividad eléctrica del suelo $\left(C E, \mu S \mathrm{~cm}^{-1}\right)$ en verano a las distintas profundidades de muestreo en las parcelas herbáceas y forestales, en seis sitios (A2, A3, A4, A5, A6 y A7) ubicados en la localidad de Azul (sector centro de la transecta). El asterisco muestra la profundidad en la que se encontraron diferencias significativas $(p<0,05)$.

En las localidades de Balcarce-Lobería ubicadas al este de la transecta, donde el balance hídrico es más positivo y las precipitaciones más elevadas, se observaron diferencias significativas en una sola parcela apareada (B1, Gráfico II.14.), en donde se encontró una mayor CE de la parcela herbácea en todo el perfil estudiado, alcanzando las mayores diferencias a medida que profundizamos en el suelo (Gráfico II.14.). 


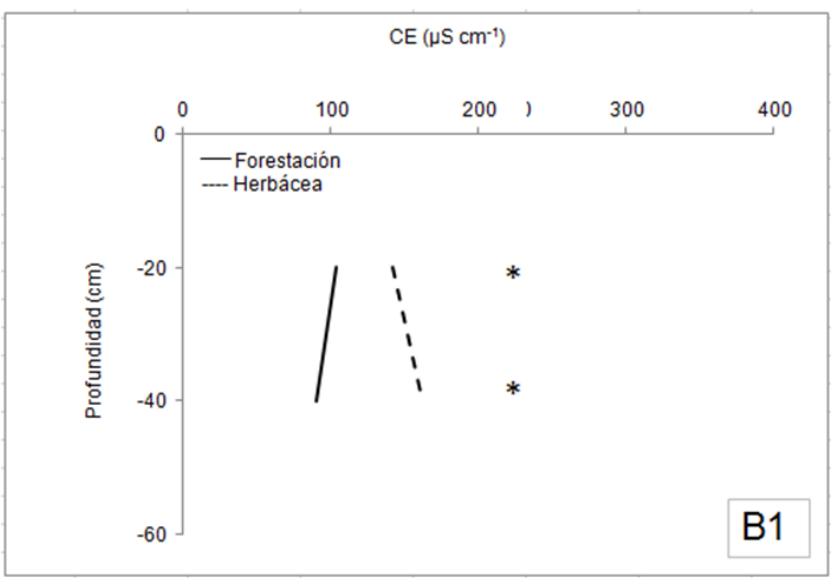

Gráfico II.14. Conductividad eléctrica del suelo (CE, $\mu S \mathrm{~cm}^{-1}$ ) en verano a las distintas profundidades de muestreo de las parcelas herbáceas y forestales en el sitio B1, ubicado en la localidad de Balcarce-Lobería (sector este de la transecta). El asterisco muestra la profundidad en la que se encontraron diferencias significativas $(p<0,05)$.

\subsubsection{CE del suelo: verano vs invierno}

Realizando una comparación entre localidades para un mismo uso y estación del año, Azul mostró valores de CE del suelo superiores a las otras dos localidades, tanto en verano como en invierno. Es interesante resaltar que de manera excepcional, en la localidad de Balcarce-Lobería, se midieron mayores valores de la CE del suelo en parcelas herbáceas durante la estación estival que en el resto de las localidades (Gráfico II.15.).

El análisis de cada localidad por separado mostró que Guaminí tuvo una clara disminución de la CE del suelo en invierno, tanto para las parcelas herbáceas como para las forestales. Se observó el caso contrario en la localidad de Azul donde la CE en el invierno fue mayor que en el verano. Mientras que en Balcarce-Lobería al pasar del verano al invierno, las herbáceas sufrieron una disminución de la CE del suelo y las forestaciones un incremento de la misma (Gráfico II.15.). 


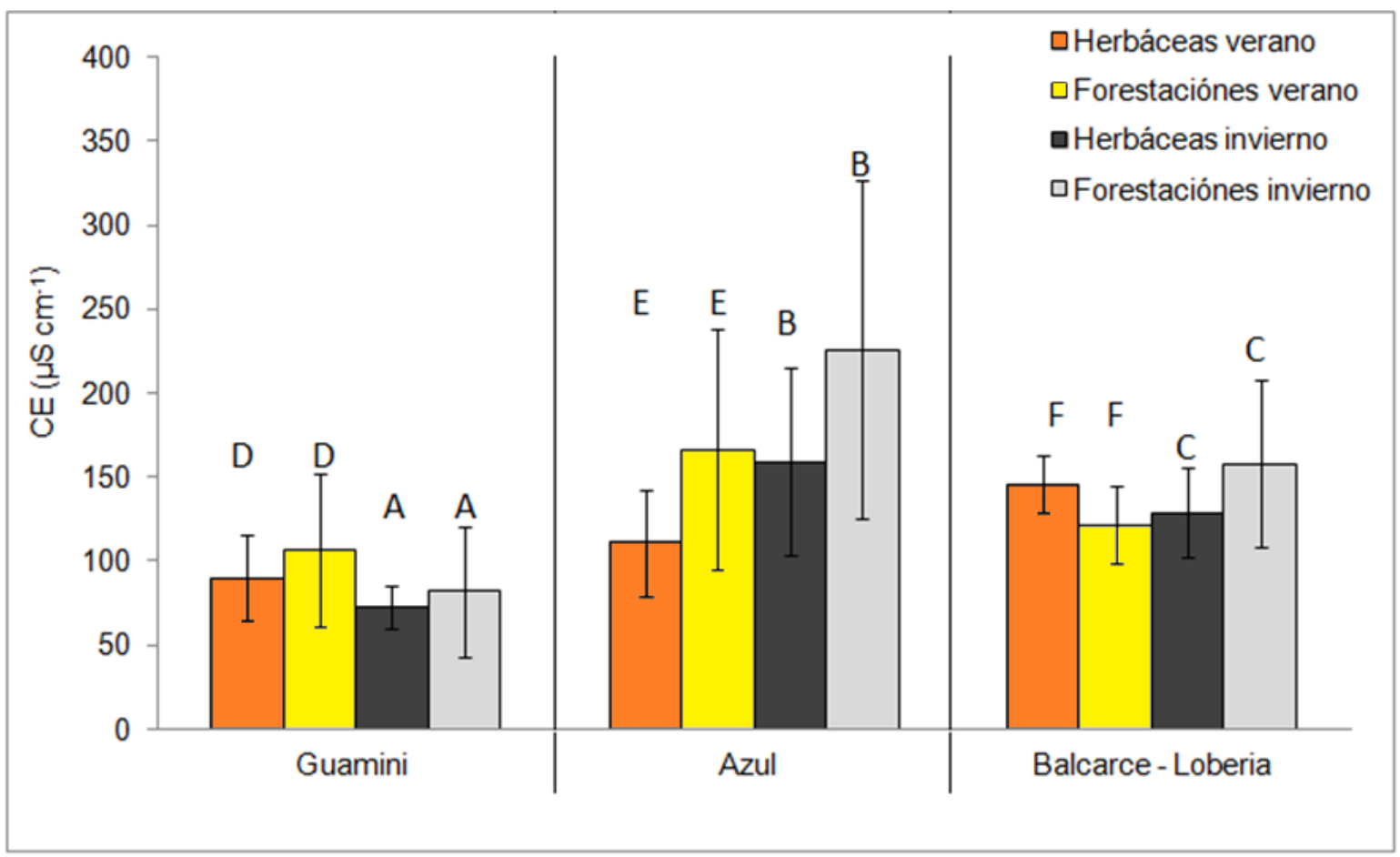

Gráfico II.15. Conductividad eléctrica del suelo $\left(\mathrm{CE}, \mu \mathrm{S} \mathrm{cm}^{-1}\right)$ verano vs invierno hasta los $40 \mathrm{~cm}$ de profundidad, de las parcelas con una cobertura herbácea (cultivos y pastizales) y forestal, en las distintas localidades (Balcarce-Lobería, Azul y Guaminí) a lo largo de la transecta estudiada. Letras diferentes indican diferencias significativas para un $p<0,05$

\subsection{DISCUSIÓN}

Los resultados alcanzados no son concluyentes en cuanto a la generalización de un proceso de salinización secundaria ocurrido en el suelo sometido a forestaciones con Eucalyptus spp. tal como se postuló en el trabajo de Nosetto et al. (2008). Si bien se observaron incrementos de la CE, las mismas no ocurrieron en una profundidad determinada del suelo. Más allá de esto, a nivel regional, en la mayoría de los casos los valores de CE se encontraron por debajo de $1000 \mu \mathrm{S} \mathrm{cm}^{-1}\left(1 \mathrm{dS} \mathrm{m}^{-1}\right.$ ), lo que resulta alentador por no presentar una magnitud tal como para generar consecuencias negativas en el rendimiento de la mayoría de los cultivos agrícolas o forestales más sensibles (Hillel 2000).

\subsubsection{Factores biológicos, hidrogeológicos y climáticos}

Para poder analizar esta ausencia clara de patrones es necesario discutir los distintos factores propuestos por Jobbágy et al. (2008) y Nosetto et al. (2009) que condicionarían este proceso. 
El componente biológico parecería no ser tan importante en la región bajo estudio, aunque en general se acepta que el reemplazo de pastizales por forestaciones induce una mayor evapotranspiración, lo que reduce el lavado de sales hacia perfiles más profundos del suelo (Jobbágy and Jackson 2007). Así, existe un solo antecedente de medición del uso del agua por Eucalyptus para la región; Engel et al. (2005) quienes estimaron un consumo de agua promedio anual por parte de los árboles de $2 \mathrm{~mm}$ día $^{-1}$. Este valor no difiere en gran medida al de los cultivos o pastizales que se realizan (p.e. Rivas y Carmona 2013). Uno de los principales procesos que determinan un mayor uso de agua de las forestaciones con respecto a los pastizales es la capacidad de explorar suelos profundos y así, lograr una mayor disponibilidad del recurso (Canadell et al. 1996). Si bien, en este estudio no se analizó la profundidad del acuífero, ni su CE, la presencia de horizontes petrocálcicos limitaría la capacidad de los árboles de explorar niveles profundos del suelo, tal como se ha observado en otros ecosistemas forestales (Schwinning 2008). A la vez, la existencia de este tipo de horizontes también afecta las tasas de infiltración y drenaje del agua en el suelo, por lo que su presencia influenciará tanto los procesos hidrológicos del sitio como la productividad vegetal (Dietrich et al. 2014). Estas características podrían inducir una acumulación de sales en el suelo sobre el perfil petrocálcico que permitiría explicar la mayor CE en los perfiles inferiores de los sitios con profundidades de suelo cercanas a los $80 \mathrm{~cm}$ (Gráfico II.4. y II.5.). Por el contrario, los suelos muy someros (horizontes petrocálcicos a $40 \mathrm{~cm}$ de profundidad o menos) no mostraron patrones claros, lo que posiblemente, podrían deberse a condiciones homogéneas de distribución de sales y raíces en todo el perfil. En este sentido, se debería estudiar la limitación que el perfil petrocálcico ejerce sobre el crecimiento de las raíces de las especies vegetales de mayor uso en la región, así como también, la capacidad de las forestaciones de hacer un mayor uso de agua que otras coberturas vegetales e inducir flujos subterráneos que alimenten dicha capacidad.

Por otro lado, se ha estimado que la interceptación de las precipitaciones en forestaciones con Eucalyptus del territorio estaría en el orden del 12\%, en donde sería necesario aproximadamente $5 \mathrm{~mm}$ para saturar la capacidad de retención de agua de las copas (Besteiro y Rodríguez Vagaría 2012). De esta manera, es posible que la presencia de árboles genere una menor recarga de agua en el suelo que lo que se produce ante la presencia de los usos herbáceos y esto explique las posibles diferencias entre parcelas apareadas, principalmente durante el verano. Sin embargo, este proceso no permitiría explicar los dos casos en donde se observa una mayor CE en las parcelas herbáceas (G2, Gráfico II.4. y A2, Gráfico II.5.). 
Un aspecto hidrogeológico analizado en el modelo teórico propuesto por Jobbágy et al. (2008) y Nosetto et al. $(2008,2009)$ fue la textura del suelo. En este modelo se hace énfasis en una mayor probabilidad de la salinización secundaria del suelo en aquellos con una conductividad hidráulica más alta. En este sentido, aquellos suelos con una mayor cantidad de arena permitirían el movimiento de agua con sales desde los sitios circundados a las parcelas forestadas (Jobbágy y Jackson 2004). Sin embargo, se midieron los valores más altos de CE en forestaciones donde los suelos tenían mayores proporciones de arcilla, maximizándose estas diferencias durante el invierno (Gráfico II.2., Grafico II.11.). Esto permitiría proponer como hipótesis que en aquellos sitios con un drenaje pobre, debido a la arcilla o capas petrocálcicas, se podría fomentar la acumulación de sales sobre el horizonte petrocálcico. Esto debido a que los suelos arcillosos y la presencia de estas capas petrocálcicas disminuye los flujos verticales de agua (Dietrich et al. 2014, Weil y Brady 2017) por lo que podrían acumular las sales lixiviadas. Por otro lado, los suelos arenosos y más profundos podrían favorecer la lixiviación de las sales en mayor medida evitando la acumulación en una capa particular, principalmente en la época del año donde el balance hídrico es más positivo. Estos resultados indican que sería necesario un mayor esfuerzo para comprender la distribución de las raíces en interacción con este tipo de capas de suelo y la capacidad de las diferentes especies para excluir y / o redistribuir los iones del suelo como se describió en Kong et al. (2012)

Por último, teniendo en cuenta el balance hídrico regional, los sitios en el Oeste de la transecta (Guaminí) muestran un balance hídrico negativo y coinciden con los suelos más profundos (Figura 2.I). A pesar de que estas son condiciones que predispondrían un proceso de salinización secundaria (Nosetto et al. 2008), sólo se encontraron 2 situaciones en verano y 2 en invierno de las 7 analizadas, en donde la CE fue mayor en las parcelas forestadas (sitios G4 y G5, Tabla II.3., Figuras II.4. y II.12.). Estas observaciones se produjeron en sitios que se encontraban en una posición baja en el paisaje (datos no mostrados) y que a la vez, poseían mayor edad, cobertura y área basal (Tabla II.2.). Es posible también que en el resto de las parcelas, los valores similares de CE entre los distintos tipos de usos del suelo sean producto de la sinergia del lavado de sales y el emplazamiento sobre médanos. Esta situación podría promover el drenaje profundo y lixiviado de sales.

En cuanto al $\mathrm{pH}$, es claro como las parcelas donde no se encontraron diferencias significativas entre vegetación herbácea y forestación (A1, A3 y G3) mostraron una baja cobertura aérea y/o edad, por lo que los diferentes usos no impactarían en el pH (Tabla II.2.). En el resto de los casos donde la diferencia se expreso a favor de un menor $\mathrm{pH}$ en la parcela forestal (B1, B2, B3, A2, A4, A5, A7, G2, 
G4, G5 y G6, Gráficos II.7., II.8. y II.9.), podría deberse al mayor aporte de materia orgánica que posee un sistema forestal con respecto a un cultivo anual o una pastura (Caldato 2011 y Delgado et al. 2006) o debido a una elevada extracción de cationes por parte de las plantas (calcio y magnesio), que quedan acumulados en la biomasa arbórea (Jobbágy and Jackson 2003). El sitio A6 se conforma como excepcional por no haberse encontrado diferencias significativas. Esto podría explicarse debido a que, probablemente, se trata de una zona caracterizada por poseer un alto $\mathrm{pH}$ como lo muestran las cartas de suelo INTA (INTA 1989) (Tabla II.3.).

Finalmente en el único caso donde el $\mathrm{pH}$ fue superior en la parcela forestal que en la herbácea (G1, Gráfico II.7.), se puede deber a que el cultivo acompañante (Triticum sp.) había recibido una fertilización nitrogenada al arranque, factor que se ha citado como una fuente de disminución del pH (FAO 1985, Zapata Hernández 2004)

\subsubsection{Efecto de la estación del año en la CE}

Se observó un cambio de la CE del suelo cuya diferencia en magnitud y sentido varió según la temporada del año. En general se midió una disminución en la CE durante el invierno en los suelos de textura arenosa excesivamente drenados, situación que parece estar más influenciada por la vegetación presente cuando la textura del suelo es más fina.

De esta manera, en el Oeste de la transecta (parcelas de Guaminí) la disminución de la CE del suelo tanto para las parcelas herbáceas como para las forestales en el invierno (Gráfico II.15.) podría explicarse por un proceso de lixiviado de sales (Juan 2011) favorecida por los suelos de textura gruesa y el balance hídrico más positivo durante esta estación (Barros 2013) (Tabla II.3.).

En el caso de las parcelas en Azul, cuyos suelos presentaron una textura franca a fina y el balance hídrico más cercano a cero (Tabla II.1., Figura II.1.) es posible que la vegetación (tanto herbácea como arbórea) pueda estar aprovechando la mayor cantidad de agua aportada por las precipitaciones en invierno, evitando el lavado con el consecuente incremento de la CE del suelo. Bajo estas circunstancias de mayor disponibilidad de agua, es posible que las forestaciones muestren una mayor tasa de consumo de agua que los pastizales dada su mayor conductancia aerodinámica (Kelliher et al. 1993) juntamente con una mayor posibilidad de captura de energía advectiva (Calder 1998) y radiativa (a través de su menor albedo), maximizando las diferencias entre el verano y el invierno.

Finalmente en Balcarce-Lobería, donde el balance hídrico es el más positivo de la transecta (Figura II.1.), al pasar del verano al invierno, los sitios con cultivos herbáceos mostraron una disminución de la CE del suelo (Gráfico II.15.) 
probablemente debido a que los procesos de lavado superan a los de acumulación. En cambio las forestaciones con su mayor capacidad de exploración radicular, menor albedo y mayor rugosidad (Kelliher et al. 1993, Calder 1998) podrían aprovechar el mayor aporte de agua de las precipitaciones en la estación invernal (Barros 2013) generando un proceso de exclusión de sales. En este sentido como mencionan Jobbágy and Jackson 2004, Nosetto et al. 2008, Nosetto et al. 2012, generalmente las raíces hacen un uso selectivo de iones, excluyendo los que se encuentran en exceso, los cuales al predominar los procesos de acumulación a los de lavado pueden llevar a un progresivo aumento de la CE del suelo.

\subsubsection{Efecto de las especies de Eucalyptus en la CE}

Si bien este estudio no permite analizar la relación entre la acumulación de sales en el suelo y la tolerancia de las especies a la salinidad ya que no contamos con parcelas con las tres especies en todos los sitios, es interesante resaltar que los mayores valores de CE fueron estimados durante el invierno en forestaciones con Eucalyptus globulus y Eucalyptus viminalis (sitios B3 y A6, respetivamente, Tabla II.3.). Por otro lado, las forestaciones con Eucalyptus camaldulensis (sitios A3 y A7) mostraron valores de CE menores a los anteriores. En este sentido, Eucalyptus globulus fue descripta como de tolerancia baja a moderada (Niknam y McComb 2000), mientras que Eucalyptus viminalis y Eucalyptus camaldulensis se describen como de media a alta tolerancia respectivamente (Niknam y McComb 2000, FAO 1981). Esto no quita que cuando las condiciones predisponen a una acumulación de sales en el perfil, las especies más tolerantes lleven a una acumulación mayor de estas antes de sufrir los efectos negativos, como sugieren Nosetto et al. (2008). Sin embargo, como es evidente, una especie tolerante a la salinidad sin las condiciones que propicien el desarrollo de un proceso de salinización secundaría no representaría un riesgo.

\subsubsection{Efecto de la edad y el manejo de las forestaciones en la CE}

El tiempo de permanencia de las forestaciones es también un factor importante a tener en cuenta. Así, los máximos valores de CE observados en cada localidad se produjeron en las forestaciones de mayor edad (sitios G4 y A6, Tabla II.3.). Esto estaría de acuerdo con el patrón de acumulación de sales en el suelo de los sitios descriptos en Nosetto et al. (2008) con 40-56 años de plantación o los sitios de mayor acumulación de sales en Jobbágy y Jakson (2004) con 42, 50 y 96 años según el tipo de suelo. En este sentido, hay que destacar estos tiempos de permanencia de las forestaciones por largos períodos sobrepasan a los recomendados para un manejo con un rédito económico, debido a que se habrían superado los turnos de corta de las 
especies estudiadas (Daniel et al. 1982, MAGyP 2014). Es decir, esta particularidad no se debería observar en las forestaciones, las que deberían ser cosechadas y manejadas según el objetivo comercial de la madera. Así, surge la necesidad de analizar este proceso prestando especial atención al efecto que podría tener el manejo silvícola (podas y raleos) sobre la masa forestal y por ende sobre la dinámica de sales en el suelo. En este sentido, en la región se observan largos períodos de persistencia de las forestaciones sin ningún tipo de manejo silvícola. De esta manera, se debería poner énfasis en políticas de intervención buscando no sólo la generación de materia prima de calidad, sino también favorecer el lavado de sales del suelo y reducir la expresión de la situación descripta. Así, se necesitarían mayores estudios para conocer la dinámica del agua y sales del suelo en esta región, atendiendo la posible dificultad del drenaje producida por los horizontes petrocálcicos, como lo describe Dietrich et al. (2014).

\subsection{CONSIDERACIONES FINALES}

El cambio de uso de suelo inducido por la introducción de forestaciones con especies de Eucalyptus ha generado diferencias en los valores de $\mathrm{CE}$ y $\mathrm{pH}$, pero en la mayoría de los casos, no fue de una magnitud tal como para generar consecuencias negativas en los cultivos agrícolas o forestales. A nivel de sitio, es posible que la cobertura vegetal juegue un rol determinante tanto en el uso, como en la interceptación de las precipitaciones, limitando o facilitando el lavado de sales hacia perfiles más profundos del suelo, más aun cuando las condiciones de CE del suelo son naturalmente desfavorables. El tiempo de permanencia de las forestaciones, el grado de ocupación del sitio y el manejo silvícola parecen ser factores claves a tener en cuenta. De esta manera una menor expresión del proceso de salinización secundaria puede ir de la mano de un manejo adecuado de turnos de corta, densidades de plantación y escamondos. Por otro lado está claro que la ocurrencia de este proceso no depende exclusivamente de la especie vegetal dominante, el gradiente hídrico y la textura del suelo, sino que dependería también de otros factores como la posición en el paisaje y las condiciones físicas que afectan los movimientos de agua (como sucede con la presencia de horizontes petrocálcicos).

$\mathrm{El} \mathrm{pH}$ del suelo estuvo influenciado por la presencia de forestaciones, por lo que serían necesarios futuros estudios sobre la dinámica o velocidad del cambio y su efecto sobre la productividad de los mismos rodales forestales.

Es importante destacar que en varias ocasiones la profundidad de los muestreos se vio limitada por la presencia de un horizonte petrocálcico o por condiciones de sequía en la temporada estival y esto no permitió constatar si 
ocurrieron procesos de salinización secundaria en perfiles más profundos. Sin embargo los resultados de este trabajo pueden aportar al entendimiento del impacto en los cambios de vegetación y la dinámica de las sales en el suelo, mostrando que varios factores interactúan dando como consecuencia, distintos y complejos escenarios. 


\section{Capítulo 3}

\section{Especies forestales y manejo ¿Cómo afectan la $\mathrm{CE}$ y el pH del suelo? Estudio de dos sitios con suelos contrastantes*}

*Este capítulo está basado en el artículo: Milione G. M., C. R. Mujica; S. A. Bea, D. Dominguez Daguer y J. E. Gyenge 2018. Forestación en pastizales: el rol de las especies y el manejo forestal sobre el proceso de salinización secundaria de suelos. Aceptado el 13 de noviembre del 2018 por la Revista de Investigaciones Agropecuarias (RIA), en prensa para su publicación. 


\subsection{INTRODUCCIÓN}

El proceso de salinización secundaria, en nuestro caso la acumulación de sales debajo de forestaciones en ambientes donde la vegetación originaria es el pastizal, posee tres componentes predisponentes fundamentales; aspectos de índole biológico, hidrogeológicos y climáticos (Nosetto et al. 2008, Jobbágy et al. 2008). En este capítulo se puso a prueba la importancia del factor biológico relacionado con la cobertura vegetal. Este factor incide en el proceso de salinización secundaria a través de distintos mecanismos relacionados con el consumo diferencial de agua dado por las características ecofisiológicas de las especies (Gyenge et al. 2011), la tolerancia a la salinidad (Nosetto et al. 2008) y su efecto en la redistribución de las precipitaciones a través de la cobertura (Besteiro y Rodríguez Vagaría 2012).

En general, el consumo de agua por parte de las forestaciones se encuentra ligado con su productividad. Así los árboles de rápido crecimiento consumen más recursos que los de menor productividad. Por ejemplo, los bosques implantados de rápido crecimiento consumen más agua en comparación con ciertos bosques nativos, quienes generalmente muestran menores valores de productividad (e.g. Gyenge et al. 2011, Nosetto et al. 2008, 2012) por lo que siguiendo el modelo hipotético propuesto, serían más propensos a generar un proceso de salinización secundaria (Nosetto et al. 2008, Jobbágy et al. 2008). De manera lógica, se esperarían procesos de salinización de distinta magnitud dada la distinta productividad de las principales especies forestales cultivadas en el centro de la provincia de Buenos Aires, en donde Eucalyptus viminalis muestra una mayor productividad (con 35-40 $\mathrm{m}^{3} \mathrm{ha}^{-1}$ año ${ }^{-1}$, SINAVIMO 2014) que Pinus radiata (alrededor de $15 \mathrm{~m}^{3} \mathrm{ha}^{-1}$ año-1, Ferrere et al. 2015). De manera similar, la productividad de Eucalyptus viminalis supera a la de Eucalyptus camaldulensis (BA Buenos Aires Forestal 2010). Estas observaciones dan pie para ser usadas como casos de estudio, teniendo en cuenta que se desconoce la ocurrencia y magnitud del proceso en suelos bonaerenses forestados con estas especies.

Sumado al consumo de agua, la acumulación de sales también dependerá de la capacidad intrínseca de las especies a tolerar una mayor o menor concentración en el suelo y acuífero. De esta manera Nosetto et al. (2008), observaron que cuando las condiciones predisponen a una acumulación de sales en el perfil, las especies más tolerantes pueden llevar a una acumulación mayor de sales antes de sufrir los efectos negativos. Así, se han encontrado evidencias de que en un paisaje inicialmente ocupado por pastizales y con acuíferos homogéneamente no salinos, el establecimiento de forestaciones con especies tolerantes y poco tolerantes a la salinidad condujo a salinizaciones mucho más intensas de los suelos y de los acuíferos en sitios con especies pertenecientes al primer grupo que en el segundo (Nosetto et al. 2008). De esta manera, 
los grupos de especies tolerantes o moderadamente tolerantes a la salinidad fueron Eucalyptus camaldulensis, Quercus robur, Casuarina cunninghamiana, Pinus radiata (especies que toleran 4000 a $8000 \mu \mathrm{S} \mathrm{cm}^{-1}$ ) mientras que las del grupo poco tolerantes fueron Populus deltoides, Cedrus deodara, Eucalyptus viminalis (especies que toleran de 2000 a $4000 \mu \mathrm{S} \mathrm{cm}^{-1}$ ) (Nosetto et al. 2008, Marcar et al. 2002, Stirzaker et al. 2002).

El otro aspecto importante del componente biológico está ligado con la redistribución del agua de lluvia generado por la interceptación de las precipitaciones. Tal como menciona Besteiro et al. (2013), el cambio de cobertura vegetal modifica los procesos de lavado/lixiviado de sales y el escurrimiento superficial del suelo. En este sentido, como la cobertura de una forestación puede ser modificada por el manejo (densidad de plantación, podas, raleos), es posible disminuir la evapotranspiración del ecosistema lo que podría generar mayores excesos hídricos y por lo tanto, un mayor lixiviado de sales del suelo (Zhang 2001). Por otro lado, atendiendo a las diferencias entre especies forestales, Besteiro et al. (2012) estimó que la interceptación de las precipitaciones de forestaciones con eucalipto fueron inferiores a la estimada para una forestación de pino. Estas estimaciones determinaron que son necesarios 5,1 $\mathrm{mm}$ de lluvia para saturar la capacidad de retención de agua en copas de eucalipto y 17,2 mm para las de pino. Estas diferencias en la interceptación de las precipitaciones generarían cambios en la cantidad de trascolación que llegue al suelo, pudiendo generar mayores flujos de drenaje y por lo tanto, un mayor lavado de sales del perfil del suelo (Nosetto et al. 2008, Jobbágy et al. 2008).

A partir de estos conceptos es posible sintetizar que, siempre y cuando el resto de las condiciones hidrogeológicas, del suelo y climáticas lo permitan, el proceso de salinización secundaria sería más acentuado en aquellas especies con mayor productividad y que además, sean más tolerantes a la salinidad (Nosetto 2008) y generen una mayor cobertura (dependiente no solo de la especie, sino también del manejo según Gyenge et al. 2009).

Por otro lado, las forestaciones sobre pastizales también producen cambios en otra de las propiedades del suelo como el pH. En un trabajo de síntesis del conocimiento sobre el impacto de las plantaciones de Eucalyptus spp. sobre algunos suelos de Uruguay, se ha encontrado sistemáticamente, que los suelos plantados con Eucalyptus spp. presentan menor $\mathrm{pH}$ (diferencias hasta de 0,5 puntos en todas las profundidades), que los que permanecen bajo la vegetación previa a la plantación (Delgado 2006). De manera similar, en la región Pampeana, Jobbágy et al. (2006) encontraron que en promedio las plantaciones tuvieron 0,3 unidades de $\mathrm{pH}$ menos que los pastizales en la superficie del suelo mineral, en donde las forestaciones con Eucalyptus spp. generaron caídas de $\mathrm{pH}$ significativamente más fuertes que los pinos (debido principalmente a la 
extracción de calcio del sistema que realizan los eucaliptos). Así, la selección de especies en conjunto con las características del suelo y el manejo producen cambios en algunas propiedades del suelo, conocimiento que debe ser estudiado para generar normas de manejo sustentable.

El objetivo de este capítulo fue el de cuantificar el efecto que tienen las principales especies forestales cultivadas en el sudeste de la provincia de Buenos Aires y el sistema de manejo silvícola sobre la salinización secundaria en dos áreas; i) un paisaje de sierras e intersierras en el partido de Tandil y ii) un sitio en la Pampa deprimida en las proximidades a la ciudad de Pila. A la vez se estudió el efecto de las distintas especies forestales y manejos, sobre el $\mathrm{pH}$ del suelo.

\subsection{MATERIALES Y MÉTODOS}

Los muestreos se realizaron en dos sitios: sierras de Tandilia (SST; $37^{\circ} 37^{\prime}$ - 37 ${ }^{\circ} 40^{\prime}$ S, $59^{\circ} 05^{\prime}$ - $59^{\circ} 01^{\prime}$ O) y Pampa Deprimida situada en la localidad de Pila, cuenca del río Salado (CRS; $36^{\circ} 29^{\prime}$ - $36^{\circ} 27^{\prime} \mathrm{S}, 58^{\circ} 13^{\prime}$ - $58^{\circ} 11^{\prime}$ O). 


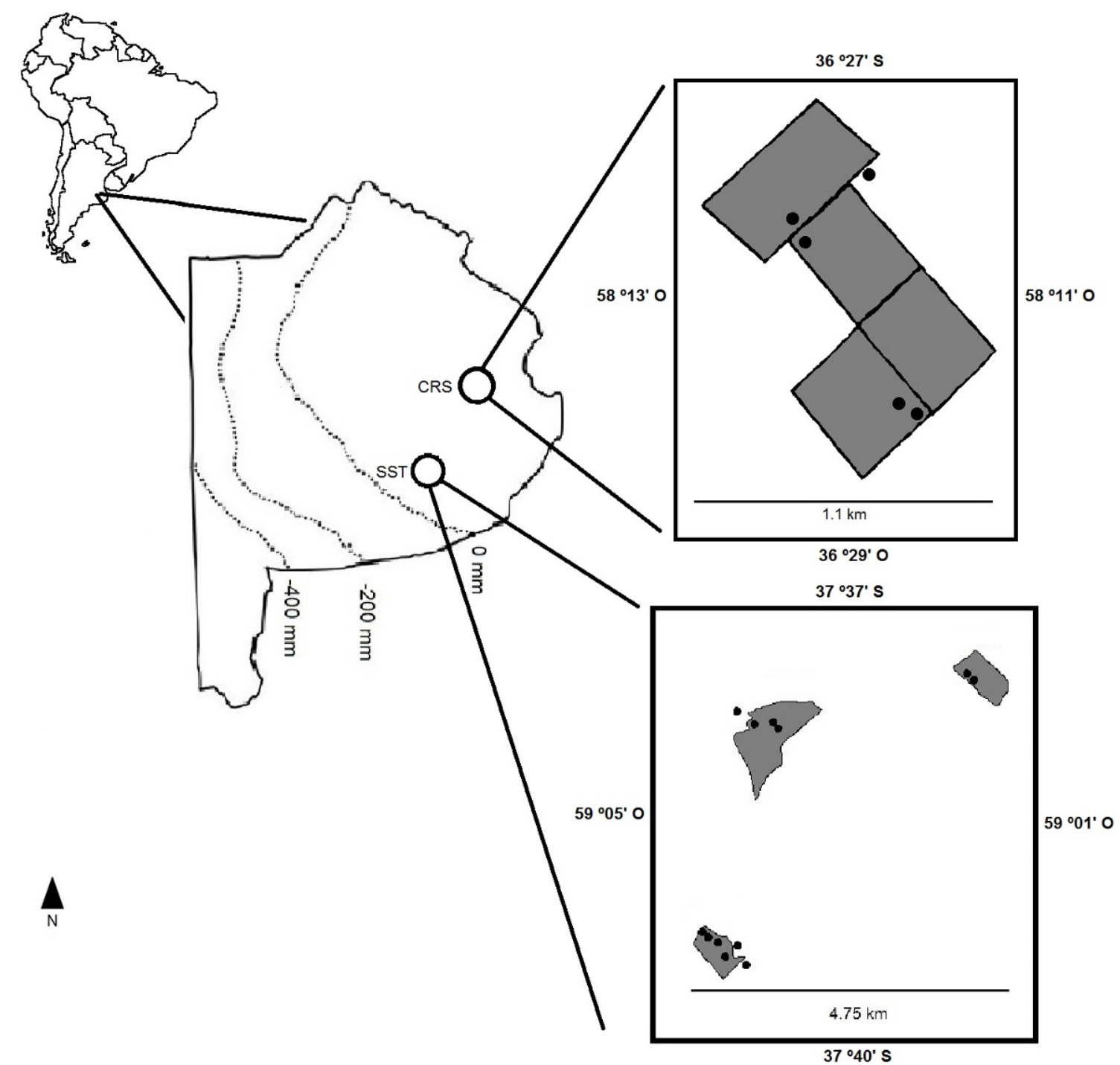

Figura III.1. Ubicación de las zonas de muestreo (círculos huecos donde SST; sierras de Tandil y CRS; Pampa Deprimida situada en la cuenca del río Salado) con sus parcelas apareadas (puntos negros), en gris se denota las forestaciones. Con líneas punteadas se denotan los balances hídricos calculados como la diferencia entre la precipitación media anual y la evapotranspiración potencial de Penman-Montheith (modificado a partir de Nosetto et al. 2008)

Se describieron los rodales usando la misma metodología empleada en el capítulo 2. Se establecieron parcelas de superficie variable en donde se midió el diámetro a la altura del pecho (DAP, $\mathrm{cm}$ ) de todos los árboles presentes en la parcela y la altura de los árboles dominantes. $A$ partir de estos estadísticos se estimó la densidad (árboles ha-1) y área basal del rodal $\left(A B, \mathrm{~m}^{2} \mathrm{ha}^{-1}\right)$. La cobertura forestal se estimó a partir del análisis de fotografías planas y se mantuvo el mismo sistema de análisis estadístico que el empleado en el capítulo 2. 


\subsubsection{Descripción y toma de muestras en el sitio SST:}

Las sierras de Tandilia, con una altura máxima de 524 m. s. m., se alza sobre la llanura bonaerense con orientación NO-SE y tiene una longitud de $350 \mathrm{~km}$ desde la ciudad de Mar del Plata hasta la ciudad de Olavarria y un ancho máximo de $60 \mathrm{~km}$ (Sota de la et al. 2004, Dalla Salda et al. 2006). El área de estudio se encuentra en la zona central de este sistema, en el grupo serrano de Tandil-Barker, provincia de Buenos Aires (Figura III.1.). La vegetación predominante son los Pajonales y matorrales (Frangi J. L. 1975). El clima es templado húmedo con precipitaciones promedio que rondan los 893 $\mathrm{mm}$ año ${ }^{-1}$ y distribuidas de manera más o menos homogénea a lo largo del año (Aeródromo Tandil, 2016), lo que genera un balance hídrico positivo de 0-200 mm año-1 (Nosetto et al. 2008). Los suelos son de textura franca a franca fina, profundos en el piedemonte y en las sierras son poco desarrollados y están emplazados sobre un manto rocoso (INTA 1989).

Durante el mes de Febrero, se establecieron parcelas apareadas en sitios con una cobertura vegetal herbácea (pastura y/o pastizal) y otras en forestaciones de Pinus radiata y/o Eucalyptus spp. con diferentes manejos silvícolas (Tabla III.1.). Los manejos silvícolas abarcaron macizos de Eucalyptus spp. y Pinus radiata. (códigos EU1, EU2, EU3 y PD1, PD2, PD3 respectivamente, Tabla III.1.), una faja silvopastoril de 10 metros de ancho abierta en el año 2011 (código F11, Tabla III.1.), una faja silvopastoril de 14 metros de ancho abierta en el año 2013 (código F21, Tabla III.1.) ambas a partir de un macizo de Pinus radiata y una tala rasa de Pinus radiata con dos años de antigüedad desde la cosecha (código TR2, Tabla III.1.). En estas parcelas se extrajeron muestras de suelo en 5 puntos al azar hasta máxima profundidad posible (las limitaciones de profundidad están dadas en todos los casos por la presencia de un manto rocoso y/o carbonato de calcio cementado). Se agruparon las parcelas por manejo silvícola y especies, se analizo estadísticamente la conductividad eléctrica (CE), el pH y la textura para una misma profundidad del suelo y de la misma forma que la descripta en el capítulo 2. 
Tabla III.1. Sitios (SST = sierras de Tandil y CRS = Pampa Deprimida situada en la cuenca del río Salado), ubicación geodésica de las parcelas, textura del suelo, cobertura $(\mathrm{Ed}=$ Eucalyptus dalrympeana, $\mathrm{Ev}=$ Eucalyptus viminalis, $\mathrm{Pr}=$ Pinus radiata, $\mathrm{Pn}=$ Pastizal natural, Av = Avena sativa, TR = Tala rasa)

\begin{tabular}{|c|c|c|c|c|c|}
\hline Sitio & Código & Ubicación & $\begin{array}{l}\text { Profundidad } \\
\text { del suelo }(\mathrm{cm})\end{array}$ & Textura del suelo & Cobertura \\
\hline \multirow[t]{12}{*}{ SST } & EU1 & $\begin{array}{l}37^{\circ} 40^{\prime} 9,14 " \mathrm{~S} \\
59^{\circ} 4 ' 52,62 " \mathrm{O}\end{array}$ & 110 & \multirow{6}{*}{$\begin{array}{l}\text { Franco } \\
\text { a } \\
\text { Franco } \\
\text { arcillo } \\
\text { arenoso }\end{array}$} & Ed \\
\hline & $\mathrm{F} 21$ & $\begin{array}{l}37^{\circ} 40^{\prime} 8,47^{\prime \prime} \mathrm{S} \\
59^{\circ} 4{ }^{\prime} 57,75^{\prime \prime O}\end{array}$ & 40 & & $\operatorname{Pr}$ \\
\hline & PD1 & $\begin{array}{l}37^{\circ} 40^{\prime} 16,92 " \mathrm{~S} \\
59^{\circ} 44^{\prime} 41,28^{\prime \prime O}\end{array}$ & 40 & & $\operatorname{Pr}$ \\
\hline & Pas1 & $\begin{array}{l}37^{\circ} 40^{\prime} 13,38 " \mathrm{~S} \\
59^{\circ} 4{ }^{\prime} 38,31^{\prime \prime O}\end{array}$ & 80 & & $A v$ \\
\hline & $\mathrm{F} 11$ & $\begin{array}{l}37^{\circ} 40^{\prime} 10,92 " \mathrm{~S} \\
59^{\circ} 4{ }^{\prime} 47,02 " \mathrm{O}\end{array}$ & 40 & & $\operatorname{Pr}$ \\
\hline & Nat1 & $\begin{array}{l}37^{\circ} 40^{\prime} 19,69^{\prime \prime S} \\
59^{\circ} 4 ' 31,21^{\prime \prime O}\end{array}$ & 40 & & $\mathrm{Pn}$ \\
\hline & EU2 & $\begin{array}{l}37^{\circ} 38^{\prime} 28,75 " \mathrm{~S} \\
59^{\circ} 44^{\prime} 43,62 " \mathrm{O}\end{array}$ & 80 & \multirow{4}{*}{$\begin{array}{l}\text { Franco } \\
\text { arcilloso } \\
\text { a } \\
\text { arcillo } \\
\text { arenoso }\end{array}$} & Ev \\
\hline & TR2 & $\begin{array}{l}37^{\circ} 38^{\prime} 28,09 " \mathrm{~S} \\
59^{\circ} 4{ }^{\prime} 32,36 " \mathrm{O}\end{array}$ & 40 & & TR \\
\hline & Nat2 & $\begin{array}{l}37^{\circ} 38^{\prime} 24,99^{\prime \prime S} \\
59^{\circ} 4^{\prime} 50,05^{\prime \prime O}\end{array}$ & 40 & & $\mathrm{Pn}$ \\
\hline & PD2 & $\begin{array}{l}37^{\circ} 38^{\prime} 30,86 " \mathrm{~S} \\
59^{\circ} 4 ' 28,31 " \mathrm{O}\end{array}$ & 40 & & $\operatorname{Pr}$ \\
\hline & PD3 & $\begin{array}{l}37^{\circ} 37^{\prime} 59,38 " \mathrm{~S} \\
59^{\circ} 2 ' 33,88^{\prime \prime O}\end{array}$ & 40 & \multirow[t]{2}{*}{ Franco arcilloso } & $\operatorname{Pr}$ \\
\hline & EU3 & $\begin{array}{l}37^{\circ} 38^{\prime} 2,17^{\prime \prime S} \\
59^{\circ} 2 ' 29,64 " \mathrm{O}\end{array}$ & 80 & & Ev \\
\hline \multirow[t]{5}{*}{ CRS } & Cam1 & $\begin{array}{l}36^{\circ} 28^{\prime} 5,40 " \mathrm{~S} \\
58^{\circ} 12^{\prime} 24,60 " \mathrm{O}\end{array}$ & 60 & \multirow{5}{*}{$\begin{array}{l}\text { Franco } \\
\text { a } \\
\text { Franco } \\
\text { arcilloso }\end{array}$} & Ec \\
\hline & Vim1 & $\begin{array}{l}36^{\circ} 28^{\prime} 2,46^{\prime \prime S} \\
58^{\circ} 12^{\prime} 27,18^{\prime \prime O}\end{array}$ & 60 & & $E v$ \\
\hline & Cam2 & $\begin{array}{l}36^{\circ} 28^{\prime} 30,00 " \mathrm{~S} \\
58^{\circ} 12 ' 2,28^{\prime \prime O}\end{array}$ & 60 & & Ec \\
\hline & Vim2 & $\begin{array}{l}36^{\circ} 28^{\prime} 28,86^{\prime \prime S} \\
58^{\circ} 12^{\prime} 5,94^{\prime \prime O}\end{array}$ & 60 & & $E v$ \\
\hline & Nat & $\begin{array}{l}36^{\circ} 27^{\prime} 53,58^{\prime \prime S} \\
58^{\circ} 12^{\prime} 13,38^{\prime \prime}\end{array}$ & 60 & & $P n$ \\
\hline
\end{tabular}

\subsubsection{Descripción y toma de muestras en el sitio CRS:}

El otro sitio de estudio se encuentra ubicado hacia el centro Este de la provincia de Buenos Aires, en el partido Pila dentro de la región conocida como Pampa Deprimida (cuenca del Río Salado). Esta región es una planicie sedimentaria cuaternaria, de origen 
eólico con una pobre red de escurrimiento (Lavado y Taboada 1988). Se encuentra emplazada entre los $34,6^{\circ}-38^{\circ} \mathrm{S}$ y los $56,72^{\circ}-63,43^{\circ} \mathrm{O}$ y sus suelos de texturas franca a franca arcillosa se clasifican como Argiudoles o Hapludoles en las lomas y Natracuoles, Natracualfes, Natralboles en los bajos (INTA 1989). El clima de la región es templado húmedo, con temperaturas medias anuales de $12,5-15^{\circ} \mathrm{C}$ y precipitaciones de $900-1000$ $\mathrm{mm}$ año ${ }^{-1}$, distribuidas de manera más o menos homogénea a lo largo del año (Barros et al. 2013). Según Nosetto et al. (2008) se verifica un gradiente de balance hídrico de cero hasta $200 \mathrm{~mm}_{\text {año }}{ }^{-1}$ (Figura III.1).

Durante la temporada estival se establecieron 5 parcelas de medición (Figura III.1) sobre suelos medianamente profundos, hidromórficos y con abundantes concreciones de calcio en profundidad (INTA 1989). Se analizó la conductividad eléctrica (CE) y el pH del suelo manteniendo la metodología usada en el capítulo 2. Dos parcelas se realizaron en forestaciones de Eucalyptus viminalis Labill, dos con Eucalyptus camaldulensis Dehnh, y otra un pastizal natural bajo uso pastoril (Tabla III.1.). Las dos forestaciones no fueron sometidas a ningún tipo de manejo silvícola luego de su última cosecha realizada durante los años (2003 al 2005) y del control de rebrotes realizado en los años 2006 y 2007 (ARAUCO S.A., comunicación personal). Se extrajeron muestras de suelo en 5 puntos al azar hasta máxima profundidad posible debido a la presencia de horizontes compactados (dados por la presencia de tosca) y se analizo estadísticamente la conductividad eléctrica (CE), el pH y la textura para una misma profundidad del suelo y de la misma forma que la descripta en el capítulo 2.

\subsection{RESULTADOS}

\subsubsection{Caracterización de las forestaciones}

En ambas localidades las forestaciones densas carecían de manejo silvícola, es decir no fueron intervenidas con podas y raleos.

En el sitio SST (localidad de Tandil) todas las forestaciones fueron plantadas en el año 1990, por lo que al momento de la medición tenían 28 años de edad. La densidad de plantación varió desde 127,3 hasta 925,6 árboles ha ${ }^{-1}$ para macizos de Eucalyptus spp. y desde 700,3 hasta 1572,6 árboles ha ${ }^{-1}$ para macizos de Pinus radiata. El área basal de los rodales estuvo entre los 22,9 a los 66,1 y de 26,9 a $91,9 \mathrm{~m}^{2} \mathrm{ha}^{-1}$ para macizos de Eucalyptus spp. y Pinus radiata, respectivamente (Tabla III.2.). La cobertura del dosel arbóreo varió entre $11,2 \%$ y $76,3 \%$, mostrando el menor valor una de las fajas silvopastoriles de Pinus radiata y el mayor en una plantación en macizo de la misma especie (Grafico III.1., Tabla III.2.). Los macizos de Eucalyptus spp. mostraron valores intermedios de cobertura (Grafico III.1.). 
Tabla III.2. Variables descriptoras de los rodales. Sp. $=$ especie $(\mathrm{Ed}=$ Eucalyptus dalrympeana, $\mathrm{Ev}=$ Eucalyptus viminalis, $\mathrm{Pr}=$ Pinus radiata); $\mathrm{N}=$ Densidad (árboles ha ${ }^{-1}$ ); DAP = diámetro del fuste a $1,30 \mathrm{~m} ; \mathrm{AB}=$ área basal $\left(\mathrm{m}^{2} \mathrm{ha}^{-1}\right) ; \mathrm{H}=$ altura dominante $(\mathrm{m})$; $\mathrm{Cob}=$ cobertura aérea del dosel arbóreo (\%) y Edad en años desde la plantación.

\begin{tabular}{lllllll}
\hline Sitio & Sp. & $\mathrm{N}$ & $\mathrm{DAP}$ & $\mathrm{AB}$ & $\mathrm{H}$ & $\mathrm{Cob}$ \\
\hline EU1 & Ed & 636,6 & 34,4 & 66,1 & 27 & 60,8 \\
F21 & Pr & - & - & - & - & 11,2 \\
PD1 & Pr & 1572,6 & 26,9 & 91,9 & 16,7 & 71,6 \\
F11 & Pr & - & - & - & - & 19,9 \\
EU2 & Ev & 127,3 & 46,4 & 22,9 & 26,2 & 49,2 \\
PD2 & Pr & 700,3 & 32,2 & 58,7 & 20,2 & 67,1 \\
PD3 & Pr & 790,7 & 27,9 & 51,1 & 16,5 & 76,3 \\
EU3 & Ev & 925,9 & 22,9 & 43,6 & 21,2 & 57,1 \\
\hline
\end{tabular}

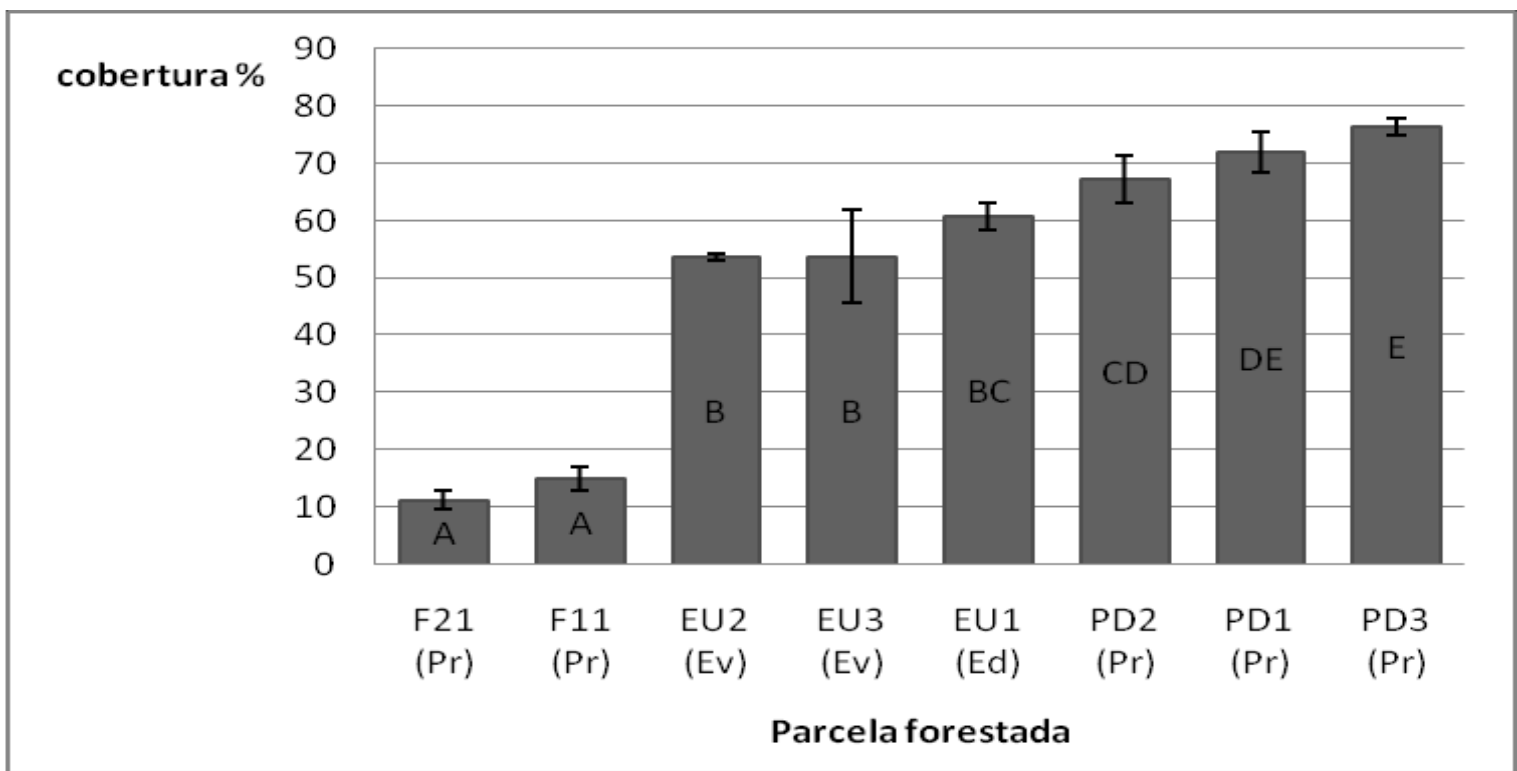

Gráfico III.1. Cobertura del dosel arbóreo (\%) y sus desvíos para cada parcela de la localidad de Tandil. Entre paréntesis especie correspondiente a cada parcela $(\mathrm{Pr}=\mathrm{Pinus}$ radiata, Ev = Eucalyptus viminalis, Ed = Eucalyptus dalrympeana). Letras distintas indican diferencias significativas entre parcelas con un $p<0,05$

Por otro lado, se ajustó una relación lineal positiva entre la CE promedio del perfil de suelo y la cobertura forestal para la especie Pinus radiata $\left(\mathrm{R}^{2}=0,94\right.$, Gráfico III.2.). 


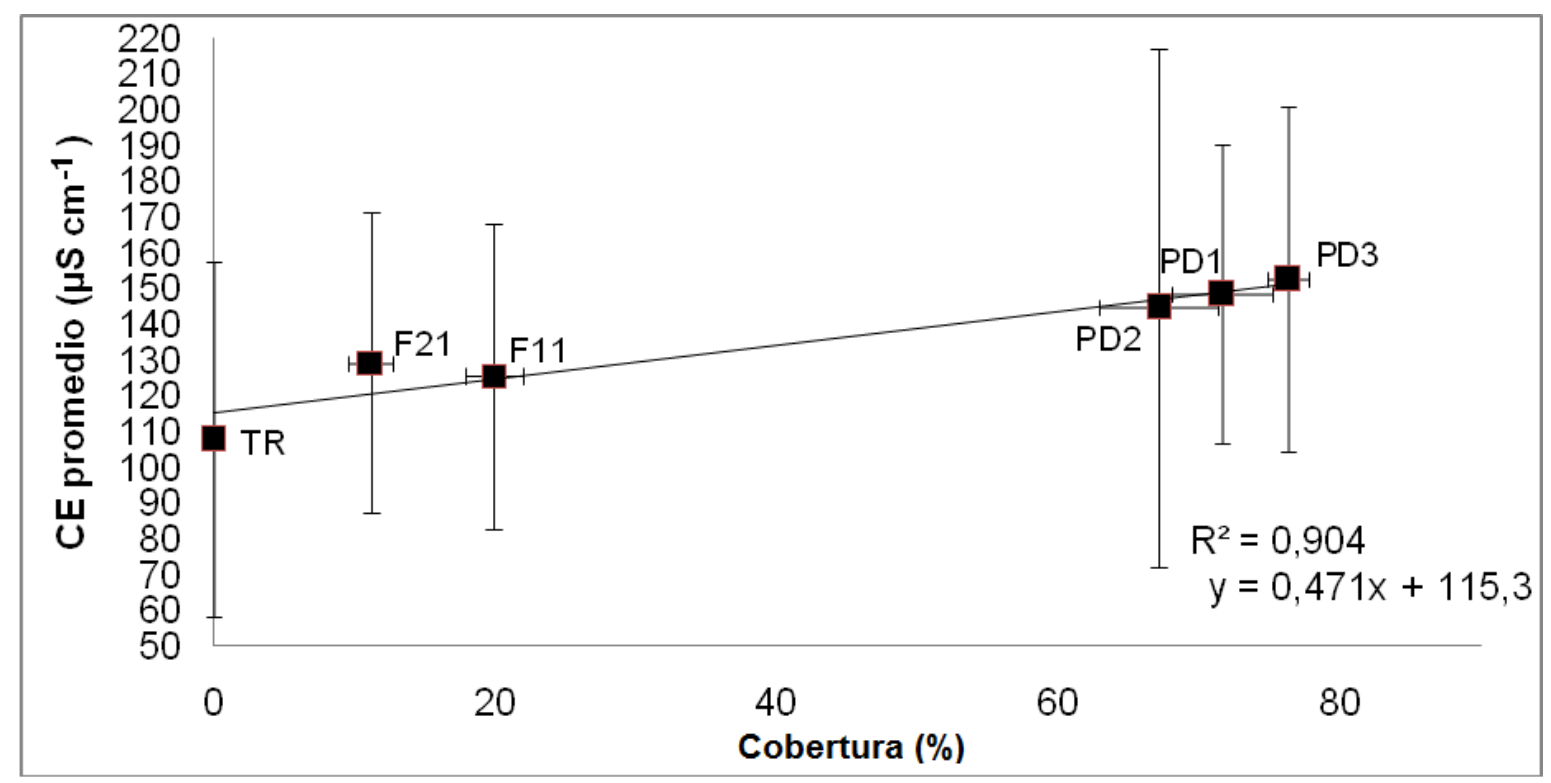

Gráfico III.2. Relación entre la cobertura (\%) de distintas parcelas forestadas con Pinus radiata y la $\mathrm{CE}$ del suelo promedio $\left(\mu \mathrm{S} \mathrm{cm}^{-1}\right)$. PD1, PD2 y PD3 representan macizos forestales sin manejo; F11 y F21 representan las fajas silvopastoriles y TR la tala rasa

En el sitio CRS (localidad de Pila) todas las forestaciones eran rebrotes sin manejo que fueron cortados por última vez en el año 2005. Su densidad de plantación varió desde 3573,3 (para Eucalyptus camaldulensis) hasta 5181,8 árboles ha ${ }^{-1}$ (para Eucalyptus viminalis), mientras que la edad desde la plantación fue de unos 44 años (Tabla III.3.). El área basal de los rodales fue de unos $29 \mathrm{~m}^{2} \mathrm{ha}^{-1}$ hasta un máximo de $42,9 \mathrm{~m}^{2}$ ha $^{-1}$ (Tabla III.3.). La cobertura del dosel arbóreo varió de 44,5\% a un 62,8\%, para Eucalyptus viminalis y Eucalyptus camaldulensis respectivamente, siendo mayor en los rodales de la especie Eucalyptus camaldulensis y menor en Eucalyptus viminalis (Gráfico III.3., Tabla III.3.)

Tabla III.3. Variables descriptoras de los rodales. Sp. $=$ especie $(\mathrm{Ec}=$ Eucalyptus camaldulensis, $\mathrm{Ev}=$ Eucalyptus viminalis); $\mathrm{N}=$ Densidad (árboles ha ${ }^{-1}$ ); $\mathrm{DAP}=$ diámetro del fuste a $1,30 \mathrm{~m} ; \mathrm{AB}=$ área basal $\left(\mathrm{m}^{2}\right.$ ha $\left.{ }^{-1}\right) ; \mathrm{H}=$ altura dominante $(\mathrm{m})$ y Cob = cobertura aérea del dosel arbóreo (\%).

\begin{tabular}{lllllll}
\hline Sitio & Sp. & N & DAP & AB & H & Cob \\
\hline Cam1 & Ec & 5181,8 & 9,1 & 42,9 & 11,4 & 54,5 \\
Vim1 & Ev & 3573,3 & 8,9 & 29 & 7,9 & 44,5 \\
Cam2 & Ec & 4859,3 & 8,2 & 41,7 & 7,2 & 62,8 \\
Vim2 & Ev & 3680,0 & 9,3 & 30,7 & 13,1 & 44,6 \\
\hline
\end{tabular}




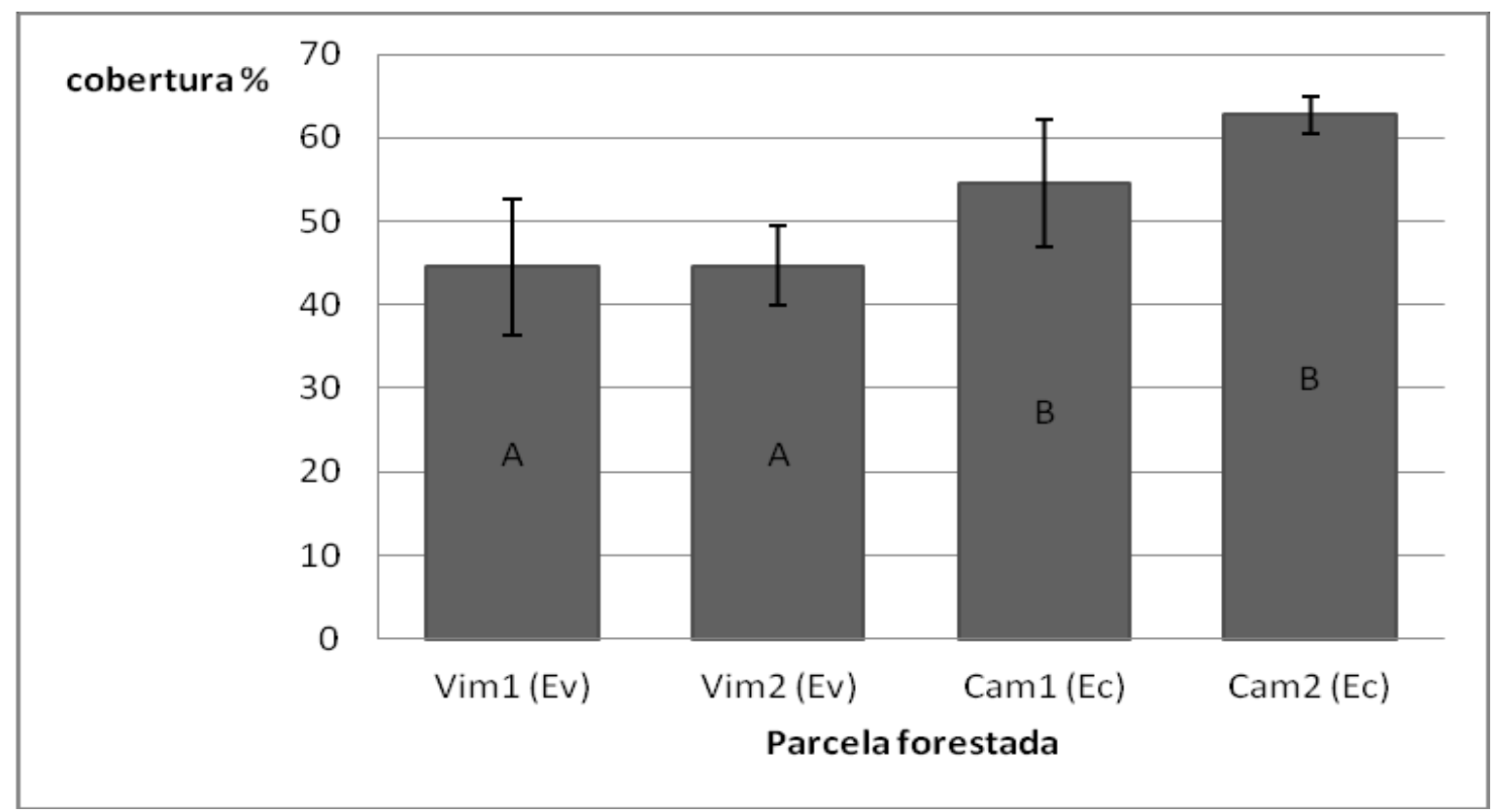

Gráfico III.3. Cobertura del dosel arbóreo (\%) y sus desvíos para cada parcela del sitio CRS (localidad de Pila). Entre paréntesis especie correspondiente a cada parcela (Ev = Eucalyptus viminalis, Ec = Eucalyptus camaldulensis). Letras distintas indican diferencias significativas entre parcelas forestadas con un $p<0,05$

\subsubsection{Variables de suelo por especie y manejo en SST}

La textura en esta localidad fue franca en la superficie a franca arcillosa o arcillosa arenosa en profundidad (Tabla III.1.). Se observo una tendencia general a obtener menores valores de CE en los perfiles más profundos (Tabla III.4.).

No se encontraron diferencias significativas entre la $C E$ del suelo a una profundidad de $0-20 \mathrm{~cm}$ a pesar de los manejos contrastantes y la diversidad de especies (Tabla III.4.). Por el contrario, sí se encontraron diferencias a la profundidad de $20-40 \mathrm{~cm}$ lo que demuestran una respuesta al uso y al manejo silvícola. Así, en el aprovechamiento a tala rasa, con tan solo 2 años de antigüedad, se midieron los valores más bajos de CE mostrando diferencias significativas con todas las demás parcelas: herbáceas, silvopastoriles y macizos de pinos, excepto con el suelo donde se forestó con Eucalyptus spp. los que mostraron valores tan bajos como en la tala rasa (Tabla III.4.). Por otro lado, las forestaciones con Pinus radiata mostraron los valores más altos de CE a esta profundidad del suelo $\left(110,44 \mu \mathrm{S} \mathrm{cm}^{-1}\right.$, Tabla III.4.). En el caso de los sistemas silvopastoriles, la CE del suelo mostró valores intermedios sin tener diferencias significativas con el pastizal y cultivo. 
Tabla III.4. Conductividad eléctrica del suelo promedio (CE, $\mu \mathrm{S} \mathrm{cm}^{-1}$ ) y desvíos en la localidad de Tandil de las parcelas por especie y tipo de sistema de producción, discriminando los valores por profundidad de muestreo. Letras distintas indican diferencias significativas para cada profundidad con un $p<0,05$

\begin{tabular}{lcc}
\hline & \multicolumn{2}{c}{$\mathrm{CE}\left(\mu \mathrm{cm}^{-1}\right)$} \\
Especie y sistema de producción & Profundidad 0-20 cm & Profundidad 20-40 cm \\
\hline Eucaliptos macizo & $148,05 \pm 61,40 \mathrm{a}$ & $71,71 \pm 25,87 \mathrm{ab}$ \\
Pinos macizo & $186,73 \pm 44,62 \mathrm{a}$ & $110,44 \pm 30,19 \mathrm{c}$ \\
Pinos silvopastoril & $153,46 \pm 40,66 \mathrm{a}$ & $101,31 \pm 20,77 \mathrm{bc}$ \\
Pastizal natural & $170,46 \pm 37,37 \mathrm{a}$ & $101,42 \pm 33,53 \mathrm{bc}$ \\
Avena & $150,66 \pm 23,21 \mathrm{a}$ & $109,38 \pm 24,21 \mathrm{bc}$ \\
Tala rasa & $150,60 \pm 28,53 \mathrm{a}$ & $65,08 \pm 11,25 \mathrm{a}$ \\
\hline
\end{tabular}

En cuanto al $\mathrm{pH}$, en general, se observa una tendencia a un aumento del $\mathrm{pH}$ a medida que profundizamos en el suelo (Tabla III.5). Se encontró además que los macizos de Eucalyptus spp. poseyeron valores más bajos que el resto de las especies y manejos ( $\mathrm{pH} 6,07$ a $0-20 \mathrm{~cm}$ y 6,38 a $20-40 \mathrm{~cm}$ ), excepto con los sistemas de fajas silvopastoriles donde se observaron valores intermedios (Tabla III.5.).

Tabla III.5. pH del suelo promedio y desvíos en el sitio SSP (localidad de Tandil), de las parcelas por especie y tipo de sistema de producción, discriminando los valores por profundidad de muestreo. Letras distintas indican diferencias significativas entre sitios para cada profundidad con un $p<0,05$.

$\mathrm{pH}$

Especie y sistema de producción Profundidad 0-20 cm Profundidad $20-40 \mathrm{~cm}$

\begin{tabular}{lll}
\hline Eucaliptos macizo & $6,07 \pm 0,60 \mathrm{a}$ & $6,38 \pm 0,72 \mathrm{a}$ \\
Pinos macizo & $6,69 \pm 0,68 \mathrm{~b}$ & $6,97 \pm 0,60 \mathrm{~b}$ \\
Pinos silvopastoríl & $6,47 \pm 0,68 \mathrm{ab}$ & $6,73 \pm 0,54 \mathrm{ab}$ \\
Pastizal natural & $6,74 \pm 0,10 \mathrm{~b}$ & $6,96 \pm 0,12 \mathrm{~b}$ \\
Avena & $6,97 \pm 0,10 \mathrm{~b}$ & $7,21 \pm 0,10 \mathrm{~b}$ \\
Tala rasa & $6,84 \pm 0,15 \mathrm{~b}$ & $7,18 \pm 0,16 \mathrm{~b}$ \\
\hline
\end{tabular}




\subsubsection{Variables de suelo para cada especie en CRS}

El suelo, mostró una textura franca a franca arcillosa a medida que profundizamos (Tabla III.1.), no presentando diferencias entre las parcelas estudiadas.

Se encontraron diferencias significativas en la CE del suelo a lo largo de todo el perfil estudiado, mostrando los suelos forestados valores similares entre sí a pesar de las diferencias entre especies. En las parcelas forestadas se observaron mayores valores de CE en los perfiles más profundos, sin mostrar un patrón claro la parcela del pastizal (Tabla III.6). A una profundidad de $0-20 \mathrm{~cm}$, el pastizal natural obtuvo los valores más altos de CE del suelo $\left(232,62 \pm 36,21 \mu \mathrm{S} \mathrm{cm}^{-1}\right)$ mostrando diferencias significativas con las parcelas forestadas con Eucalyptus camaldulensis $\left(161 \pm 49,52 \mu \mathrm{S} \mathrm{cm}^{-1}\right)$, mientras que en Eucalyptus viminalis se encontraron valores intermedios $\left(192,8 \pm 76 \mu \mathrm{S} \mathrm{cm}^{-1}\right)$ (Tabla III.6.). Sin embargo, los macizos de Eucalyptus spp. mostraron valores más altos de CE a mayores profundidades.

Tabla III.6. Conductividad eléctrica del suelo promedio (CE, $\left.\mu \mathrm{S} \mathrm{cm}^{-1}\right)$ y desvíos en el sitio CRS (localidad de Pila), de las parcelas por especie y discriminando los valores por profundidad de muestreo. Letras distintas indican diferencias significativas para cada profundidad con un $\mathrm{p}<0,05$

\begin{tabular}{llll}
\hline Especie & Profundidad & $\begin{array}{l}\text { CE }\left(\mu \mathrm{cm}^{-1}\right) \\
\text { Profundidad }\end{array}$ & $\begin{array}{l}\text { Profundidad } \\
\\
\end{array}$ \\
& $0-20 \mathrm{~cm}$ & $20-40 \mathrm{~cm}$ & $40-60 \mathrm{~cm}$ \\
\hline Eucalyptus camaldulensis & $161 \pm 49,52 \mathrm{a}$ & $334 \pm 94,87 \mathrm{~b}$ & $1393 \pm 126 \mathrm{~b}$ \\
Eucalyptus viminalis & $192,8 \pm 76 \mathrm{ab}$ & $267,38 \pm 153 \mathrm{~b}$ & $1027 \pm 557 \mathrm{~b}$ \\
Pastizal natural & $232,62 \pm 36,21 \mathrm{~b}$ & $105,38 \pm 11,66 \mathrm{a}$ & $208,9 \pm 53,16 \mathrm{a}$ \\
\hline
\end{tabular}

La variación del pH del suelo siguió un patrón similar al observado en otros sitios, incrementándose en las mayores profundidades del suelo (Tabla III.7.). Por otro lado se encontraron los valores más bajos de $\mathrm{pH}$ en macizos de Eucalyptus viminalis $(6,78 ; 7,14$ y 7,30 a 0-20 cm, $20-40 \mathrm{~cm}$ y $40-60 \mathrm{~cm}$ respectivamente). Mientras tanto, las forestaciones con Eucalyptus camaldulensis no mostraron diferencias con el pastizal natural a ninguna profundidad (Tabla III.7.). 
Tabla III.7. pH del suelo promedio y desvíos en la localidad de Pila, de las parcelas por especie y discriminando los valores por profundidad de muestreo. Letras distintas indican diferencias significativas para cada profundidad con un $p<0,05$

$\mathrm{pH}$

\begin{tabular}{llll} 
Especie & Profundidad & Profundidad & Profundidad \\
& $0-20 \mathrm{~cm}$ & $20-40 \mathrm{~cm}$ & $40-60 \mathrm{~cm}$ \\
\hline Eucalyptus camaldulensis & $7,52 \pm 0,48 \mathrm{~b}$ & $7,76 \pm 0,69 \mathrm{~b}$ & $8,04 \pm 0,42 \mathrm{~b}$ \\
Eucalyptus viminalis & $6,78 \pm 0,37 \mathrm{a}$ & $7,14 \pm 0,44 \mathrm{a}$ & $7,30 \pm 0,38 \mathrm{a}$ \\
Pastizal natural & $7,37 \pm 0,27 \mathrm{~b}$ & $7,55 \pm 0,16 \mathrm{ab}$ & $7,88 \pm 0,2 \mathrm{~b}$
\end{tabular}

\subsection{DISCUSIÓN}

\subsubsection{Características de las forestaciones}

En el sitio SST (localidad de Tandil) la variación de la cobertura estuvo en relación con los manejos forestales. Como se esperaba, hay una respuesta del porcentaje de cobertura en función de la densidad (árboles ha-1 ${ }^{-1}$ Tabla III.2.). Así, las coberturas más altas alcanzadas por el dosel arbóreo fueron coincidentes con las parcelas que poseen una mayor densidad y área basimétrica, mientras que las fajas silvopastoriles mostraron valores bajos de cobertura (Gráfico III.1.), propios de estos sistemas de manejo (Fassola et al. 2005).

Mientras tanto en el sitio CRS (localidad de Pila), las mayores coberturas (Gráfico III.3.) fueron encontradas en las forestaciones con Eucalyptus camaldulensis, lo que se relaciona con la mayor densidad y $A B$ encontrada en estas parcelas, tal como se describió para el sitio SST (Tabla III.3.).

\subsubsection{Efectos en la CE y el pH del suelo producto del cambio de uso del suelo en SST}

No se observaron diferencias en la CE del suelo en los primeros $20 \mathrm{~cm}$ de profundidad, más allá del tipo de cobertura vegetal y manejo. Por otro lado las diferencias fueron significativas a una profundidad de $20-40 \mathrm{~cm}$, observándose una mayor CE del suelo en las forestaciones con Pinus radiata en macizo (Tabla III.4.). Este efecto puede ser producto de la mayor cobertura (Gráfico III.1.), mientras que las forestaciones con Eucalyptus spp., con una menor CE a $20-40 \mathrm{~cm}$ poseían una menor cobertura (Gráfico III.1.) y se encontraban sobre suelos más profundos (Tabla III.1.). Así también, existen antecedentes que plantean la baja capacidad de retención de agua en el suelo forestal en rodales de Eucalyptus spp. frente a pastizales naturales. Esto debido a un mayor 
porcentaje de macro-mesoporos y a una mayor hidrofobicidad de la materia orgánica (Silveira et al. 2006). Esta combinación de factores, favorecerían el lavado de sales hacia perfiles más profundos durante los periodos de exceso hídrico.

La relación positiva entre la CE del suelo y la cobertura forestal (Gráfico III.2.) pone de manifiesto el valor del manejo silvícola como herramienta para disminuir la acumulación de sales en la rizósfera. En este sentido, las fajas silvopastoriles a una profundidad de $20-40 \mathrm{~cm}$, obtuvieron valores intermedios de CE, solo diferenciándose de la tala rasa (mínimo valor absoluto de CE para todas las situaciones consideradas) y muy similares a los del pastizal natural (Tabla III.4.). Así, es importante resaltar el valor del manejo forestal en cuanto a la acumulación de sales en el suelo, como también a la disponibilidad relativa de los recursos que limitan la productividad (por ejemplo, el agua; Martínez Meier et al., 2015). De esta manera, tal como mencionan Jobbágy et al. (2006), la instalación de plantaciones con bajas densidades podría ser considerada como una alternativa de menor impacto en estas regiones, que pueda reducir la intensidad de los procesos de salinización secundaría.

Otro resultado interesante surge al observar que, a una profundidad de $20-40 \mathrm{~cm}$, el aprovechamiento a tala rasa obtuvo los valores más bajos de CE (Tabla III.4.). Como es de esperar, el efecto más notorio ocurre al disminuir bruscamente la cobertura forestal. Tal como menciona Roberts (2001), la tala rasa genera un aumento instantáneo del rendimiento hídrico debido a la consecuente caída del consumo de agua. Así, es interesante recalcar lo rápido que se observa una reversibilidad del proceso, ya que se midió una disminución significativa de la CE con solo dos años desde que la forestación fue cosechada. Como complemento, sería interesante analizar los cambios en la calidad de las salidas de agua en las forestaciones sometidas a este tipo de manejo.

En lo referido al $\mathrm{pH}$ y reafirmando lo observado en el capítulo 2, se cuantifico un descenso del $\mathrm{pH}$ para ambas profundidades del suelo bajo las forestaciones de Eucalyptus spp., al ser comparadas con los otros sistemas productivos (Tabla III.5.). Esto probablemente es debido a una elevada extracción de cationes por parte de las plantas (calcio y magnesio), que quedan acumulados en la biomasa arbórea (Jobbágy y Jackson 2003, Amiottiet al., 2000). Este descenso del pH, como lo mencionan Castro Diez et al. (2012), está condicionado al tipo de especie forestal, y de esta manera en nuestro estudio las forestaciones con pinos no mostraron diferencias significativas con el pastizal natural, la tala raza y el cultivo (Tabla III.5.). 


\subsubsection{Efectos en la CE y el pH del suelo producto de la forestación con dos especies de Eucalyptus}

A pesar de que las especies contrastadas poseen una tolerancia a la CE del suelo diferente; alta en Eucalyptus camaldulensis e intermedia en Eucalyptus viminalis (Niknam and McComb 2000, FAO 1981), no mostraron diferencias en la CE alcanzada (Tabla III.6.). Posiblemente este patrón surja como producto del escaso tiempo de presencia de la cobertura forestal (13-15 años desde el último corte). Es de esperarse que luego de mayor tiempo de uso forestal, la acumulación de sales en el perfil sea mayor en la especie más tolerante antes de sufrir los efectos negativos, como sugieren Nosetto et al. (2008).

Por otro lado si bien en las muestras más superficiales la pastura mostró valores más altos de CE que las forestaciones con Eucalyptus camaldulensis, este patrón puede ser causado por las deyecciones de los bovinos que lo pastorean, como lo menciona Losinno et al. (2008). A pesar de ello, se observó en el sitio CRS una mayor CE en los perfiles más profundos del suelo debajo de las forestaciones con Eucalyptus spp. que llegaron incluso a valores 6 veces superiores a los encontrados en la parcela herbácea (Tabla III.6.). Esta situación pudo haberse generado por el mayor uso de agua y la exclusión de solutos por las raíces de las forestaciones, tal como lo mencionan numerosos autores para la región (Jobbágy and Jackson 2004, Nosetto et al. 2012, entre otros). Mientras que en el caso del pastizal, la menor cobertura generaría un mayor lavado de sales.

Con respecto al $\mathrm{pH}$, se pudieron observar diferencias entre el Eucalyptus viminalis y el Eucalyptus camaldulensis (Tabla III.7.), dado que como ya fue mencionado por Castro Diez et al. (2012), estas modificaciones en el pH estarían condicionadas por la especie forestal. Es posible que este proceso sea el resultado de las diferencias en la extracción de cationes y acumulación de los mismos en la biomasa forestal de ambas especies (Amiottiet al., 2000). Sin embargo, se necesitarían más estudios para corroborarlo.

\subsection{CONSIDERACIONES FINALES}

Bajo las condiciones estudiadas las propiedades de suelo analizadas se vieron modificadas en mayor o menor medida en relación a la especie dominante y el manejo.

En el ambiente de serranía, el cambio de uso del suelo, los manejos contrastantes y las diferentes especies forestales han generado diferencias en los valores de CE, pero rápidamente reversibles y no de una magnitud tal como para generar consecuencias negativas en los cultivos agrícolas o forestales. En estos ambientes, el principal factor de aumento o disminución de la salinidad fue la cobertura vegetal, influenciado por los 
perfiles de suelo poco profundos limitados por roca y la imposibilidad de la vegetación de acceder al acuífero. También se diferenció en Eucalyptus sp. un suelo más profundo, con una tendencia al lavado de sales debido a un mayor porcentaje de macro-mesoporos y a una mayor hidrofobicidad de la materia orgánica.

Por otro lado en el ambiente de la Pampa Deprimida, con suelos hidromórficos, la influencia de la cobertura vegetal sobre el proceso de salinización secundaria parece ser más importante. En estos ambientes sería fundamental el manejo de la cobertura por podas y raleos, la regulación del tiempo de permanencia de la cobertura forestal sin manejo, la selección de especies forestales y la implementación de manejos alternativos que impliquen menores densidades de plantación como sucede con los sistemas silvopastoriles

De la misma manera los cambios en el pH no afectarían a las producciones más conspicuas de la región y el proceso es rápidamente revertido como pudo observarse luego de la tala rasa. Sin embargo serian necesarios más estudios para determinar las causas que generan este diferencial de $\mathrm{pH}$ en cada especie

De esta manera, se puede decir que la especie vegetal dominante y el manejo son factores claves a tener en cuenta. Sin embargo, no son los únicos y las modificaciones de la $\mathrm{CE}$ y el pH del suelo que puedan generar, van a estar condicionados por la interacción de otros factores del ambiente y sitio (como profundidad efectiva y textura del suelo, acceso al acuífero, etc.). Así, estudiar cada ambiente particular parece ser clave para determinar el impacto generado. 


\title{
Capítulo 4
}

\author{
¿Los Eucalyptus son bombas de agua? \\ Evaluación del impacto hidrogeoquímico de \\ una forestación de Eucalyptus viminalis vs un \\ pastizal natural.
}




\subsection{INTRODUCCIÓN}

Numerosos estudios mencionan que aquellos cambios en la vegetación que involucran transiciones de sistemas herbáceos a leñosos, suelen tener las improntas hídricas más significativas (Zhang et al. 2001; Brown et al. 2005; van Dijk y Keenan 2007). Asimismo Lane y BassiriRad (2005) después de haber contrastado la capacidad de utilización del agua en el suelo y de nutrientes, destacaron que cada conjunto particular de vegetación tiene diferentes efectos en la evapotranspiración, la escorrentía, los patrones de drenaje profundo y redistribución de sales a través de relaciones de retroalimentación entre las plantas y el suelo. Así, este efecto sobre el recurso hídrico podría magnificase tratándose de territorios llanos donde casi la totalidad de la precipitación que reciben vuelve a la atmósfera por transpiración o evaporación directa (Scanlon et al. 2006; Jobbágy et al. 2008).

La presencia de una estructura leñosa genera una redistribución de las precipitaciones; el agua puede atravesar el canopeo del árbol para llegar al suelo (trascolación) o escurrir por los tallos de ramas y tronco (escurrimiento fustal). La trascolación es el elemento más significativo, mientras que el escurrimiento fustal tendría relevancia porque penetra muy cerca a la base del tronco y de esta manera puede infiltrar más rápida y efectivamente (Poore y Fries, 1987). Sumado a ello, en comparación con un ambiente de pastizal, se ven disminuidos los procesos de drenaje (flujos superficiales y subsuperficiales, drenaje profundo), provocando un menor contenido de humedad en el suelo y aumentando las pérdidas de agua a través de la interceptación de lluvias y evapotranspiración (Le Maitre et al. 2000, Jobbágy y Jackson 2004, Huber et al. 2010). Así se ha descripto de manera amplia que las especies leñosas pueden consumir más agua por evapotranspiración que otros tipos de vegetación, como los pastizales naturales o los cultivos de secano (Cao et al., 2011; Zhang et al. 2001; Hibbert, 1967; Bosch y Hewlett, 1982). En este sentido, Benyon et al. (2006), remarcan que la mayor demanda evapotranspiratoria que caracteriza a las forestaciones es resultado de su mayor porcentaje de interceptación, rugosidad y altura del conopeo, su menor albedo, y a su capacidad de acceder a fuentes de agua más profundas (ver también Zhang et al., 1999, Jobbágy y Jackson 2004). Esto factores, pueden generar que la recarga de agua subterránea bajo los bosques sea menor que la de los pastos y cultivos, incluso cercana a cero, pudiendo de esta manera reducir los niveles del acuífero (Robins 2004). De esta manera en los pastizales pampeanos, las forestaciones podrían cambiar el régimen hidrológico de una situación de recarga a otra de descarga neta cuando las precipitaciones son inferiores a $1100 \mathrm{~mm}$ año-1 (Nosetto et al. 2008). Este mayor consumo por parte de las forestaciones puede generar una depresión del acuífero en la zona forestal similar al bombeo mecánico. Así, Jobbágy (2009) menciona que puede 
haber fluctuaciones en la altura de la freática de hasta $10 \mathrm{~cm}$ (descensos diurnos, ascensos nocturnos) y que la misma tiene buena correlación con la transpiración. Por otro lado, según Jobbágy et al. (2006), las forestaciones estudiadas en la pampa, de solo diez kilómetros cuadrados como máxima superficie, producen una estabilización de los niveles freáticos a no más de un metro por debajo de los valores originales como producto del balance entre el aporte de agua subterránea desde áreas adyacentes de pastizal y la evapotranspiración de la masa boscosa. Sin embargo otros autores han demostrado que las plantaciones estudiadas solo fueron capaces de hacer uso del agua freática bajo una combinación de suelos con texturas medias y capa freática superficial y de baja salinidad (Benyon et al. 2006).

Es importante aclarar que junto a los cambios hidrogeológicos que acompañan a la forestación de pastizales, se han producido alteraciones muy importantes en el contenido de sales del suelos y aguas subterráneas (Nosetto et al. 2008, Jobbágy y Jackson 2007, entre otros). Así Jobbágy (2014), menciona que la forestación de ambientes de alta calidad de sitio en la Pampa Deprimida e Interior llevaría en el plazo de décadas a la salinización progresiva de suelos y del acuífero por exclusión selectiva de solutos.

Este capítulo tiene como objetivo determinar, en un ambiente típico del centro de la provincia de Buenos Aires, el impacto hídrico y en la dinámica de sales que puede tener la forestación de pastizales. A la vez se caracterizará la magnitud y dinámica temporal de los cambios en la CE del acuífero y del suelo, producto de la forestación en un ambiente de pastizal. Asimismo se determinará si el consumo de agua de una forestación es superior a los cultivos más usuales de la región.

\subsection{MATERIALES Y MÉTODOS}

\subsubsection{Descripción del sitio, clima y suelo}

Las parcelas se establecieron en el Partido de Azul, provincia de Buenos Aires, cuartel VII (Figura IV.1. y IV.2.). Las coordenadas correspondientes a las cuatro esquinas del lote forestal medidas utilizando un GPS 12 XL Garmin son $37^{\circ} 07^{\prime} 45.60^{\prime \prime} \mathrm{S}$ y $60^{\circ} 03^{\prime} 41.00^{\prime \prime} \mathrm{O}, 37^{\circ} 08^{\prime} 00.50^{\prime \prime} \mathrm{S}$ y $60^{\circ} 03^{\prime} 44.30^{\prime \prime} \mathrm{O}, 37^{\circ} 07^{\prime} 43.90^{\prime \prime} \mathrm{S}$ y $60^{\circ} 03^{\prime} 47.90^{\prime \prime} \mathrm{S}$, $37^{\circ} 07^{\prime} 58.60^{\prime \prime} \mathrm{S}$ y $60^{\circ} 03^{\prime} 50.5^{\prime \prime} \mathrm{O}$. La parcela herbácea se encontraba adyacente a la forestación mencionada (37²'3.03"S y 60³'48.30"O).

El sitio de estudio se encuentra dentro de la llanura Chaco-Pampeana Argentina, una gran extensión del territorio Argentino, ubicada en el centro-este del país entre las latitudes $32^{\circ}$ y $40^{\circ} \mathrm{W}$, y longitudes $57^{\circ}$ y $63^{\circ} \mathrm{S}$ (SAGPyA 2001).

El clima de la región es templado (Barros et al., 2013), la precipitación promedio anual es de $898,3 \mathrm{~mm}$ distribuidos en primavera-verano-otoño principalmente y la 
temperatura media anual de unos $13,8^{\circ} \mathrm{C}$ ) (observaciones considerando el período 1931 - 1990, World Climate 2013).

Los suelos de la región se describen como Argiudoles típicos y Paleudoles petrocálcicos, que se presentan como una consociación en la carta de suelos Cerro Negro 3760-21-2 (INTA). Se realizó una calicata en ambas parcelas en donde se describió la siguiente secuencia de horizontes (Figura IV.4.): O (0-0,03 m) mantillo mayormente compuesto por hojarasca en distintos grados de descomposición; Ap $(0,03-$ $0,27 \mathrm{~m}$ ) una capa de textura arcillosa, con estructura granular moderada y fina, muy friable; BA $(0,27-0,47 \mathrm{~m})$ también arcilloso, con bloques subangulares moderados que se rompen a granulado, muy friable; Bt1 $(0,47-0,59 \mathrm{~m})$ es de textura arcillosa con prismas medianos que se rompen en prismas subangulares medianos, débiles y delgados y abundantes barnices de arcilla; Bt2 $(0,59-0,76 \mathrm{~m})$ con textura arcillosa, prismas moderados que se rompen en bloques angulares y subangulares, barnices de arcilla muy comunes y $2 \mathrm{Ckkm}(0,76-1,06 \mathrm{~m})$ una capa de carbonatos cementados. En la parcela herbácea se tomaron muestras de suelo de cada horizonte, usando un barreno helicoidal, donde al igual que en la forestación se estimo la textura del suelo por el método de Bouyoucos (p.ej., Bouyoucos, 1962; Elliot et al., 1999).

\subsubsection{Características de bosques y pastizales}

El rodal es coetáneo y homogéneo, integrado por individuos de Eucalyptus viminalis Labill., especie comúnmente elegida en la zona debido a su buena adaptación a las condiciones ambientales locales (Cozzo 1976). La forestación tiene forma de paralelepípedo y una superficie total de 7,84 ha. La orientación de su eje mayor es de 20,6 $6^{\circ} \mathrm{NE}$, medida utilizando una brújula Suunto. El marco de plantación, medido usando un metro láser marca Bosch DEL 70 , es de $3 \mathrm{~m}$ por $2,5 \mathrm{~m}$, de esto se deduce que la plantación fue realizada para la obtención de madera con destino de trituración, en un planteo típico del régimen de tallar. Se estableció una parcela permanente de 4 filas por 10 árboles (Figura IV.2.), midiendo a posteriori la superficie ocupada. Dentro de la superficie delimitada se midió con cinta diamétrica el diámetro a la altura del pecho (DAP, $\mathrm{cm}$ ) de todos los árboles vivos. También se determinó la altura de los árboles dominantes $(\mathrm{H}, \mathrm{m})$ mediante clinómetro Suunto PM-5/360PC (Suunto, Finlandia). Se consideró como pie individual a todos aquellos fustes mayores de $3 \mathrm{~cm}$ de diámetro. A partir de estos estadísticos se estimó la densidad (árboles ha ${ }^{-1}$ ) y área basal del rodal $\left(A B, m^{2}\right)$ estimada a partir de la sumatoria de todas las áreas individuales obtenidas a partir del DAP. La cobertura forestal se estimó a partir del análisis de fotografías planas mediante el programa ImageJ 1.48v (Wayne Rasband, National Institutes of Health, EEUU). 
El estado de desarrollo el rodal se corresponde con la etapa de crecimiento conocida como fustal, dado que se trata de un arbolado adulto capaz de fructificar y en donde se encuentra un gran número de individuos dominados, muchos de ellos muertos en pie (Montoya Oliver XII y Mesón García 2004). No tuvo intervenciones silviculturales y el sotobosque está prácticamente ausente, estando conformado en su mayor parte por individuos de Cynodon dactylon.

En forma paralela se realizaron mediciones en un pastizal natural semi-alterado por la presencia de especies herbáceas exóticas. Este pastizal poseía una superficie de 3,6 ha y estaba sometido a pastoreo de llamas, caballos, ovejas y ocasionalmente ganado bovino, siempre con alta carga (Figura IV.1. y IV.2.). Dentro del mismo se estableció una parcela $16 \mathrm{~m}^{2}$ a la que se clausuró por medio de un alambrado romboidal para evitar el ingreso de los animales (Figura IV.2.).

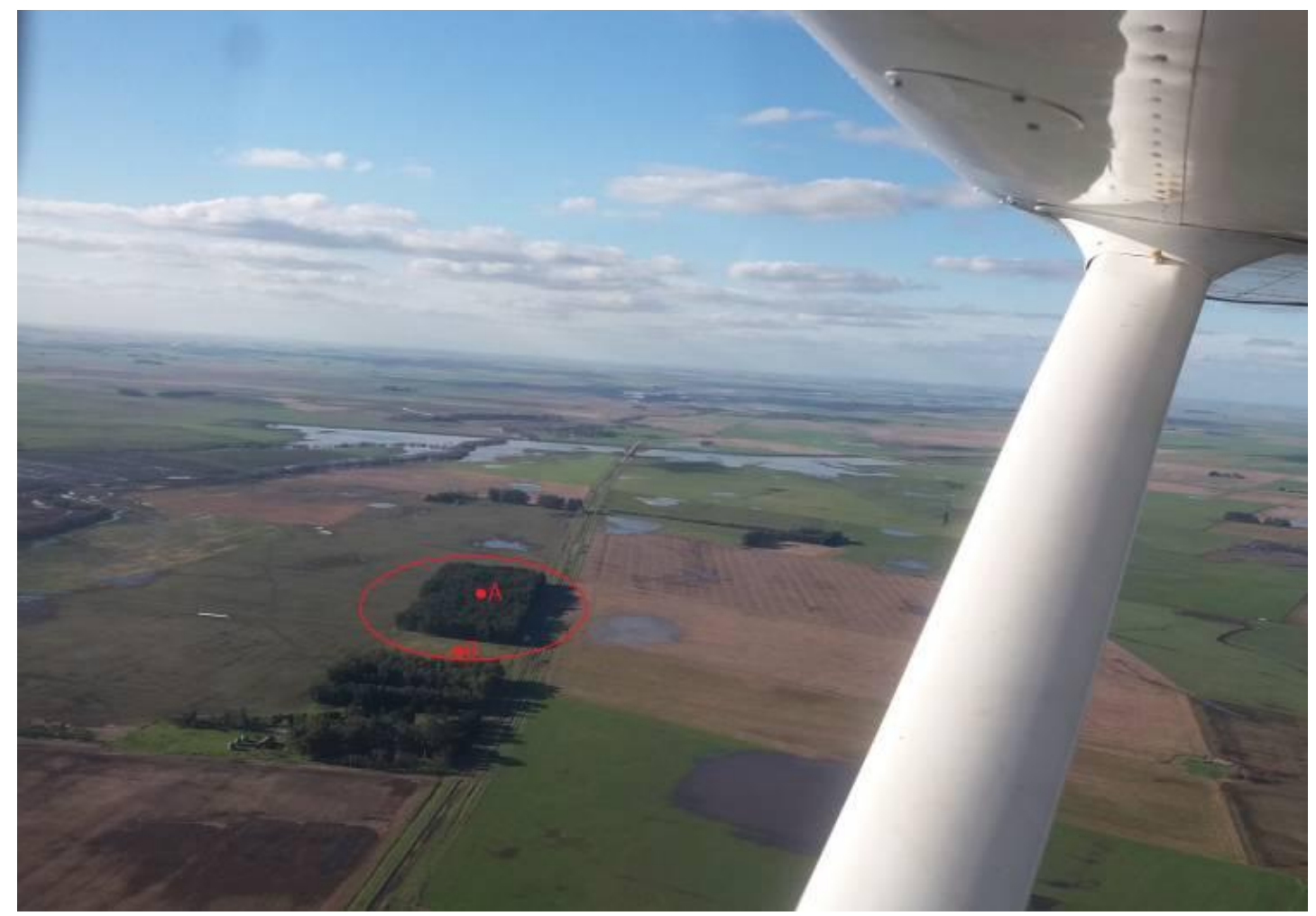

Figura IV.1. Vista aérea de las parcelas intensivas forestal (A) y herbácea (B). Foto gentileza de la Ing. Georgina Cazenave. 


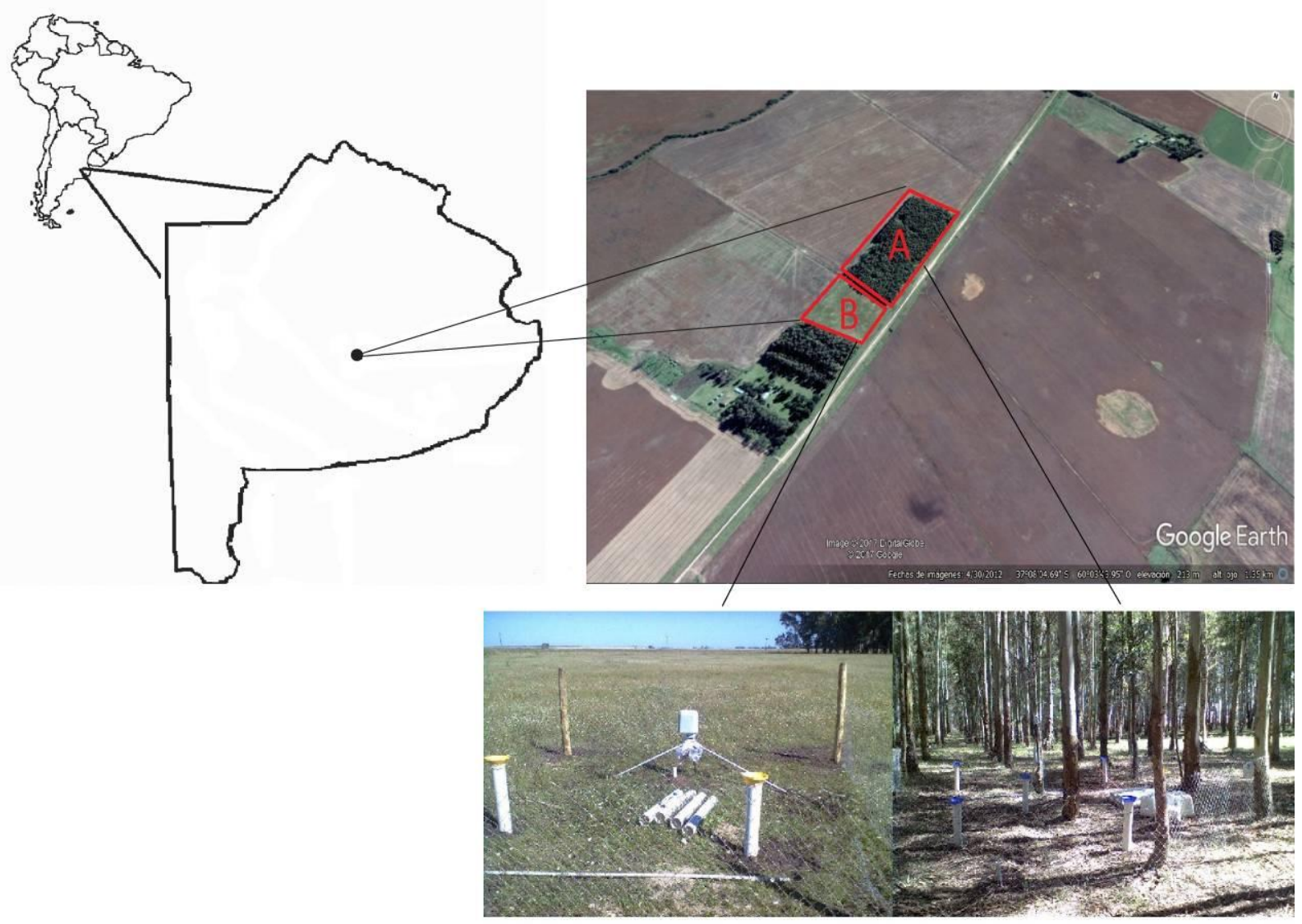

Parcela herbácea Parcela forestal

Figura IV.2. Ubicación de las parcelas intensivas forestal $(A)$ y herbácea $(B)$ y vista de las mismas a campo. Imagen Google Earth@ 2017

\subsubsection{Mediciones climáticas e hidrológicas}

Los parámetros atmosféricos, temperatura y humedad relativa, fueron registrados cada hora en la parcela de la forestación con un sensor Cavadevices modelo 2K14. En la misma parcela, la trascolación fue medida con un total de 9 pluviómetros de embudo, los que fueron reubicados mensualmente para evitar errores de muestreo por captación en sitios preferenciales de escurrimiento (Figura IV.3; Besteiro y Rodriguez Vagaria, 2012). El escurrimiento fustal se estimó por medio de 4 embudos instalados en el fuste de 4 árboles tipo (Figura IV.3). La cantidad de agua colectada en ambas mediciones se realizó con una frecuencia mensual o quincenal durante el período completo de esta tesis. La precipitación total en la parcela herbácea fue determinada usando dos pluviómetros de embudo de la misma forma que la trascolación. Estos datos climáticos, fueron complementados por los obtenidos de dos estaciones meteorológicas regionales denominadas "La Chiquita" y "La Germania" (precipitación, temperatura, humedad relativa y velocidad del viento con frecuencia horaria), las cuales se sitúan alrededor de 
4,3 y $8,2 \mathrm{~km}$ del sitio de estudio, respectivamente. Por último la interceptación $(\mathrm{mm})$ fue calculada según la siguiente ecuación;

$$
I=p p-(T r+E f)
$$

donde pp son las precipitaciones totales que inciden sobre la forestación $(\mathrm{mm})$, Ef el escurrimiento fustal ( $\mathrm{mm}$ ) y Tr la trascolación $(\mathrm{mm})$.

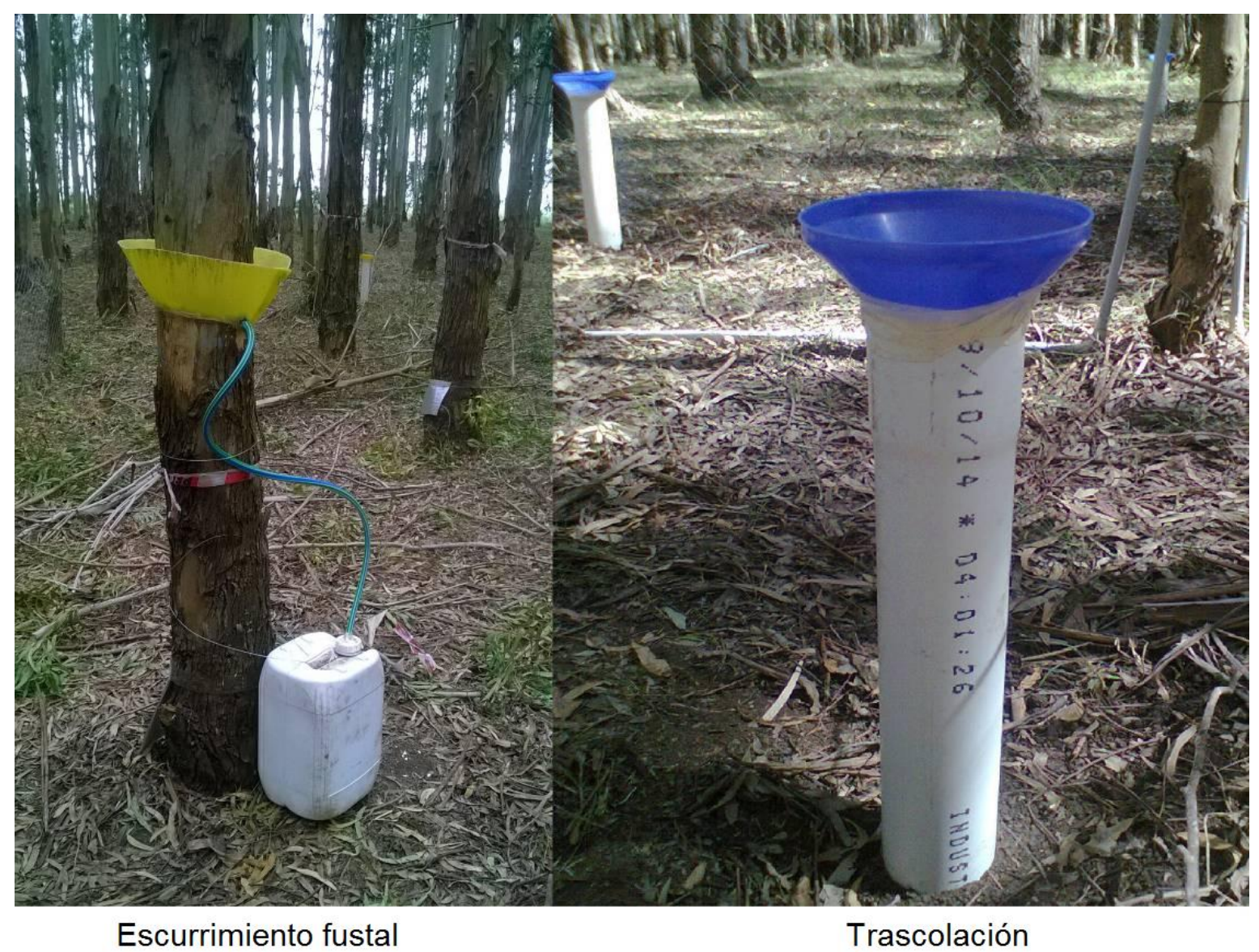

Figura IV.3. Fotografías de los embudos instalados en 4 árboles tipo, para medir escurrimiento fustaly detalle de los pluviómetros utilizados para cuantificar la trascolación.

Los parámetros del suelo y del acuífero se registraron cada hora con un colector automático de datos Em50 (Decagon Devices, Inc., Pullman, WA, EE.UU.). El contenido volumétrico de agua $\left(\mathrm{m}^{3} \mathrm{~m}^{-3}\right)$, la conductividad eléctrica (CE, $\left.\mathrm{dS} \mathrm{m}^{-1}\right)$ y la temperatura del suelo $\left(\mathrm{T}^{\circ},{ }^{\circ} \mathrm{C}\right)$ se midieron cada hora a lo largo del período de tiempo utilizando sensores Decagon 5TE (Decagon Devices, Inc., Pullman, WA, EE.UU.) a dos profundidades diferentes $(0,2 \mathrm{~m}$ y $0,5 \mathrm{~m})$ por duplicado tanto debajo de la forestación como en el pastizal (Figura IV.4.). La profundidad del acuífero, su CE y temperatura se midieron cada hora utilizando un sensor Decagon CTD-10 (Decagon Devices, Inc., Pullman, WA, EE.UU.), 
instalado en dos freatímetros de seis metros de profundidad tanto en la forestación como en el pastizal (Figura IV.4.). Las mediciones de profundidad del acuífero del sensor se verificaron mensualmente con un medidor de nivel de agua manual, mientras que las mediciones de CE en laboratorio a través de muestras de agua subterránea.

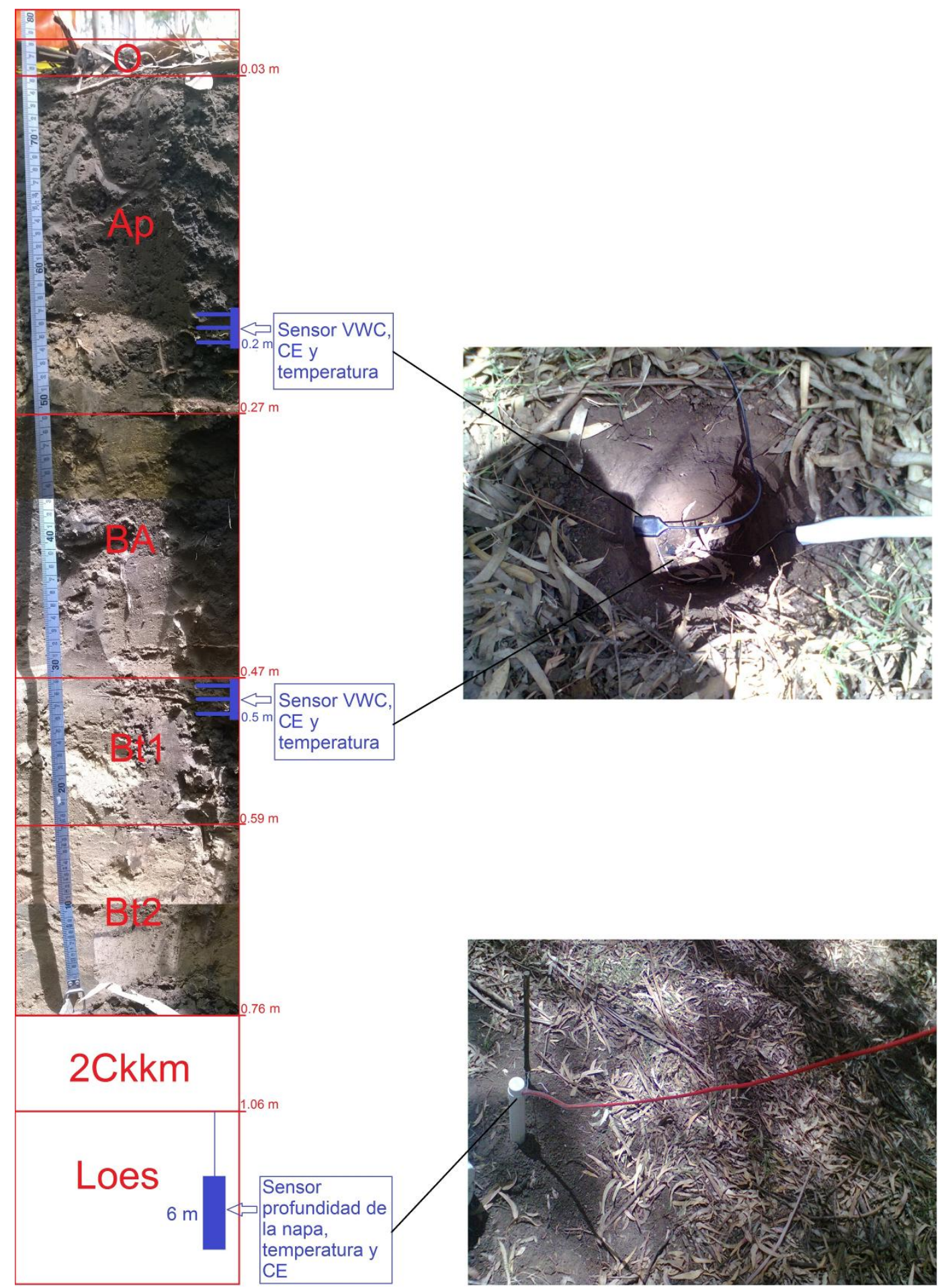

Figura IV.4. Perfil de suelo en la parcela forestal. Se observan la secuencia de horizontes y la ubicación de los sensores del acuífero y suelo. 


\subsubsection{Estimación de la transpiración individual y a nivel de rodal}

Se estimó el flujo de la savia de 9 árboles por medio de la aplicación del método de disipación de temperatura desarrollado por Granier (Granier, 1985 y 1987; un mayor detalle de la implementación del mismo en Gyenge et al. 2010). En cada árbol se instaló un par de termocuplas a lo largo de su eje vertical, a una altura de $1 \mathrm{~m}$ desde el piso y separada a 0,1 m entre ellas. Para insertar las termocuplas se extrajo la corteza y el floema utilizando un punzón, utilizando un taladro de baja velocidad para perforar el xilema (Figura IV.5). Siguiendo la metodología propuesta (Gyenge et al. 2010), la termocupla superior se calentó de manera constante mediante la aplicación de energía constante $(0,2 \mathrm{~W})$, estimándose la diferencia de temperatura con respecto a la termocupla de referencia cada 30 minutos. Los datos se registraron de manera sistemática en un colector automático de datos (Campbell CR10X, Campbell Scientific, Logan, Utah, EE.UU.). Finalmente, se utilizó un aislante aluminizado para evitar el calentamiento del tronco del árbol en la región en donde se insertaron las termocuplas, (Figura IV.5). Así se calculó la densidad del flujo de savia $\left(\boldsymbol{u}, \mathrm{ml} \mathrm{cm}^{-2} \mathrm{~min}^{-1}\right)$ la cual se define como la cantidad de agua que pasa por un área conocida de madera por unidad de tiempo. La $\boldsymbol{u}$ se estimó a partir de la siguiente ecuación (Granier 1985):

$\boldsymbol{u}=0,714\left(\left(\Delta \mathrm{T}_{\text {máxima }} / \Delta \mathrm{T}_{\text {real }}\right)-1\right)^{1,231}\left[\mathrm{ml} \mathrm{cm}^{-2} \mathrm{~min}^{-1}\right]$

donde $\Delta \mathrm{T}_{\text {máxima }}$ es la diferencia máxima de temperatura entre las termocuplas de cada par (generalmente en la noche) y $\Delta \mathrm{T}_{\text {real }}$ es la diferencia de temperatura en cada momento.

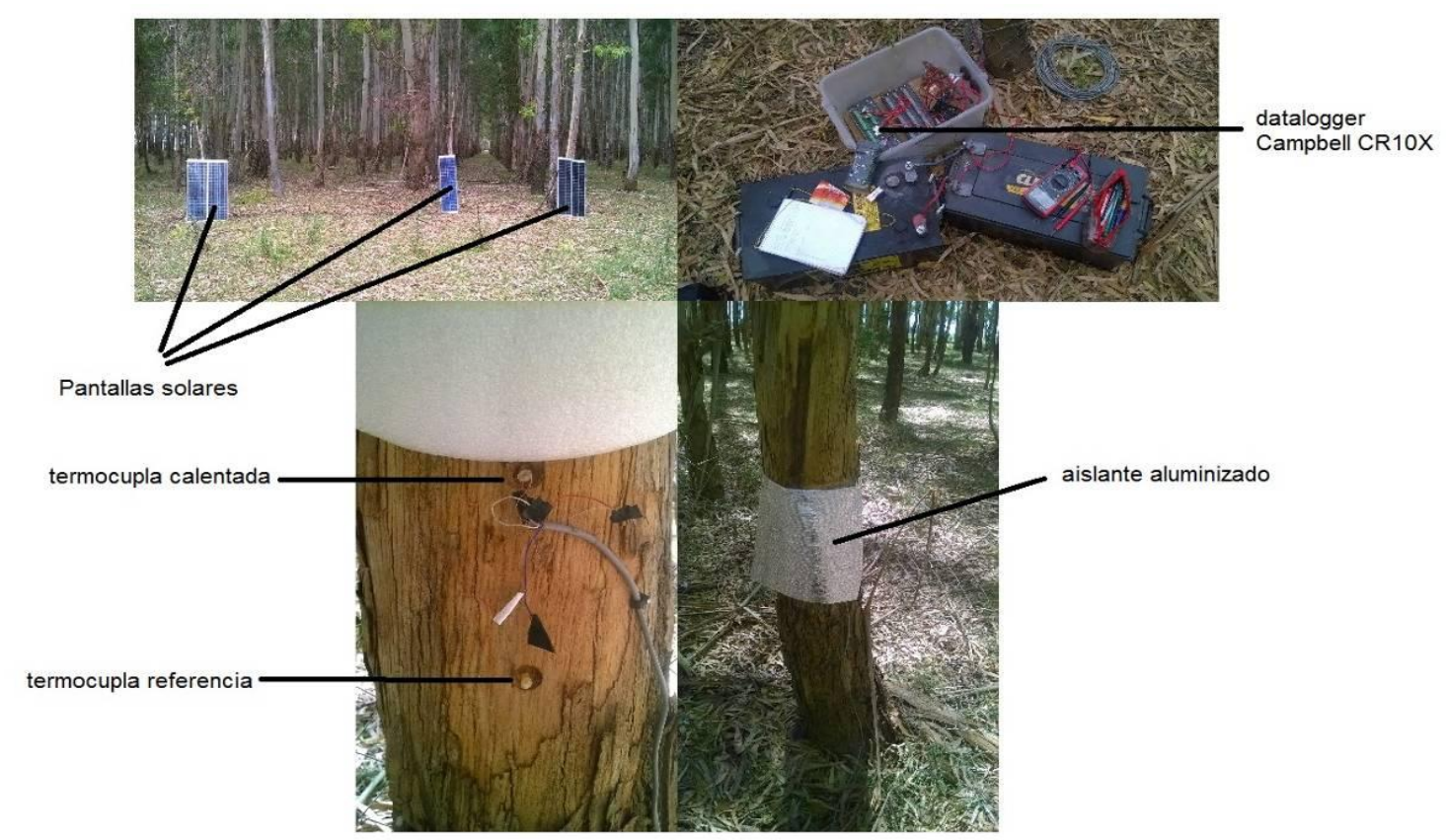

Figura IV.5. Instalación de sensores para la medición del flujo de savia por el método de Granier (p.ej., véase Granier 1985 y 1987). 
El flujo de savia $(F)$ se obtuvo según la fórmula:

$$
\mathrm{F}=\sum(\boldsymbol{u} \mathrm{SA}) \quad\left[\mathrm{ml} \mathrm{\textrm {min } ^ { - 1 } ]}\right.
$$

donde $\boldsymbol{u}$ es la densidad del flujo de savia y SA es el área del xilema activo en $\mathrm{cm}^{2}$. Para determinar la profundidad del xilema hidroactivo y así estimar el SA, se tomaron muestras de madera de árboles de distinto tamaño utilizando un barreno de Pressler de $0,51 \mathrm{~cm}$ y se calculó la relación entre SA y DAP, lo cual permite normalizar la cantidad de agua transpirada (Granier et al. 1990).

La transpiración diaria promedio para el rodal $\left(\mathrm{T}, \mathrm{mm}\right.$ día $\left.\mathrm{a}^{-1}\right)$ fue estimada según la siguiente fórmula basada en las propuestas por Granier et al. (1990):

$$
T=\sum_{i=1}^{i}\left(\mathrm{SA}_{c i} \cup \quad p_{i} \quad \delta \text { área }\right)
$$

donde SAci es el área del xilema activo de la clase diamétrica i $\left(\mathrm{cm}^{2}\right)$; $U$ es el flujo medio diario, calculado como el promedio de la integral diaria de $u ; p_{i}$ es la proporción de cada clase diamétrica $\mathrm{i} ; \delta$ es la densidad de plantación y área $=1$ ha.

\subsubsection{Simulación de la transpiración cultivos}

Para estimar el uso consuntivo de agua que tendrían las especies de verano más cultivadas en la región (Zea mays, Helianthus annuus y Glycine max), en el mismo momento y sitio donde se realizó la forestación, se llevaron a cabo tres simulaciones. Se empleó el programa AquaCrop Versión 5.0 (FAO; www.fao.org/aquacrop), al cual se lo configuró con los datos climáticos y de suelo obtenidos en la parcela intensiva forestal (temperatura, humedad ambiente, precipitaciones, perfil del suelo, profundidad del acuífero y salinidad del mismo) y los parámetros estándar para cada cultivo agrícola (Raes et al. 2009, 2012). De esta manera, se simulo la siembra directa de los cultivos agrícolas para el 15 de Noviembre del 2015, a una densidad de plantación para Zea mays, Helianthus annuus y Glycine max de 7,5 plantas $\mathrm{m}^{2}, 5,8$ plantas $\mathrm{m}^{2}$ y 33 plantas $\mathrm{m}^{2}$ respectivamente. Usando InfoStat versión 2011, se verificaron las suposiciones de ANOVA y se aplicó test de LSD de Fisher $(p<0,05)$, como una comparación entre los valores de transpiración media diaria modelados en cada cultivo herbáceo y medidos en la forestación. 


\subsection{RESULTADOS}

\subsubsection{Características de la forestación y pastizal}

La forestación bajo estudio carecía de manejo silvícola (podas y raleos) y al momento de las mediciones poseía 19 años de edad. La densidad de plantación fue de 1033,3 árboles ha- ${ }^{-1}$, con un $31,6 \%$ de fallas. El área basal fue de $46,9 \mathrm{~m}^{2} \mathrm{ha}^{-1} \mathrm{y}$ el volumen de madera sin corteza $293,7 \mathrm{~m}^{3} \mathrm{ha}^{-1}$. Finalmente la cobertura aérea fue de 66,6 $\pm 4,4 \%$ (Tabla IV.1).

Tabla IV.1. Variables descriptoras del rodal. Especie; $\mathrm{N}=$ Densidad (árboles ha ${ }^{-1}$ ); $\mathrm{DAP}=$ diámetro del fuste a $1,30 \mathrm{~m} ; \mathrm{AB}=$ área basal $\left(\mathrm{m}^{2} \mathrm{ha} \mathrm{a}^{-1}\right) ; \mathrm{H}=$ altura promedio $(\mathrm{m})$; Vol.sc = volumen sin corteza; Cob. = cobertura aérea del dosel arbóreo (\%) y Edad en años desde la plantación.

\begin{tabular}{lllllllll}
\hline Especie & $\left.\begin{array}{l}\mathrm{N} \\
(\text { árb. ha }\end{array}{ }^{-1}\right)$ & $\begin{array}{l}\mathrm{DAP} \\
(\mathrm{cm})\end{array}$ & $\begin{array}{l}\mathrm{AB} \\
\left(\mathrm{m}^{2}\right)\end{array}$ & $\begin{array}{l}\mathrm{H} \\
(\mathrm{m})\end{array}$ & $\begin{array}{l}\text { Fallas } \\
(\%)\end{array}$ & $\begin{array}{l}\text { Vol.sc } \\
\left(\mathrm{m}^{3} \mathrm{ha}^{-1}\right)\end{array}$ & $\begin{array}{l}\text { Cob. } \\
(\%)\end{array}$ & $\begin{array}{l}\text { Edad } \\
(\text { años })\end{array}$ \\
\hline E.viminalis & 1033,3 & $22,5 \pm 8,5$ & 46,9 & $24,9 \pm 2,9$ & 31,6 & 293,7 & $66,6 \pm 4,4$ & 19 \\
\hline
\end{tabular}

En la parcela herbácea adyacente, las especies de plantas dominantes pertenecían a las familias; Poaceas (Paspalum quadrifarium, Stipa brachychaeta, Pithochaetium spp., Mellica spp., Bothriochloa laguroides), y Apiaceas (Eryngium paniculatum). Además, se encontraron especímenes de Asteraceas como Carduus acanthoides, Dispsacus fullonum, Bellis spp. e Hypochaeris spp..

\subsubsection{Mediciones climáticas e hidrológicas}

\subsubsection{Mediciones climáticas}

La temperatura media del aire, medida con el sensor ubicado en la parcela forestal durante todo el período de estudio fue de $13,25^{\circ} \mathrm{C}$, siendo la mínima absoluta de $-5^{\circ} \mathrm{C}$ y la máxima absoluta de $38,1^{\circ} \mathrm{C}$. La temperatura media obtenida, se encontró apenas $0,55^{\circ} \mathrm{C}$ por debajo de la media histórica (World Climate 2013).

El año 2016 registró un valor de precipitaciones acumuladas de 728,4 mm, encontrándose 169,9 mm por debajo de la media histórica (898,3 mm según World Climate 2013), mientras que el año 2017 registró 1385,8 mm siendo superior al promedio histórico por 487,5 mm (Gráfico IV.1.). 


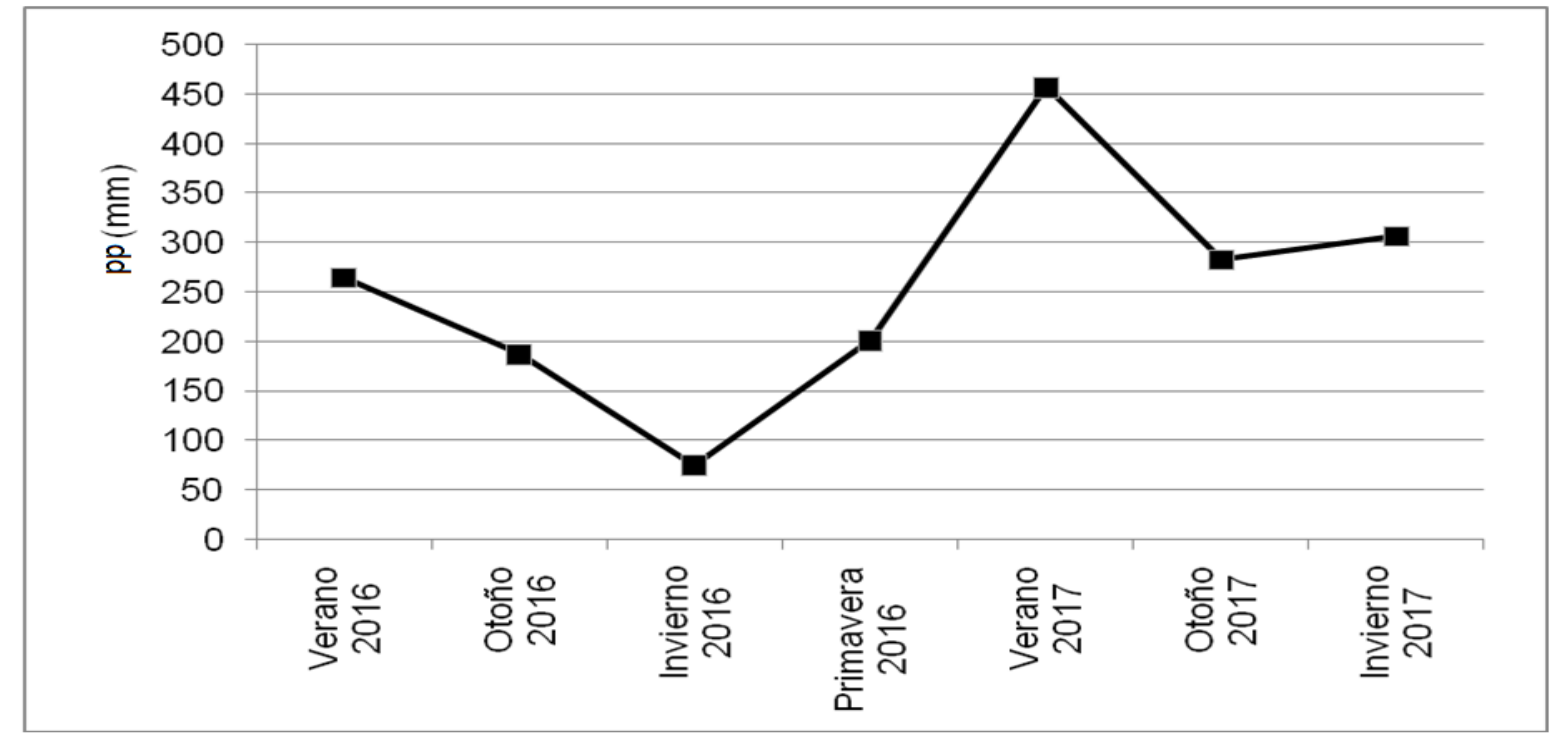

Gráfico IV.1. Evolución de las precipitaciones totales 2016 - 2017 a lo largo de las estaciones del año. $\mathrm{pp}=$ precipitaciones en $\mathrm{mm}$.

El comportamiento de los componentes resultantes de la redistribución de las precipitaciones sobre la forestación de Eucalyptus viminalis se visualiza en los Gráficos IV.2. y IV.3.. Así las ecuaciones fueron lineales con respecto a la precipitación total, mostrando un grado de ajuste $\left(R^{2}\right)$ para trascolación, interceptación y escurrimiento fustal de 0,988, 0,749 y 0,528 respectivamente (Gráfico IV.2.). Asimismo, la trascolación representa el componente mayoritario con un $80,49 \pm 9,20 \%$ de las precipitaciones totales, seguido por la interceptación con un $16,40 \pm 8,96 \%$ y por último el escurrimiento fustal un $3,10 \pm 1,16 \%$. El componente interceptación constituye un porcentaje mayoritario cuando las precipitaciones totales son menores y su peso en la distribución porcentual de los componentes disminuye a medida que las precipitaciones son más abundantes (Gráfico IV.3.). Lo opuesto ocurre con la trascolación que se comporta de manera más o menos complementaria a las precipitaciones totales. Finalmente el escurrimiento fustal se mantuvo en un porcentaje más o menos estable (Gráfico IV.3.). 


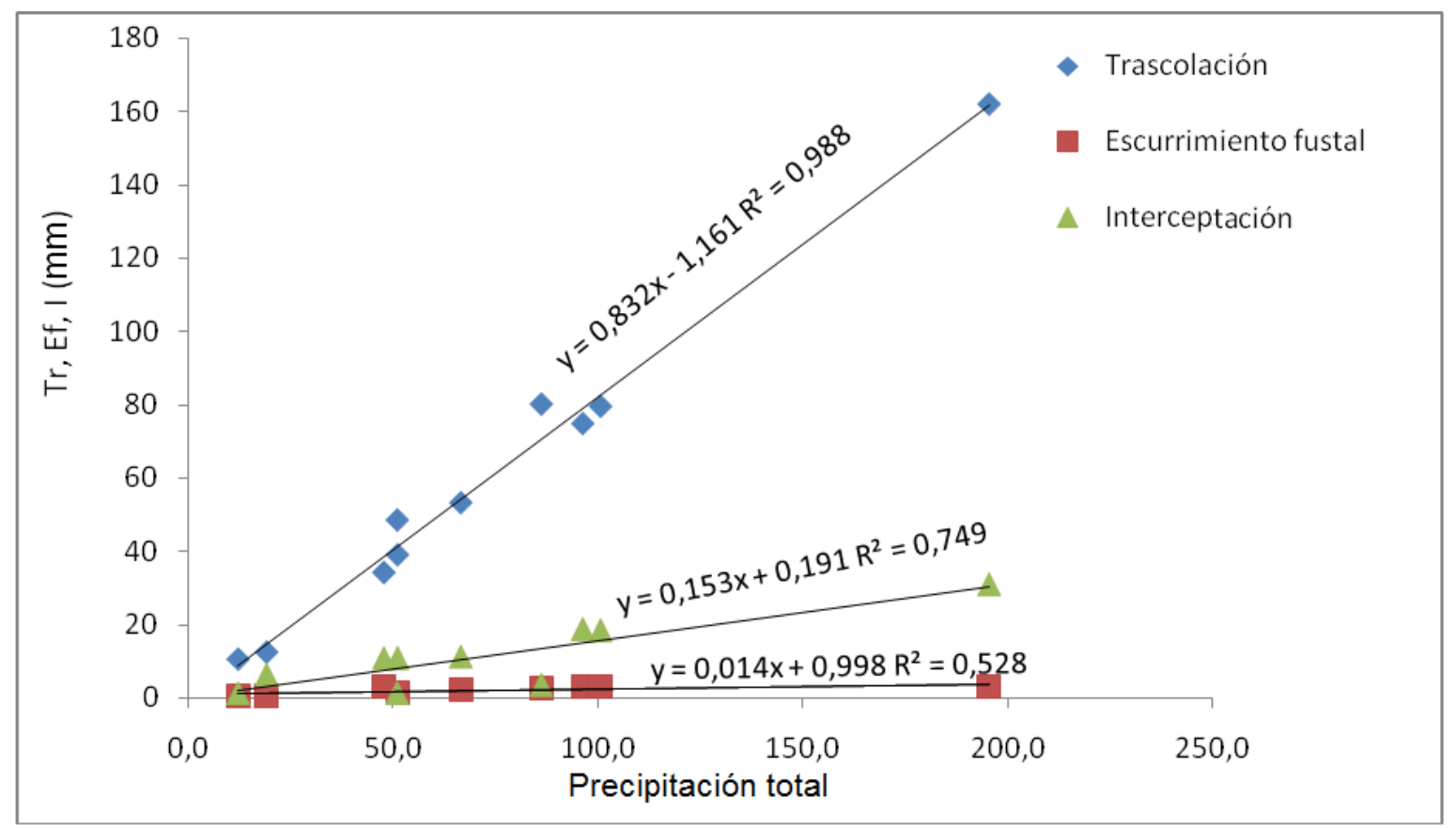

Gráfico IV.2. Distribución de los componentes; $\operatorname{Tr}=$ trascolación, Ef = escurrimiento fustal e I = Interceptación, en relación con la precipitación total que incide sobre la plantación de Eucalyptus viminalis.

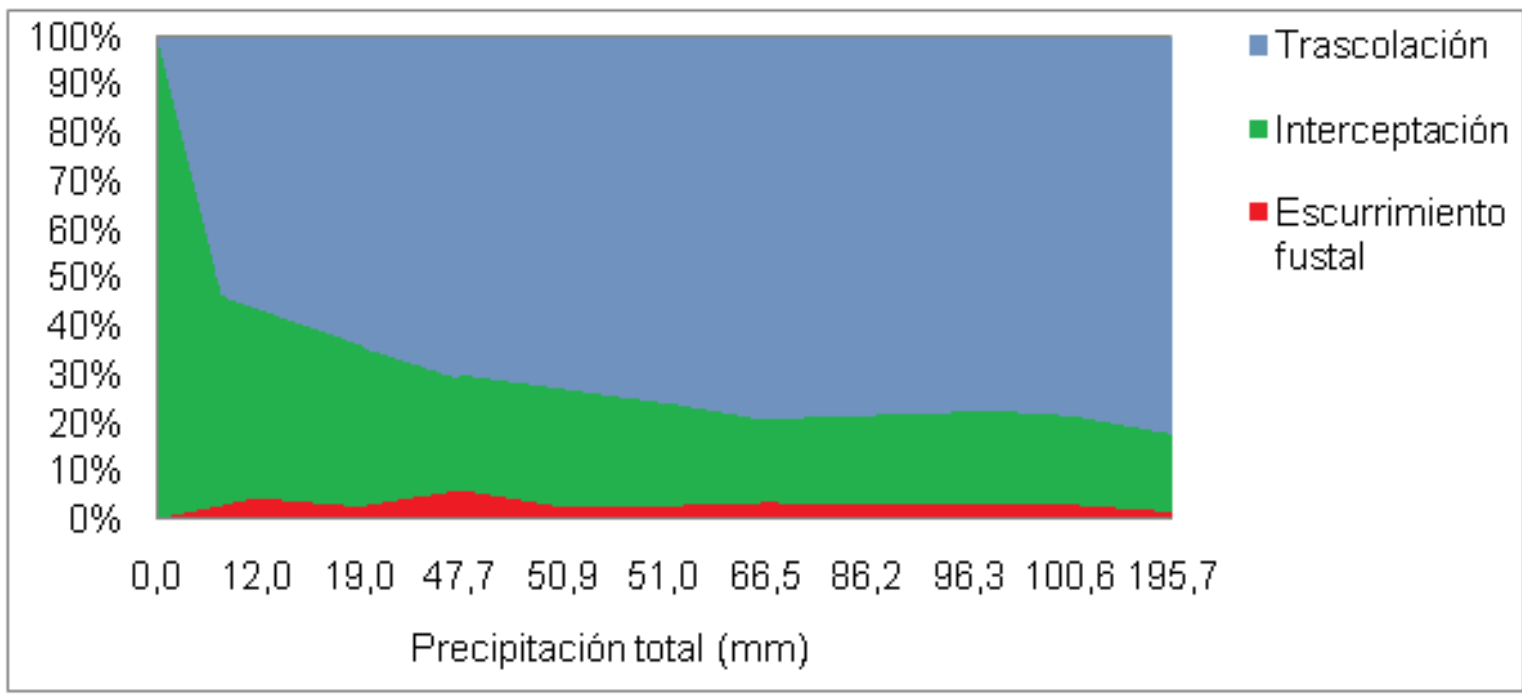

Gráfico IV.3. Redistribución porcentual de los componentes; Trascolación, interceptación y escurrimiento fustal sobre la forestación de Eucalyptus viminalis

\subsubsection{Mediciones en el perfil del suelo}

En general, el contenido volumétrico de agua en el suelo fue mayor en la parcela herbácea que en la forestal, mostrando la parcela herbácea unos valores mínimos similares a los máximos medidos en la parcela forestal (Gráficos IV.4. y IV.5.). EI contenido volumétrico promedio por estación del año de agua en el suelo $\left(\mathrm{m}^{3} \mathrm{~m}^{-3}\right)$ a $20 \mathrm{~cm}$ de profundidad en la parcela forestal, varió desde un mínimo de $0,17 \pm 0,02 \mathrm{~m}^{3} \mathrm{~m}^{-3}$ en el 
invierno del 2016, hasta un máximo de 0,27 $\pm 0,05 \mathrm{~m}^{3} \mathrm{~m}^{-3}$ en el invierno del 2017 . Mientras que en la parcela herbácea se registró un mínimo de 0,25 $\pm 0,07 \mathrm{~m}^{3} \mathrm{~m}^{-3}$ en la primavera del 2016, hasta un máximo de 0,33 $\pm 0,02 \mathrm{~m}^{3} \mathrm{~m}^{-3}$ en el invierno del 2017. Por otro lado, a $50 \mathrm{~cm}$ de profundidad en la parcela forestal se midió un mínimo de 0,23 \pm $0,02 \mathrm{~m}^{3} \mathrm{~m}^{-3}$ en el invierno del 2016, hasta un máximo de $0,31 \pm 0,04 \mathrm{~m}^{3} \mathrm{~m}^{-3}$ en el invierno del 2017. Mientras que en la herbácea se registró un mínimo de $0,30 \pm 0,14 \mathrm{~m}^{3} \mathrm{~m}^{-3}$ en el verano del 2017 y un máximo de 0,40 $\pm 0,09 \mathrm{~m}^{3} \mathrm{~m}^{-3}$ en el invierno del 2017 .

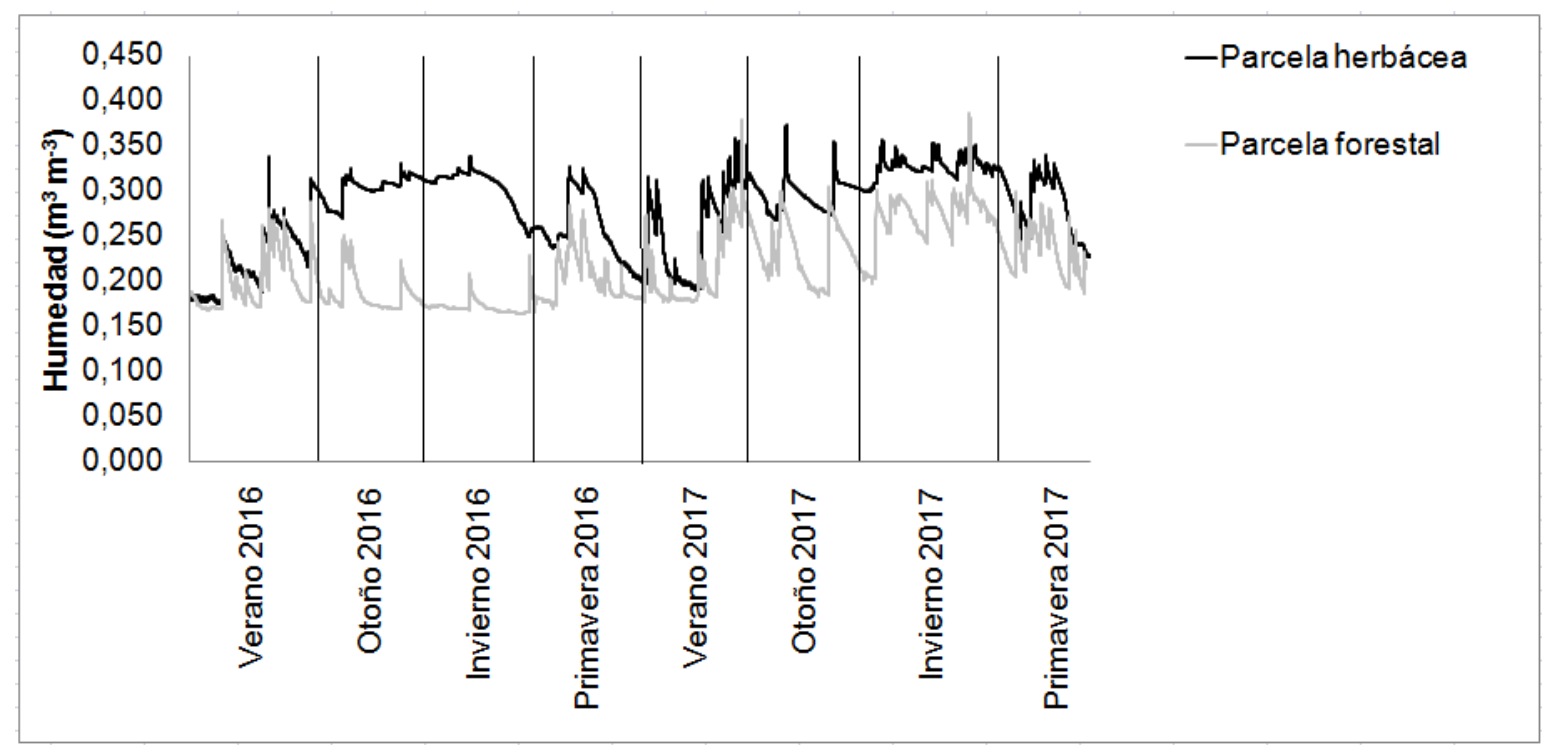

Gráfico IV.4. Humedad volumétrica del suelo promedio $\left(\mathrm{m}^{3} \mathrm{~m}^{-3}\right)$ a $20 \mathrm{~cm}$ de profundidad, para la parcela herbácea y forestal en cada estación del año, a lo largo de los dos años de muestreo (no se muestran los desvíos en orden de tener mayor claridad en el gráfico). 


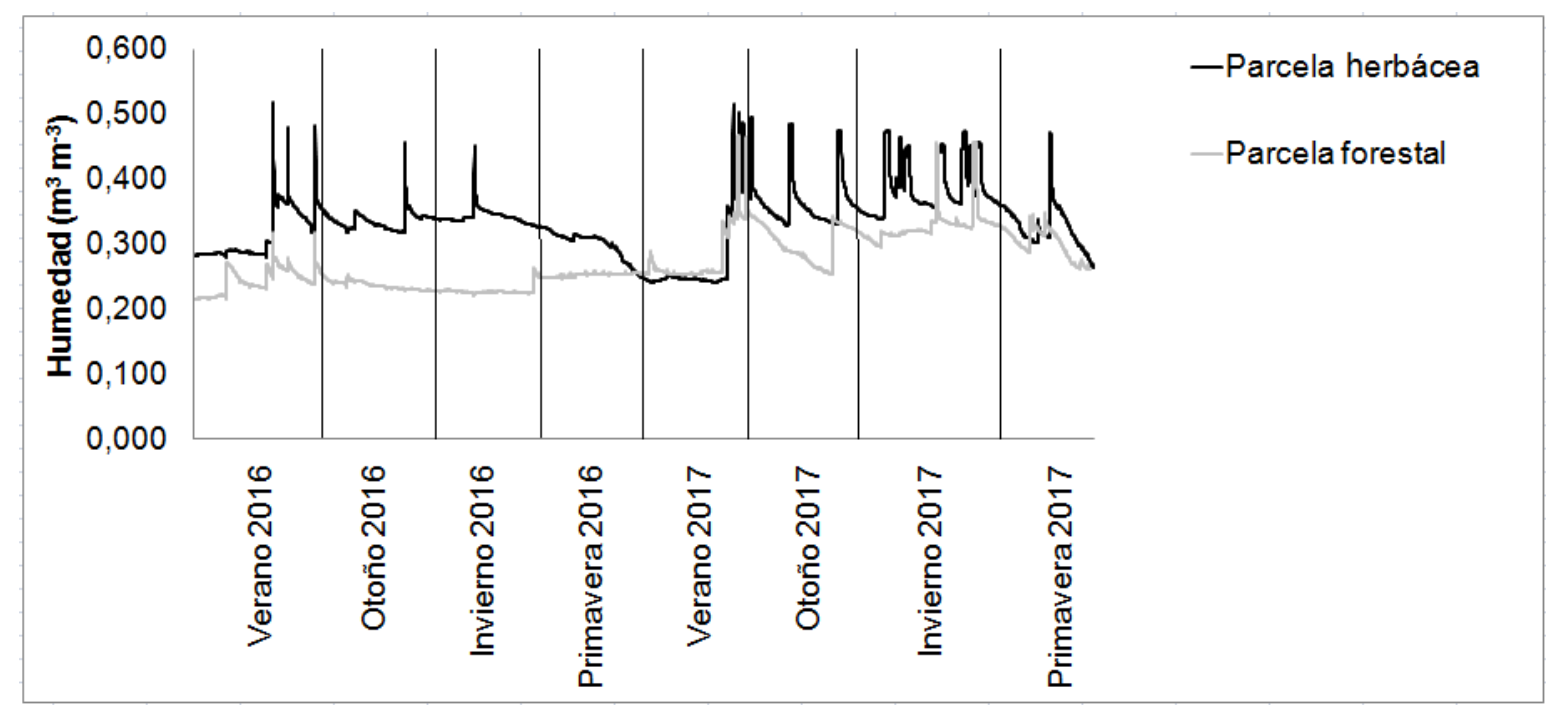

Gráfico IV.5. Humedad volumétrica del suelo promedio $\left(\mathrm{m}^{3} \mathrm{~m}^{-3}\right)$ a $50 \mathrm{~cm}$ de profundidad para la parcela herbácea y forestal en cada estación del año, a lo largo de los dos años de muestreo (no se muestran los desvíos en orden de tener mayor claridad en el gráfico).

Al contrario de lo observado en el contenido volumétrico de agua del suelo, en general, los valores de CE promedio por estación del año $\left(\mu \mathrm{S}^{-1}\right)$ fueron superiores en la parcela herbácea que en la forestal (Gráficos IV.6. y IV.7.). De esta manera, la CE del suelo a los $20 \mathrm{~cm}$ de profundidad en la parcela forestal varió desde un mínimo de $80 \pm 10$ $\mu \mathrm{S} \mathrm{cm} \mathrm{cm}^{-1}$ en el invierno del 2016, hasta un máximo de $110 \pm 30 \mu \mathrm{S} \mathrm{cm}^{-1}$ en el invierno del 2017. Mientras que en la parcela herbácea se registró un mínimo de $390 \pm 50 \mu \mathrm{S} \mathrm{cm}^{-1}$ en el verano del 2017 y un máximo de $790 \pm 100 \mu \mathrm{S} \mathrm{cm}{ }^{-1}$ durante el verano del 2016 . Asimismo, durante el año más seco y para ambas profundidades, la CE fue mayor en la parcela herbácea (temporada otoño-invierno 2016; ver gráficos IV.1., IV.6. y IV.7.). Por otro lado durante el 2017 (año más húmedo) se observan valores similares de las CE para ambas parcelas a $20 \mathrm{~cm}$ (gráfico IV.6.), mientras que a los $50 \mathrm{~cm}$ las curvas se separan y se observa una menor CE del suelo en la parcela forestal (gráfico IV.7.). 


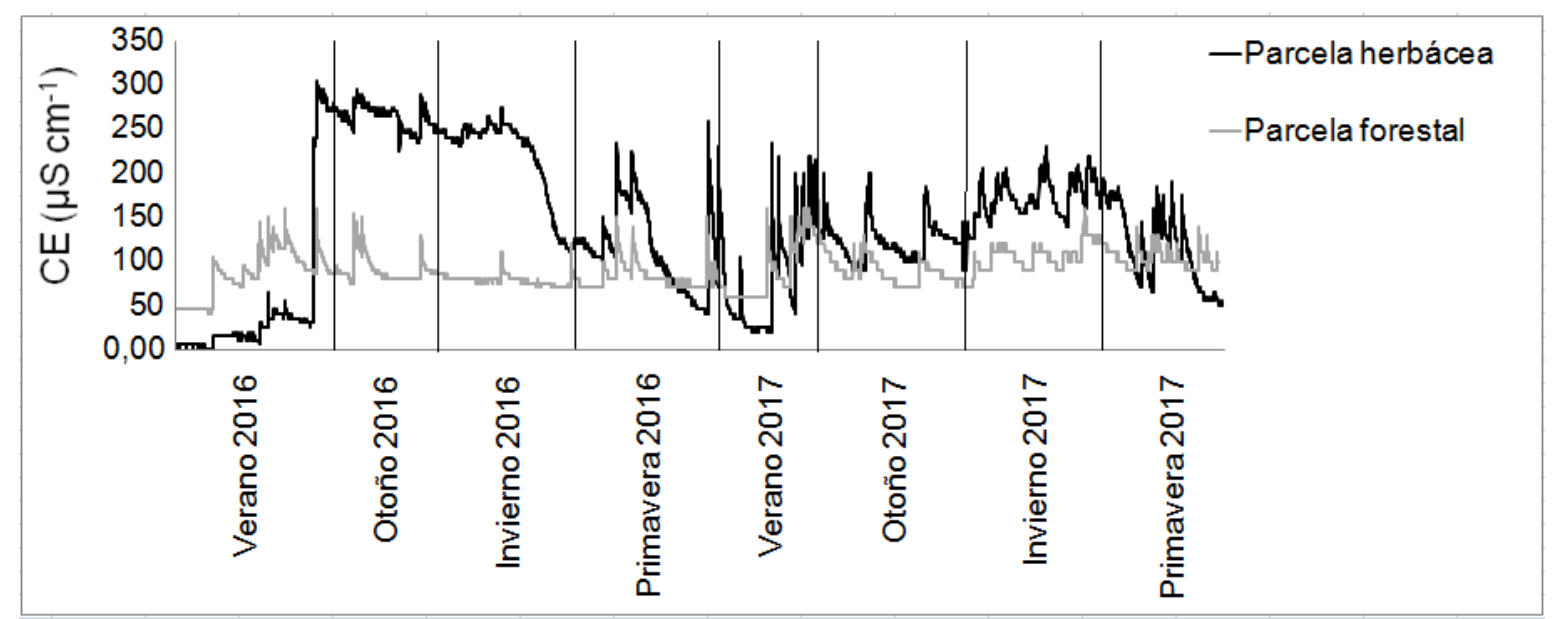

Gráfico IV.6. Conductividad eléctrica del suelo promedio (CE; $\left.\mu S \mathrm{~cm}^{-1}\right)$ a $20 \mathrm{~cm}$ de profundidad, para la parcela herbácea y forestal en cada estación del año, a lo largo de los dos años de muestreo (no se muestran los desvíos en orden de tener mayor claridad en el gráfico).

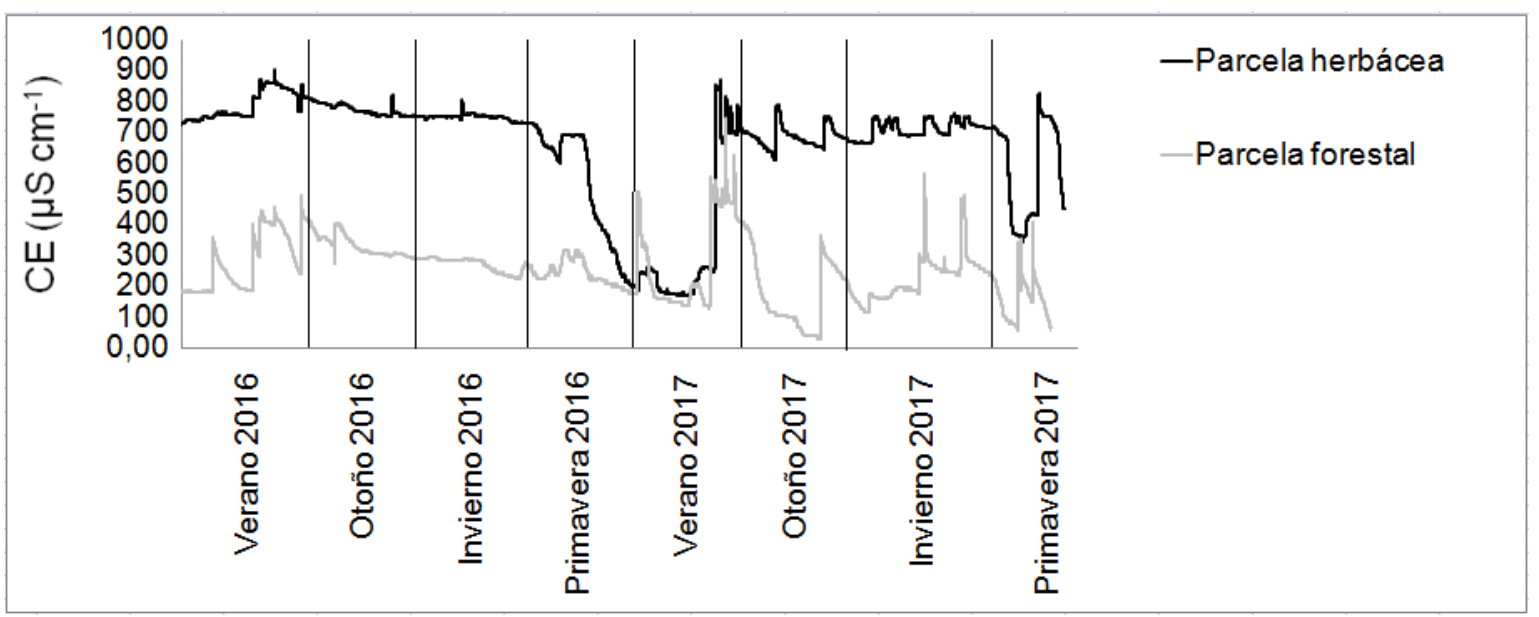

Gráfico IV.7. Conductividad eléctrica del suelo promedio $\left(C E ; \mu S \mathrm{~cm}^{-1}\right)$ a $50 \mathrm{~cm}$ de profundidad para la parcela herbácea y forestal en cada estación del año, a lo largo de los dos años de muestreo (no se muestran los desvíos en orden de tener mayor claridad en el gráfico).

\subsubsection{Mediciones en el acuífero freático}

La profundidad del nivel freático varió a lo largo de los dos años de muestreo, desde un mínimo registrado de 2,16 m durante el invierno del 2017 hasta un máximo de 5,46 m durante el verano del 2017 (Gráfico IV.8). En general se observó que en la mayor parte del tiempo el acuífero bajo la forestación estuvo a menor profundidad que el de la pastura, aunque las diferencias fueron pequeñas (Gráfico IV.8). Esto último cambió durante las distintas temporadas de los año analizados; por ejemplo durante la primavera del año 2017 y el otoño del 2016 la profundidad del acuífero fue mayor en la parcela 
forestal (Gráfico IV.8). En particular, no se registraron datos en la parcela herbácea durante la primavera del 2016 y el verano del 2017 dado que el acuífero estuvo por debajo de la profundidad del freatímetro instalado (6 m; Figura IV.4.).

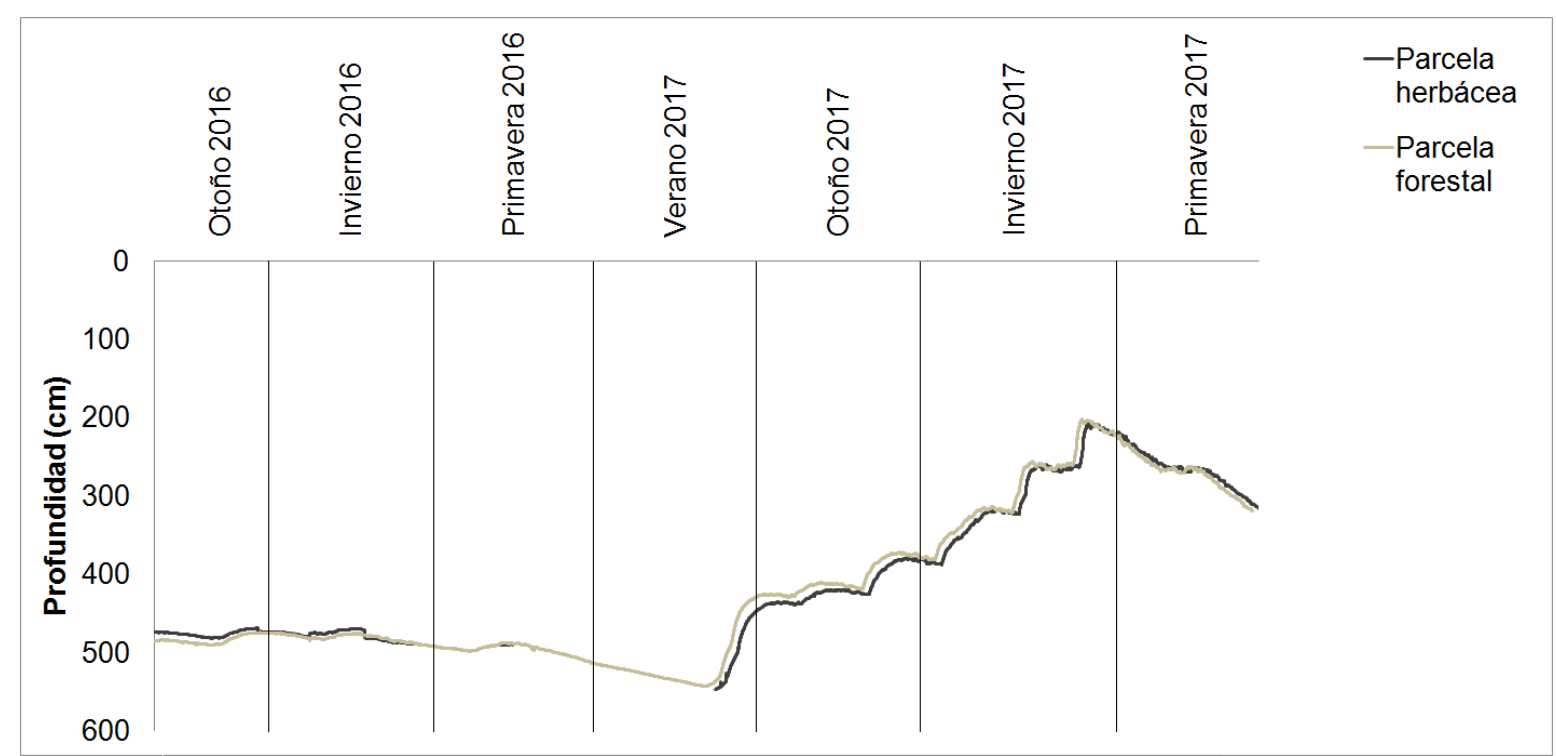

Gráfico IV.8. Profundidad del acuífero freático $(\mathrm{m})$ para la parcela herbácea y forestal en cada estación del año, a lo largo de los dos años de muestreo.

A una escala diaria, no se observaron fluctuaciones del acuífero durante el día y la noche (Gráfico IV.9). El comportamiento para ambas parcelas fue muy similar, tanto cuando la profundidad fue menor en la parcela forestal (septiembre del 2017; Gráfico IV.9) como cuando fue menor en la parcela herbácea (diciembre del 2017; Gráfico IV.10).

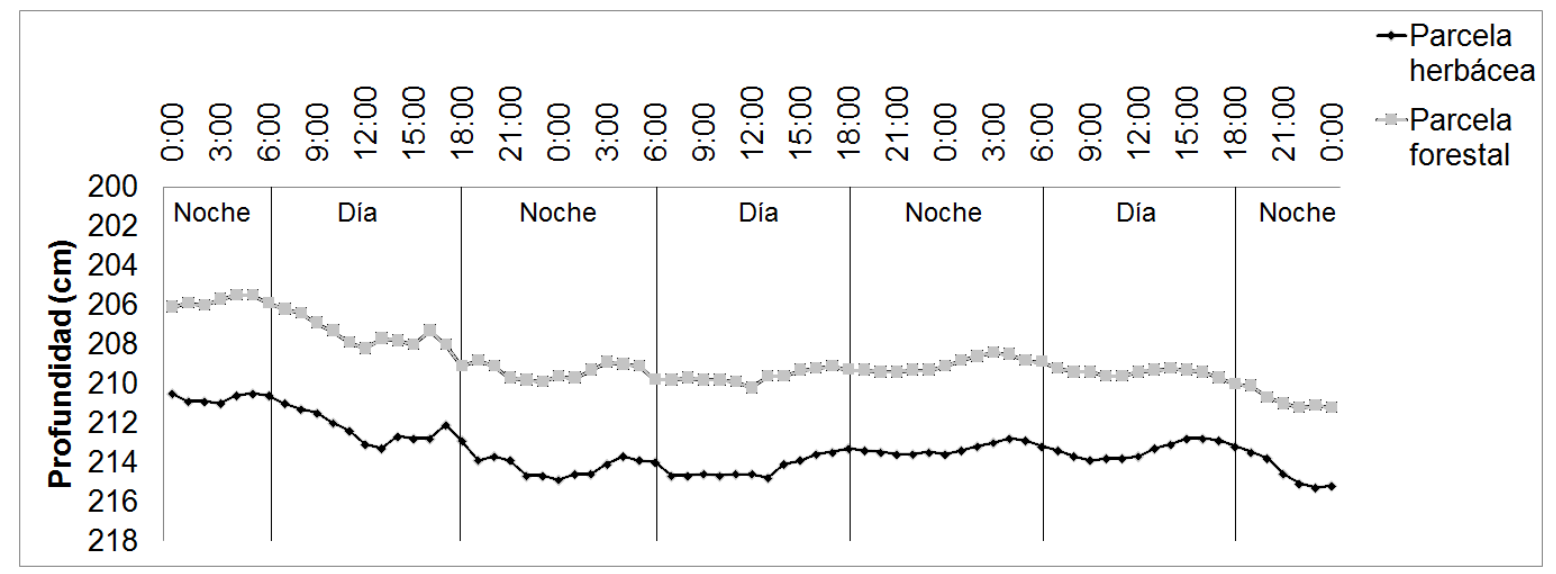

Gráfico IV.9. Profundidad del acuífero freático $(\mathrm{m})$ para la parcela herbácea y forestal, desde el 20/9/2017 al 22/9/17, durante la mínima profundidad medida. 


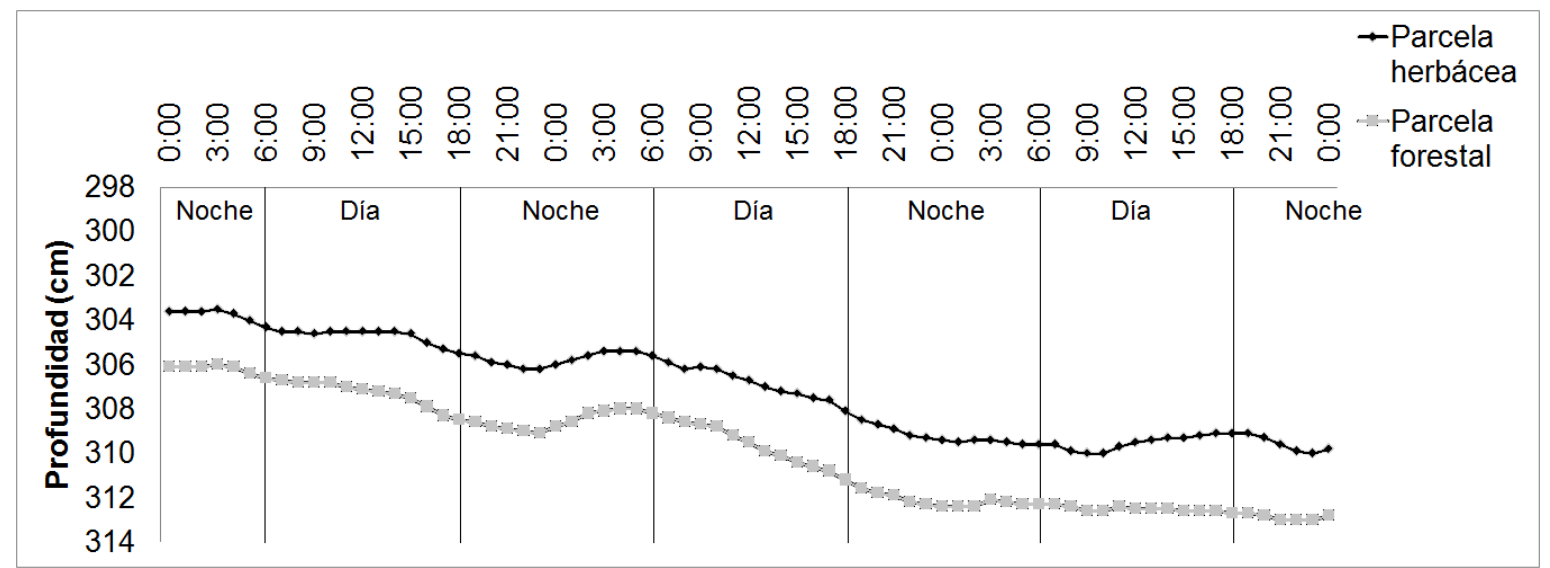

Gráfico IV.10. Profundidad del acuífero freático $(\mathrm{m})$ para la parcela herbácea y forestal, desde el 9/12/2017 al 11/12/2017, cuando la profundidad es menor en la parcela herbácea.

La CE del acuífero fue distinta en cada parcela (test LSD Fisher, $p<0,05$ ) mostrando un promedio general de $670 \pm 30 \mu \mathrm{S} \mathrm{cm}^{-1}$ y $830 \pm 150 \mu \mathrm{S} \mathrm{cm}^{-1}$ para la parcela herbácea y forestal, respectivamente. La CE también fluctuó durante las temporadas del año, registrándose un valor mínimo promedio de $640 \pm 10 \mu \mathrm{S} \mathrm{cm}^{-1}$ durante el invierno del 2016 en la parcela herbácea y un valor promedio máximo de $1070 \pm 70 \mu \mathrm{S} \mathrm{cm}^{-1}$ durante el otoño del 2017 en la parcela forestal. En general la CE fue mayor en la parcela forestal, midiendo un máximo de $1350 \mu \mathrm{S} \mathrm{cm}^{-1}$ durante el verano del año 2017 y coincidente con el periodo de recarga del acuífero (gráficos IV.11. y IV.8.). En la parcela herbácea el máximo registrado fue de $720 \mu \mathrm{S} \mathrm{cm}^{-1}$, medido durante la primavera del año 2017 (gráfico IV.11).

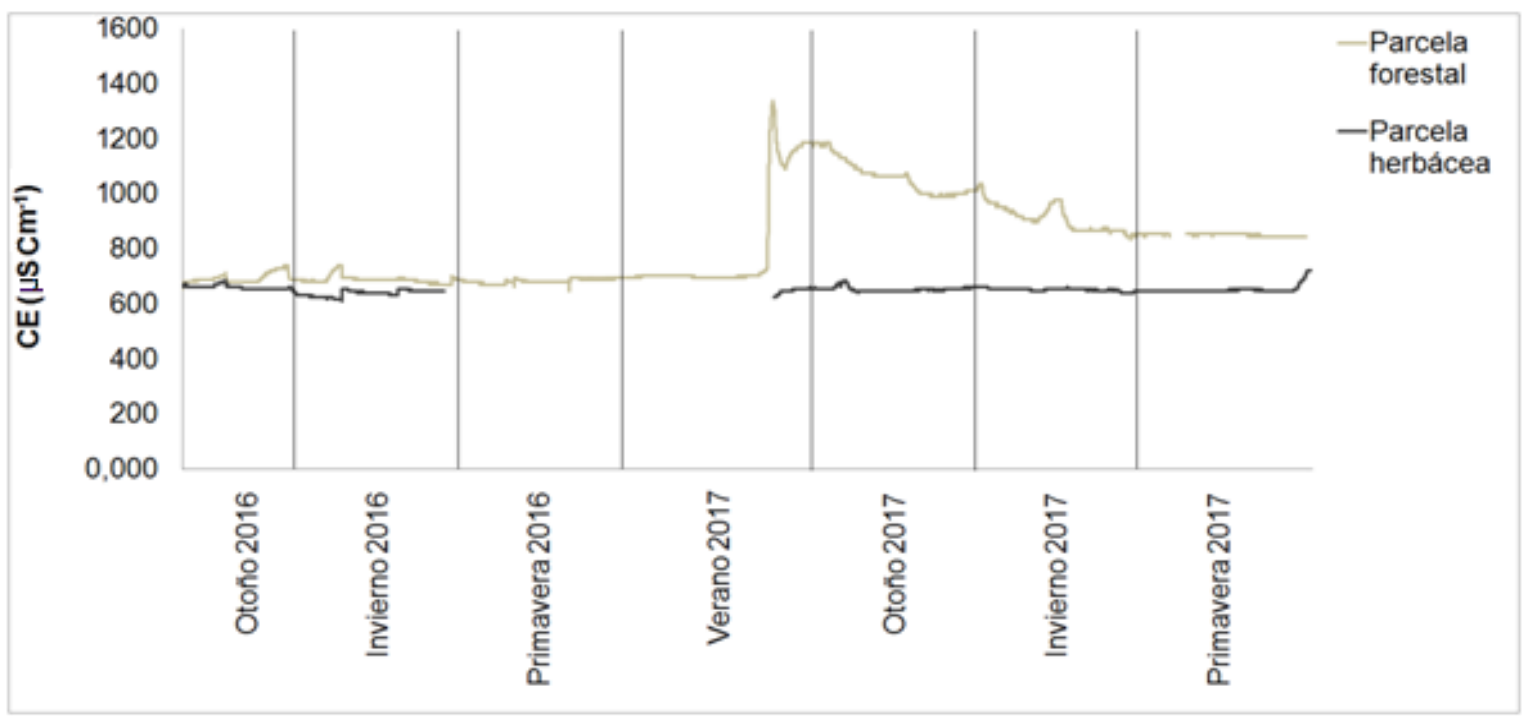

Gráfico IV.11. Conductividad eléctrica del acuífero freático (CE; $\mu S \mathrm{~cm}^{-11}$ ) para la parcela herbácea y forestal en cada estación del año, a lo largo de los dos años de muestreo. 


\subsubsection{Estimación de la transpiración individual y a nivel de rodal}

En el caso de la estimación de la transpiración, lamentablemente no se pudo lograr una serie anual completa, debido a la imposibilidad de visitar la forestación con la suficiente regularidad para hacer el mantenimiento que los sensores demandan. Por dicho motivo, se desestimaron series incompletas y sólo fueron considerados para el análisis los meses de Febrero y Marzo del año 2016.

Durante esta temporada, la transpiración diaria promedio para el rodal fue de 4,89 $\pm 1,03 \mathrm{~mm}$ día $^{-1}$, con valores máximo y mínimo de $7,05 \mathrm{~mm}$ día $^{-1}$ y $2,41 \mathrm{~mm}$ día ${ }^{-1}$ respectivamente, siendo registrado un incremento de la transpiración luego de los eventos de precipitaciones (gráfico IV.12). Sin embargo, se observó un retraso del incremento de la tasa transpirativa luego de los eventos, a pesar que el DPV fue alto (ver grafico IV.12, por ejemplo 26 - 27 y 28 de febrero del 2016).

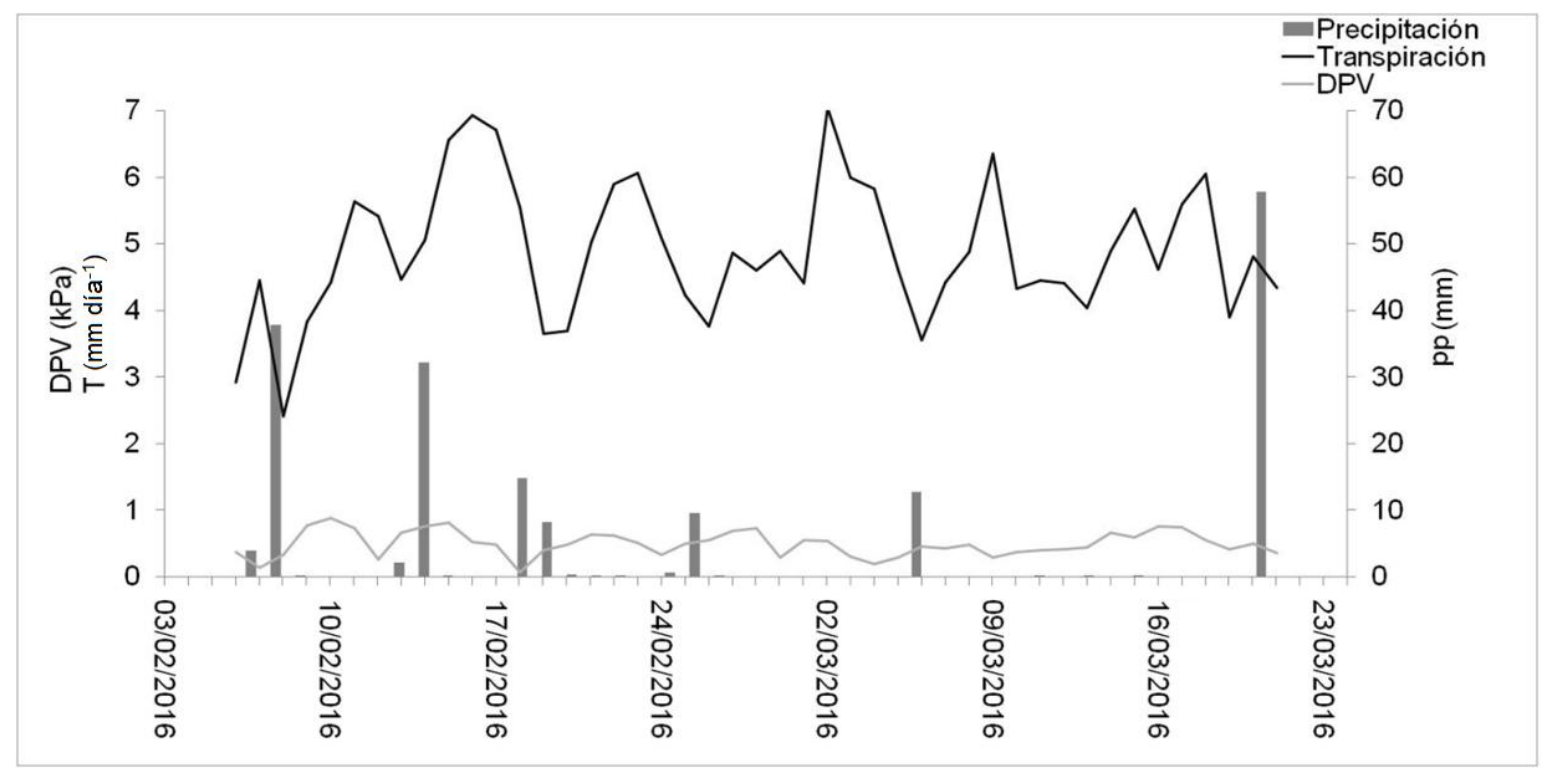

Gráfico IV.12. Precipitación ( $\mathrm{pp}, \mathrm{mm}$ ), transpiración promedio $\left(\mathrm{T} ; \mathrm{mm}\right.$ día ${ }^{-1}$ ) y déficit de presión de vapor (DPV; kPa) durante los meses de Febrero y Marzo del 2016.

Se obtuvo una buena correlación entre las variables DAP y transpiración promedio $\left(R^{2}=0,858\right)$, observándose un incremento de la transpiración a medida que aumenta el diámetro a la altura del pecho (Gráfico IV.13.). 


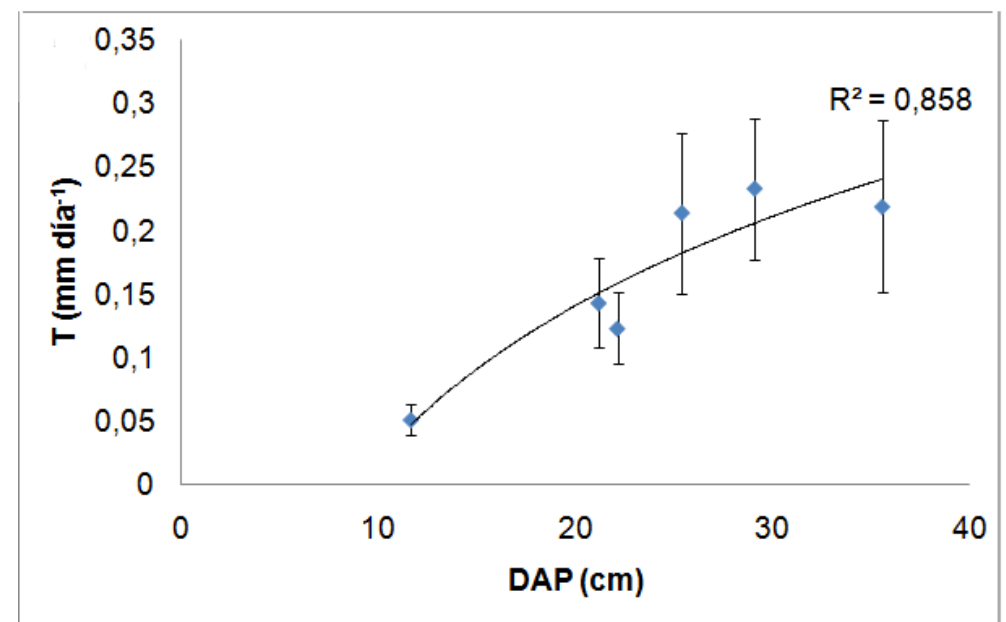

Gráfico IV.13. Transpiración promedio $\left(T ; \mathrm{mm}_{\text {día }}{ }^{-1}\right)$ en función de cada una de las clases diamétricas.

\subsubsection{Transpiración de cultivos vs forestación}

Para el período bajo estudio (del 6 de febrero al 21 de marzo del 2016), el modelo AquaCrop V5 arrojó una estimación promedio de la transpiración de distintos cultivos que fue desde aproximadamente $2 \mathrm{~mm}$ día $^{-1}$ para Zea mays hasta unos $4,5 \mathrm{~mm}$ día $^{-1}$ para Glycine max (Tabla IV.2.). Las simulaciones realizadas, estiman que un cultivo agrícola típico de la región, llevado a cabo en el mismo momento y sitio poseería tasas de transpiración similares a las medidas en el rodal forestal. Así, con respecto al cultivo de Glycine max, que durante el periodo bajo estudio no ha alcanzado la madurez fisiológica, se observa que la transpiración promedio no posee diferencias significativas a la medida en el rodal forestal (Tabla IV.2.). Por otro lado en el gráfico IV.14., se observa una estimación de la transpiración diaria de los cultivos obtenida con el modelo, en comparación con la medida en la forestación de Eucalyptus viminalis. En el caso de Zea mays y Helianthus annuus, los valores son muy similares a los obtenidos en la forestación y Glycine max, hasta aproximadamente el 12 de Febrero del 2016, para luego alcanzar su madurez fisiológica (aproximadamente el 28 de febrero del 2016) con la consecuente caída de la tasa transpiratoria (Gráfico IV.14.).

Tabla IV.2. Transpiración promedio $\left(\mathrm{mm} \mathrm{día}^{-1}\right)$ simulada para los cultivos agrícolas vs medida en la forestación. Letras diferentes indican diferencias significativas. Test LSD Fisher para un $p<0,05$

\begin{tabular}{ll}
\hline Cultivo & $\mathrm{T}\left(\mathrm{mm} \mathrm{dí}^{-1}\right)$ \\
\hline Zea mays & $2,10 \pm 1,41 \mathrm{a}$ \\
Helianthus annuus & $2,79 \pm 1,74 \mathrm{~b}$ \\
Glycine max & $4,55 \pm 0,32 \mathrm{c}$ \\
Eucalyptus viminalis & $4,89 \pm 1,03 \mathrm{c}$ \\
\hline
\end{tabular}




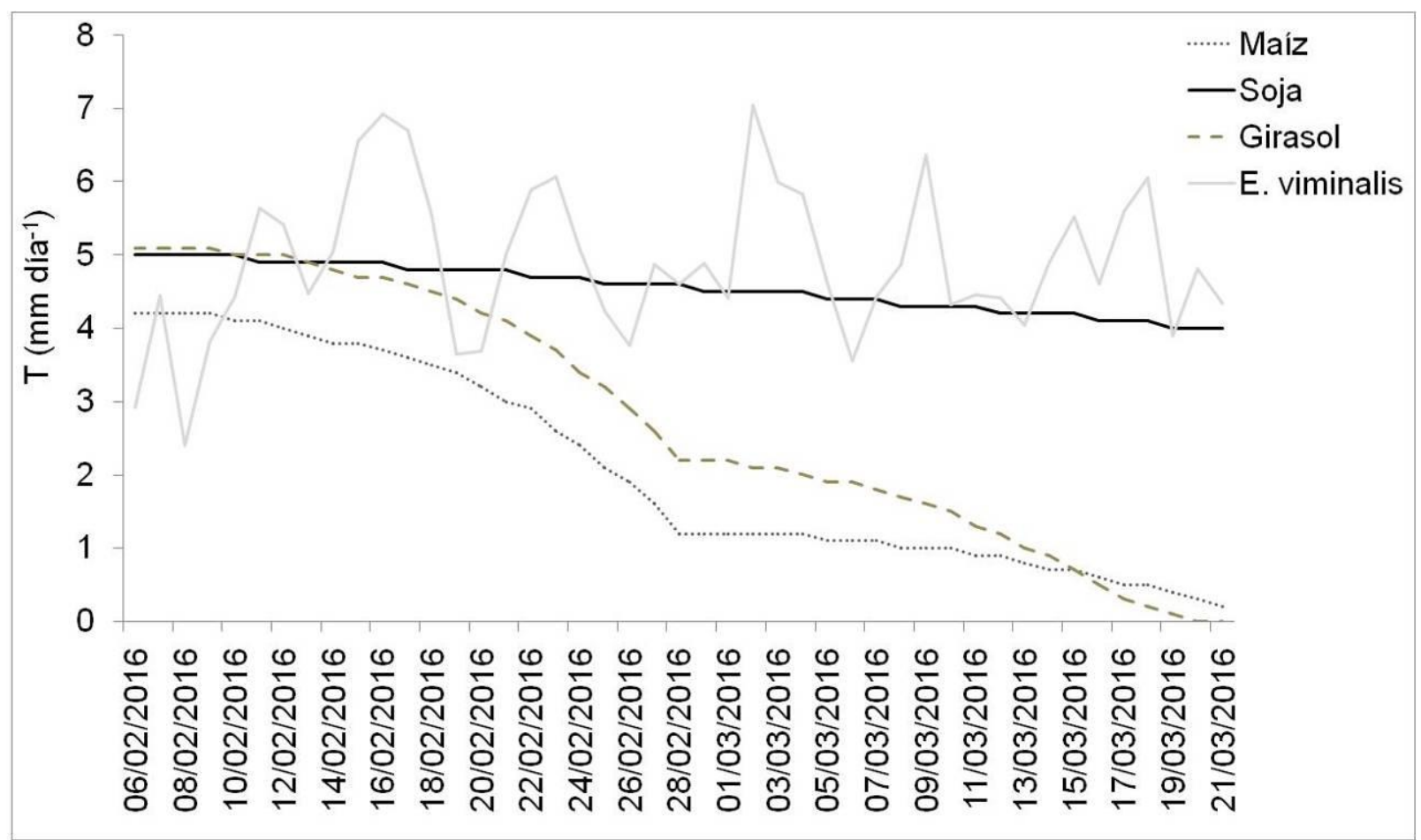

Gráfico IV.14. Transpiración diaria $\left(\mathrm{T}, \mathrm{mm}\right.$ día $\left.^{-1}\right)$ medida para Eucalyptus viminalis y simulada durante el mismo periodo para los cultivos de maíz (Zea mays), soja (Glycine max) y girasol (Helianthus annuus).

\subsection{DISCUSIÓN}

\subsubsection{Mediciones climáticas e hidrológicas}

La cantidad de trascolación y de interceptación estuvieron condicionadas principalmente por el monto de precipitación, tal como lo mencionan Rodrigo Domínguez y Ávila Castells (1997). Los resultados estimados para esta tesis fueron similares a los encontrados para forestaciones situadas en el partido de La Plata (Prov. de Buenos Aires). Así, Besteiro y Rodríguez Vagaría (2012), estudiaron una forestación de Eucalyptus viminalis con un distanciamiento de 2,5 por $2,5 \mathrm{~m}$, fallas del $10 \%$ y cobertura del $36,7 \%$,y estimaron un valor porcentual con respecto a las precipitaciones totales de $4,7 \%$ para el escurrimiento fustal, $12,2 \%$ para la interceptación y 84,2 \% para la trascolación.

Sin embargo, es posible distinguir la menor importancia de los componentes interceptación y escurrimiento fustal con respecto a la trascolación (gráfico IV.3.), siendo esta la principal fuente que abastece de agua al ciclo hidrológico en un bosque (ver por ejemplo Besteiro y Rodríguez Vagaría 2012, Huber y Oyarzún, 1983). Sin embargo, la interceptación y el flujo fustal cobrarían importancia en periodos de escasa pluviometría. De esta manera en el caso de la interceptación, un mayor porcentaje del total de 
precipitaciones se perdería como evaporación directa desde el canopeo y en el caso del escurrimiento fustal representaría un flujo vital de agua alrededor del tronco donde se localiza la mayor cantidad de raíces (Jobbágy et al. 2008, Besteiro y Rodríguez Vagaría 2012).

\subsubsection{Mediciones en el perfil del suelo}

\subsubsection{Humedad volumétrica}

Se observó en general, un menor contenido de humedad del suelo a lo largo de todo el año en la parcela forestal y para ambas profundidades. Estas diferencias se vieron acentuadas en el periodo de menor pluvimetría (otoño-invierno 2016; ver gráficos IV.1., IV.4. y IV.5.). En este sentido las diferencias en la humedad del suelo entre las parcelas forestales y herbáceas se expresaron más durante el año 2016 dado que llovieron 657,4 mm menos que en el 2017 (gráfico IV.1.). Corroborando estos resultados, Jobbágy y Jackson (2004) mencionan que las forestaciones poseen una mayor superficie foliar, un canopeo más denso y un sistema radical con acceso más profundo a fuentes de agua. Estos cambios usualmente resultan en un aumento de pérdida de agua por transpiración e interceptación y por lo tanto un menor contenido de humedad en el suelo. Otros estudios muestran que en forestaciones con Pinus radiata en el sur de Chile, las reservas de agua del suelo durante el periodo seco del verano, se agotan considerablemente y hasta mayores profundidades que en una pradera pareada (Huber et al. 1985). Sin embargo, estos mismos autores mencionan que el raleo, densidades de plantación adecuadas y las alternativas productivas como los sistemas silvopastoriles, son opciones para aumentar la reservas de agua del suelo.

\subsubsection{Conductividad eléctrica}

Para ambas profundidades y parcelas estudiadas, los valores máximos promedios no superan los $800 \mu \mathrm{S} \mathrm{cm}^{-1}$, siendo un valor por debajo del límite de tolerancia para los cultivos agrícolas más comunes de la región (ver por ejemplo; Hillel 2000, Maas 1984, Maas y Hoffman 1977). Se observó en general una mayor CE en el sensor ubicado a 50 cm (gráficos IV.6. y IV.7.), en el horizonte Bt (ver figura IV.4.), tanto en la parcela forestal como en la herbácea. Esto pudo deberse a la mayor capacidad de intercambio catiónico propia de los suelos arcillosos (p.e. Otero 1998). Además, como han observado Dietrich et al. 2014 y Weil y Brady 2017, estos suelos disminuyen los flujos verticales de agua, por lo que podrían generar una zona de acumulación las sales lixiviadas.

Contrariamente a lo esperado, cuando las precipitaciones fueron menores (periodo otoño-invierno 2016, ver gráfico IV.1.) la parcela herbácea muestra mayores 
valores de CE que la parcela forestal. Esta mayor CE en la parcela herbácea durante el periodo más seco, puede deberse a que el pastizal fue pastoreado durante muchos años bajo una alta carga animal, y por ende recibió un gran aporte de deyecciones en la superficie lo cual ha sido mencionado como una fuente de aumento de CE de los suelos (Losinno et al. 2008). Así también, existen antecedentes que plantean la baja capacidad de retención de agua en el suelo forestal en rodales de Eucalyptus spp. frente a pastizales naturales. Esto debido a un mayor porcentaje de macro-mesoporos y a una mayor hidrofobicidad de la materia orgánica (Silveira et al. 2006). Esta combinación de factores, favorecerían el lavado de sales hacia perfiles más profundos. Por otro lado, cuando comienza el periodo más húmedo (verano del 2017) se observa una caída de los valores de CE, probablemente producto de un lixiviado de sales acumuladas durante el periodo más seco. Luego, como ya se remarcó en los resultados obtenidos, a los $20 \mathrm{~cm}$ de profundidad las diferencias entre las parcelas forestal y herbácea se reducen (gráfico IV.6.). Esto último puede ser ocasionado por la abundancia de precipitaciones que genera un excedente de agua en ambas parcelas provocando un lavado de las sales del perfil superior (ver gráficos IV.1. y IV.6.). A los $50 \mathrm{~cm}$ de profundidad la parcela forestal mantiene menores valores de CE del suelo que la parcela herbácea (gráfico IV.7.), debido probablemente, como ya se hizo hincapié, a la baja retención de agua en el suelo forestal (Silveira et al. 2006), incluso en perfiles más profundos que la parcela herbácea, lo que puede favorecer el lixiviado de sales.

\subsubsection{Mediciones en el acuífero freático}

\subsubsection{Profundidad del acuífero}

El nivel freático, en ambas parcelas, claramente varió su profundidad en respuesta a las precipitaciones. Así durante el año más seco (2016) alcanzó las mayores profundidades y durante el año más húmedo (2017) tuvo un progresivo ascenso (ver gráficos IV.1. y IV.8.). Por otro lado, en este estudio, la profundidad del acuífero no dependió del tipo de vegetación. Esto se diferencia con lo detallado por otros autores como Nosetto et al. (2007), Jobbágy et al. (2008), Jobbágy (2009), entre otros. El mayor uso de agua de la parcela forestal en comparación con la parcela herbácea (evidenciado por el menor contenido de humedad del suelo a lo largo de todo el periodo bajo estudio, ver gráficos IV.4. y IV.5) no generó un flujo neto de agua del acuífero hacia la vegetación con la consecuente profundización del mismo. De esta manera, incluso en el momento que la freática estuvo más cerca de la superficie (a unos 2 metros durante la primavera del 2017) la profundidad de ésta fue mayor en la parcela herbácea (gráfico IV.8). Esta independencia del comportamiento del acuífero freático a la vegetación dominante, se puede corroborar, observando los gráficos IV.9. y IV.10. elaborados en dos momentos 
contrastantes (profundidad del acuífero mayor o menor en la parcela forestal con respecto a la herbácea). Como prueba adicional, incluso cuando el acuífero se encontraba más cerca de la superficie, claramente no se registran asensos nocturnos y descensos diurnos, como fueron mencionados por ejemplo en Jobággy 2009. La desconexión entre el acuífero freático y la vegetación dominante, probablemente se deba a la presencia de tosca (carbonato de calcio cementado) sumado a un horizonte Bt (alto contenido de arcillas), lo que dificulta el acceso de las raíces a la misma (Schwinning 2008, Nosetto et al. 2009). Esto es sugerido por Mujica et al. (2019), quienes mediante simulaciones llevadas a cabo con el modelo de simulación numérica MIN3P code (swMATH; www.swmath.org/software/11519) muestran que la forestación utiliza la mayor parte del agua necesaria para transpirar del perfil de suelo que se encuentra por encima del horizonte petrocálcico. Esta aseveración también lo corrobora el gráfico IV.11. donde se observa que las variaciones de CE de la napa no guardan relación con la CE del suelo medida en la parcela forestal y herbácea. Así a lo largo de dos años la CE del acuífero fue mayor para la forestal que para la herbácea (gráfico IV.11.), contrariamente a lo que sucede con la CE del suelo (ver gráficos IV.6. y IV.7.). A pesar de estos patrones la aseveración de que la vegetación leñosa no se encuentra conectada a la freática debe ser tomada con precaución. Sería importante un estudio más detallado de los flujos subterráneos mediante la instalación de un mayor número de freatímetros o incluso, mediante el uso de firmas isotópicas que permitan establecer el origen del agua usada por los árboles (p.e. Fernández et al. 2008).

\subsubsection{Conductividad eléctrica del acuífero}

La conductividad del acuífero fue mayor durante todo el periodo estudiado en la parcela forestal. Analizando el gráfico IV.11., la presencia del máximo de CE ocurrido en la parcela forestal durante el verano 2017, coincide con la época de mayores precipitaciones del periodo bajo estudio (gráfico IV.1.). Así, se podrían formular dos hipótesis para explicar este pico de CE; a) Las altas precipitaciones del verano del 2017 lixiviaron las sales acumuladas por la forestación durante el periodo seco del año 2016 hacia el acuífero incrementando su conductividad, o bien b) El exceso de precipitaciones generó un ascenso del acuífero que al contacto con las capas de suelos superiores, se cargó de iones incrementando su conductividad. En cualquier caso, luego de este pico máximo, la CE del acuífero en la forestación va disminuyendo conforme continua el avance del año 2017 (periodo más lluvioso estudiado) (gráfico IV.11).

Atendiendo a la calidad de agua para consumo humano, algunos autores mencionan que las plantaciones forestales incrementan la salinidad del agua freática 3 a 30 veces respecto a la de pastizales naturales, elevando en casi todos los casos la CE 
del agua por encima de los valores considerados seguros para el consumo humano (Jobbágy y Jackson 2004, Jackson et al. 2005). Sin embargo, en nuestro sitio de estudio, la CE promedio fue solo un $24 \%$ mayor en la parcela forestal. En este sentido, si bien la organización mundial de la salud y el código alimentario Argentino no establecen límites para el agua de consumo humano en lo referido a la CE máxima admisible, en las normas IBNORCA NB512, NGO 29001 y NOM127- SSA1 (de Bolivia, Guatemala y México respectivamente) figuran límites de $1500-1600 \mu \mathrm{S} \mathrm{cm}{ }^{-1}$ como parámetro que puede producir quejas en los usuarios. Así, los valores promedios de CE de ambas parcelas no superan este límite, incluso el máximo alcanzado por la parcela forestal estaría por debajo de los valores de referencia.

Otro aspecto interesante de analizar, es la calidad que posee el acuífero para su uso en regadío. Así, como mencionan Ayers y Westcot (1985), acuíferos con valores de CE menores a los $700 \mu \mathrm{S} \mathrm{cm}^{-1}$ son considerados como sin restricciones para su uso. De esta manera, el acuífero de la parcela herbácea no tendría restricciones y en el caso de la parcela forestal al estar levemente por encima de este valor, tendría una ligera restricción. Sin embargo, en ninguno de los caso la CE del acuífero supera los $3000 \mu \mathrm{S}$ $\mathrm{cm}^{-1}$, considerados por estos mismos autores como de alto riesgo para uso en regadío. Incluso considerando el pico máximo alcanzado por la forestación durante el verano del 2017 (gráfico IV.11), los valores de CE medidos en el acuífero son muy inferiores a este límite.

\subsubsection{Estimación de la transpiración individual y a nivel de rodal}

Como se menciono en la introducción general de esta tesis, existen escasos antecedentes sobre el uso del agua de las forestaciones en la región. Pudiéndose mencionar el estudio de Engel et al. (2005) y el de Rébori et al. (2001) que estimaron una tasa de transpiración promedio anual de 2 y $3.8 \mathrm{~mm}$ día $^{-1}$ para Eucalyptus dunni y Eucalyptus camaldulensis respectivamente. En este sentido la transpiración medida para el rodal de Eucalyptus viminalis bajo estudio $\left(4,89 \pm 1,03 \mathrm{~mm}\right.$ día $\left.^{-1}\right)$ si bien difiere de estos valores, se trata de otra especie forestal y los promedios obtenidos solo incluyen dos meses estivales, donde la demanda evapotranspirativa es la más alta. Asimismo, estos valores no sugieren un consumo excesivo de agua, ya que, en términos comparativos, se corresponden con los estimados por Rivas y Carmona (2013) y Sakalauskas et al. 2001 para lotes de Glycine max y pastizal en la misma región (3 y 4 $\mathrm{mm}$ día $\left.^{-1}\right)$.

Por otro lado, como se observó en el grafico IV.12, existe un retraso del incremento de la tasa transpirativa luego de los eventos de lluvia. En este sentido Lambers et al. (2008), menciona que después de un estímulo negativo de horas o de días 
el desempeño fisiológico de la planta disminuye, y si las condiciones vuelven a ser favorables, recupera poco a poco su desempeño, aclimatándose. Otro trabajo, llevado a cabo en Norte América sobre rodales de Pinus banksiana, confirma que existe poca respuesta a los eventos de precipitación cuando la sequia se vuelve crónica (Baldocchi et al. 1997). De esta manera es probable, que la forestación se encuentre en un estado de estrés hídrico, dado que se observa una demora para recuperar su máxima tasa evapotranspirativa luego de un evento de precipitación (grafico IV.12). Como se mencionó anteriormente los contenidos de humedad del suelo durante el periodo analizado fueron muy bajos (gráfico IV.4. y gráfico IV.5.), y a esto podría sumarse la posible falta de conexión de la vegetación con el acuífero. De esta manera, aun cuando la demanda evapotranspirativa es alta, el rodal no transpira con iguales tasas.

Finalmente en el gráfico IV.13., se observa una buena correlación entre el DAP y la transpiración promedio. De esta manera, los individuos dominados de bajo DAP, al estar un corto tiempo expuestos a la radiación directa, tener una menor rugosidad y posibilidad de captura de energía advectiva (menor área foliar), generarían una menor transpiración que en el caso de los individuos dominantes con un alto DAP (Calder 1998, Kelliher et al. 1993, Anandacoomaraswamy et al. 2000, Vertessy et al. 1997).

\subsubsection{Transpiración de cultivos vs forestación}

Las valores de tasas transpiratorias similares estimados por el modelo AquaCrop V5 (Gráfico IV.14.), pueden deberse a que la forestación posee una limitación en la exploración del sistema radical a causa de horizonte petrocálcico (ver figura IV.4.). A pesar del menor albedo, rugosidad y capacidad de explorar perfiles más profundos de las forestaciones (Zhang et al. 2001), en estas condiciones de sitio donde los cultivos se encuentran con una limitante a la penetración radicular y con pocas posibilidades de hacer uso del acuífero, la capacidad de transpirar sería dependiente de las precipitaciones y estaría limitada por la humedad de los horizontes que se encuentran sobre la tosca (Poore y Fries 1987, Schwinning 2008).

\subsection{CONSIDERACIONES FINALES}

En conclusión, con respecto al impacto hidrológico y en la acumulación de sales, los resultados de este capítulo concuerdan parcialmente con las hipótesis planteadas. Es cierto que el consumo de agua por parte de la forestación, debido a sus características ecofisiológicas, provoca un menor contenido de humedad del suelo a lo largo del año que en el caso del pastizal. Esto parece generar un mayor aprovechamiento de las precipitaciones, pero no hay evidencias que demuestren un impacto a largo plazo de la forestación a través de la acumulación de sales en suelo/acuífero. Asimismo, el uso de 
agua de la forestación parece no alejarse del consumo que podría realizar durante su desarrollo un cultivo agronómico herbáceo. Aunque es cierto que durante el periodo de barbecho propio de los cultivos agrícolas, podría existir un excedente de agua, que no ocurrió en la forestación bajo estudio. Según lo observado, este excedente sería aprovechado para generar biomasa, sin un impacto en el ciclo hidrológico o en el reciclaje de sales del suelo/acuífero que pueda comprometer la producción futura. En este sentido, parece fundamental el rol del horizonte petrocálcico en el ciclo hidrogeoquímico del sistema. Así, la resistencia que genera este horizonte a la penetración radical (sumado a los horizontes arcillosos), podría estar limitando a la forestación, y por lo tanto a los cultivos, a generar biomasa usando el agua proveniente de las precipitaciones y reduciendo el acceso a una fuente subterránea de agua.

Dada la heterogeneidad de los suelos presentes en la llanura Pampeana, resultaría necesario contar con una red de flujo subterráneo en las parcelas estudiadas. Por otro lado, serían necesarios más estudios para evaluar el efecto de un acuífero que se encuentre sobre el horizonte petrocálcico, en el perfil de suelo más explorado por el sistema radical de las forestaciones y cultivos. 


\section{Capítulo 5}

\section{Discusión final y conclusiones}




\subsection{DISCUSIÓN FINAL}

La hipótesis planteada, elaborada a partir del modelo conceptual propuesto por Nosetto et al. (2008) y Jobbágy et al. (2006) fue la siguiente;

1) La salinización secundaria de suelos en los sistemas vegetales se relacionará directamente con la capacidad evaporativa de las especies, su resistencia a la salinidad, su posibilidad de conectase a un acuífero y la conductividad hidráulica del suelo determinada por la textura del mismo. A la vez, se relacionará de manera negativa con el balance hídrico local.

Partiendo de este marco hipotético se pusieron a prueba las siguientes predicciones en los distintos capítulos de esta tesis;

1. ante similares condiciones ecológicas y debido a su mayor uso consuntivo de agua, se observará mayor CE de suelos en las forestaciones con Eucalyptus spp. que en los ciclos anuales de cultivo o bajo uso pastoril (capítulos 2 y 4 );

2. en el caso de suelos arenosos (Oeste bonaerense) se registrará una mayor CE del suelo bajo forestaciones que en cultivos o pastizales, mientras que las diferencias no serán tan marcadas en los suelos con mayor contenido de arcillas (capítulo $2)$;

3. la diferencia en el contenido de sales del suelo entre forestaciones y otros usos del suelo, será mayor en la región oeste de la provincia debido a las diferencias en balance hídrico entre regiones (capítulo 2);

4. los cultivos más importantes en la región y las forestaciones, presentarán un ciclo determinado por una acumulación de sales durante los períodos de mayor actividad biológica seguidos de una disminución en el contenido de sales por lavado en los momentos de menor actividad o postcosecha (capítulo 2 y 4);

5. habría una menor acumulación de sales, y por lo tanto, menores valores de $\mathrm{CE}$ en el suelo con baja cobertura forestal (bajas densidades) debido al lavado de sales especialmente durante el invierno (capítulo 3);

6. se espera un mayor contenido de sales en el suelo bajo forestaciones de alta resistencia a la salinidad que aquel sometido a otros usos (capítulos 2 y 3);

En esta tesis se analizó la salinidad del suelo de sistemas dominados por Eucalyptus spp. vs pastizales/cultivos anuales apareados a lo largo de una transecta en el centro sur de la provincia de Buenos Aires. Los resultados obtenidos no mostraron una generalización del proceso de salinización bajo las forestaciones con Eucalyptus spp., 
como fueron determinados para otras áreas forestadas de la región Pampeana por Jobbágy y Jackson $(2004,2006)$. En este sentido, se observaron casos donde la conductividad eléctrica (CE) del suelo fue mayor en el cultivo anual y otros donde lo fue en los pastizales o en las forestaciones, incluso ante similares condiciones ecológicas. En el capítulo 4, mediante mediciones in situ y la aplicación de un modelo matemático de simulación, se pudo demostrar que la transpiración de una forestación con Eucalyptus viminalis, a pesar de su menor albedo y mayor rugosidad (Zhang et al. 2001), alcanzó valores similares a los estimados para un cultivo de Glycine max implantado en el mismo sitio. Estos estudios indican que se rechaza la predicción 1, debido a que no hay evidencias de que la salinidad del suelo sea mayor en las forestaciones con Eucalyptus spp., así como también, que no es generalizable que las forestaciones tengan un mayor uso de agua con respecto a los cultivos agrícolas.

La textura del suelo conforma un aspecto edafológico planteado en el modelo teórico propuesto por Jobbágy et al. (2006) y Nosetto et al. (2008). En este modelo se propuso que existe una mayor probabilidad de salinización secundaria del suelo en aquellos con textura arenosa. Esto se produciría dada la conductividad hidráulica más alta, lo que permite mayores flujos de agua hacia las raíces. Sin embargo, los resultados expuestos en el capítulo 2 muestran que los valores más altos de CE en forestaciones fueron encontrados en los suelos con mayores proporciones de arcilla. De manera contraria, las forestaciones situadas en sitios con suelo arenoso mostraron los menores valores de CE. En este sentido, es esperable que los suelos arcillosos tengan esta respuesta debido a su mayor capacidad de intercambio catiónico. Asimismo, los resultados obtenidos permiten formular la hipótesis de que en aquellos sitios arcillosos con un drenaje pobre, se acumularían las sales excluidas por las raíces en las capas más arcillosas, las que se encuentran normalmente sobre el horizonte petrocálcico. Esto es debido a que dichos horizontes son un freno para el movimiento vertical de agua tal como lo mencionan Dietrich et al. (2014) y Weil y Brady (2017). Por otro lado en los suelos arenosos, que generalmente muestran un drenaje excesivo, predominaría la lixiviación de solutos sobre la acumulación. De esta manera, es posible rechazar la predicción 2, dado que en la zona bajo estudio no se encontraron evidencias que demuestren que los suelos con mayor conductividad hidráulica favorezcan la ocurrencia de un proceso de salinización secundaria debajo de las forestaciones.

Tampoco se observó una mayor CE en suelos situados en sitios con balances hídricos más negativos (predicción 3). Así, se encontraron solo 2 casos de 7 (tanto en verano como en invierno) en la localidad ubicada más hacia el Oeste, en donde los valores de CE fueron mayores en la forestación que en la parcela herbácea pareada. Es importante destacar que en los casos donde la CE fue mayor en la forestación, los 
valores alcanzados están muy lejos de los límites que pueden provocar una caída de la productividad de los cultivos agrícolas o forestales (Hillel 2000, Mass 1984). Este patrón, como mencionan Nosetto et al. (2008) y Jobbágy et al. (2006) puede ser resultado de tres situaciones: A) la ausencia de conexión de la vegetación con el acuífero, B) que la vegetación genere un proceso de salinización secundaría por debajo de profundidad estudiada o C) que dada la textura arenosa el drenaje se vea facilitado, evitando la acumulación de sales en los suelos con forestaciones. Sumado a estos resultados, se observó que durante el verano las CE del suelo de la localidad ubicada más hacia el Oeste (Guaminí, balance hídrico negativo) no presentaron diferencias significativas con las de la localidad ubicada hacia el este de la transecta (Balcarce-Lobería, balance hídrico positivo). Incluso, durante el invierno, las CE del suelo en las forestaciones situadas en Balcarce-Lobería fueron mayores a las medidas en Guaminí. Por otro lado, en los sitios donde el balance hídrico es cero (como sucede en el centro de la transecta estudiada), se encontraron mayores valores de CE bajo suelos forestados en las parcelas 5 (invierno) y 4 (verano), de un total de 7 parcelas apareadas. Como puede observarse, fue más común encontrar mayores valores de CE en la forestación que en la parcela herbácea pareada. Estos resultados permiten rechazar lo postulado en la predicción 3.

En la predicción 4 se postula que se generará fluctuaciones de la CE del suelo en concordancia con los balances hídricos que se verifican en las distintas épocas del año (verano vs. invierno). En este sentido, no se encontró un patrón claro de variación estacional, ya que la magnitud del cambio de la CE varió en función del balance hídrico, la textura del suelo y la cobertura vegetal dominante. Así, en los suelos de textura arenosa y balance hídricos negativos, se encontró una disminución en la CE del suelo durante la época de receso invernal, tanto en forestaciones como en cultivos y pastizales. Sin embargo, esto no sucedió en los suelos de textura más fina y balances hídricos más positivos. En estos sitios se observó un incremento de la CE tanto en las parcelas herbáceas como arbóreas y hacia el este un incremento en las forestaciones, por lo que no se cumpliría la predicción 4, al menos en toda la región. Por otro lado, en las parcelas de mediciones intensivas detalladas en el capítulo 4, se observó que se cumple dicha predicción. Así, los suelos mostraron una menor CE durante el periodo invernal, tanto para la herbácea como para la forestación lo que generó una disminución de las diferencias de CE. Esto, como ya fue discutido, probablemente debido al lixiviado de sales acumuladas. Entonces, los resultados obtenidos, estarían diciendo que son varios los factores que influyen para que la predicción $\mathbf{4}$ se cumpla y que no solo depende de la cobertura vegetal dominante, sino de las condiciones de sitio (clima, suelo, etc..).

Con respecto a la predicción $\mathbf{5}$, la relación positiva encontrada entre el porcentaje de cobertura vegetal y la CE del suelo puso de manifiesto el valor del manejo 
silvícola como herramienta para disminuir la acumulación de sales en la rizósfera. Así se comprobó el cumplimiento de la predicción 5, demostrando que, tal como lo observaron Jobbágy et al. (2006), las plantaciones con baja densidad podría ser considerada como una alternativa de menor impacto en estas regiones, que pueda reducir la intensidad de los procesos de salinización secundaría.

Finalmente, también se analizó la existencia de una mayor o menor acumulación de sales, y por lo tanto de cambios en la CE del suelo, según la tolerancia a la salinidad de la especie forestal dominante. En el capítulo 3 se midieron las diferencias en la magnitud de la CE alcanzada a distintas profundidades del suelo en parcelas pareadas de Eucalyptus camaldulensis y Eucalyptus viminalis. Sin embargo, a pesar de haber encontrado CE del suelo 6 veces superiores en las parcelas forestadas con respecto a las herbáceas, no se detectaron diferencias entre las especies forestales estudiadas, rechazando así la predicción 6. Apoyando este patrón y de manera observacional, en el capítulo 2 se encontró una mayor CE en los suelos forestados con Eucalyptus globulus y Eucalyptus viminalis, especies que, según la bibliografía, son menos tolerantes a la salinidad que Eucalyptus camaldulensis. Estos hallazgos no implican que en forestaciones de alta densidad, sin manejo forestal y con mucho tiempo de ocupación del sitio, cuando las condiciones son favorables para llevar a salinizaciones elevadas, la acumulación de sales en el perfil sea mayor en la especie más tolerante antes de sufrir los efectos negativos, como sugieren Nosetto et al. (2008).

Basado en el contraste de las predicciones con los resultados, es claro que para que suceda el proceso de salinización secundaria son varios los factores que deben armonizar. En este sentido se deberían desarrollar normas de manejo sustentable en la escala de predio o parcela atendiendo a las condiciones que deben coincidir para la ocurrencia de este proceso de salinización provocado por cambios de vegetación. Así para la región, es posible reformular el modelo propuesto por Nosetto et al. (2008) y Jobbágy et al. (2006) indicando cuáles serían las condiciones que favorezcan un proceso de salinización secundaria;

1) Hidrogeología:

A) Geomorfología: Acuífero accesible para las raíces. Es decir perfiles de suelo sin limitantes en la profundidad (p.ej. horizontes petrocálcicos, roca) que impidan o reduzcan el acceso de las raíces a la fuente de agua subterránea.

B) Pedología: En general suelos con problemas naturales de presencia de sales. Las texturas arcillosas o limosas (finas a intermedias), favorecerían la acumulación de estas sales. 


\section{2) Biológicos:}

A) Ecofisiología: Especies más tolerantes a la salinidad, con mayor capacidad transpirativa.

B) Manejo: Altas densidades, ausencia de podas y raleos.

El factor climático, específicamente el balance hídrico, parecería no ser una condición importante en relación a los factores mencionados. En este sentido, se encontraron los mayores valores de CE hacia el centro este de la transecta bajo estudio, y casos puntuales donde la CE del suelo fue mayor en las forestaciones para las tres localidades, por lo que este factor fue desestimado del modelo. Esto no implicaría que cuando las condiciones sean las adecuadas, el balance hídrico juegue un rol importante, así como también otros factores que no fueron tenidos en cuenta.

Por otro lado, cuando las condiciones sean predisponentes a la acumulación de sales, si bien difícilmente se pueda actuar sobre la geomorfología y la pedología, aún se podría actuar sobre los factores biológicos. En este sentido el manejo y la elección de especies son fundamentales. Así, como se vio en el capítulo 3 de esta tesis, el manejo de la masa forestal que reduzca o atrase la máxima ocupación del sitio tal como las densidades de plantación bajas (p. ej.; distanciamientos de $4 \mathrm{~m} \times 4$ m, $3 \mathrm{~m} \times 4$ m, $4 \mathrm{~m} \times 5$ $\mathrm{m}$, etc), así como la intervención mediante la aplicación de podas adecuadas y oportunas, de raleos y de turnos de corta acorde a un manejo económicamente sustentable, conformarían un conjunto de herramientas claves en el manejo de la CE del suelo. Así, el desarrollo de plantaciones de producción mixta, como los sistemas silvopastoriles, caracterizadas por bajas densidades de plantación, serían prácticas recomendadas para minimizar el impacto, tal como lo mencionan Jobbágy et al. (2006). Además, la ejecución de actividades de raleo (eliminación de arboles para evitar el estancamiento de la tasa de crecimiento) y podas, permitiría mantener una estructura más eficiente en el uso de los recursos debido a la disminución del área foliar (Binkley et al. 2002, Dillon et al. 2001) y por ende la interceptación, existiendo además una relación muy estrecha entre el uso del agua y la densidad de árboles (Gyenge et al. 2011), por lo que estas prácticas favorecerían el lixiviado de las sales. Asimismo, el aprovechamiento de la masa forestal mediante un adecuado turno de corta, también favorecería a la restauración del equilibrio salino-hídrico ya que se generaría un proceso de lavado de sales al quitar la cobertura forestal. Esto pudo comprobarse en la investigación llevada a cabo en la localidad de Tandil, donde la tala rasa reciente mostró los menores valores de CE del suelo. 


\subsubsection{Nuevos interrogantes}

Los estudios llevados a cabo, ponen de manifiesto que si bien la presencia de forestaciones en un ambiente de pastizal genera cambios en la dinámica de agua, y la redistribución de nutrientes y sales, la magnitud de los mismos dependerá de la especie forestal utilizada en sinergia con el ambiente (entre otros, profundidad y salinidad de la freática, tipo de suelo) y el manejo forestal (sistemas densos vs ralos). En este sentido, en esta tesis y en el modelo conceptual propuesto por Nosetto et al. (2008) y Jobbágy et al. (2006), se resalta la importancia del factor biológico en el proceso de salinización secundaria. En este marco, sería importante abarcar a los sistemas forestales caducos, debido a que según este modelo podrían presentar una dinámica distinta. En las forestaciones con especies caducifolias (salicáceas o especies del género Acacia, por ejemplo), se podría esperar un lavado de sales del suelo durante el invierno (momento del año con balance hídrico más positivo), dado que se caracterizan por presentar un menor uso de agua anual que las especies perennes (Bosch y Hewlett 1982), debido a su periodo de latencia invernal. En este sentido, se ha documentado una gran disminución del déficit de presión de vapor de la atmosfera (DPV) y un consecuente incremento de los excesos hídricos durante la etapa de latencia en Populussp. (Alvarez 2018). Por este motivo, el balance de sales podría ser similar a los pastizales naturales, al permitir un lavado de las que fueron acumuladas durante el periodo vegetativo. Aunque también existen antecedentes donde se han detectado sectores puntuales con presencia/acumulación de sales para especies caducas (por ejemplo en álamos, Alvarez 2018).

Por otro lado, los resultados sugieren que un estudio extensivo de la dinámica de los acuíferos aportarían al conocimiento del movimiento de sales en el suelo. Si bien se analizó el comportamiento del acuífero en una forestación puntual de Eucalyptus viminalis, estos estudios deberían ser ampliados y como se hizo con la CE del suelo, abarcar las distintas situaciones presentes en la región. Además, para el análisis acerca de los procesos de recarga / descarga del acuífero sería necesario instalar una red de freatímetros en las parcelas estudiadas que permita darle mayor peso a las hipótesis planteadas. Asimismo, una incógnita importante se presenta a mayores profundidades del suelo, por ejemplo debajo de los horizontes petrocálcicos.

Finalmente, el modelado de transporte reactivo basado en balances de masa de agua, energía y solutos, aparece como una herramienta numérica actual. Esta herramienta es capaz de explicar los procesos físicos / biológicos acoplados que son responsables de la salinización del suelo y el impacto de las heterogeneidades en los flujos de agua de la zona vadosa (Mayer, 1999; Bea et al., 2012). Así surge la necesidad de evaluar la compleja dinámica temporal del flujo de agua en la zona no saturada de 
estos suelos productivos. Para esto se debería prestar especial atención al impacto de las heterogeneidades del suelo sobre: (1) la dinámica de la captación de agua del bosque, (2) el comportamiento freatófito del bosque, (3) la ocurrencia y consecuente respuesta fisiológica del bosque a los períodos de estrés hídrico, y (3) el riesgo potencial de salinización de estos suelos loéssicos con presencia de horizontes petrocálcicos altamente cementados.

\subsection{CONCLUSIONES}

Los resultados de los estudios llevados a cabo en esta tesis, permiten determinar que en la zona de estudio, no existen evidencias de un proceso generalizado de salinización secundaria del suelo debido al cambio de vegetación, en particular, a la introducción de especies forestales. Asimismo, en un ambiente típico de la región, el aprovechamiento de las precipitaciones fue mayor en un cultivo forestal que en un pastizal, sin embargo el uso consuntivo de agua de la forestación no resulto ser mayor a un cultivo de soja. Estos estudios ponen en duda la aseveración de que los Eucalyptus $s p$. son bombas de agua. Por otro lado, aunque es común en la región bajo estudio la existencia de un acuífero libre a menos de $6 \mathrm{~m}$ de la superficie del suelo, se pudo dejar en claro que son varias las condiciones que deben coexistir para que la vegetación realice un aprovechamiento del mismo que implique una depresión del acuífero y un problema de salinización generalizado. En este sentido y dado la diversidad de ambientes propios de la extensa llanura Pampeana, es necesario resaltar la importancia del estudio a escala local. De esta manera sería posible actuar a nivel predial, donde los productores pueden aplicar normas de manejo sustentable en base a los impactos sobre los recursos del suelo producidos por las actividades productivas mencionadas. Así, la instalación de plantaciones forestales debería ir de la mano del manejo silvícola, siendo fundamental la intervención de las forestaciones con adecuados y oportunos raleos, podas y turnos de corta. El desarrollo de plantaciones que involucren un menor grado de ocupación de sitio, como es el caso de los sistema silvopastoriles y las cortinas forestales, también emerge como una herramienta para mitigar el desarrollo de procesos de salinización en los sitios donde las condiciones estén dadas. 


\section{Bibliografía}


Aeródromo Tandil 2016. Datos del periodo 1973-2015, reportados por la estación meteorológica: 876450 (SAZT). Latitud: -37.23, longitud: -59.25, Altitud: 175.

Alvarez J. 2018. Estabilidad productiva y plasticidad fenotípica de Populus spp. en relación con el contenido de agua y sales en el suelo. Tesis doctoral. Escuela para Graduados Ing. Agr. Alberto Soriano de la Facultad de Agronomía - UBA

Amdan M. L., R. Aragón, E. G.Jobbágy, J. N. Volante and J. M. Paruelo 2013. Onset of deep drainage and salt mobilization following forest clearing and cultivation in the Chaco plains (Argentina). Water resources research, vol. 49, 6601-6612.

Amiotti N.M., P. Zalba, L. Sanchez and N. Peinemann 2000. The impact of single trees on properties of loess-derived grassland soils in Argentina. Ecology. 81(12): 3283-3290.

Anandacoomaraswamy A., W.A.J.M. De Costa, H.W. Shyamalie and G.S. Campbell 2000. Factors controlling transpiration of mature field-grown tea and its relationship with yield. Agric. For. Meteor. 103: 375-386.

Aussenac G. 2000. Interactions between forest stands and microclimate: ecophysiological aspects and consecuences for silviculture. Ann. For. Sci. 57: 287-301.

Ayers R.S. and D.W. Westcot 1985. Water quality for agriculture. FAO. Irrigation and Drainage Series. Roma.

BA Buenos Aires Forestal 2010. Revista Forestal, Ministerio de Agroindustria de la Provincia de Buenos Aires. Available online at http://www.maa.gba.gov.ar/2010/SubPED/Agricultura/archivos/BAForestal Revista; last accessed Apr. 12, 2018.

Baldocchi D.D., C.A. Vogel, B. Hall 1997. Seasonal variation of energy and water vapor exchange rates above and below a boreal jack pine forest canopy. J. Geophys. Research 102(D24); 28939-28951.

Barros V. , C. Vera, E. Agosta, D. Araneo, I. Camilloni, A. Carril, M. Doyle, O. Frumento, M. Nuñez, M. I. Ortiz de Zárate, O. Penalba, M. Rusticucci, C. Saulo y S. Solman 2013. Cambio climático en Argentina; tendencias y proyecciones, Centro de Investigaciones del Mar y la Atmósfera. Cap. 2 y 5. 
BCBA 2015. El mercado de carbono en la bolsa de comercio de Buenos Aires, resumen general.

Bea S. A., S. A. Wilson, K. U. Mayer, G. M. Dipple, I. M. Power, and P. Gamazo 2012. Reactive Transport Modeling of Natural Carbon Sequestration in Ultramafic Mine Tailings, Vadose Zo. J., 11(2), 0, doi:10.2136/vzj2011.0053.

Benyon R.G., S. Theiveyanathan and T.M. Doody 2006. Impacts of tree plantations on groundwater in south-eastern Australia. Australian Journal of Botany, 54: 181-192.

Besteiro 2013. Evaluación de la influencia hidrológica de forestaciones en la llanura pampeana. Tesis doctoral. Facultad de ciencias agrarias y forestales UNLP. La plata, Bs. As., Argentina.

Besteiro y Rodríguez Vagaría 2012. Redistribución de las precipitaciones sobre plantaciones forestales en un predio del partido de La Plata, Buenos Aires. Rev. Fac. Agron. 111: 75-82.

Binkley D., J. L. Stape, M. G. Ryan, H. R. Barnard and J. Fownes. 2002. Agerelated decline in forest ecosystem growth: An individual-tree, standstructure hypothesis. Ecosystems 5:58-67.

Bosch J.M. and J.D. Hewlett. 1982. A review of catchment experiments to determine the effects of vegetation changes on water yield and evaporation. Journal of Hydrology 55: 323.

Bouyoucos G. J. 1962. Hydrometer method improved for making particle size analysis of soils, Agron. J., 54, 464-465.

Brown A.E., L. Zhang, T.A. Mcmahon, A.W. Western and R.A. Vertessy 2005. A review of paired catchment studies for determining changes in water yield resulting from alterations in vegetation. Journal of Hydrology, 310:28-61.

Caldato S.L. 2011. Ciclagem biogeoquímica dos nutrientes Em uma plantação de Pinus taeda L. No Nordeste argentino. Tesis doctoral. Santa Maria, RS, Brasil. 
Calder I.A. 1998. Water use by forests, limits and controls. Tree Physiology, 18, 625-631.

Cao C.Y., S.Y. Jiang, Y. Zhang, F.X. Zhang, X.S. Han 2011. Spatial variability of soil nutrients and microbiological properties after the establishment of leguminous shrub Caragana microphylla Lam. plantation on sand dune in the Horqin Sandy Land of Northeast China. Ecol. Eng. 37, 1467-1475

Castro Díez P., N. Fierro-Brunnenmeister, N. González-Muñoz and A. Gallardo 2012. Effects of exotic and native tree leaf litter on soil properties of two contrasting sites in the Iberian Peninsula. Plant and Soil 350:179-191

Chen S. and A. Polle 2010. Salinity tolerance of Populus. Plant Biology 12: 317-333

Cortés D. L., J. H. Pérez and J. H. Camacho-Tamayo 2013. Spatial relation between electrical conductivity and some chemical soil propierties. Revista U.D.C.A Actualidad y Divulgación Científica 16 (2): 401 - 408

Dalla Salda L., L. Spalletti, D. Poiré, R. De arrio, H. Echeveste y A. Benialgo 2006. Tandilia. INSUGEO, Serie Correlación Geológica, 21: 17-46. ISSN 1514-4186, ISSN online 1666-9479.

Delgado S., F. Alliaume, F. García Préchac y J. Hernández 2006. Efecto de las plantaciones de Eucalyptus sp. sobre el recurso suelo en Uruguay. Agrociencia. Vol. X $\mathrm{N}^{\circ}$ 2 pág. $95-107$

Dillon P., R. Benyon, P. Cook, T. Hatton, S. Marvanek, and J. Gillooly 2001. Review of Research on Plantation Forest Water Requirements in Relation to Groundwater Resources in the Southeast of South Australia. Centre for Groundwater Studies Report No 99. Department for Water Resources, South Australia

Divito G.A., H.R. Sainz Rozas, H.E. Echeverría, G.A. Studdert and N. Wyngaard 2011. Long term nitrogen fertilization: soil property changes in an Argentinean Pampas soil under no tillage. Soil Tillage Res. 114(2): 117-126.

Elliot E.T., J.W. Jeil, E.F. Kelly, and H. Curtis Monger 1999. Soil structural and other physical properties, in Standard Sail Methods for Long Term Ecological Research, edited by G. P. Robertson et al., pp. 74-85, Oxford Univ. Press, New York. 
Engel V., E.G. Jobbágy, M. Stieglitz, M. Williams, and R.B. Jackson 2005. Hydrological consequences of Eucalyptus afforestation in the Argentine Pampas, Water resources research, 41, W10409, doi:10.1029/2004WR003761.

FAO 1981. El eucalipto en la repoblación forestal. Via delle Terme di Caracalla, 00100 Roma, Italia. ISBN 92-5-300570-X

FAO 1985. Manual on Fertilizer distribution. FAO fertilizer and plant nutrition bulletin 8. Rome, Italy.

Farley K.A., E.G. Jobbágy and R.B. Jackson 2005. "Effects of afforestation on water yield: a global synthesis with implications for policy." Global Change Biology (2005) 11(doi: 10.1111/j.1365-2486.2005.01011.x): p. 1565-1576.

Fassola H., N. Pachas, y S. Lacorte 2005. Estimación de la radiación fotosintéticamente activa (PAR) y niveles de sombra bajo dosel de Pinus Taeda en la provincia de Misiones y NE de Corrientes. INTA EEA Montecarlo.

Fernández M.E., J.E. Gyenge and T.M. Schlichter. 2009. Water flux and canopy conductance of natural versus planted forests in Patagonia, South America. Trees 23: 415-427.

Fernández M.E., J.E. Gyenge, J. Licata, T. Schlichter and B.J. Bond. 2008. Belowground interactions for water between trees and grasses in a temperate semiarid agroforestry system. Agroforestry Systems 74: 185-197.

Ferrere P., A.M. Lupi and T. Boca 2015. Growth of Pinus radiata undergoing different thinning and pruning treatments in the Southeast of the province of Buenos Aires, Argentina. Bosque 36(3): 423-434, 2015 DOI: 10.4067/S0717-92002015000300009

Frangi J. L. 1975. Sinopsis de las comunidades vegetales y el medio en las Sierras de Tandil (provincia de Buenos Aires). Boletín de la Sociedad Argentina de Botánica 16: 293-319

Friedman S.P. 2005. Soil properties influencing apparent electrical conductivity: a review. Comp. Electron. Agric. (USA). 46(1-3):45-70. 
Fuschini Mejía M. 1994. El agua de las llanuras. UNESCO/ORCYT. Montevideo, Uruguay. 58 pp.

George R. J., D. J. McFarlane, and R. A. Nulsen 1997. Salinity threatens the viability of agriculture and ecosystems in Western Australia. Hydrogeology Journal 5:6-21.

Granier A. 1985. Une nouvelle méthode pour la mesure du flux de sève brute dans le tronc desarbres. Ann Sci For. 42 : 193-200.

Granier A. 1987. Mesure du flux de sève brute dansle tronc du Douglas par une nouvelle méthode thermique. Ann Sci For. $44: 1-14$.

Gyenge J.E., M.E. Fernández and S. Varela 2012. Short- and long-term responses to seasonal drought in ponderosa pines growing at different plantation densities in Patagonia, South America. Trees 26:1905-1917.

Gyenge J.E., M.E. Fernández., J. Licata, M. Weigandt, B. Bond y T. Schlichter 2011. Uso del agua y productividad de los bosques nativos e implantados en el N.O. de la Patagonia: aproximaciones desde la ecohidrología y la ecofisiología. Ecología Austral (Número especial: Ecofisiología de especies leñosas) 21: 271-284.

Gyenge, J.E., M.E. Fernández and T.M. Schlichter. 2009. Effect of pruning on branch production and water relations in widely spaced ponderosa pines. Agrof. Syst. 77:223235.

Gyenge J.E., M.E. Fernández, M. Sarasola and T.M. Schlichter. 2008. Testing a hypothesis of the relationship between productivity and water use efficiency in Patagonian forests with native and exotic species. For. Ecol. Manage. 255:3281-3287.

Gyenge J.E., N. Tesón, J. Licata y A. Keller 2010. Cap. 3: Flujo de savia mediante el método de disipación de calor. En: Fernández ME y Gyenge JE. Eds. En: Técnicas de medición en ecofisiología vegetal: conceptos y procedimientos. Ediciones INTA, Buenos Aires, Argentina ISBN 978-987-1623-76-1, pág. 35-52.

Hibbert A.R. 1967. Forest treatment effects on water yield. In: International symposium on forest hydrology. Eds WE Sopper, HW Lull. Pergamon, Oxford. 527-543. 
Hillel D. 2000. Salinity Management for Sustainable Irrigation. Integrating Science, Environment, and Economics. The International Bank for Reconstruction and Development/The World Bank 1818 H Street, N.W. Washington, D.C. 20433, U.S.A.

Huber A., A. Iroumé, C. Mohrc y C. Frênea 2010. Efecto de plantaciones de Pinus radiata y Eucalyptus globulus sobre el recurso agua en la Cordillera de la Costa de la región del Biobío, Chile. Bosque 31(3): 219-230.

Huber A., C. Oyarzún, E. Ellies 1985. Balance hídrico en tres plantaciones de Pinus radiata y una pradera. II: Humedad del suelo y evapotranspiración. Bosque, 6(2), 74-82.

Huber J. A. y C.O. Oyarzún 1983. Precipitación neta e interceptación en un bosque adulto de Pinus radiata (D. Don). Bosque 5(1):13-20.

INTA 1989. Mapa de suelos de la Provincia de Buenos Aires. Instituto de suelos - INTA Buenos Aires, 525p. ISBN 9789509853171.

Jackson R.B., E.G. Jobbágy, R. Avissar, S.B. Roy, D. Barrett, C.W. Cook, K.A. Farley, D.C. Le Maitre, B.A. MCcarl and B.C. Murray 2005. Trading water for carbon with biological carbon sequestration. Science, 310, 1944-1947.

Jobbágy E.G. 2009. Regímenes hidrológicos según usos de la tierra: Efectos de la actividad forestal en sistemas semiáridos y húmedos. Pp: 7-16 en: PJ Donoso (editor) Tala Rasa: Implicancias y desafíos. Universidad Austral de Chile, Valdivia.

Jobbágy E.G. and R. B. Jackson 2004. Groundwater use and salinization with grassland afforestation. Global Change Biology, 10, 1299-1312

Jobbágy E.G., M. Nosetto, J.M. Paruelo y G. Piñeiro 2006. Las forestaciones rioplatenses y el agua. Ciencia hoy, volumen 16 № 95.

Jobbágy E.G., M. Nosetto, C. Santoni y G. Baldi 2008. El desafío ecohidrológico de las transiciones entre sistemas leñosos y herbáceos en la llanura Chaco-Pampeana. Ecología Austral 18:305-322. Doi:10.1029/2007GB003000 
Jobbágy E.G. and R.B. Jackson 2003. Patterns and mechanisms of soil acidification in the conversion of grasslands to forests. Biogeochemistry 64: 205-229, 2003.

Jobbágy E.G., R. Aragón y M. D. Nosetto 2007. Los cultivos y la napa freática en la llanura pampeana. Agromercado, Agosto, № 268: 8-10.

Jobbágy E.G. 2014. ¿Hay lugar para las salicáceas en la pampa? Revisión de los incentivos ecológicos. Jornadas de Salicáceas, IV Congreso Internacional de Salicáceas en Argentina. Facultad de Ciencias Agrarias y Forestales, Universidad Nacional de La Plata. La Plata, Buenos Aires.

Jobbágy E. G., M. Vasallo, K. A. Farley, G. Piñeiro, M. F. Garbulsky, M. D. Nosetto, R. B. Jackson y J. M. Paruelo 2006. Forestación en pastizales: hacia una visión integral de sus oportunidades y costos ecológicos. Agrociencia. Vol. X N² 2 pág. 109 - 124.

Juan P., J. Mateu, M.M. Jordan, J. Mataix Solera, I. Meléndez Pastor and J. Navarro Pedreño 2011. Geostatistical methods to identify and map spatial variations of soil salinity. J. Geochem. Explor. (USA). 108(1):62-72.

Karmakar R., D. Indranil , D. Debashis and R. Amitava 2016. Potential Effects of Climate Change on Soil Properties: A Review. Science International, 4:51-73. DOI: 10.17311 / sciintl.2016.51.73

Kelliher F.M., R. Leuning and E.D. Schulze 1993. Evaporation and canopy characteristics of coniferous forests and grasslands. Oecologia, 95, 153-163.

Kong X., Z. Luo, H. Dong, E. Eneji and W. Li 2012. Effects of non-uniform root zones salinity on water use, $\mathrm{Na}+$ recirculation, and $\mathrm{Na}+$ and $\mathrm{H}+$ flux in cotton. J. Exp. Bot. 63:2105-2116.

Lambers, H., S. Chapin and T. Pons 2008. Plant physiological ecology. Springer. New York. 604 p.

Lane, D. R. and BassiriRad, H. 2005. Diminishing spatial heterogeneity in soil organic matter across a prairie restoration chronosequence. Restor. Ecol. 13, 403-412. 
Lavado, R. S., and M. A. Taboada. 1988. Water, salt and sodium dynamics in a natraquoll in Argentina. CATENA 15:577-594

Le Maitre D.C., D.B. Versfeld and R.A. Chapman 2000. The impact of invading alien plants on surface water resources in South Africa: A preliminary assessment. Water SA Vol. 26 No. 3. ISSN 0378-4738

Lizeaga J., J. Zapirain y M. Lizeaga 1992. Estudio de las temperaturas del suelo a 15,30 y $45 \mathrm{~cm}$. De profundidad en 3 ecosistemas ( hayedo, robledal y argomal) de Artikutza (Navarra). Cuadernos de Sección. Historia 20. (1992) p. 313-325 ISSN: 0212-6397

Losinno B.N., C.M. Sainato, H.J. Malleville y G. Galindo 2008. Tomografía de resistividad eléctrica aplicada a la caracterización de sitios contaminados en tambos. Ci. suelo, argentina 26(2): 141-152

MAGPyA. 2016. Mapa de Plantaciones Forestales, Inventario de Plantaciones Forestales Provinciales y Nacionales, Ley de Promoción Forestal 25.080.

MAGyP 2014. Argentina: plantaciones forestales y gestión sostenible. Dirección de Producción Forestal.

Marcar N., D. Crawford, P. Leppert, T. Jovanovic, R. Floyd and R. Farrow 2002. Trees for saltland; a guide to selecting native species for Australia. CSIRO Press, Melbourne Victoria, Australia. $72 \mathrm{p}$.

Marshall T.J. and J.W. Holmes 1979. Soil physics Cambridge University Press. 345 p.

Maas E.V. 1984. Salt Tolerance of plants. En: The handbook of plant Science in Agriculture, (ed. RB Christie), CRC Press Boca Raton (Florida).

Maas E.V. and G.J. Hoffman 1977. Crop salt tolerance: Current assessment. J Irrig Drain E-ASCE 103: 115-134

Mayer K. U. 1999. A numerical model for multicomponent reactive transport in variably nsaturated porous media, Earth Sci. , Doctor of, 306. 
Mirck J. and R.S. Zalesny Jr. 2015. Mini-Review of Knowledge Gaps in Salt Tolerance of Plants Applied to Willows and Poplars, International Journal of Phytoremediation, 17:7, 640-650.

Mujica C.R., G.M. Milione, S.A. Bea, J.E. Gyenge 2019. Impacto en los flujos hídricos por la presencia de horizontes petrocálcicos en parcelas forestadas en ambientes de llanura. Revista de investigaciones agropecuarias (RIA). ISSN 1669-2314. En prensa

Nair V., K. Portier, D. Graetz, and M. Walker 2004. An environmental threshold for degree of phosphorus saturation in sandy soils. J. Environ. Qual. 33(1): 107-113.

Niknam S.R. and J. McComb 2000. Salt tolerance screening of selected Australian woody species - a review. Forest Ecology and Management . DOI: 10.1016/S03781127(99)00334-5.

Nosetto M., E. Jobbágy, A. Brizuela and R. Jackson 2012. The hydrologic consequences of land cover change in central Argentina. Agriculture, Ecosystems and Environment, 154: $2-11$.

Nosetto M., E. Jobbágy, R. Jackson and G. Sznaider 2009. Reciprocal influence of crops and shallow ground water in sandy landscapes of the Inland Pampas. Field Crops Research 113: 138-148.

Nosetto M., E. Jobbágy, T. Tóth and C. Di Bella 2007. The effects of tree establishment on water and salt dynamics in naturally salt-affected grasslands. Oecologia (2007) 152:695-705. DOI 10.1007/s00442-007-0694-2

Nosetto M., E. Jobbágy, T. Tóth and R. Jackson 2008. Regional patterns and controls of ecosystem salinization with grassland afforestation along a rainfall gradient. Global Biogechemical Cycles. 22 (2), art. no. GB2015.

Otero, L., F. Ortega Sastriquez y M. Morales 1998. Participación de la arcilla y la materia orgánica en la capacidad de intercambio catiónico de Vertisoles de la provincia Granma. Terra Latinoamericana, vol. 16, núm. 3, pp. 189-194. Chapingo, México 
Poore M.E. y C. Fries. 1987. Efectos ecológicos de los eucaliptos. Estudio FAO Montes 59, Roma. 106 p.

Postel S. L., G. C. Daily and P. R. Ehrlich 1996. Human appropriation of renewable fresh water. Science 271:785-788.

Raes, D., P. Steduto, T.C. Hsiao and E. Fereres 2009. Main algorithms and software description. Agron. J. 101(3): 438-447.

Raes, D., P. Steduto, T.C. Hsiao and E. Fereres 2012. Reference manual AquaCrop 4.0, FAO, Rome.

Rébori G., F. Damiano, R.A. Díaz, J. Rodríguez Traverso y A. Grassi 2001. Requerimientos de agua del Eucalyptus dunnii en su implantación y monte adulto. Medición y contribución al balance hídrico regional. Seminario Internacional sobre Manejo Integral de Cuencas Hidrográficas. 8 al 12 de octubre, Rosario, Santa Fe. Resúmenes: 85-86 pp.

Rengasamy P. 2006. World salinization with emphasis on Australia. Journal of Experimental Botany, Vol 57, No. 5, pp. 1017-1023. Doi:10.1093/jxb/erj108.

Rivas y Carmona 2013. Evapotranspiration in the Pampean Region using field measurements and satellite data. Physics and Chemistry of the Earth 55-57: 27-34.

Robins L. 2004. Dryland Salinity and Catchment Management - A Resource Directory and Action Manual for Catchment Managers, National Dryland Salinity Program, Land and Water Australia, Canberra ACT.

Rodrigo Domínguez y Ávila I Castells 1997. Trascolación y escorrentía cortical en dos encinares (quercus ilex I) del macizo del montseny (Barcelona). Congreso Forestal Español, Barcelona, España.

Rucks L., F. García, A. Kaplán, J. Ponce de León y M. Hill 2004. Propiedades Físicas del Suelo. Facultad de agronomía universidad de la república, dpto. suelos y aguas. Montevideo, Uruguay. 
Ruíz de Galarreta V. A. y C. I. Rodríguez 2013. Conceptos básicos de hidrología: resolución del balance hidrológico. 1ra edición, Tandil, UNCPBA, 2013. 164 p. ISBN: 978950-658-311-8.

SAGPyA 2001. Argentina investment opportunities in plantation forest. Edited by Secretariat of Agriculture, Livestock, Fisheries and Food. Buenos Aires, Argentina. 212 pp.

SAGPyA 2002. Primer inventario nacional de plantaciones forestales en macizo. SAGPyA Forestal.

Sakalauskas K. M., J. L. Costa, P. Laterra, L. Hidalgo and L. Aguirrezabal 2001. Effects of burning on soil-water content and water use in a Paspalum quadrifarium grassland. Agricultural Water Management 50: 97-108.

Santoni C. S., E. G. Jobbágy, V. Marchesini y S. Contreras 2008. Diferentes usos del suelo: consecuencias sobre balance hídrico y drenaje profundo en zonas semiáridas. XXI congreso de suelo de la ciencia del suelo. Potrero de funes, San Luis, Argentina.

Scanlon B.R., K.E. Keese, A.L. Flint, L.E. Flint and C.B. Gaye 2006. Global synthesis of groundwater recharge in semiarid and arid regions. Hydrological Processes, 20:33353370 .

Schwinning S. 2008. The water relations of two evergreen tree species in a karst savanna. Oecología 158(3):373-83. doi: 10.1007/s00442-008-1147-2.

SINAVIMO 2014. Ficha de Eucalyptus viminalis. http://www.sinavimo.gov.ar/cultivo/eucalyptus-viminalis . Consultado el 08/02/2018

Sota E.R. de la. 1967. Composición, origen y vinculaciones de la flora pteridológica de las Sierras de Buenos Aires (Argentina). Bol. Soc. Argent. Bot. 11: 105-128.

Stirzaker R., R. Vertessy and A. Sarre 2002. Trees, Water and Salt: An Australian guide to using trees for healthy catchments and productive farms, Canberra. 
Taboada M.A., F. Damiano y R.S. Lavado 2009. Inundaciones en la región pampeana. Consecuencias sobre los suelos. p.103-127. En: M. A. Taboada y R. S. Lavado (ed). Alteraciones de la fertilidad de los suelos. Editorial Facultad de Agronomía Universidad de Buenos Aires.

Valenzuela C., A.I. Della Maggiora, L. Echarte, M. Cambareri y M. Polizzi 2009. Evapotranspiración y eficiencia en el uso de agua en intercultivos maíz-soja vs cultivos puros. Meteorológica 34: 29-37

van Dijk A. and R.J. Keenan 2007. Planted forests and water in perspective. Forest Ecology and Management, 251:1-9.

Varni M. and E. Usunoff 1999. Simulation of regional-scale groundwater flow in the Azul River basin, Buenos Aires Province, Argentina. Hydrogeol. Journal 7:180-187.

Vertessy R. A., R. G. Benyon, S. K. O'Sullivan and P. R. Gribben 1997. Relationships between stem diameter, sapwood area, leaf area and transpiration in a young mountain ash forest. Tree Physiology 15, 559-567

Weil R.R. and N.C. Brady 2017. The Nature and Properties of Soils. Fifteenth Edition, Pearson Education, Inc.. United States of America. 1071p. ISBN-13: 978-0-13-325448-8 ISBN-10: 0-13-325448-8

Wyngaard N., H.E. Echeverría, H.R. Sainz Rozas and G. Divito 2012. Long-term fertilization and tillage effects on soil properties and maize yield in a Southern Pampas Argiudol. Soil Till. Res. 119:22-30.

World Climate. Climate data for $36^{\circ} \mathrm{S} 59^{\circ} \mathrm{W}$. http://www.worldclimate.com/cgibin/grid.pl?gr=S36W059. Consultado el 04/10/2017

Wright J.A., A. Di Nicola and E. Gaitan 2000. Latin American forest plantations Opportunities for carbon sequestration, economic development and financial returns, Forestry J., 98, 20- 23.

WWAP (United Nations World Water Assessment Programme). 2015. The United Nations World Water Development Report 2015: Water for a Sustainable World. Paris, UNESCO 
Zapata Hernández R.D. 2004. Química de la acidez del suelo. Cargraphics, Cali. Medellin, Colombia 208p.

Zhang L., W.R. Dawes and G.R. Walker 2001. Response of mean annual evapotranspiration to vegetation changes at catchment scale. Water Resource Research 37: 701

Zhang L., W.R. Dawes and G.R. Walker 1999. Predicting the effect of vegetation changes on catchment average water balance. (Co-operative Research Centre for Catchment Hydrology: Canberra) 